University of Rhode Island

DigitalCommons@URI

Open Access Master's Theses

2020

\title{
IMPROVING THE UTILIZATION OF RENEWABLE ENERGIES IN WATER SUPPLY SYSTEMS USING DEMAND SIDE MANAGEMENT
}

Lukas Siemon

University of Rhode Island, Lukas_Siemon@gmx.de

Follow this and additional works at: https://digitalcommons.uri.edu/theses

\section{Recommended Citation}

Siemon, Lukas, "IMPROVING THE UTILIZATION OF RENEWABLE ENERGIES IN WATER SUPPLY SYSTEMS USING DEMAND SIDE MANAGEMENT" (2020). Open Access Master's Theses. Paper 1888.

https://digitalcommons.uri.edu/theses/1888

This Thesis is brought to you for free and open access by DigitalCommons@URI. It has been accepted for inclusion in Open Access Master's Theses by an authorized administrator of DigitalCommons@URI. For more information, please contact digitalcommons-group@uri.edu. 


\section{IMPROVING THE UTILIZATION OF RENEWABLE ENERGIES IN WATER SUPPLY SYSTEMS USING DEMAND SIDE MANAGEMENT}

BY

LUKAS SIEMON

A THESIS SUBMITTED IN PARTIAL FULFILLMENT OF THE

REQUIREMENTS FOR THE DEGREE OF

MASTER OF SCIENCE

IN

CIVIL AND ENVIRONMENTAL ENGINEERING

UNIVERSITY OF RHODE ISLAND

2020 


\section{MASTER OF SCIENCE THESIS}

OF

\section{LUKAS SIEMON}

\section{APPROVED:}

Thesis Committee:

Major Professor: Ali Shafqat Akanda

Vinka Oyanedel-Craver

Valerie Maier-Speredelozzi

Brenton DeBoef

DEAN OF THE GRADUATE SCHOOL 


\begin{abstract}
The mitigation of global warming is one of the greatest challenges of the $21^{\text {st }}$ century. To reduce the emission of greenhouse gases, fossil fuels are being replaced with renewable energies. The increased share of solar and wind energy poses a complex challenge to the electricity grid due to the temporal variability in energy generation. Water supply is an energy intensive sector and entails a great potential to apply measures to synchronize the system's energy demand to the renewable energy supply.
\end{abstract}

In this study, the potential of implementing demand side management into the water supply system operation is assessed with the goal of increasing the utilization of on-site variable renewable energy. Digital-twin modelling of different simulation scenarios provides a tool to comparatively evaluate the reference scenario and the proposed scenarios with integrated demand side management measures and integration of variable renewable energies. The challenge of this study lies in the goal of increasing renewable energy self-sufficiency and consequentially reducing greenhouse gas emissions while maintaining the physical integrity of the water within the system.

The comparative evaluation shows that by integrating on-site variable renewable energies and demand side management measures, a degree of energy selfsufficiency of $78.5 \%$ could be achieved, resulting in a cut of carbon emissions by $69.4 \%$. The water pressure in the system showed no increase while the average retention time could be reduced by $16 \%$. The results reveal the untapped potential to use water supply systems to foster the integration of renewable energies and thus reduce the associated environmental impact. 


\section{ACKNOWLEDGEMENTS}

First off, I would like to thank my parents and my whole family for their continuous support during my educational career and my studies at the University of Rhode Island Graduate School. Especially during the unprecedented times of a global pandemic, their encouragement helped me to stay strong and not lose focus.

I want to thank my beloved girlfriend Eva for her unconditioned love and support. Though being thousands of miles apart for most of the last year, we strengthened our bond and I look forward to the many years that we will spend together. Additionally, I would like to thank my close friends both in Rhode Island and in Germany for their continuous support and the great times we shared.

I would like to express my gratitude to Prof. Ali Shafqat Akanda for his advice and efforts throughout my year at the URI. His guidance and his valuable feedback in our endless discussions have substantially led to the continuous improvement of this study. Furthermore, I would like to thank my additional thesis committee members Prof. Vinka Oyanedel-Craver and Prof. Valerie Maier-Speredelozzi for their time and support regarding this study. I also want to thank my course instructors Prof. Samantha Meenach and Prof. Sunshine Menezes for their valuable input and advice.

Lastly, I want to acknowledge Dr. Sigrid Berka and Prof. Christoph Baxter from URI, Dr. Ute Kopka and Prof. Jörg Gattermann from the Technische Universität Braunschweig, the German Academic Exchange Service and all others involved in the organization of the exchange program between the URI and the TU Braunschweig. 


\section{TABLE OF CONTENTS}

ABSTRACT ...........................................................................................................................ii

ACKNOWLEDGEMENTS ...............................................................................ii

TABLE OF CONTENTS...........................................................................................

LIST OF FIGURES ......................................................................................viii

LIST OF TABLES ................................................................................................

LIST OF ABBREVIATIONS.....................................................................................................xiii

LIST OF SYMBOLS ....................................................................................................................... Xv

1 INTRODUCTION ..........................................................................................................

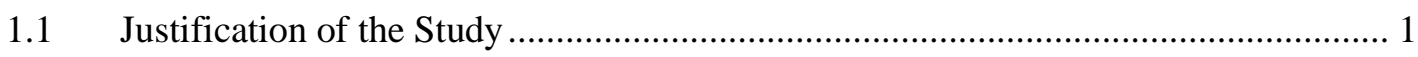

1.1.1 Climate Change and Energy Supply ......................................................... 1

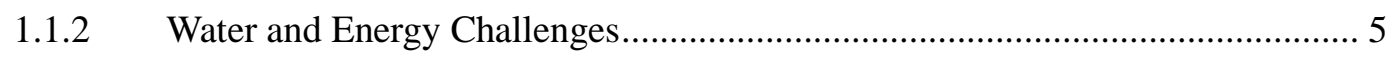

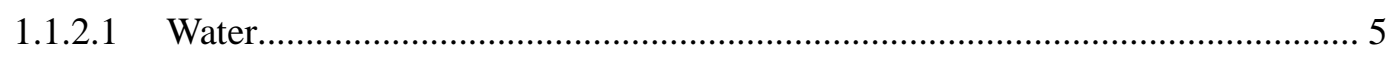

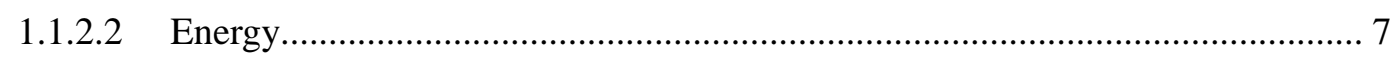

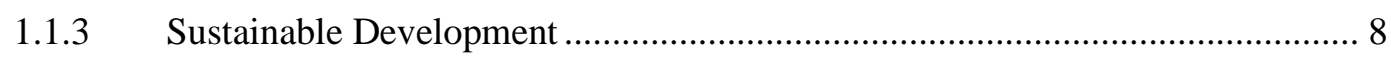

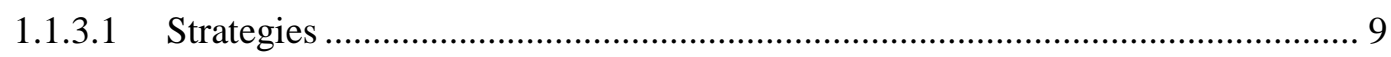

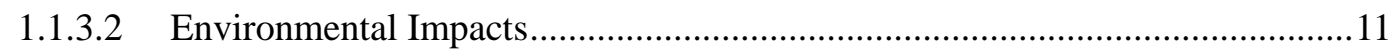

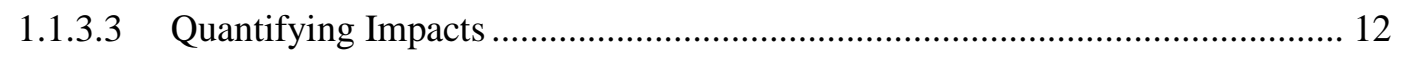

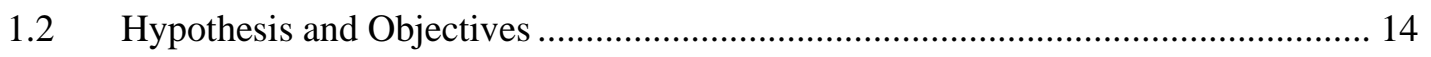

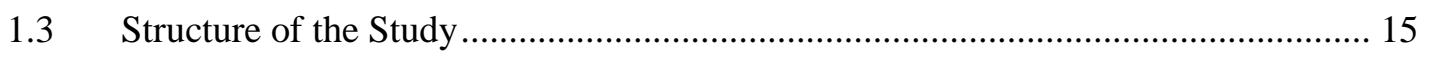

2 LITERATURE REVIEW ........................................................................................... 16 


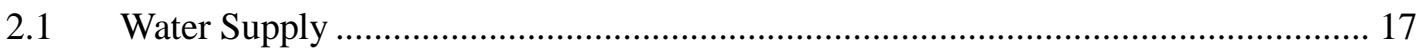

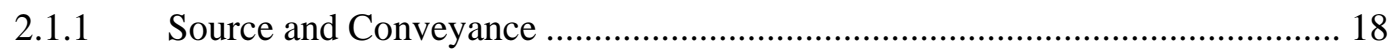

2.1.2 Water Distribution Systems ................................................................. 20

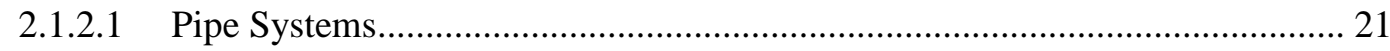

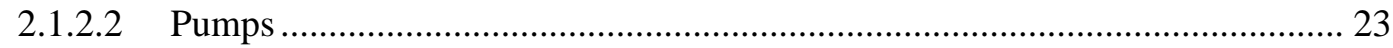

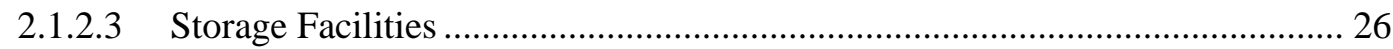

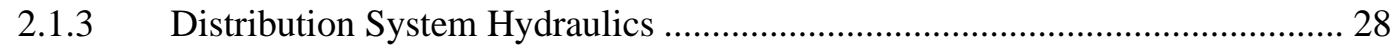

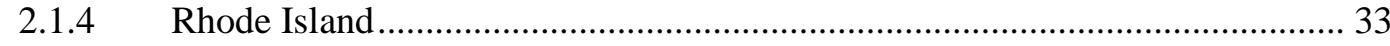

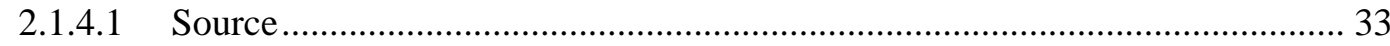

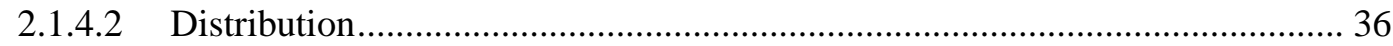

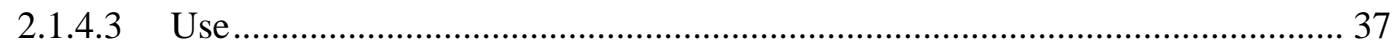

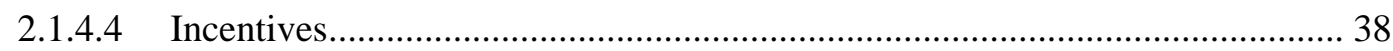

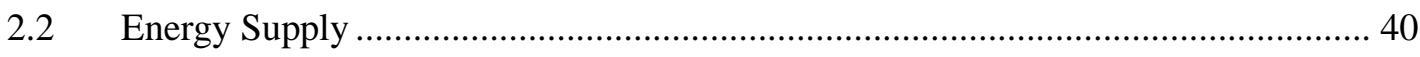

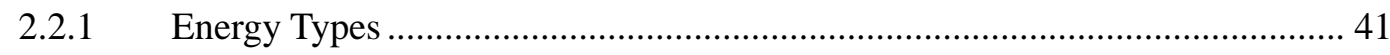

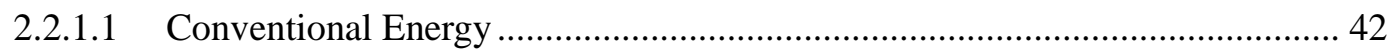

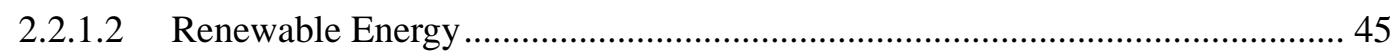

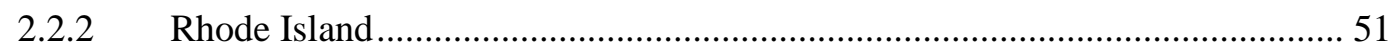

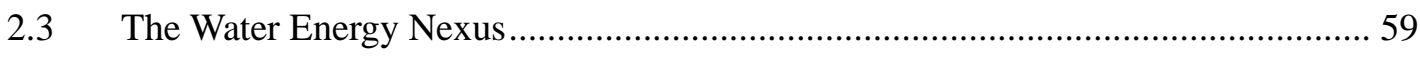

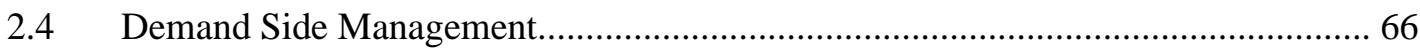

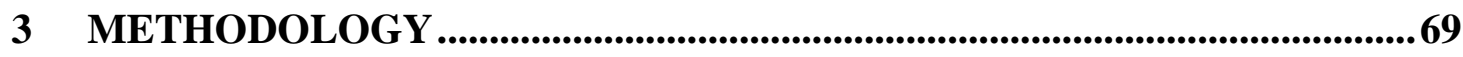

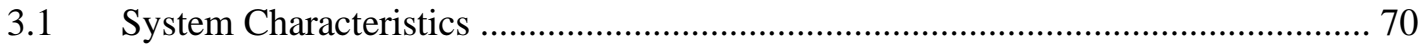

3.1.1 Water Supply System Characteristics ..................................................... 71

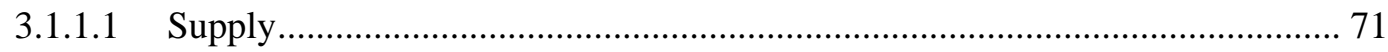

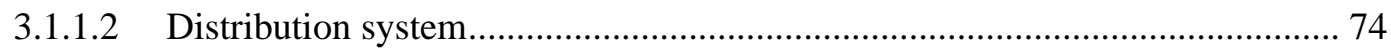

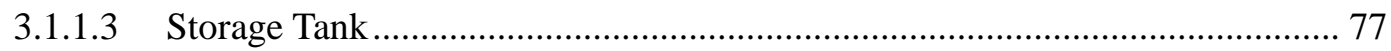




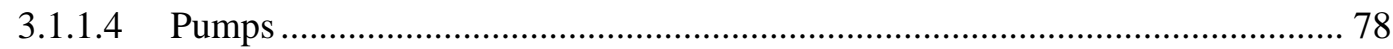

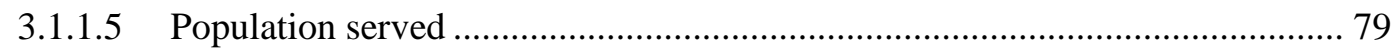

3.1.2 Energy Supply System Characteristics ................................................... 82

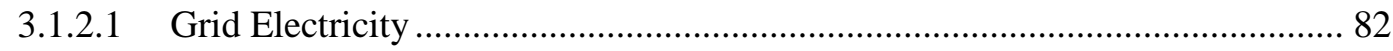

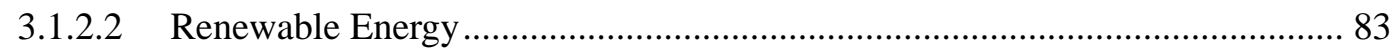

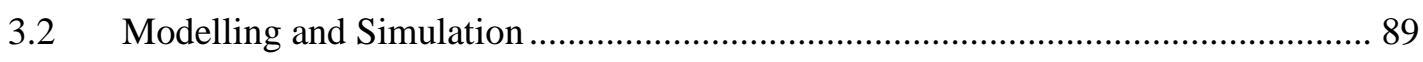

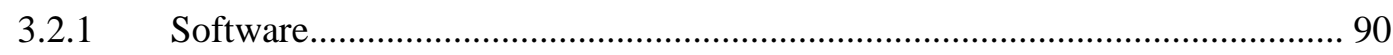

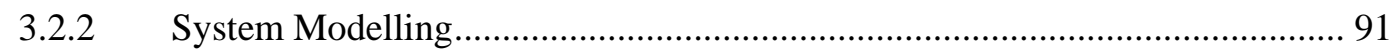

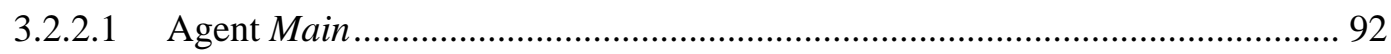

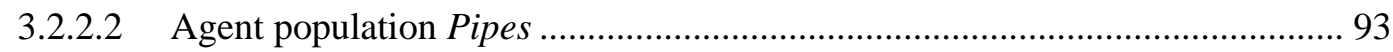

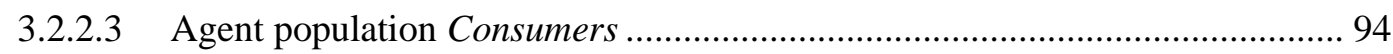

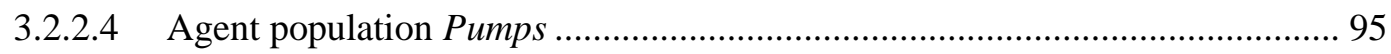

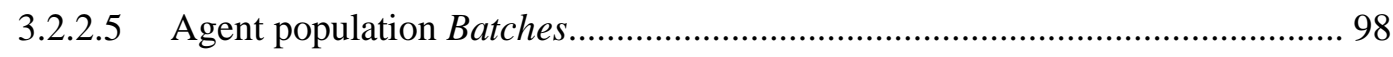

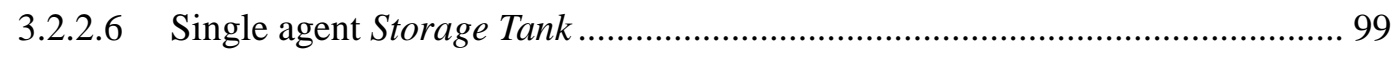

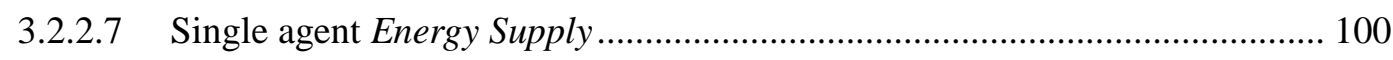

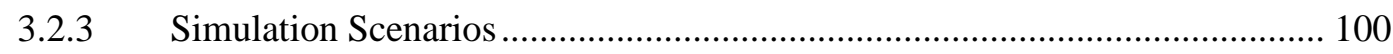

3.2.3.1 Sc. 1: Reference Scenario................................................................... 101

3.2.3.2 Sc. 2: Integration of VRE and DSM Measures......................................... 102

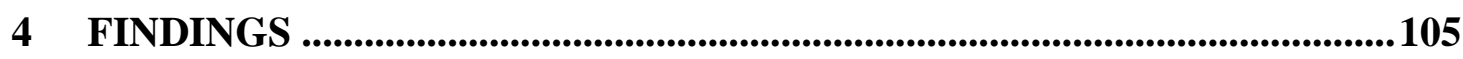

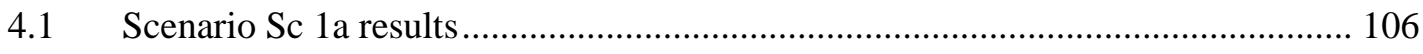

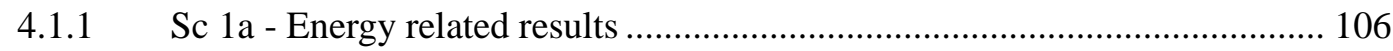

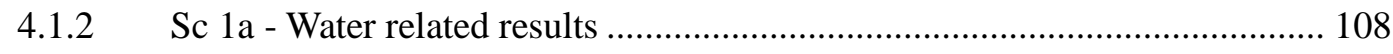

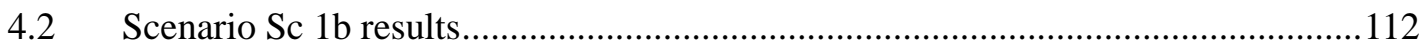

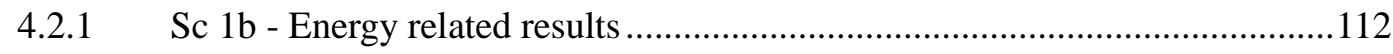

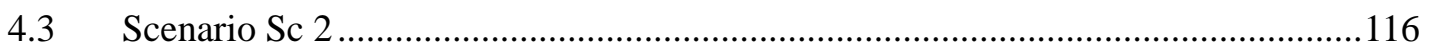




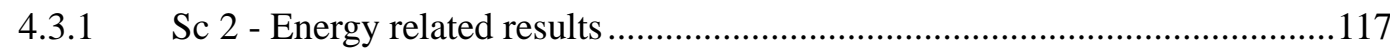

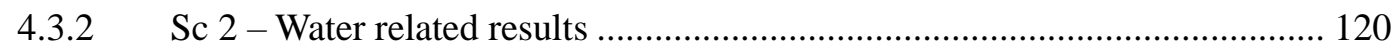

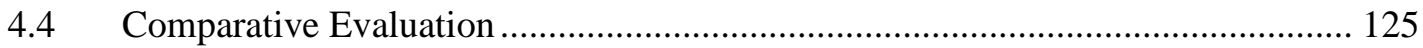

4.4.1 Comparative Evaluation - Energy related results ........................................ 126

4.4.2 Comparative Evaluation - Water related Results ........................................ 132

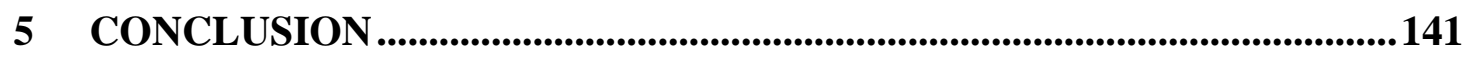

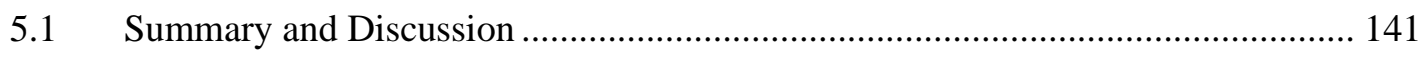

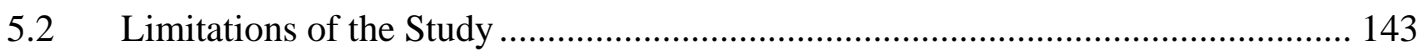

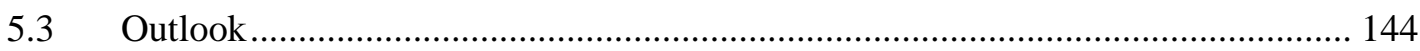

LIST OF REFERENCES ............................................................................... 146

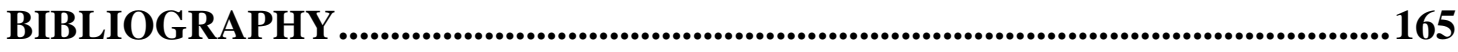




\section{LIST OF FIGURES}

Figure 1: Atmospheric $\mathrm{CO}_{2}$-concentration in the past 800,000 years ...........................2

Figure 2: Global temperature anomaly, annual and 5-year average ........................... 3

Figure 3: Global anthropogenic greenhouse gas emissions by sector, 2013 ................ 3

Figure 4: Projected annual replacement needs for transmission and distribution pipes.6

Figure 5: The three dimensions of sustainable development.................................. 8

Figure 6: Novel representation of the three dimensions of sustainable development ....9

Figure 7: Cause-effect chain from midpoint to endpoint indicators .......................... 12

Figure 8: Overview of energy and water system interaction ................................ 17

Figure 9: The global hydrological cycle ..................................................... 18

Figure 10: Ground-water aquifers, replenishment rates and flow paths...................... 19

Figure 11: Types of water distribution systems .............................................. 21

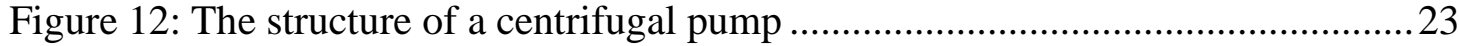

Figure 13: Pump curve (H-Q curve) and efficiency curve of a centrifugal pump.......24

Figure 14: Adapted control loop theory for water supply systems ...........................25

Figure 15: Typical diurnal water demand curve ............................................ 26

Figure 16: Water storage tank construction types in relation to system hydraulics......27

Figure 17: Water storage tank elevation and system pressure levels ..........................28

Figure 18: Moody's diagram to estimate friction losses in circular pipes ..................31

Figure 19: Annual average precipitation (inch/a) in Rhode Island 1961 - 1990.........34

Figure 20: Map of potable water sources in Rhode Island ..................................... 35

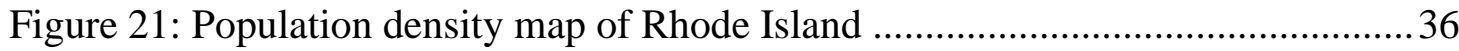


Figure 22: Use of fresh and saline water by sector in Rhode Island 37

Figure 23: Energy intensive processes in groundwater-based water supply systems... 41

Figure 24: Specific life cycle greenhouse gas emissions of energy sources .............. 43

Figure 25: Specific statistical depletion time of conventional energy carriers .............44

Figure 26: Specific annual capacity factor of energy sources ................................ 48

Figure 27: Global horizontal solar irradiance in the US, annual average.................. 49

Figure 28: Daily fluctuations and weather influence on solar power output...............50

Figure 29: Annual variability of global horizontal irradiance ...............................51

Figure 30: Global conventional and renewable net electricity generation projections. 52

Figure 31: US electricity generation by energy source .....................................53

Figure 32: Electricity generation in Rhode Island by Source, $2001-2017 \ldots \ldots \ldots \ldots \ldots . . .54$

Figure 33: Rhode Island energy consumption by end-use sector 2017 .....................55

Figure 34: Embodied energy of surface water facilities .....................................56

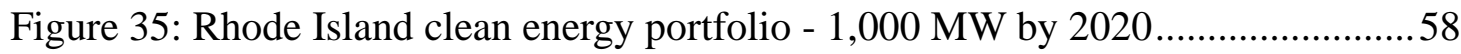

Figure 36: Left: Revolution Wind Project; Right: Solar projects in Rhode Island.......59

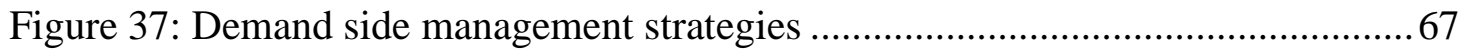

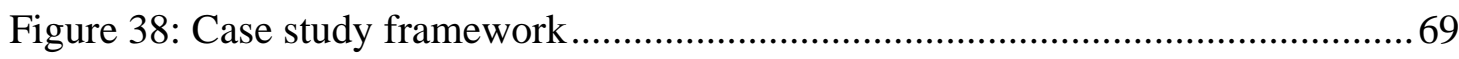

Figure 39: The URI water district and adjacent Kingston water district .................... 71

Figure 40: URI freshwater source: The Chipuxet aquifer ................................... 72

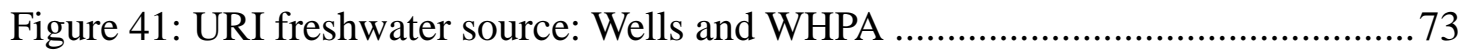

Figure 42: University of Rhode Island topographic map, $5 \mathrm{ft}$ contour lines ...............73

Figure 43: Distribution system volume balance ............................................... 74

Figure 44: Assumed URI water distribution mains and service lines........................ 76 
Figure 45: Life on campus - Residence halls, fraternity circle and other 79

Figure 46: Life on campus - Number of residents and building elevation 80

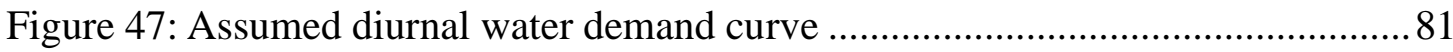

Figure 48: Assumed normal distribution of individual water demand data................. 82

Figure 49: Electricity grid mix, standard offer service in Rhode Island..................... 83

Figure 50: Roof-mounted wind turbine and photovoltaic system ............................ 84

Figure 51: PV and wind power output, relocation considered, power scaled .............88

Figure 52: Specific global warming potential of selected electricity supply sources... 89

Figure 53: Overview of the Anylogic simulation software ...................................... 90

Figure 54: Pump scheduling according to storage tank fill level ........................... 97

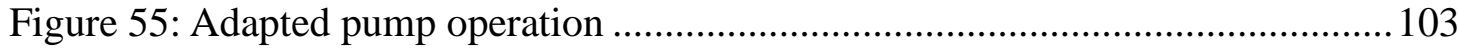

Figure 56: Sc 1a - Dynamic power demand and storage tank fill level.................... 106

Figure 57: Sc 1a - Cumulated energy demand and resulting $\mathrm{CO}_{2}$-emissions ............. 107

Figure 58: Sc 1a - Dynamic water demand and water supply .............................. 108

Figure 59: Sc 1a - Differential flow and storage tank fill level ............................. 109

Figure 60: Sc 1a - Dynamic pressure level at Hillside Hall ...................................... 110

Figure 61: Sc 1a - Retention time of sample water batches and tank fill level .......... 111

Figure 62: Sc 1b - VRE power supply and water supply system power demand....... 113

Figure 63: Sc 1b - VRE power supply and grid power supply ............................. 114

Figure 64: Sc 1b - Energy demand and supply by VRE and grid electricity ............. 115

Figure 65: Sc 1 b - Cumulated $\mathrm{CO}_{2}$-emissions and cumulated energy supply ........... 116

Figure 66: Sc 2 - VRE power supply and water supply system power demand......... 117

Figure 67: Sc 2 - VRE power supply and grid power supply ............................... 118 
Figure 68: Sc 2 - Energy demand and supply by VRE and grid electricity ............... 119

Figure 69: Sc 2 - Cumulated $\mathrm{CO}_{2}$-emissions and cumulated energy supply .............. 120

Figure 70: Sc 2 - Dynamic water demand and water supply ............................... 121

Figure 71: Sc 2 - Differential flow and storage tank fill level ................................ 122

Figure 72: Sc 2 - Dynamic pressure level at Hillside Hall ...................................... 123

Figure 73: Sc 2 - Retention time of sample water batches and tank fill level ........... 124

Figure 74: Comparative evaluation - Power demand and VRE supply ................... 126

Figure 75: Comparative evaluation - Total energy demand and VRE supply share .. 128

Figure 76: Comparative evaluation - Energy self-sufficiency and $\mathrm{CO}_{2}$-emissions ... 129

Figure 77: Comparative evaluation - Cumulated VRE supply ............................ 130

Figure 78: Comparative evaluation - Dynamic water demand and water supply ...... 132

Figure 79: Comparative evaluation - Water balance........................................... 133

Figure 80: Comparative evaluation - Storage tank fill level................................ 135

Figure 81: Comparative evaluation - Pressure level at Hillside Hall....................... 136

Figure 82: Comparative evaluation - Retention time of sample water batches .........137

Figure 83: Comparative evaluation - Total number of pump switches .....................139 


\section{LIST OF TABLES}

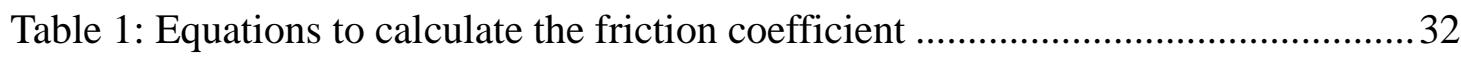

Table 2: Absolute pipe roughness of predominantly used pipe materials................... 32

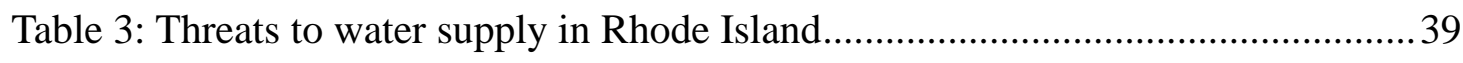

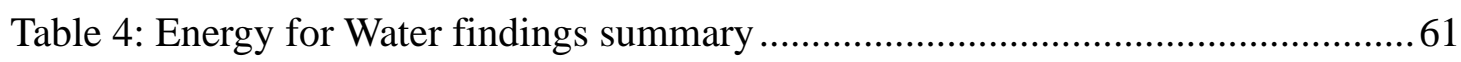

Table 5: Calculation of a relocation coefficient for photovoltaic power data.............. 85

Table 6: Calculation of a relocation coefficient for wind turbine power data ..............86

Table 7: Key performance indicators for the evaluation of the simulation scenarios. 105

Table 8: Comparative evaluation - Summary of energy related results ................... 131

Table 9: Comparative evaluation - Summary of water related results ...................... 140 


\section{LIST OF ABBREVIATIONS}

\begin{tabular}{|c|c|c|}
\hline AFOLU & - & Agriculture, forestry and other land use \\
\hline AoP & - & Areas of Protection \\
\hline BEP & - & Best efficiency point \\
\hline $\mathrm{CF}$ & - & Capacity factor \\
\hline $\mathrm{CH}_{4}$ & - & Methane \\
\hline $\mathrm{CO}_{2}$ & - & Carbon dioxide \\
\hline DSM & - & Demand side management \\
\hline $\mathrm{EE}$ & - & Embodied energy \\
\hline EIA & - & Energy Information Administration \\
\hline $\mathrm{EPA}$ & - & Environmental Protection Agency \\
\hline eq. & - & Equivalent \\
\hline $\mathrm{FH}$ & - & Friction head \\
\hline FIFO & - & First in first out \\
\hline GDP & - & Gross domestic product \\
\hline GHG & - & Greenhouse gas \\
\hline GHI & - & Global horizontal irradiance \\
\hline GIS & - & Geographical information system \\
\hline GW & - & Groundwater \\
\hline GWA & - & Global wind atlas \\
\hline GWP & - & Global warming potential \\
\hline ID & - & Identification \\
\hline IEP & - & International Engineering Program \\
\hline IPCC & - & Intergovernmental Panel on Climate Change \\
\hline IWF & - & Institute of Machine Tools and Production Technology \\
\hline JML & - & Java Modelling Language \\
\hline KPI & - & Key performance indicator \\
\hline MGD & - & Mega-gallons per day \\
\hline MSY & - & Maximum sustainable yield \\
\hline NASA & - & National Aeronautics and Space Administration \\
\hline
\end{tabular}




\begin{tabular}{|c|c|c|}
\hline $\mathrm{N}_{2} \mathrm{O}$ & - & Nitrous oxide \\
\hline NCEI & - & National Centers for Environmental Information \\
\hline NEPOOL & - & New England Power Pool \\
\hline NOAA & - & National Oceanographic and Atmospheric Administration \\
\hline $\mathrm{P}$ & - & Population (Kaya) \\
\hline $\mathrm{PH}$ & - & Pressure head \\
\hline ppm & - & Parts per million \\
\hline $\mathrm{PV}$ & - & Photovoltaic \\
\hline PVC & - & Polyvinyl chloride \\
\hline REG & - & Renewable energy growth program \\
\hline REF & - & Renewable energy fund \\
\hline RI & - & Rhode Island \\
\hline RIOER & - & Rhode Island Office of Energy Resources \\
\hline RIRES & - & Rhode Island renewable energy standard \\
\hline RIWRB & - & Rhode Island Water Resources Board \\
\hline Sc & - & Scenario \\
\hline SCADA & - & Supervisory control and data acquisition \\
\hline SEIA & - & Solar Energy Industries Association \\
\hline SH & - & Static head \\
\hline SI & - & Système international d'unités \\
\hline SW & - & Surface water \\
\hline TDH & - & Total dynamic head \\
\hline TU BS & - & Technische Universität Braunschweig \\
\hline URI & - & University of Rhode Island \\
\hline US & - & United States \\
\hline US Doc & - & United States Department of Commerce \\
\hline USGS & - & United States Geological Survey \\
\hline $\mathrm{VH}$ & - & Velocity head \\
\hline VRE & - & Variable renewable energy \\
\hline WHPA & - & Wellhead protection area \\
\hline WL & - & Water level \\
\hline WSS & - & Water supply system \\
\hline
\end{tabular}




\section{LIST OF SYMBOLS}

\section{LATIN SYMBOLS}

\begin{tabular}{|c|c|c|c|}
\hline$A$ & - & Area & {$\left[\mathrm{m}^{2}\right]$} \\
\hline C & - & Carbon intensity & [g CO 2 -eq. $/ \mathrm{kWh}]$ \\
\hline$D$ & - & Diameter & {$[\mathrm{m}]$} \\
\hline$E$ & - & Energy & {$[\mathrm{W}]$} \\
\hline$e$ & - & Absolute pipe roughness & {$[\mathrm{mm}]$} \\
\hline$f$ & - & Friction coefficient & {$[-]$} \\
\hline$g$ & - & Gravity & {$\left[\mathrm{m} / \mathrm{s}^{2}\right]$} \\
\hline$h$ & - & Height & {$[\mathrm{m}]$} \\
\hline$L$ & - & Length & {$[\mathrm{m}]$} \\
\hline$P$ & - & Power & {$[\mathrm{W}]$} \\
\hline$p$ & - & Pressure & {$[\mathrm{Pa}] /[\mathrm{psi}]$} \\
\hline$Q$ & - & Flow & {$\left[\mathrm{m}^{3} / \mathrm{s}\right]$} \\
\hline$r$ & - & Radius & {$[\mathrm{m}]$} \\
\hline$R e$ & - & Reynolds number & {$[-]$} \\
\hline$t$ & - & Time & {$[\mathrm{s}],[\min ],[\mathrm{h}],[\mathrm{d}],[\mathrm{a}]$} \\
\hline$V$ & - & Volume & $\left[\mathrm{m}^{3}\right]$, gal $]$ \\
\hline$V$ & - & Velocity & {$[\mathrm{m} / \mathrm{s}]$} \\
\hline$z$ & - & Height & {$[\mathrm{m}]$} \\
\hline
\end{tabular}




\section{GREEK SYMBOLS}

$\begin{array}{llll}\Delta & - & \text { Differential } & {[-]} \\ \zeta & - & \text { Friction coefficient } & {[-]} \\ \eta & - & \text { Efficiency } & {[-],[\%]} \\ v & - & \text { Dynamic viscosity } & {\left[\mathrm{m}^{2} / \mathrm{s}\right]} \\ \pi & - & \text { Pi } & {[-]} \\ \rho & - & \text { Density } & {\left[\mathrm{kg} / \mathrm{m}^{3}\right]} \\ \sigma & - & \text { Standard deviation } & {[\mathrm{gal}]}\end{array}$

\section{UNIT PREFIXES}

\begin{tabular}{|c|c|c|c|c|c|c|c|c|c|}
\hline $\mathrm{m}$ & - & milli & - & $x 10^{-3}$ & $\mathrm{k}$ & - & kilo & - & $x 10^{3}$ \\
\hline$c$ & - & centi & - & $x 10^{-2}$ & M & - & mega & - & $\times 10^{6}$ \\
\hline & & & - & & G & - & giga & - & $\times 10^{9}$ \\
\hline & & & - & & $\mathrm{T}$ & - & tera & - & $x 10^{12}$ \\
\hline
\end{tabular}




\section{INTRODUCTION}

This introduction will underline the significance and justification of this study, emphasize the hypothesis and related objectives as well as outline the formal structure of the document.

\subsection{Justification of the Study}

This thesis seeks to evaluate the potentials of water supply systems to be used for energy flexibility measures. The development towards an increasing share of fluctuating renewable energies requires a paradigm shift across all energy-consuming sectors. Water supply systems entail a promising potential to apply energy flexibility measures by using flexible load shapes of pumps and water storage facilities to compensate for the resulting deviations in water demand and supply. Framed by the overarching goal of a sustainable development, this chapter will underline the important aspects of water and energy supply systems to emphasize the significance of the study.

\subsubsection{Climate Change and Energy Supply}

Climate change or global warming is one of the most severe threats of the $21^{\text {st }}$ century. The anthropogenic share of global warming is caused by the emissions with a global warming potential. These emissions include but are not limited to the greenhouse gases $\mathrm{CO}_{2}, \mathrm{CH}_{4}$ and $\mathrm{N}_{2} \mathrm{O}$. The concentration of these emissions in the atmosphere influence the average global temperature ${ }^{1}$. The intergovernmental panel on climate change (IPCC) provides assessment reports that both evaluate the scientific 
coherences of greenhouse gas emissions, global warming and potential resulting threats and provide recommendations for action to mitigate global warming. To avoid severe threats to human health, natural environments and natural resources, the IPCC states that the increase of the average global temperature should not exceed $2^{\circ} \mathrm{C}$ with a strong trend towards trying to stay below $1.5^{\circ} \mathrm{C}^{2}$.

Figure 1 shows the concentration of carbon dioxide in the global atmosphere for the past 800,000 years including the 2018 average concentration of $407.4 \mathrm{ppm}$ (parts per million). The concentration of $\mathrm{CO}_{2}$ in 2018 was $23.5 \%$ higher than the maximum concentration in the past 800,000 years $^{3}$. The graph visualizes the significance of reducing the emissions of greenhouse gases and thus mitigating global warming.

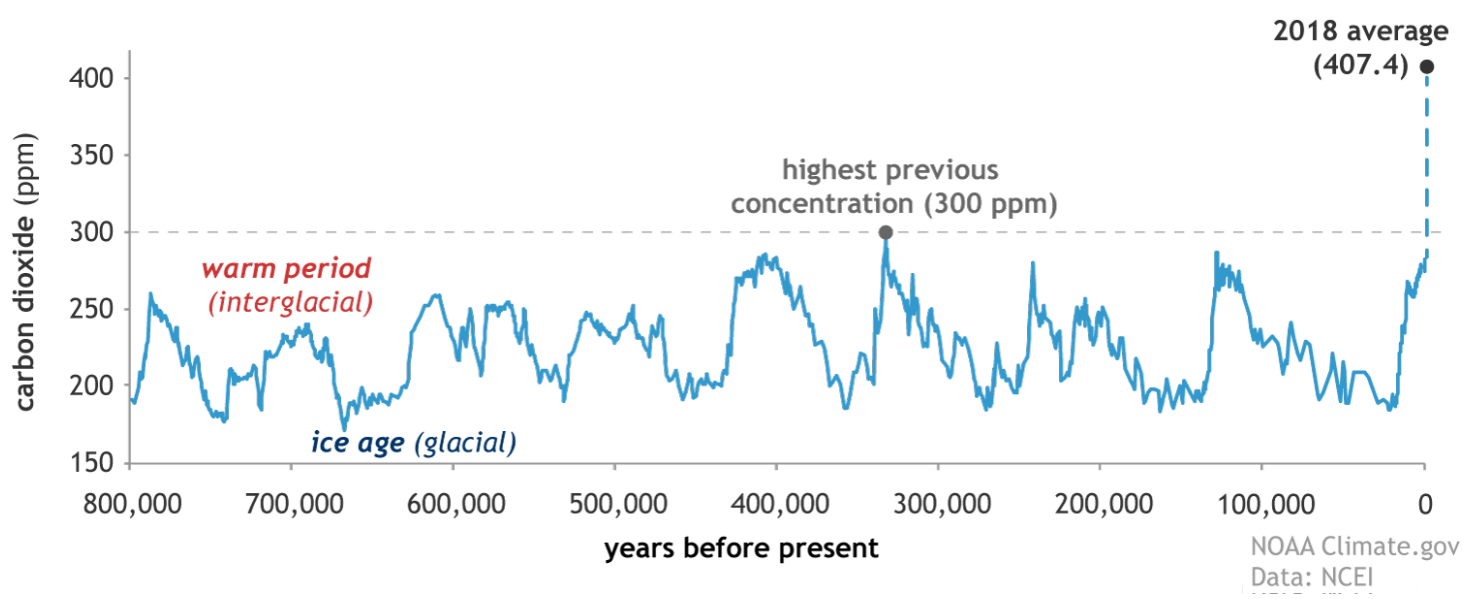

Figure 1: Atmospheric $\mathrm{CO}_{2}$-concentration in the past 800,000 years, source: NOAA, climate.gov, NCEI $2020^{3}$

Figure 2 shows the global temperature anomalies from 1880 to 2013 based on the average global temperature from 1951-19804. As of the year 2013, the global temperature anomaly has exceeded $+0.5^{\circ} \mathrm{C}$ compared to the 1980 level. As the global 
temperature anomalies are influenced by anthropogenic greenhouse gas emissions, it is necessary to determine the sources of these emissions.

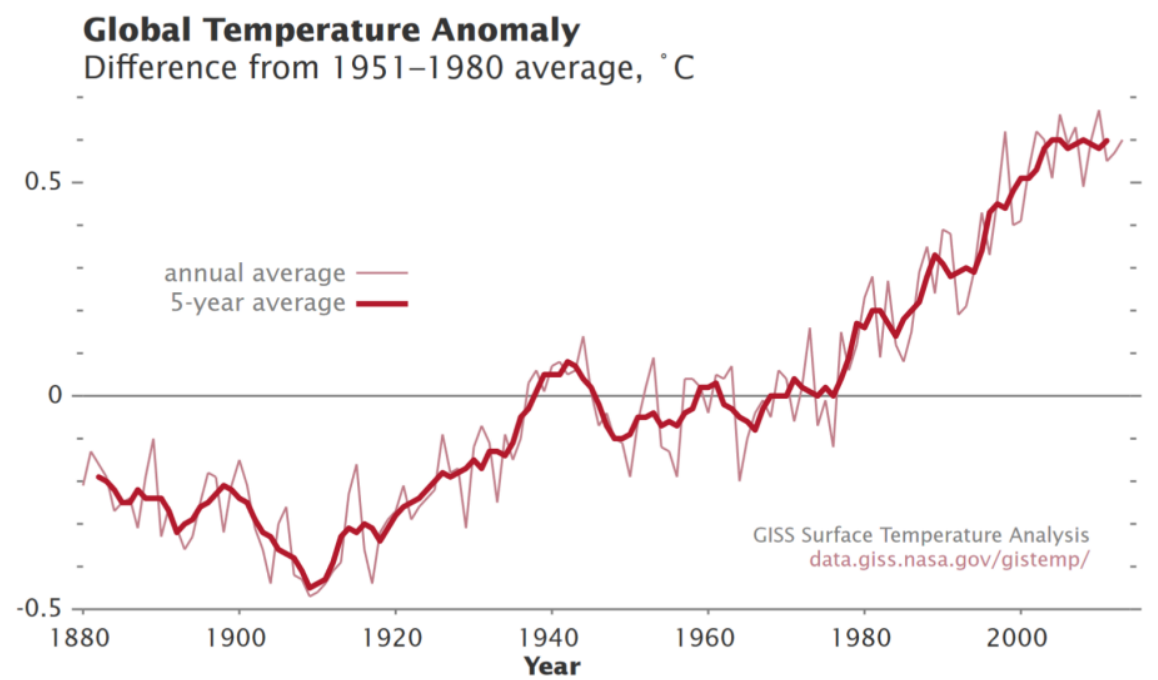

Figure 2: Global temperature anomaly, annual and 5-year average from 1880-2023 compared to the 1951-1980 average, source: NASA Earth Observatory $2020^{4}$

Figure 3 shows the total global anthropogenic greenhouse gas emissions by sector ${ }^{5}$.

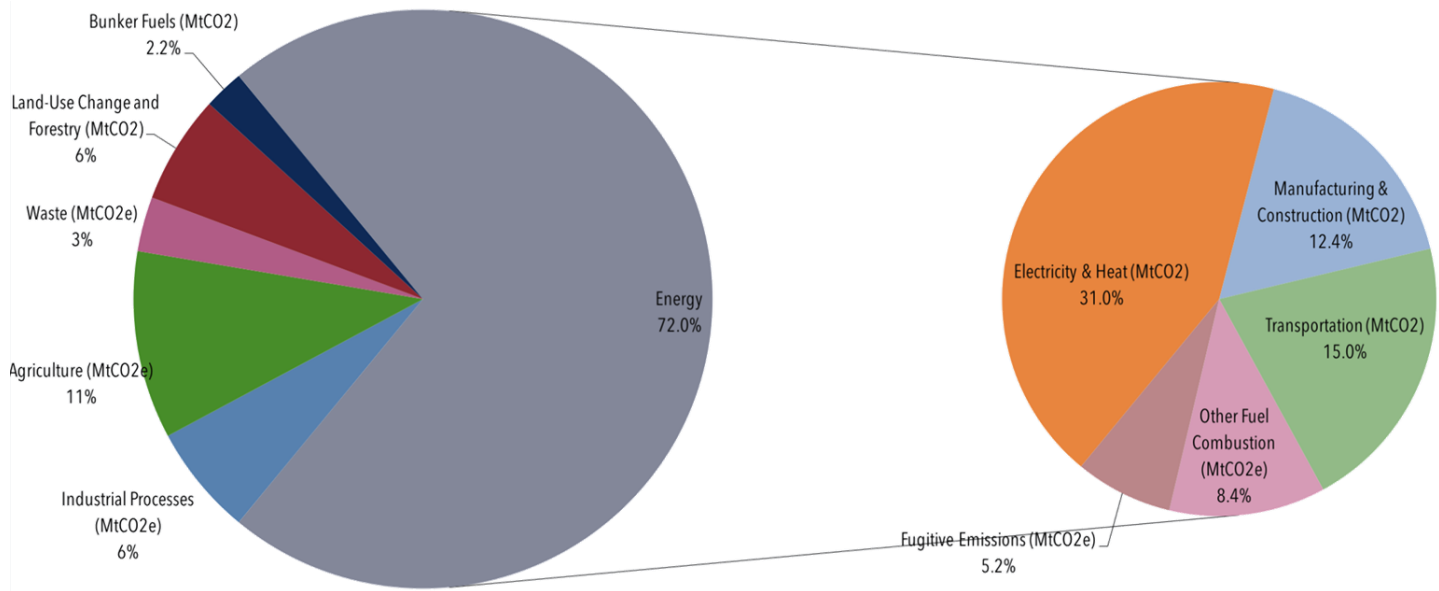

Figure 3: Global anthropogenic greenhouse gas emissions by sector, 2013, source: World Resources Institute, 2017, Center for Climate and Energy Solutions, $2020^{5}$

The pie charts show that the energy sector is by far the sector with the highest contribution to greenhouse gas emissions. Further sectors include agriculture, forestry 
and other land use (AFOLU), industrial processes, waste and bunker fuels. The energy sector can be further distinguished into electricity and heat, manufacturing and construction, as well as transportation and other fuel combustion. Inside the energy sector, electricity and heat supply has the highest share of anthropogenic GHGemissions. The increasing global temperature based on the emission of greenhouse gases and the high share of electricity supply of the anthropogenic GHG-emissions reinforce the significance of measures to reduce the specific carbon intensity of the energy sector.

To reduce the energy-related carbon emissions, renewable energies have been introduced into the energy sector. Compared to conventional fossil fuels, renewable energies emit significantly less greenhouse gas emissions. While the average life cycle greenhouse gas emission of coal and natural gas based electricity generation is $1205 \mathrm{~g} \mathrm{CO} 2 \mathrm{eq} / \mathrm{kWh}$ and $523 \mathrm{~g} \mathrm{CO}_{2 \mathrm{eq}} / \mathrm{kWh}$, the specific emissions of wind and solar power are $23 \mathrm{~g} \mathrm{CO}_{2 \mathrm{eq}} / \mathrm{kWh}$ and $42 \mathrm{~g} \mathrm{CO}_{2 \mathrm{eq}} / \mathrm{kWh}^{6}$. Additionally, renewable energies reduce the dependency on non-renewable natural resources and thus provide a sustainable foundation of future energy supply.

Despite the low carbon intensity and replenishing stock of renewable energies, the integration poses a challenge to existing energy systems. Some renewable energies like wind power and solar power are highly variable due to the fluctuations in wind speed and global irradiance. To successfully implement fluctuating renewable energies, a paradigm shift from generation follows demand towards demand follows generation is needed in the energy system. While conventional electricity generation can be controlled regarding the power output, a high share of renewable energies 
requires the demand side of the energy system to be able to adapt to the currently available power ${ }^{7}$.

\subsubsection{Water and Energy Challenges}

According to the United Nations, 3 out of 10 people lack access to safe drinking water services. Water scarcity is continuously developing for the worse and already affects $40 \%$ of the world's population. The Energy sector's numbers are equally alarming, with $13 \%$ of the global population lacking access to modern electricity services and the energy sector being responsible for approximately $60 \%$ of all global greenhouse gas emissions ${ }^{8}$. $\mathrm{CO}_{2}$-emissions alone have increased by $50 \%$ from the year $1990^{9}$. The following sections will stress the importance and significance of a sustainable development in water and energy systems.

\subsubsection{Water}

Water distribution systems in the US have existed for more than 300 years and account for approximately one million miles of water distribution pipelines including 154,000 water storage facilities ${ }^{10,11}$. Regarding water, the challenge is to maintain and optimize freshwater security as well as its biological, chemical and physical integrity with the goal of ensuring reliable and good quality drinking water ${ }^{12,13}$. To maintain this standard for future generations, an integrated approach is needed to address ease of maintenance and future projections of water sources, quality and use. Many water distribution systems will reach their end-of-life in the next 30 years and need replacement. Figure 4 shows the projected annual percentage of replacement needs for transmission and distribution lines in the US from 2000 to $2070^{14}$. This continuous 
replacement is subject to substantial costs but can also open up possibilities to implement novel innovative materials and practices ${ }^{11}$.

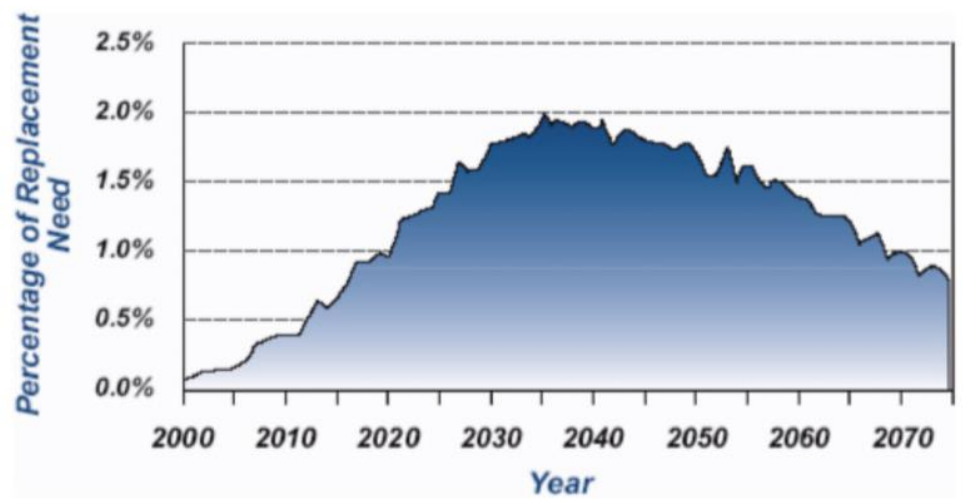

Figure 4: Projected annual replacement needs for transmission and distribution pipes, source: EPA $2002^{15}$

Water supply systems are energy intensive systems. For each mega-gallon of conveyed, treated and distributed water, $1425 \mathrm{kWh}$ of energy are consumed with distribution contributing $84.5 \%$ to that embodied energy ${ }^{16}$. Increasing the use of renewable energies to power the water supply sector is a promising approach to improve the operation of water supply systems towards reducing the environmental impact. The continuous replacement and improvement of water supply systems allows for the integration of renewable energy-based system operation approaches on local scales. Especially decentralized greenfield planning of new supply systems can profit from decentralized renewable energy supply. Still, both small and large systems can help to mitigate greenhouse gas emissions and ultimately contribute to a sustainable development. 


\subsubsection{Energy}

In the energy sector, the current development towards a reduction of fossil fuels seeks to ensure reliable and clean energy for future generations. While non-renewable resources are subject to a reducible stock that does not replenish in time periods significant to human generations, renewable energies are flow limited but replenish in sufficient time periods ${ }^{17}$. They can thus be used as a promising source for a long-term global energy strategy. The integration of renewable energies requires sophisticated energy management on both the supply and demand side to cope with the predominantly decentralized setting and fluctuating nature of renewable energy sources. Especially wind and solar power are subject to fluctuations due to changes in wind speed and global radiation intensity, respectively. These fluctuations pose a great challenge for the successful implementation of renewable energies. Flexibility measures can be used to increase the utilization of renewable energies in times of high energy generation.

Whereas efficiency always targets at minimizing the input, flexibility includes approaches that do the opposite. When there is not enough input available, flexibility can use efficiency strategies to reduce the demand of that input. On the other hand, if more than enough input is available, flexibility is also capable of using that abundance. Flexibility is a very important strategy to optimize and synchronize energy demands and fluctuating energy supply patterns of renewable energies. When enough input is available, the system will adapt and be able to run at a higher productivity. When there is a lack of that input, the system can run at a lower productivity. The 
overall output of the system will eventually be compensated by the patterns of abundance and lack.

\subsubsection{Sustainable Development}

According to the Brundtland Commission, sustainable development is " $a$ development, that meets the needs of the present without compromising on the ability of future generations to meet their own needs" $" 18$. Sustainability has been represented in different ways in the past and has often referred to as the triple bottom line or the three pillars of sustainability. The common theme in all visualizations are the three dimensions of sustainability, namely the society, the environment and the economy. These dimensions are often simplified as people, planet and profit.
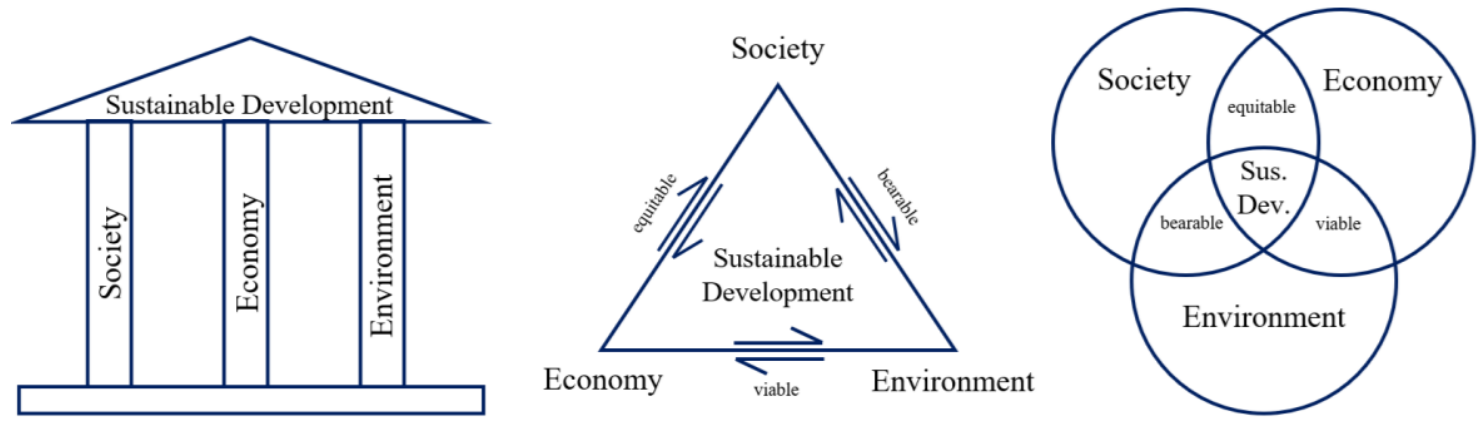

Figure 5: The three dimensions of sustainable development, own figure based on Purvis et al. $2018^{19}$

All of the above visualizations have in common that the three dimensions are equally weighted and thus equally important, indicating that sustainability can only be achieved when all three dimensions are considered. J. Rockstörm proposed a new representation in 2015, deviating from the approach of equal weighting towards recognizing the hierarchy of the three dimensions ${ }^{20}$. 


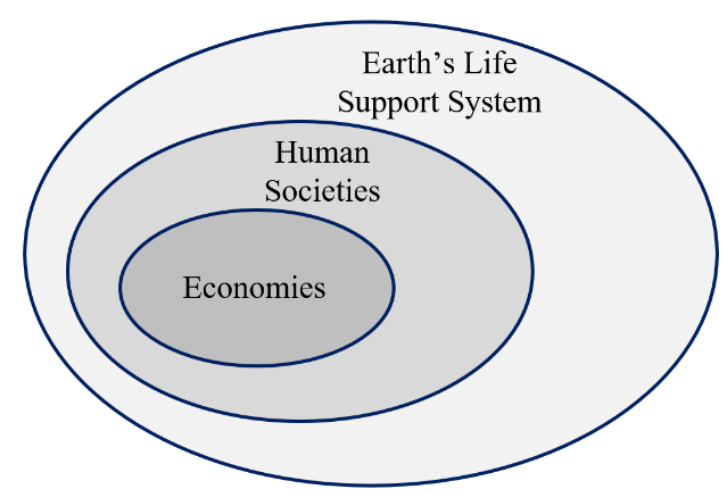

Figure 6: Novel representation of the three dimensions of sustainable development, own figure based on Rockström et al. $2015^{20}$

This representation shows, how economies are part of societies and societies are eventually part of the earth's life support system, often simplified as the environment. Especially the term Earth's Life Support System emphasizes, that protecting the environment is essential to provide a livable future for generations of humans to come and sustain the underlying conditions of human life on earth.

\subsubsection{Strategies}

Despite the dimensions of sustainability, related efforts and measures can be distinguished into three strategies, namely efficiency, consistency (also effectiveness) and sufficiency. Efficiency aims at reducing the environmental impacts of actions, services or products without compromising on their outcome ${ }^{21,22}$. Efficiency can be directly measured using the ratio of the environmental impact to the desired output, i.e. grams of $\mathrm{CO}_{2}$ per $\mathrm{kWh}$ energy produced for any electric power plants. Whereas in this example, the environmental impact is output-related (emission), it can as well be any input-related (resources) parameter, such as watts of electrical energy per lumen for the example of lightbulbs. The approach of using efficiency can aim at both reducing 
the input while keeping the output constant and increasing the output while keeping the input constant. Colloquially, efficiency is often referred to as doing things right. Efficiency is very strongly related to technological advances and innovations. It thus does not directly aim at consumer behavior or decisions, but it does affect it. Aiming at reducing environmental impacts of products and services, efficient solutions might make the service or product less expensive and induce inadvertent behavior changes towards an increased use of that service or product. Efficiency lacks to consider potential changes in the overall use of products and services, which can result in a rebound effect and consequentially increased environmental impacts. It is thus not adequate to only consider efficiency for efforts towards a sustainable development ${ }^{23}$.

Consistency aims at adjusting the anthropogenic and industrial metabolism to the natural metabolism. J. Huber refers consistency to "compatibility, coherence among things, correspondence among related aspects" ${ }^{22}$. It aims at material and energy flows within, as well as between the technosphere and the ecosphere. There are two major perceptions about achieving consistency. One is that material and energy flows within the technosphere have ideally no, but realistically minimal relation to and impact on any flows of the ecosphere. Within this perception, efficiency might be a strategy towards achieving consistency. The second perception is that the flows and their behavior within the technosphere interact so well with the natural metabolism, that even large exchanges within or between the techno- and ecosphere have only minimal impact on the ecosphere and thus minimal environmental impact ${ }^{22}$. Examples for consistency are using renewable energies and biodegradable materials. While full consonance is unlikely to be achieved by any approach, consistency can be used as an 
overarching goal or normative strategy in energy policy and product design. Colloquially, efficiency is often referred to as doing the right things.

Sufficiency is strongly related to people's behaviors and aims at reducing the overall consumption of energy, goods and services by overthinking obsolete and unsustainable consumption patterns ${ }^{24,23}$. Approaches like self-imposed restriction, frugality and simplicity can achieve sufficiency. A popular example is car sharing instead of owning a car. Private vehicles are only used for approximately $5 \%$ of the day time and sharing with others can significantly reduce the environmental impacts of this product-service system due to the higher utilization of the vehicle and reduced resource use ${ }^{25,26}$.

\subsubsection{Environmental Impacts}

Considering environmental impacts of products and services has become increasingly complex. While often, one impact category is considered in studies, approaches like life cycle engineering try to holistically address the environmental impact from different perspectives. Below, the main environmental impact categories are explained, followed by the concepts of measuring impact using the IPAT equation and Kaya Identity.

Environmental Impacts can be categorized according to their source, their cause (midpoint indicators) and their effect (endpoint indicators). The main areas that the effects can be allocated to are the three Areas of Protection (AoP), namely Human Health, Natural Environment and Natural Resources ${ }^{27}$. These three endpoint indicators 
are the result of several midpoint indicators. Figure 7 shows the cause-effect chain between the midpoint and endpoint indicators.

\section{Midpoint}

\begin{tabular}{|c|}
\hline Climate Change \\
\hline Stratospheric ozone depletion \\
\hline Human toxicity (cancer, non-cancer) \\
\hline Particulate matter formation \\
\hline Ionising radiation(humans, ecosystems) \\
\hline Photochemical ozone formation \\
\hline Acidification (terrestrial, freshwater) \\
\hline Eurtrophication (terrestrial, freshwater, marine) \\
\hline Ecotoxicity (terrestrial, freshwater, marine) \\
\hline Land use \\
\hline Larce use (mineral, fossil, biotic) \\
\hline Water use \\
\hline
\end{tabular}

Resource use (mineral, fossil, biotic)
Endpoint (AoP)

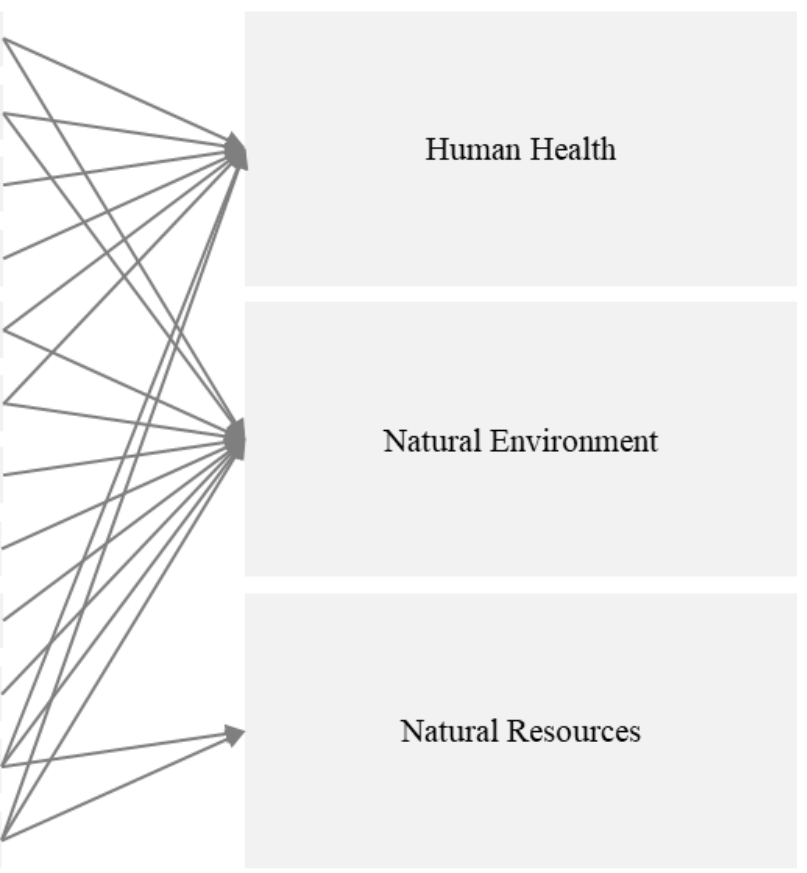

Figure 7: Cause-effect chain from midpoint to endpoint indicators, own figure based on Hauschild et al. $2017^{27}$ and European Comission $2010^{28}$

Different midpoint indicators may affect one or more areas of protection. Acidification, for example, has significant effects on natural environments but does not affect human health or natural resources. Water use, on the other hand, contributes to impacts on all three areas of protection.

\subsubsection{Quantifying Impacts}

The previously discussed strategies of sustainable development can be categorized using the IPAT-equation ${ }^{29,30}$. The IPAT-equation describes environmental impacts as a function of population, affluence and technology. 


$$
\text { Impact }=\text { Population } * \text { Affluence } * \text { Technology }
$$

Efficiency is directly related to innovations and advances in technology and can thus decrease the technology factor. Both sufficiency and consistency are related to the affluence and population factor of the equation. The IPAT-equation shows, that efficiency only would not be adequate to mitigate environmental impacts. With an increasing world population and especially developing nations striving for wealth and economic growth and the additional goal to reduce environmental impacts, the technology factor would have to be reduced drastically to compensate for the positive growth factors of both population and affluence. Sufficiency and consistency measures can help to reduce the growth rate of the affluence factor or even the population factor.

The IPAT equation was used to derive the Kaya identity, which enables the quantification of the IPAT-equation factors ${ }^{31}$. The initial equation is applied to energyrelated carbon emissions based on the gross-domestic product GDP and the total population $P$.

$$
\mathrm{CO}_{2}=P * \frac{G D P}{P} * \frac{\text { Energy }}{G D P} * \frac{\mathrm{CO}_{2}}{\text { Energy }}
$$

The identity can be altered and extended to represent any other environmental impact, as long as it entails the factors population, affluence and emission intensity. These concepts build the framework to estimate the trend of global emissions and consequentially the needs to mitigate emissions in the future. This study focusses on the technological part of the IPAT-equation to reduce the specific $\mathrm{CO}_{2}$-emissions of the product-service system water supply. 


\subsection{Hypothesis and Objectives}

In this section, the proposed study is characterized by formulating an overarching hypothesis which is further distinguished into several objectives. The hypothesis of this study is that

- The implementation of demand side management measures in water supply systems can optimize the utilization of fluctuating renewable energies without compromising on the physical integrity of the water.

A simulation model is proposed to represent the current system status as a reference and the proposed implementation of demand side management measures. The objectives of this study are listed below:

- Assess the potential of applying demand side management measures to the water supply system operation and control

- Define flexibility measures that can be applied to the water supply system operation and control

- Define energy and water related key performance indicators to compare the proposed approach to the reference system

- Model simulation scenarios that represent the initial water supply system and the proposed combined integration of variable renewable energies and demand side management measures

- Compare the simulation scenarios based on the energy and water related key performance indicators 


\subsection{Structure of the Study}

This study is organized in five chapters. Following the introduction, the two main objects of investigation, namely water supply systems and energy supply systems are discussed in chapter 2. The various types of water and energy supply systems are discussed with a focus on the interrelations along the path from the source of water and energy to their use. Additionally, a view on the current situation for both energy and water will be given from different spatial scopes. Chapter 2 finishes with a comprehensive introduction about the concepts of demand side management and associated flexibility strategies.

The characteristics of the specific water and energy supply system assessed in the case study will be stressed in chapter 3 to provide a profound basis, on which the simulation model can build. The modelling and simulation of the reference and proposed future scenarios is explained including the choice of modelling approach and detailed information about the modelling of each specific model entity. In chapter 4, the results from the simulation scenarios are evaluated individually as well as compared to each other using predefined key performance indicators. The thesis will finish with chapter 5 , in which the results will be discussed, the limitations of this study are formulated and a brief outlook into potential future research will be given. 


\section{LITERATURE REVIEW}

The literature review in this study is organized in four sections. The main topic of this study relates to the water-energy nexus with a focus on electric energy use in water supply systems (energy for water). Therefore, the topic of water supply is examined along the water's pathway from source to sink. Despite the conveyance and treatment of freshwater, the focus lies on water distribution systems. Additionally, the vast field of energy supply is stressed, including the transition from traditional, fossil fuel towards renewable energies. Narrowing down the spectrum of energy types, this study focusses on electric energy. The implications of high shares of fluctuating renewable energies are explained along with solutions towards their successful implementation into the existing electricity grid. In section 2.3 , the relation of water and energy is stressed using the concept of the water and energy nexus. Finally, demand side management is explained along with measures to increase the energy flexibility of a system. Figure 8 shows the relation of the water supply system with the energy supply system and their connecting super-system, the energy grid. 


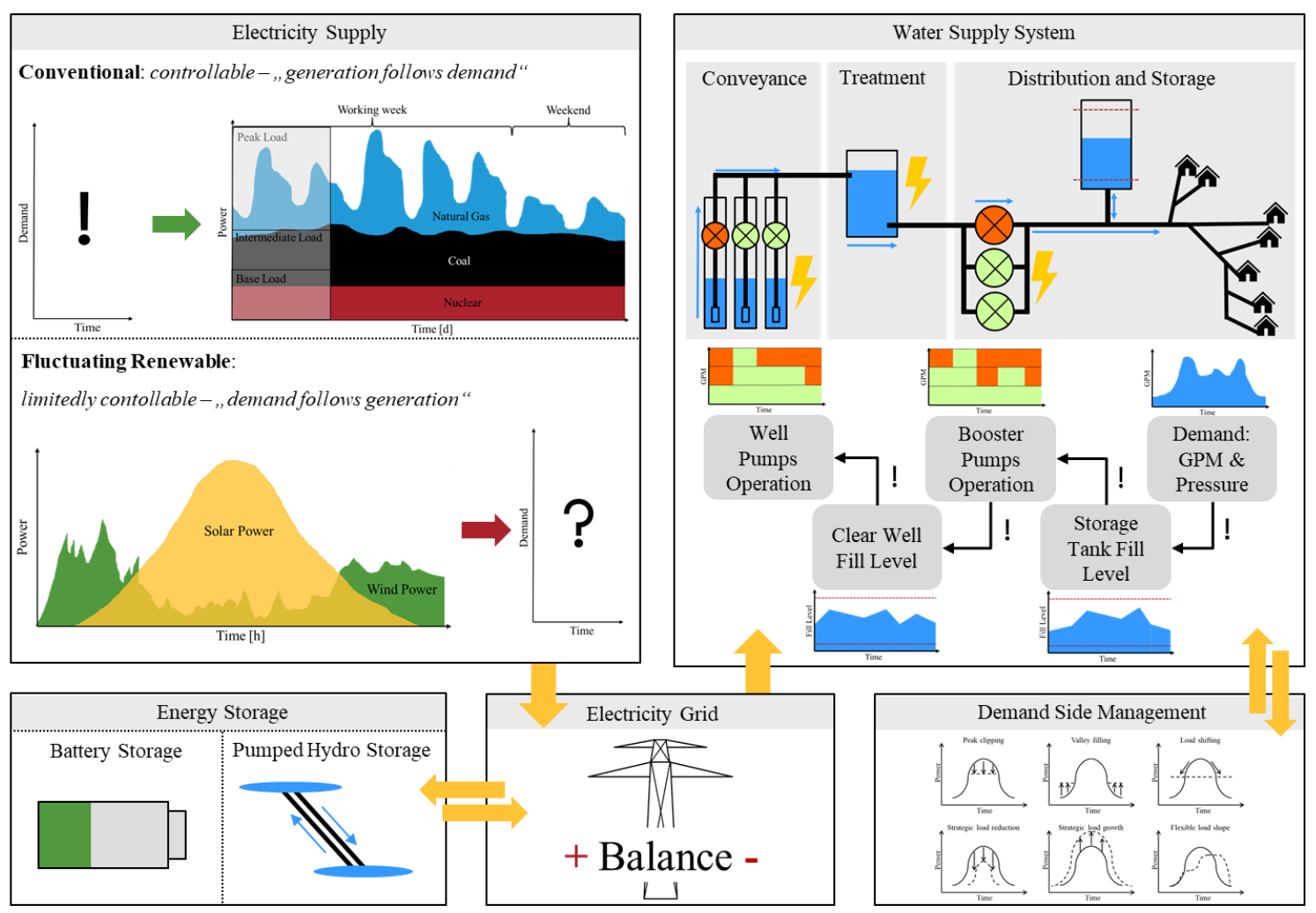

Figure 8: Overview of energy and water system interaction and strategies towards synchronizing energy demand and supply, own figure

To reduce the deviation from energy demand to energy supply, energy storage option or demand side management measures can be used to synchronize energy supply and demand. Figure 8 also provides an overview about the logical framework of the proposed study. Although energy storage potentials are not assessed in this study, they are included in the figure to demonstrate alternatives to using demand side management measures to achieve a better energy balance.

\subsection{Water Supply}

In this chapter, water supply systems are assessed in detail to build a profound basis for the methodological approach. The water supply is explained along its path from source towards the use of the water by the consumer. 


\subsubsection{Source and Conveyance}

From a general perspective, all water supply is based on the global hydrological cycle. Although water seems to be an abundant resource, only one percent is available for humans to use ${ }^{14}$. Precipitation will eventually replenish the two main sources of freshwater, which are surface water and groundwater. Figure 9 shows the global hydrological cycle, including precipitation and water storage in ice and snow as the main supply sources for surface and groundwater storage (marked in red).

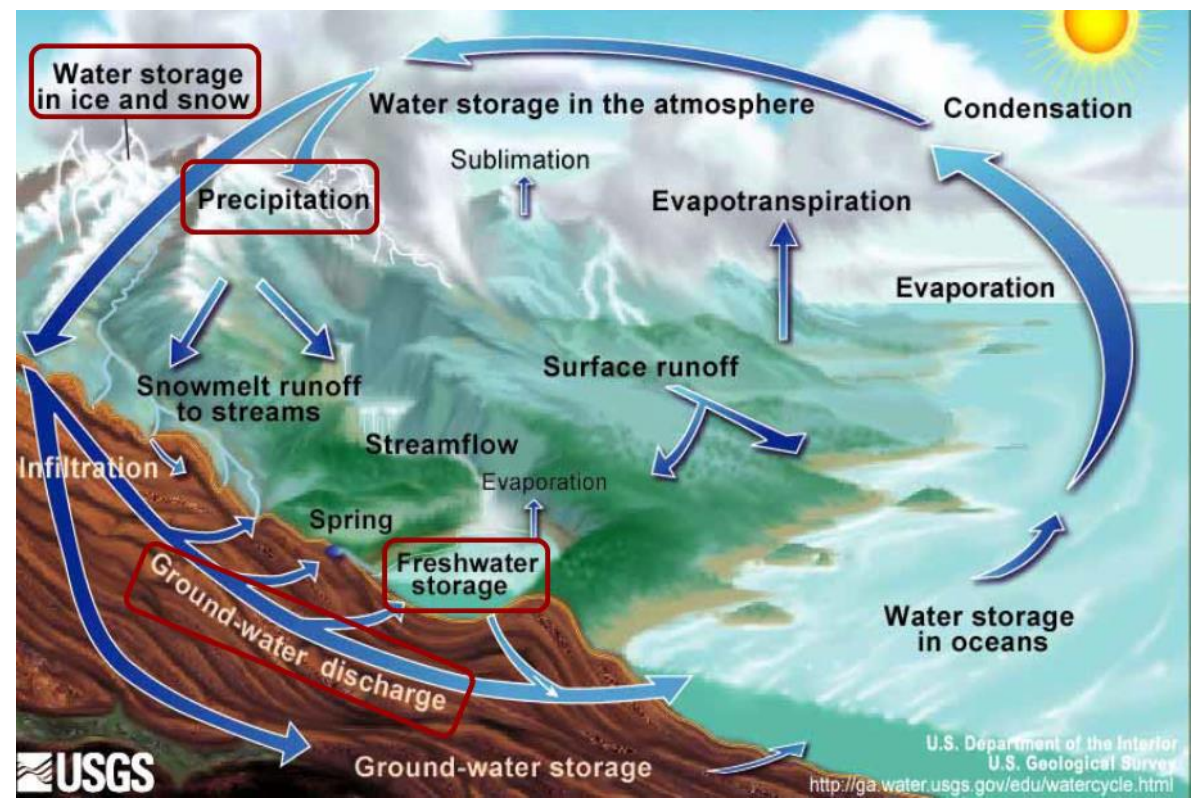

Figure 9: The global hydrological cycle, source: US Geological Survey ${ }^{32}$

Water is a renewable source. Whereas non-renewable sources do not replenish and are limited by their overall stock, renewable sources are limited by flow. Renewable resources can be further distinguished into sources with reducible stock and sources without reducible stock, also called perpetual resources. Whereas the sun is one of the only sources without a reducible stock, most renewable sources on earth do have a reducible stock. Regarding water, this stock is defined by the storage 
capacity of each freshwater source. To allow the source to sustain itself, the long-term average withdrawal rate must be lower than the replenishment rate. For every resource, there is a specific sustainable yield, to which the resource can be used without compromising on its ability to replenish itself $\mathrm{f}^{33}$.

The term maximum sustainable yield (MSY) originates from fishery science, but already constituted the deliberations of Hans Carl von Carlowitz in his book Sylvicultura Oeconomica, which marks the origins of the term sustainable ${ }^{34}$. The increasing use of freshwater poses threats on both surface- and groundwater sources. Groundwater aquifers are often very large reservoirs but replenish very slowly compared to surface water sources. While unconfined aquifers may replenish in days to years, confined aquifers can take up to centuries or even millennia to replenish, as shown in Figure 10. Those sources are thus sometimes considered non-renewable as their replenishment rate is not relevant to human generations ${ }^{35}$.

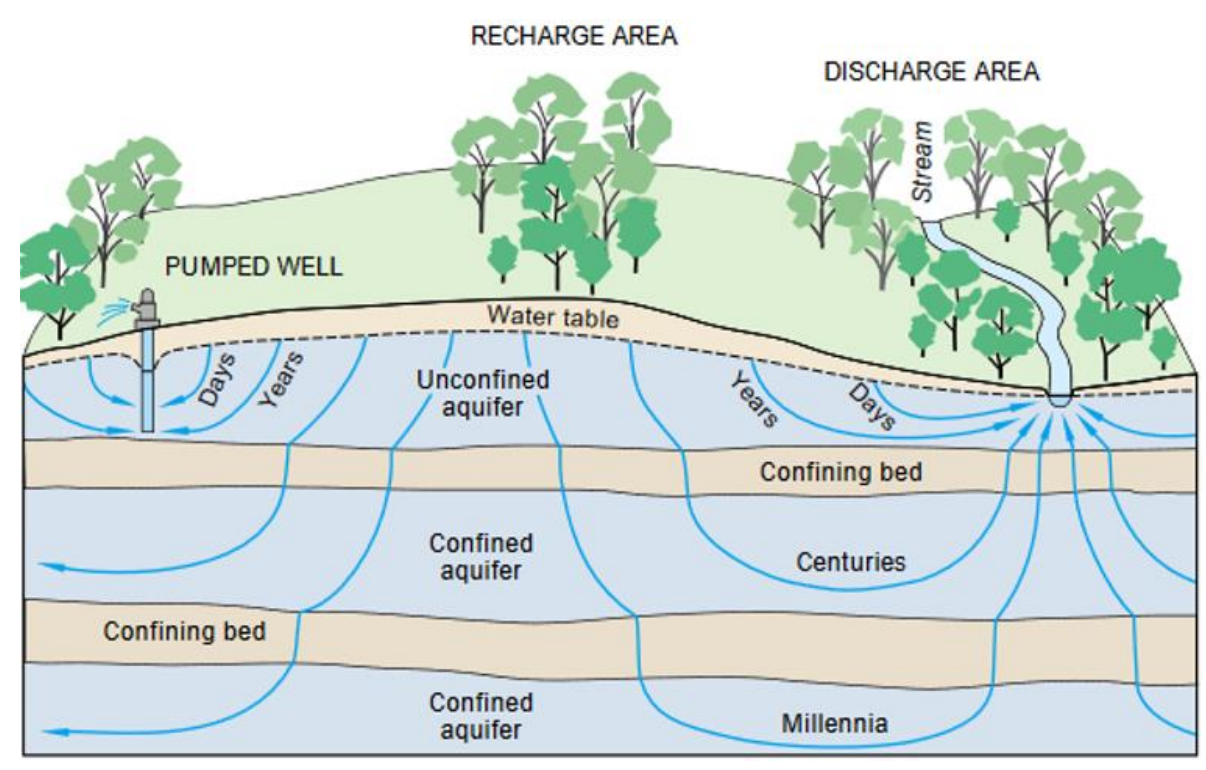

Figure 10: Ground-water aquifers, replenishment rates and flow paths, source: US Geological Survey ${ }^{35}$ 
The water-level of groundwater aquifers is declining in many regions across the $\mathrm{US}^{36}$. Due to the mixed use of ground- and surface water, surface water reservoirs are equally impacted by the increased use of freshwater in the US. $73.6 \%$ of all freshwater used in the US is supplied by surface water with the remaining $26.4 \%$ being supplied by groundwater ${ }^{37}$. Despite the industrial and domestic withdrawals, another significant loss is due to evaporation from the water surface. A Study by Zhao et al. concludes that evaporation from surface water reservoirs in the United States accounts for approximately $93 \%$ of the total annual public water supply ${ }^{38}$. A sustainable yield for the use of both surface- and groundwater resources is inevitable for maintaining freshwater security for the future.

\subsubsection{Water Distribution Systems}

Water supply systems consist of several entities, that ensure the transportation and treatment of freshwater from the source to the customer. The main elements are pipes, pumps, storage facilities, valves and treatment facilities. From a hydraulic perspective, these entities can be distinguished into passive and active according to their ability to manipulate the flow rate or direction of the water within the supply system. While pipes and storage tanks are considered passive elements, valves and pumps are the active elements in the system and can thus serve as direct operational entities that can be controlled and managed by the operation system ${ }^{39}$. Despite these solely hydraulic elements, treatment facilities will also alter the chemical and physical properties of the water. 


\subsubsection{Pipe Systems}

Distribution systems are the networks that connect the source of freshwater to every sink (consumer) within the system. While there can be multiple sources that freshwater is drawn from (e.g. 3 wellfields), from a system perspective it can be seen as one large volume of water entering the system at one input point. Through a combination of junctions and pipes, this large volume of water will be distributed and eventually supplies a relatively small amount of water to the many outputs (consumers). The design and dimensioning of water distribution system involves variables, such as the sufficient demand, amount of consumers, minimum and maximum pressure requirements and quality requirements to both supply safe drinking water and prevent corrosion or formation of biofilm within the pipes ${ }^{40}$. Distribution systems can be distinguished according to their layout. The predominantly used systems are dead-end systems, grid iron systems, ring systems and radial systems ${ }^{41}$.

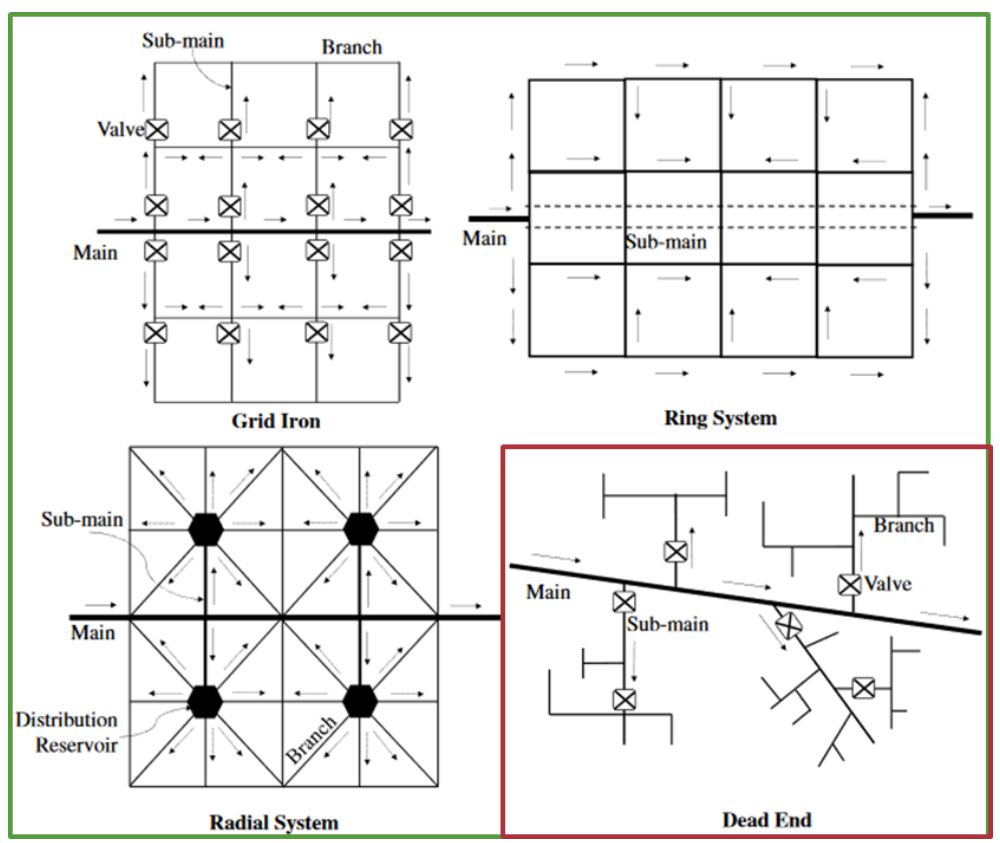

Figure 11: Types of water distribution systems, source: PWC MIWRS $2009^{41}$ 
While a lot of dead-end type systems have been used in the past due to their simple layout and design calculations, there are critical disadvantages that led to an increased use of interconnected systems, such as grid iron, ring or radial systems. Disadvantages of dead-end systems include the lack of ability to provide adequate pressure to remote areas, the dependency of the whole system on one main pipe and stagnation of water flow in less demanding areas of the system. Interconnected systems allow for multidirectional flow and free circulation of water and thus reduce the risk of stagnation, bacterial growth and sedimentation. Generally, friction losses and required pipe sizes can be reduced using interconnected systems. During damages and repairs, customers can still be supplied using alternative paths through the system.

Developers can decide which interconnected system is most suitable based on the infrastructural layout of the community or city. All interconnected systems are more complex than dead-end systems and require a larger amount of piping and valves. They are thus more complex to model, dimension and design, they require more resources and they are more costly ${ }^{42}$.

Pipes need to be dimensioned according to the volume and pressure design parameters of the system. They can be distinguished into mains, sub-mains, branches and service lines, as shown in Figure 11. The size of pipes depends on the volumetric flow and pressure in the specific pipe and generally decreases on the path from source to sink and thus from main to sub-main to branch lines. 


\subsubsection{Pumps}

In most distribution networks, gravity alone is insufficient to supply adequate amounts of water and pressure for every consumer in the system. Pumps are used to overcome height differences and increase the pressure inside the distribution network to ensure pressure and volume requirements within the system. There are several types of pumps that can be used for water supply systems. The main two cases in which pumps are used are the conveyance of groundwater to a clear well tank using well pumps and the water supply to the distribution system after treatment using booster pumps. The type and size of the pump is determined by the population served, total length of pipes in the distribution system as well as by the topographical setting of the system. While many different types of pumps exist, centrifugal pumps are most commonly used in water supply systems ${ }^{43}$. Figure 12 shows cross-section drawings of the structure of a centrifugal pump.

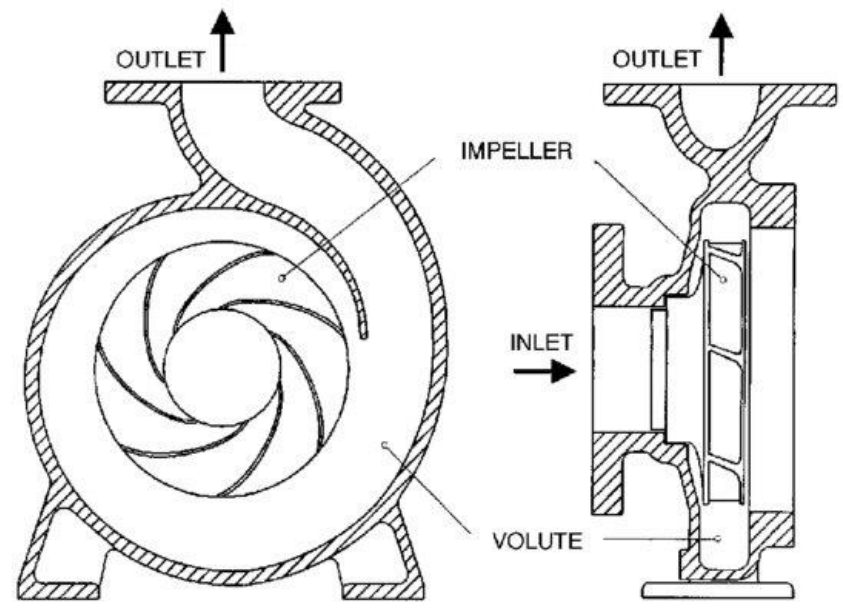

Figure 12: The structure of a centrifugal pump, source: Parrondo et al. $1998^{44}$ 
From the inlet, the impellers create centrifugal forces that move the water towards the outlet. The dimensioning of pumps is determined by the system design parameters. The two main variables to consider are the total dynamic head (TDH) and the flow rate. Pumps are characterized using a pump curve and an efficiency curve. Figure 13 shows the characteristic pump curve and the efficiency curve of a centrifugal pump.

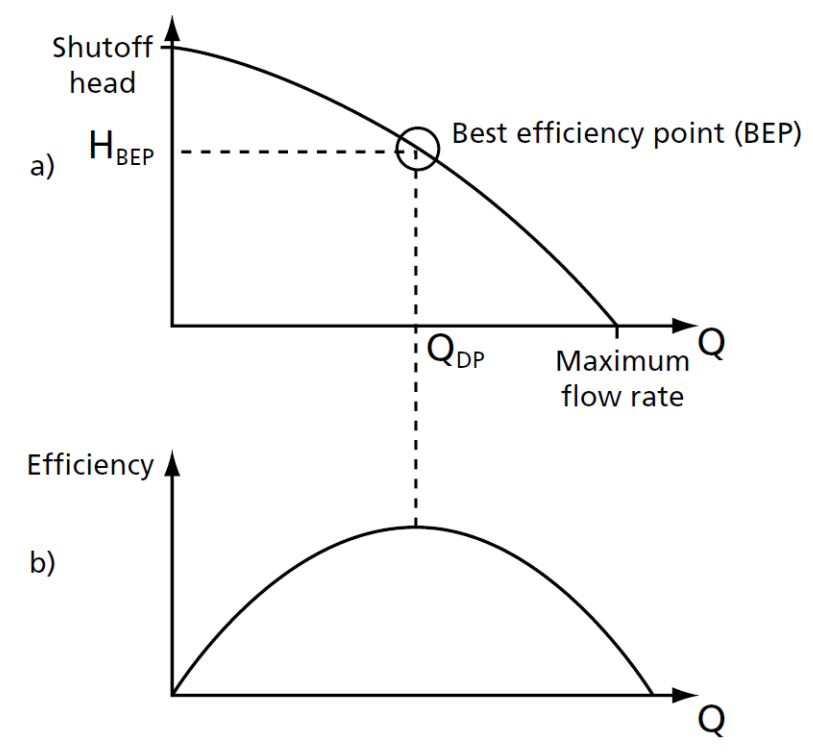

Figure 13: Pump curve (H-Q curve) and efficiency curve of a centrifugal pump, source: van Zyl et al. $2014^{43}$

From the maximum point of the efficiency curve, the head and flow rate of the best efficiency point (BEP) can be determined. While it is favorable to run pumps at the BEP, they can still be operated apart from the BEP at lower efficiency within the boundaries of the maximum flow rate or the maximum pump head (shutoff head).

Water supply systems are nowadays operated using a SCADA (Supervisory control and data acquisition) systems. Control variables are used to operate the active elements of the system, such as pumps and valves. The changes in operation will result 
in responses of both active and passive elements of the system, which will be fed back into the operation and management system. Figure 14 shows an interpretation of control loop theory applied to water distribution systems, indicating that pumps are part of the control variables in the system. The performance system will then give feedback to the operation system using variables such as pressure, water head and demand. Including the desired reference input, the pumps can be turned on or off or adjusted in flow rate or head. To determine the power of the pump, the equation 2.1 can be used.

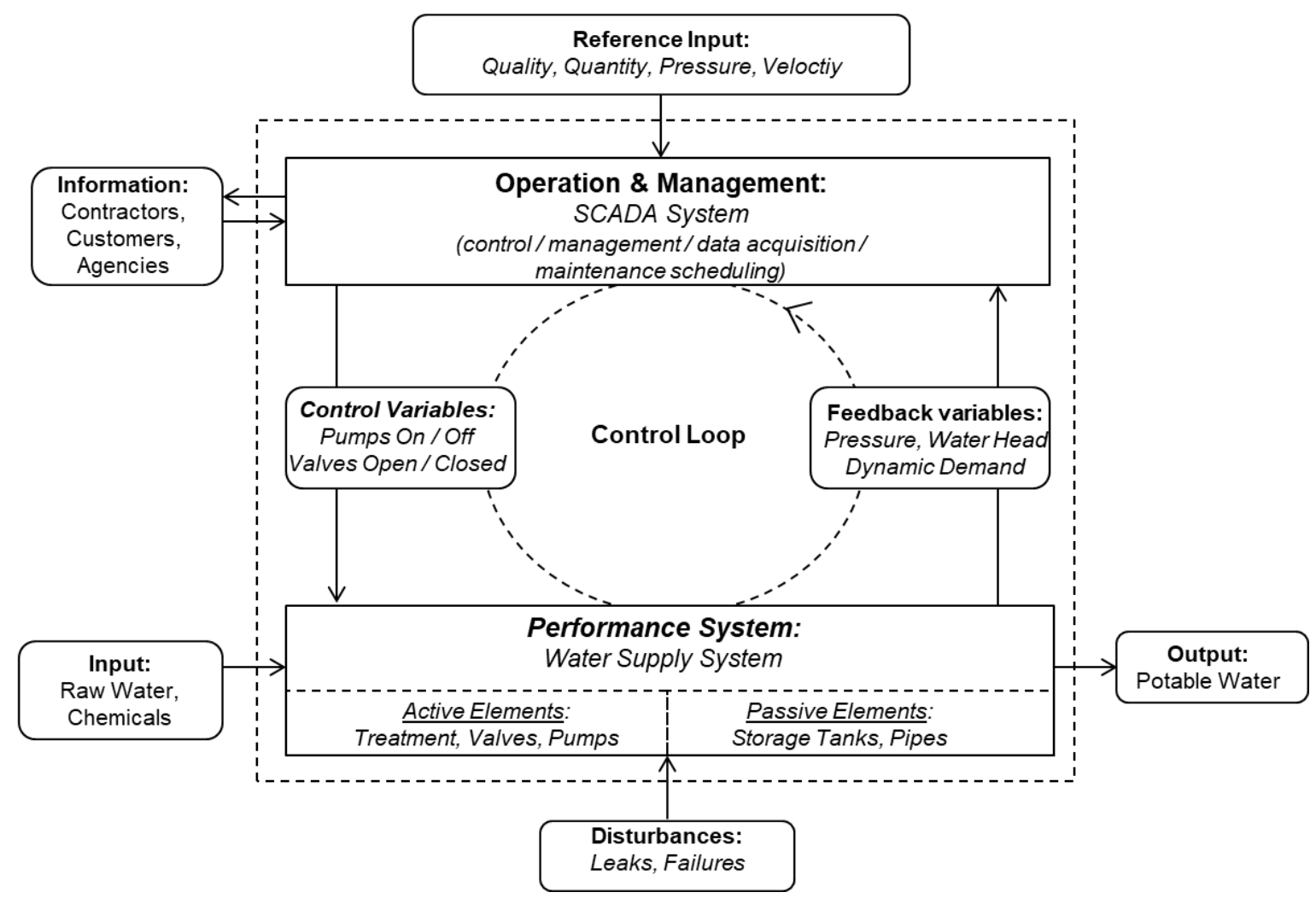

Figure 14: Adapted control loop theory for water supply systems, own figure adapted from Dyckhoff, $1994^{45}$ 


$$
P_{\text {electrical }}=\frac{\rho * g * Q * h}{\eta_{\text {pump }} * \eta_{\text {motor }}}
$$

The total efficiency of a pump is the product of the pump efficiency and the motor efficiency. The ability to calculate power from the pumping of water at a defined rate and head builds the foundation of water-energy nexus considerations in water distribution systems. In this study, equation 2.1 represents the main connection between the water and the energy system.

\subsubsection{Storage Facilities}

Water storage facilities are used in most municipal water distribution systems. They provide an equalizing storage volume which helps the supply match the dynamic diurnal water demand curve. A typical diurnal water demand curve is shown in Figure 15. Morning and evening peaks are characteristic and represent high demands caused by household activities, such as cooking, washing, toilet flushing, showering, etc.

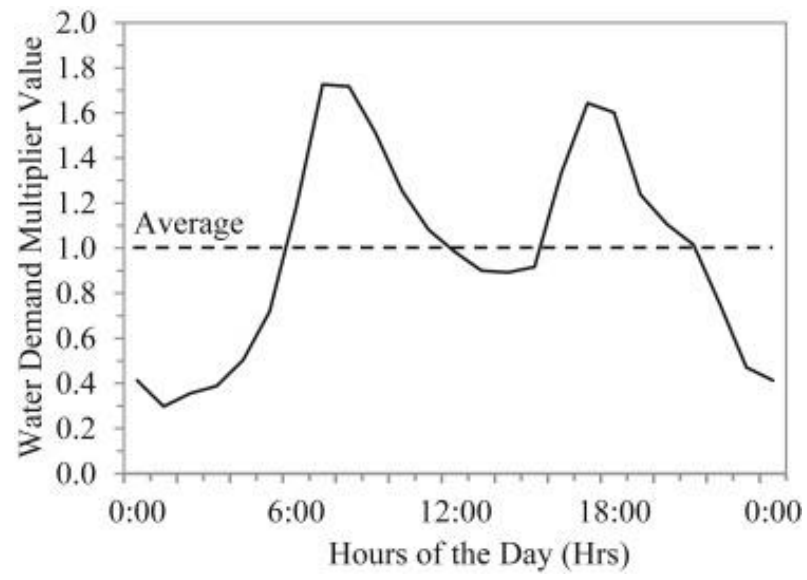

Figure 15: Typical diurnal water demand curve, source: Stokes et al. $2015^{46}$ 
Without a storage tank, the water that is fed into the system would have to match the dynamic demand of all consumers within the system at all times. Due to the inertia of the system, storage tanks are required to balance demand and supply. Besides that, storage tanks regulate the pressure within the distribution system.

If the water level in the storage tank is the highest elevation within the system, the storage tank is called a floating tank. In case of a free surface within the tank, the hydraulic gradient of a floating tank matches the gradient within the distribution system. Figure 16 shows the possible ways of integrating a storage tank into the distribution system. Floating free surface tanks are the most commonly used types. Less used constructions include pressurized floating tanks (hydropneumatic) and pumped storage tanks (left three in Figure 16) ${ }^{47}$.

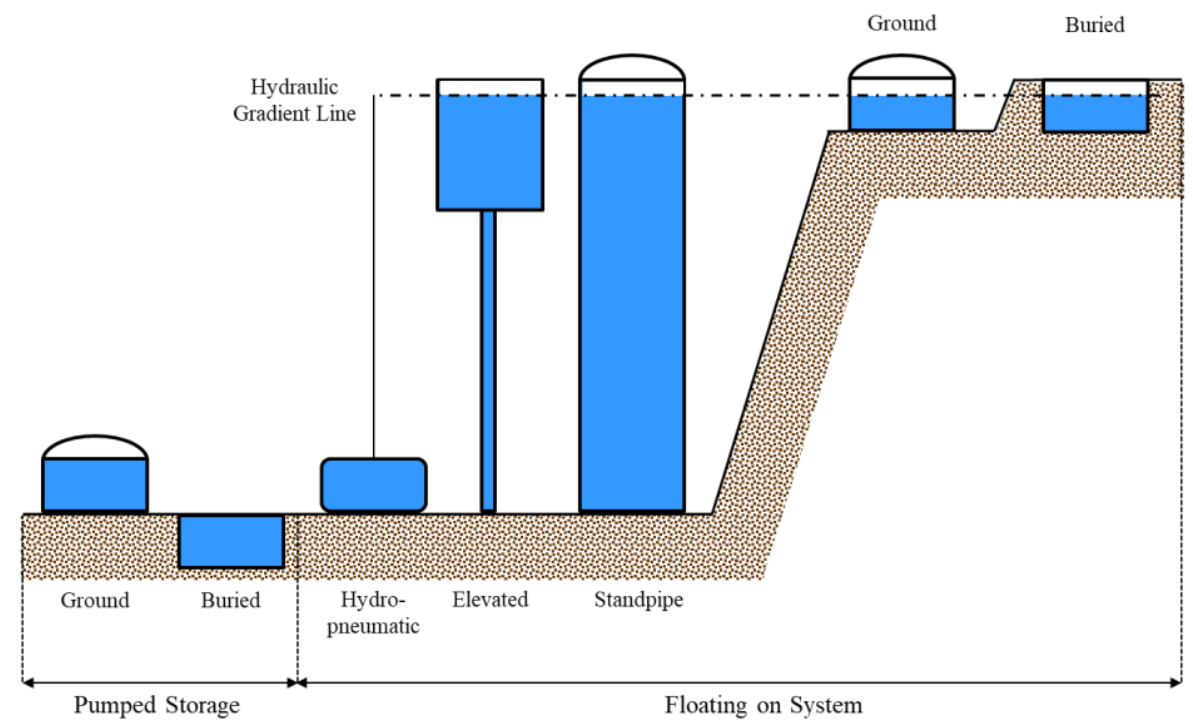

Figure 16: Water storage tank construction types in relation to system hydraulics, own figure based on Walski et al. $2003^{47}$

To avoid water supply shortage, the storage tank always contains a minimum amount of water. This minimum amount of water is also defined by the minimum 
system pressure. The State of Rhode Island Division of Public Utilities and Carriers set the minimum pressure at any service connection to $20 \mathrm{psi}^{48}$. This ensures that the consumer at the highest elevation relative to the free water surface in the storage tank is supplied water with adequate pressure. The maximum pressure of a distribution system is defined by the weakest pipe at the lowest elevation relative to the free water surface. Due to the difference in elevation, the system pressure is very high, which might lead to cracks or even pipe bursts. The maximum pressure is set to 125 psi by the RI Division of Public Utilities and Carriers ${ }^{48}$. Despite this statewide regulation, suppliers might only be able to operate in a narrower pressure range according to the topography of the system (minimum > $20 \mathrm{psi}$ ) and the age and material of the distribution pipes (maximum $<125 \mathrm{psi}$ ).

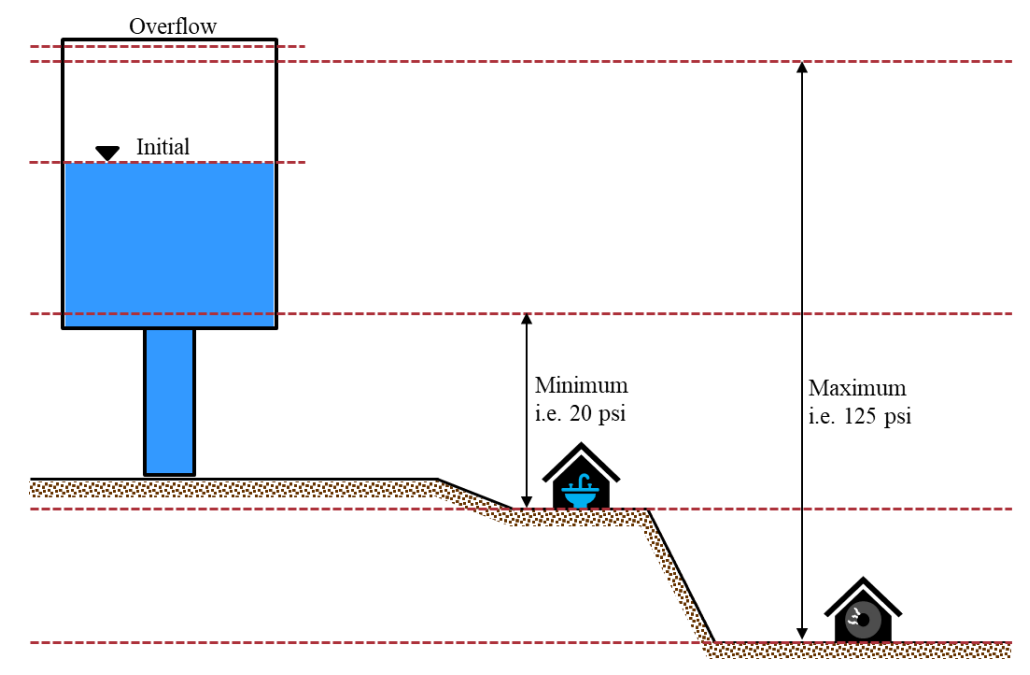

Figure 17: Water storage tank elevation and system pressure levels, own figure based on Walski et al. $2003^{47}$

\subsubsection{Distribution System Hydraulics}

The most important hydraulic and energetic concept that applies to water distribution networks is Bernoulli's equation (2.3). The energy embodied in the water 
is translated to a height, that is called the total dynamic head (TDH). The TDH is a sum of the elevation or static head $(\mathrm{SH})$, the pressure head $(\mathrm{PH})$, the velocity head $(\mathrm{VH})$ and losses, represented as the friction head $(\mathrm{FH})^{49}$.

$$
\begin{gathered}
T D H=S H+P H+V H+F H \\
h_{\text {energy }}=z+\frac{p}{\rho_{\text {liquid }} g}+\frac{v^{2}}{2 g}+h_{\text {losses,total }}
\end{gathered}
$$

The static head can be defined differently but must be uniform throughout the whole system to refer to, e.g. sea level. The pressure head can also be called static lift and refers to the difference in height that the water has to overcome. The pressure head always refers to the atmospheric pressure and can be calculated by measuring the system pressure [psi] at the desired section and translating it into feet of head or meters of head.

$$
1 \text { psi }=2.31 \mathrm{ft} \text { of head }=0.7031 \mathrm{~m} \text { of head }
$$

Under open or free-flow conditions, the pressure head is equivalent to atmospheric pressure and thus zero. The friction head represents the head equivalent of all friction losses. Friction losses are dependent on the velocity and thus occur only, when water is in motion. The two main types of friction losses are stationary and continuous losses.

$$
h_{l, \text { total }}=h_{l, \text { continuous }}+h_{l, \text { stationary }}
$$


Continuous losses in pipes with a circular cross-section are a function of the specific pipe friction coefficient, the length and diameter of the pipe, the velocity of the water flowing through the pipe and the gravity. The losses of pipe can be calculated using the Darcy-Weisbach equation

$$
h_{l, \text { continuous }}=f * \frac{l}{d} * \frac{v^{2}}{2 g}
$$

To calculate the specific pipe friction coefficient $f$, the flow regime must be determined, which is defined by the Reynolds-number Re and can be distinguished into the laminar flow regime $(\operatorname{Re}<2000)$ and the turbulent flow regime $(\operatorname{Re}>4000)$. The range between the two regimes is called the critical zone, in which friction losses can not be determined accurately ${ }^{40}$. The Reynolds-number is a function of the velocity, the internal pipe diameter and the kinematic viscosity of the fluid.

$$
R e=\frac{v * d}{v}, \text { with } \quad v_{\text {water }}=1 * 10^{-6} \frac{\mathrm{m}^{2}}{\mathrm{~s}}
$$

For laminar flow, the friction coefficient is only dependent on the Reynoldsnumber and can be calculated using the law of Hagen-Poiseuille (2.8)

$$
f=\frac{64}{R e}
$$

For Turbulent flow, the friction coefficient is a function of both the Reynoldsnumber and the relative roughness constant $e / d$. The relative roughness constant is the proportion between the relative sand roughness $e$ and the inner pipe diameter $d$. The turbulent regime is distinguished into three zones, namely the hydraulically smooth 
regime (smooth pipes in Figure 18), the transition zone and the completely turbulent regime, as shown in Moody’s diagram below ${ }^{50,51}$.

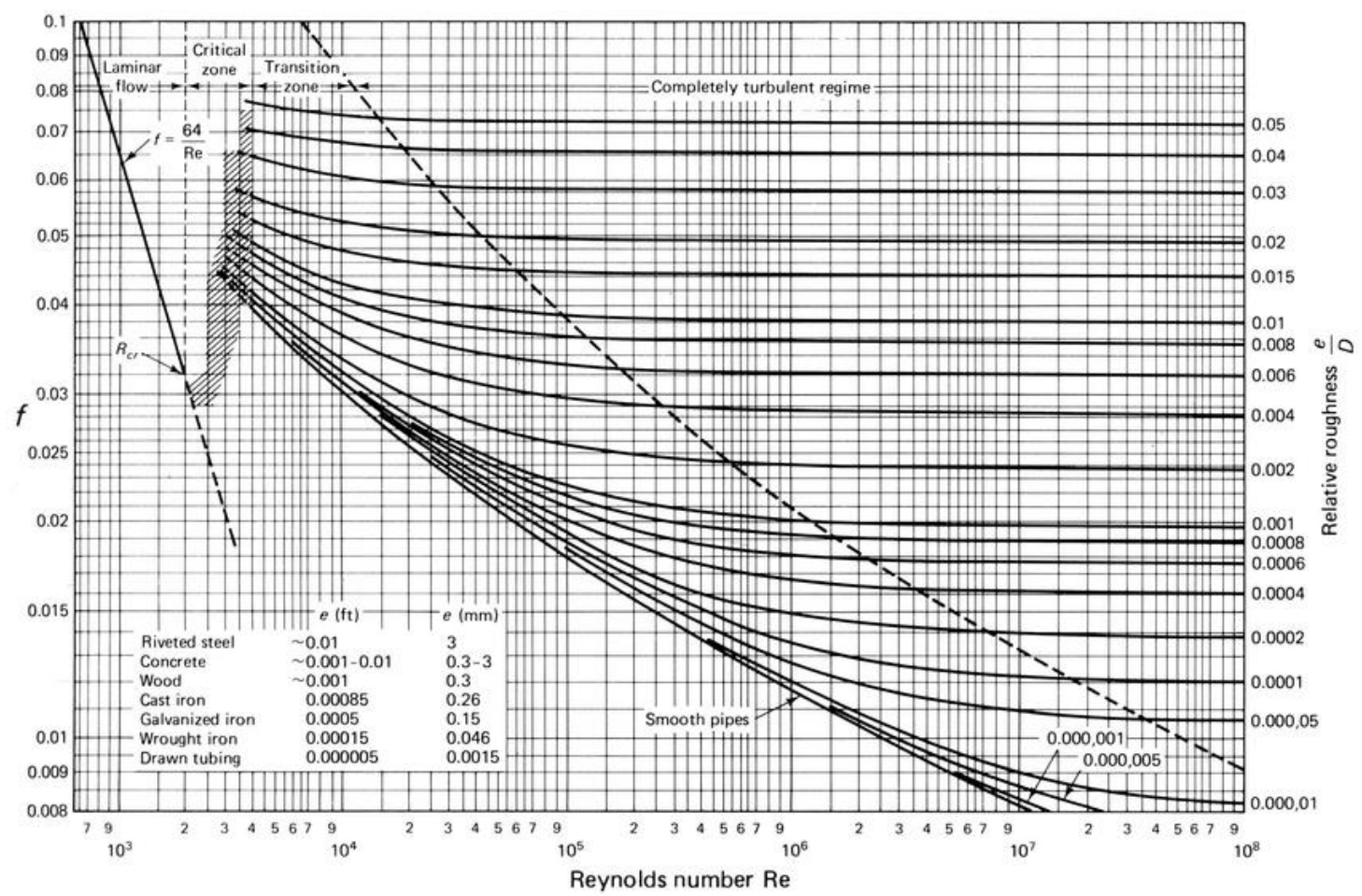

Figure 18: Moody's diagram to estimate friction losses in circular pipes, sources: Brown et al. $2002^{50}$, Ferro et al. $2012^{51}$

While for smooth pipes, the relative roughness coefficient does not affect the friction coefficient, the completely turbulent regime is independent of the Reynoldsnumber ${ }^{52}$. The implicit equations by Prandtl (2.9), Colebrook and White (2.10) and Nikuradse (2.11) to calculate the friction coefficient are listed in Table $1^{53}$. 
Table 1: Equations to calculate the friction coefficient in the smooth and turbulent regime and in the transition zone

Hydraulically

$e \rightarrow 0, \quad f=f(R e)$

smooth regime

$$
\frac{1}{\sqrt{f}}=-2 \lg \left(\frac{2.51}{\operatorname{Re} \sqrt{f}}\right)
$$

Transition zone $\quad f=f\left(\operatorname{Re}, \frac{e}{d}\right) \quad \frac{1}{\sqrt{f}}=-2 \lg \left(\frac{2.51}{R e \sqrt{f}}+\frac{e}{3.71 d}\right)$

Completely

turbulent regime

$$
R e \rightarrow \infty, \quad \frac{1}{\sqrt{f}}=-2 \lg \left(\frac{e}{3.71 d}\right)
$$

$$
f=f\left(\frac{e}{d}\right)
$$

For the hydraulically smooth regime in the range of $R e<10^{5}$, the friction coefficient can be approximated using the explicit formula by Heinrich Blasius.

$$
f=\frac{0.3164}{R e^{0.25}}
$$

The absolute roughness of predominantly used pipe materials in a new condition are listed in Table 2.

Table 2: Absolute pipe roughness of predominantly used pipe materials[mm], source: Steward et al. $2015^{54}$

\begin{tabular}{c|c} 
Pipe material (condition: new) & Absolute roughness e [mm] \\
\hline \hline Draw tubing - glass, brass, copper, plastic & 0.0015 \\
\hline Commercial steel / wrought iron & 0.0457 \\
\hline Cast Iron - uncoated & 0.259 \\
\hline Concrete & $0.3048-3.048$
\end{tabular}




\section{Stationary losses}

For larger pipeline systems, stationary losses have a relatively small impact. The major amount of friction losses is due to continuous losses. Thus, stationary losses are often considered minor losses. Stationary losses occur at "rapid changes in the direction or magnitude of liquid velocity in the pipeline"

$$
h_{l, \text { stationary }}=\zeta * \frac{v^{2}}{2 g}
$$

The most common stationary losses in pipe systems occur at entrances and exits, at bends, and sudden or gradual enlargements or contractions and at valves and fittings. The coefficient $\zeta$ represents the specific situation (exit, bend, valve) and can range from $10^{-3}$ to $10^{4} 52$.

\subsubsection{Rhode Island}

This chapter will give a brief insight about the situation of water supply in the state of Rhode Island. The chapter is organized into source, distribution, use and incentives.

\subsubsection{Source}

The main sources of freshwater are surface water and groundwater. Both are replenished by precipitation. Figure 19 shows the average annual precipitation in Rhode Island for the period 1961-1990 ${ }^{56}$. 


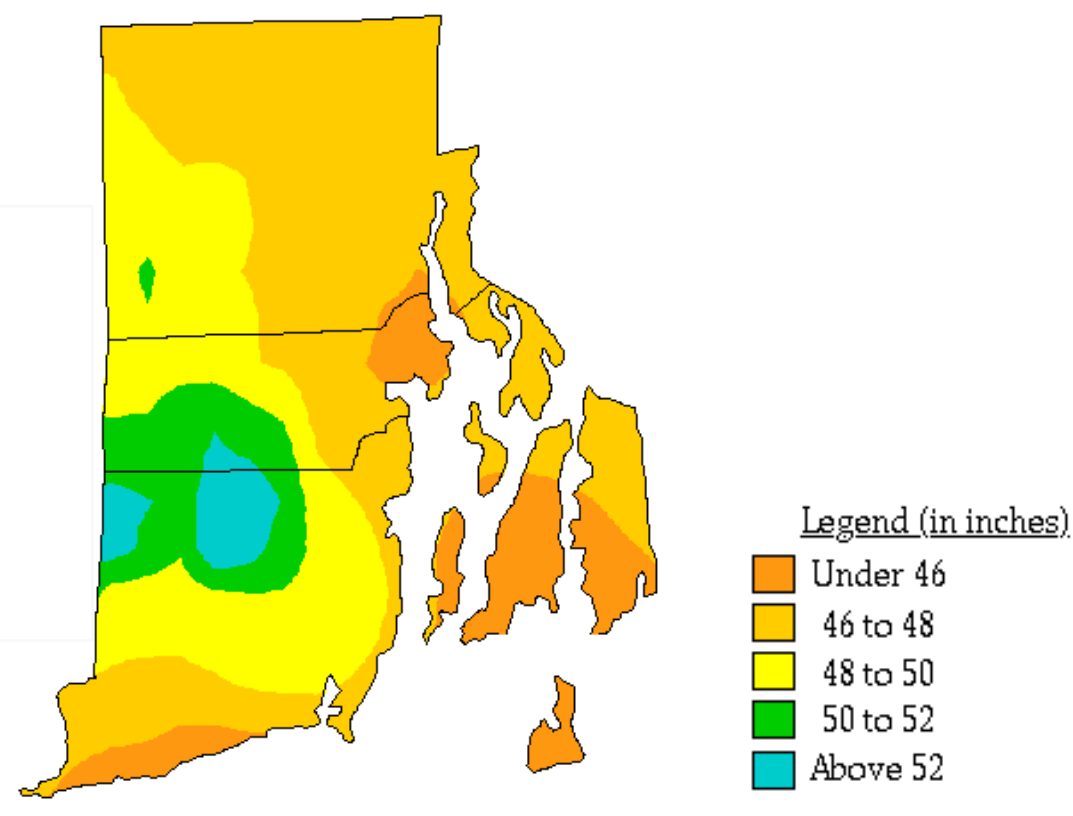

Figure 19: Annual average precipitation (inch/a) in Rhode Island 1961 - 1990, source: WorldAtlas $2019^{56}$

In Rhode Island, surface water resources exist in the form of 14 water sheds and 140 freshwater lakes. $85 \%$ of all water withdrawals in Rhode Island are supplied by surface water resources ${ }^{57}$. The remaining $15 \%$ are groundwater that is either supplied by water suppliers or by private wells. The most important contributors to the freshwater supply are the Scituate Reservoir (50\% of all surface water supplies in RI), the Big River Area (SW) and four sole-source groundwater aquifers (GW), (the Block Island, the Hunt-Annaquatucket-Pettaqumascutt, the Jamestown, and the WoodPawcatuck aquifers).

Although volume wise, surface water is the largest source, most regions in Rhode Island still rely on decentralized water supply from groundwater wells. These regions are rural regions that are not connected to water supply networks. As of 2010, 459 out of 488 water supply systems rely on groundwater but serve only $20.9 \%$ of the population. The 29 surface water-based systems provide potable water to the 
remaining $79.1 \%$ of the population. Figure 20 shows the distribution of surface water-, groundwater-, combined surface- and groundwater- and well water-supplied regions in Rhode Island.
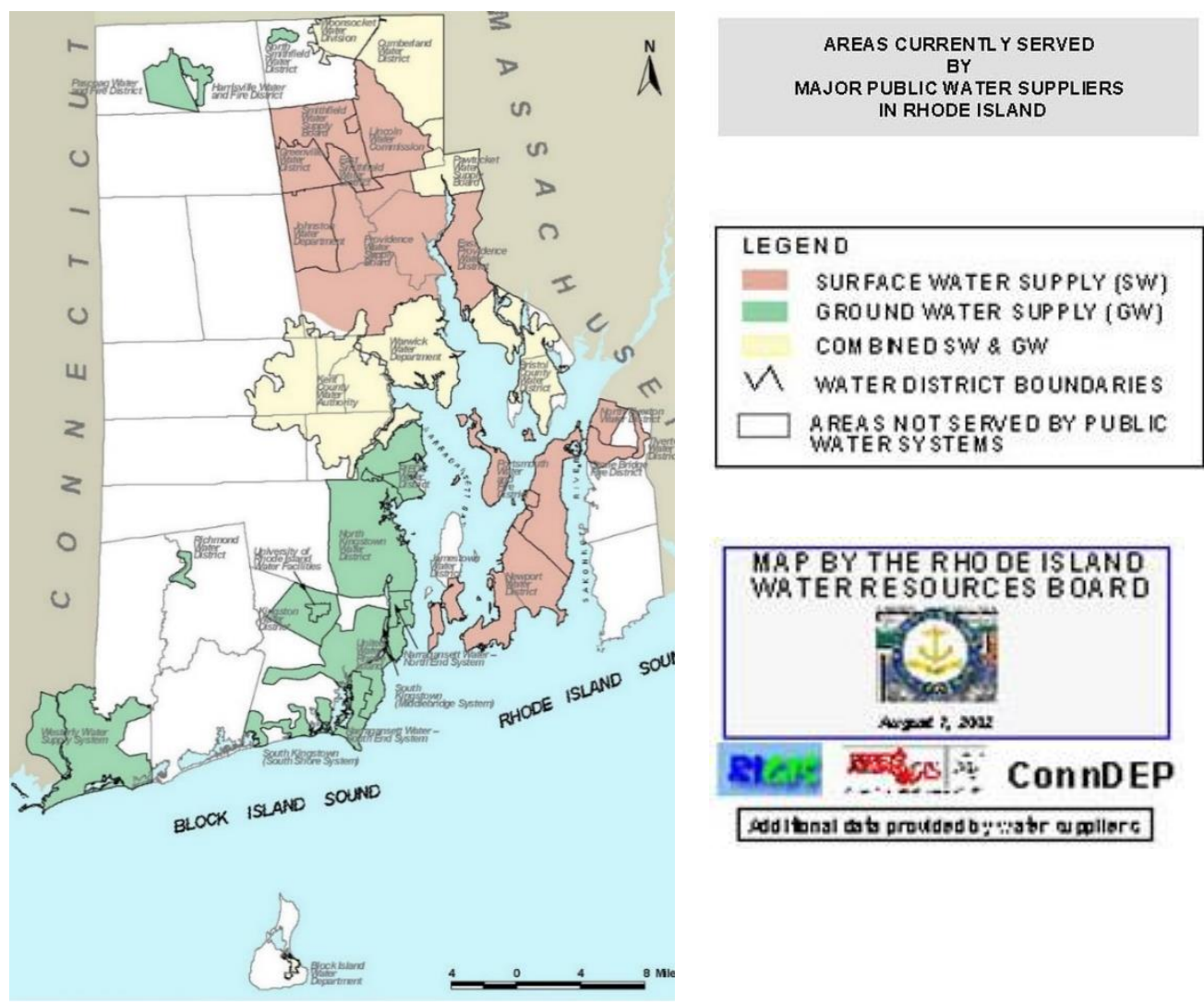

Figure 20: Map of potable water sources in Rhode Island, source: RI WRB ${ }^{58}$

A direct relation to Rhode Island's population density can be detected. Figure 21 shows the population density distribution in Rhode Island ${ }^{59}$. Most areas with a density of more than 500 people / $\mathrm{mi}^{2}$ are supplied by water supply networks, whereas below that density, more people rely on well water. In areas with less than 200 people / $\mathrm{mi}^{2}$, almost all water is supplied by decentral wells. 

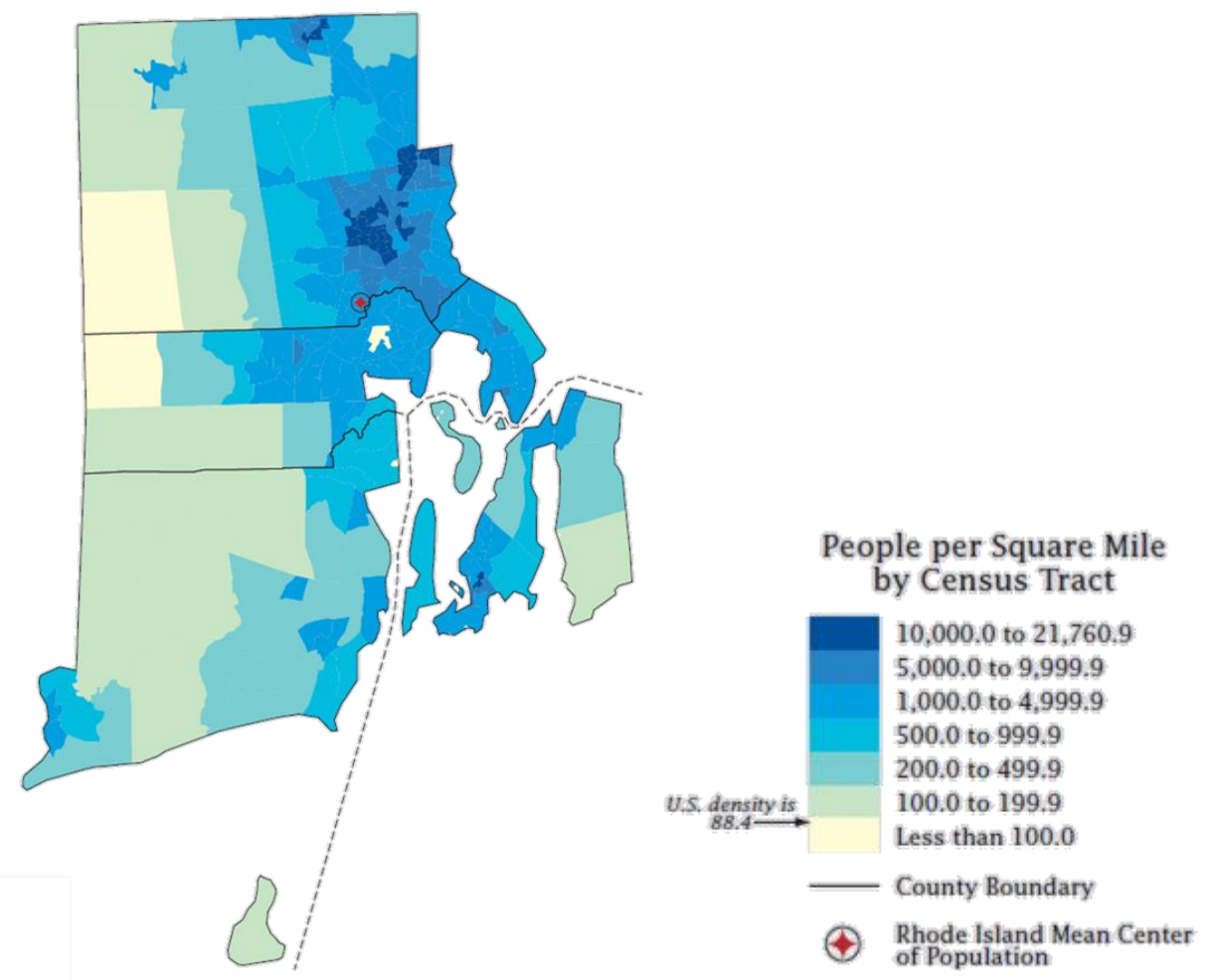

Figure 21: Population density map of Rhode Island, source: US DoC $2010^{59}$

\subsubsection{Distribution}

Rhode Island is one of the first states to introduce larger community water supply systems. The Providence water system was established in 1866 and further systems in Pawtucket, Woonsocket, Newport and Westerly were introduced not much later. The Rhode Island water distribution system consists of 490 single water supply systems, of which 29 are large water suppliers, as shown in Figure 20. These 29 suppliers are required to provide Water Supply System Management Plans every five years to prove their continuous efforts towards reliable supply systems and sustainable use of freshwater sources ${ }^{60}$. 


\subsubsection{Use}

Rhode Island's water use can be allocated to both the sources and the use sectors. The total average amount of water used is 343 million gallons per day (MGD). The Sankey diagram in Figure 22 shows the total amounts of water withdrawn from groundwater and surface water sources, as well as their use in the different economic sectors in Rhode Island. The figure also distinguishes between fresh and saline water sources.

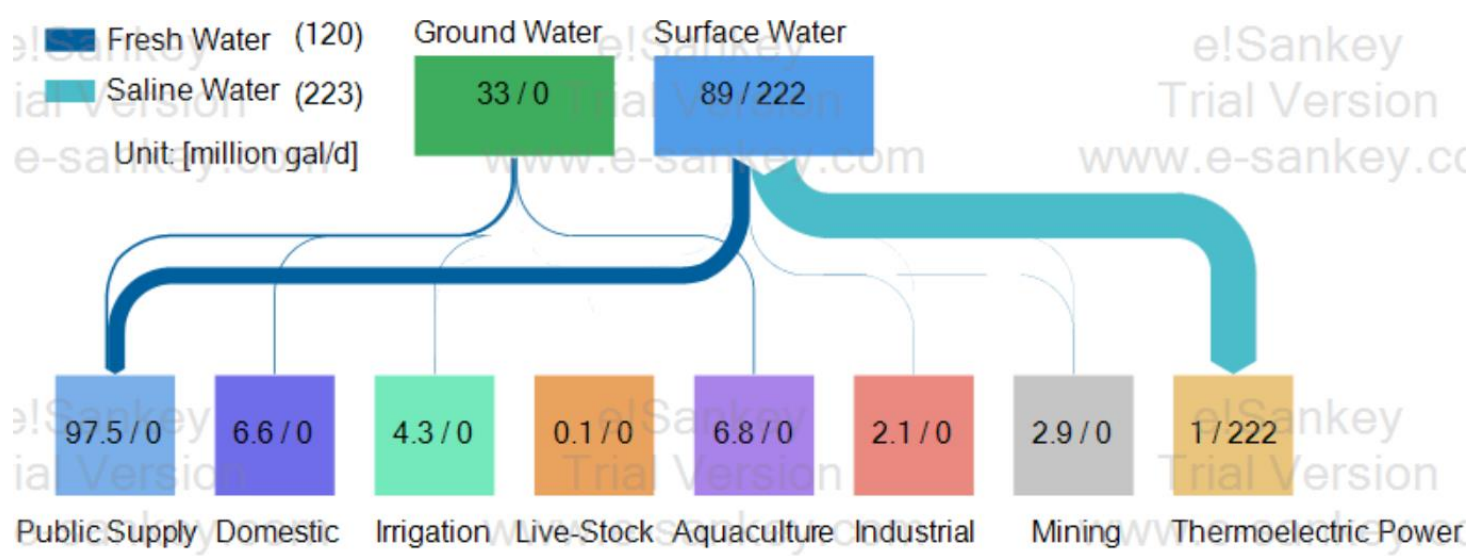

Figure 22: Use of fresh and saline water by sector in Rhode Island, own figure created with e-Sankey, data source: USGS $2019^{37}$

Besides freshwater, Rhode Island uses extensive amounts of saline water for thermoelectric power generation. Saline water use accounts for $65 \%$ of the total water use in Rhode Island, whereas freshwater accounts for the remaining $35 \%{ }^{61}$. The saline water is used for cooling cycles in the powerplants and is thus not subject to intensive water treatment. Still, its use poses threats to the environment as the warmed-up water reenters ecosystems. The major part of freshwater sources is used by the population, which is represented by the sectors Public Supply and Domestic in Figure 22. This residential use fluctuates from season to season. Whereas the average daily water use 
of one household is $58-72 \mathrm{gal} / \mathrm{day}$, it can increase by an additional $30-50 \mathrm{gal} / \mathrm{day}$ for irrigation purposes in summer ${ }^{57}$. Nationwide, thermoelectric power generation and irrigation are the major use sectors of water. Thermoelectric power generation currently consumes $41.3 \%$ of all water in the US, closely followed by irrigation with $36.7 \%$. All other sectors share the remaining $22 \%$ of water resources. While cooling water for power plants is slightly decreasing, the irrigation intensity is increasing, leading to a potential future shift of contributions to the total use $\mathrm{e}^{37}$.

\subsubsection{Incentives}

The foundations of Rhode Island's water incentives are the Rhode Island Water 2030 Plan, the Water Quality 2035 - Rhode Island Water Quality Management Plan and the 2009 Rhode Island Water Use and Efficiency Act. Additional Information is provided by US Geological Survey reports about total and domestic water withdrawals in the US, as well as the drinking water action plan from the Environmental Protection Agency EPA.

The Water 2030 report proposes a variety of important research fields, that are proposed to foster freshwater security and quality. One field of research is water recycling. Desalination has become a well-studied technology in recent years, but is not yet economically feasible in regions, that have access to surface- and groundwater resources. The main threats to the water supply in Rhode Island are summarized in the Water 2030 report and represented in Table 3. 
Table 3: Threats to water supply in Rhode Island, source: RI DoA, RI DoP 57

\begin{tabular}{l|l} 
1. & $\begin{array}{l}\text { Southern Rhode Island mainly depends on groundwater and lacks storage capacities } \\
\text { to synchronize demand and supply. }\end{array}$ \\
\hline 2. & $\begin{array}{l}\text { Islands are subject to increasing population, which increases their water crowding } \\
\text { index. }\end{array}$ \\
\hline 3. & $\begin{array}{l}\text { Although the Scituate reservoir was not intended to become the main supplier, it now } \\
\text { provides more than } 50 \% \text { of the total RI freshwater demand. It is thus of special } \\
\text { importance to protect the security and quality of that source. }\end{array}$ \\
\hline 4. & $\begin{array}{l}\text { Irrigation in Summer is a major threat regarding water management. Standards for } \\
\text { reusing non-potable recycled water for non-potable purposes need to be developed. }\end{array}$ \\
\hline 5. & $\begin{array}{l}\text { The sustainable use of water in Rhode Island needs more attention to maintain the } \\
\text { ability of the hydrological cycle to replenish the sources. }\end{array}$ \\
\hline 6. & $\begin{array}{l}\text { There is a lack of data about private well withdrawals, while in some regions (south } \\
\text { county), approximately every third person is supplied by private wells or small } \\
\text { systems. }\end{array}$ \\
\hline 7. & $\begin{array}{l}\text { Main takeaway: "Rhode Island has sufficient supplies, but water is not always located } \\
\text { where it is needed or available in sufficient quantities for all uses at all times. Storage } \\
\text { capacity must be increased in order to provide long-term supply reliability"57. }\end{array}$ \\
\hline
\end{tabular}

Despite the assumption, that water supply in the US and especially in Rhode Island is very good in terms of quality and security, many shortcomings and related investments are detected. The lack of data about smaller community and home scale self-supply plays a vital role in the assessment of groundwater source security and sustainability.

Fostering increased shares of renewable energies will have another important impact on the water-energy nexus. The operation of wind turbines and photovoltaics does not require large amounts of water. However, thermoelectric power generation, which currently supplies $93 \%$ of Rhode Island's electricity is responsible for $65 \%$ of 
the total water use in Rhode island ${ }^{61}$. Although the water used for cooling purposes in thermoelectric power plants is only saline water, which does not require thorough treatment like tap water, it still poses both input and output-related threats to the surrounding ecosystems, including the introduction of high temperature water to aquatic ecosystems. An increased share of renewable energies will thus help to reduce the water footprint of the Rhode Island energy supply system.

\subsection{Energy Supply}

Energy is very closely related to water supply. Especially the distribution of freshwater consumes a lot of energy, as most water supply systems can not rely on gravity alone to distribute the water from source to consumer. Energy in water supply systems is used for the conveyance of water, for the physical and chemical treatment of water and for the distribution of water. Energy for water supply can be distinguished into direct and indirect consumption. While indirect consumption is a complex relation between water conservation strategies and resulting use patterns (consistency), direct energy consumption refers to the short term and direct increase or decrease of energy

demand within the water supply system, such as pumps and treatment plants ${ }^{62}$. Figure 23 shows the most energy intensive processes and related variables within water supply systems allocated to the stages conveyance, treatment and distribution. 


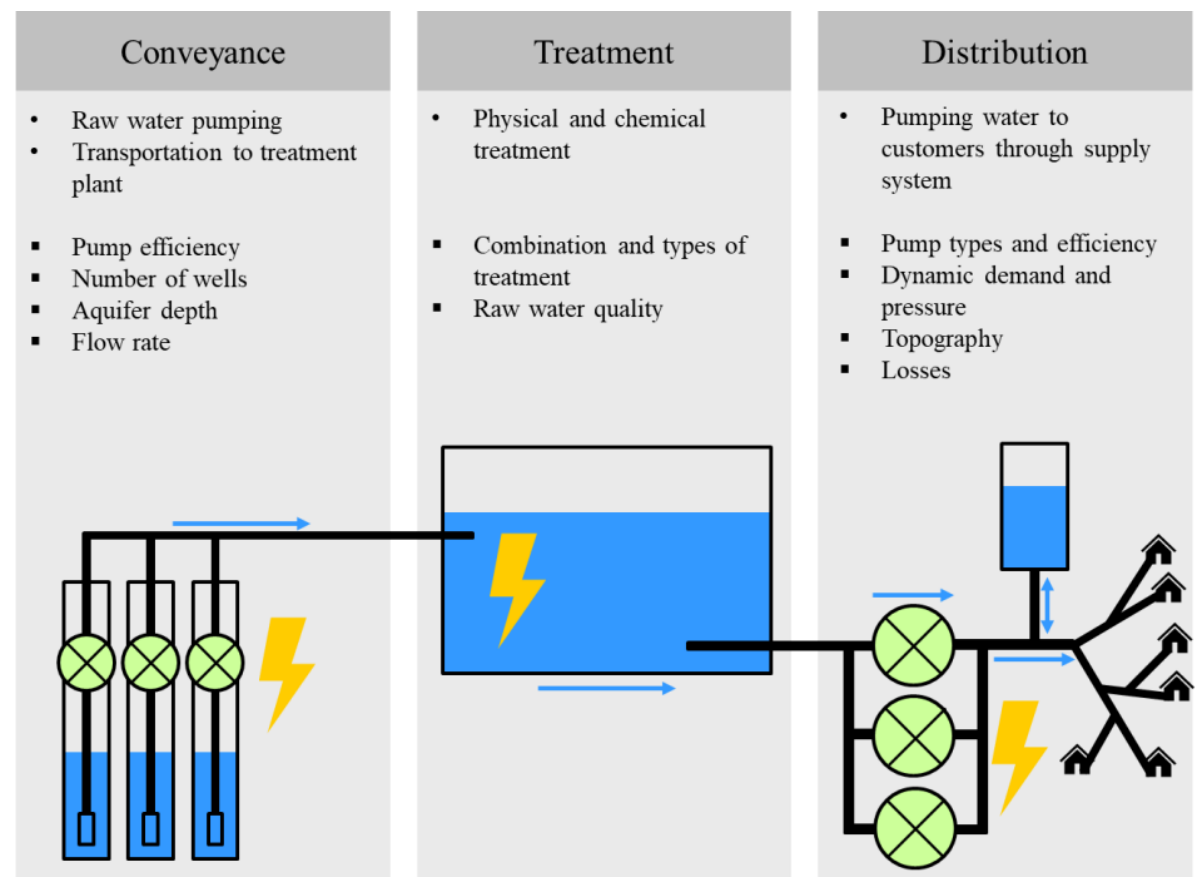

Figure 23: Energy intensive processes in groundwater-based water supply systems, own figure based on Wakeel et al. $2016^{63}$

In the past decades, the energy sector has experienced a transition from traditional, fossil energy sources towards more renewable energies. The focus of this section will be electricity. Still, at some points other types of energy will be included in the review.

\subsubsection{Energy Types}

This section explains the differences of the various existing energy sources. The focus is on electricity as well as on the differences of fossil, nuclear and renewable, especially variable renewable energies. In section 2.2.1.1, conventional energy carriers are introduced and distinguished. The relevance of the non-renewable nature of these types of energy is stressed. In section 2.2.1.2, the various types of renewable energy are presented with a focus on the potential of low-carbon intensity 
energy supply and the shortcomings regarding the fluctuating pattern of some types of renewable energy.

\subsubsection{Conventional Energy}

Conventional energy is distinguished into fossil and nuclear energy carriers. Fossil energies include coal, natural gas, oil and petroleum. For electric energy generation, all fossil energy carriers are used in a similar way. The energy carrier is combusted, and the embodied chemical energy is converted into heat energy, which is used to produce steam in a water boiler. The pressurized hot steam is sent to a turbine, which converts the translational kinetic energy into rotational kinetic energy using the flow of the steam and the blades of the turbine. The kinetic energy is ultimately converted into electrical energy using a generator. The cooled-down expanded water vapor is fed through a condenser and is then fed back into the cycle ${ }^{64}$. Fossil energy carriers can be distinguished using three categories, namely their efficiency, specific $\mathrm{CO}_{2}$-emissions and their flexibility. While coal power plants are mostly used for base load energy due to their inertia, gas power plants can react quickly and are used to meet medium load and flexible peak load ${ }^{65}$. Figure 30 and Figure 31 show the shares of fossil energy for electricity production on a global and a national scale.

Electric energy generation using nuclear energy does not differ much from the principle of electricity generation using fossil fuels. Both use water vapor powered turbines. The major difference is the source of heat to boil the water. Nuclear energy plants use nuclear fission of Uranium-235 cores. The redundant neutrons create friction with water molecules and thus create the necessary thermal energy to boil the 
water $^{66}$. Nuclear energy produces less greenhouse gas emissions, than fossil energy. Figure 24 shows the specific life cycle greenhouse gas emissions of both conventional and renewable energy sources.

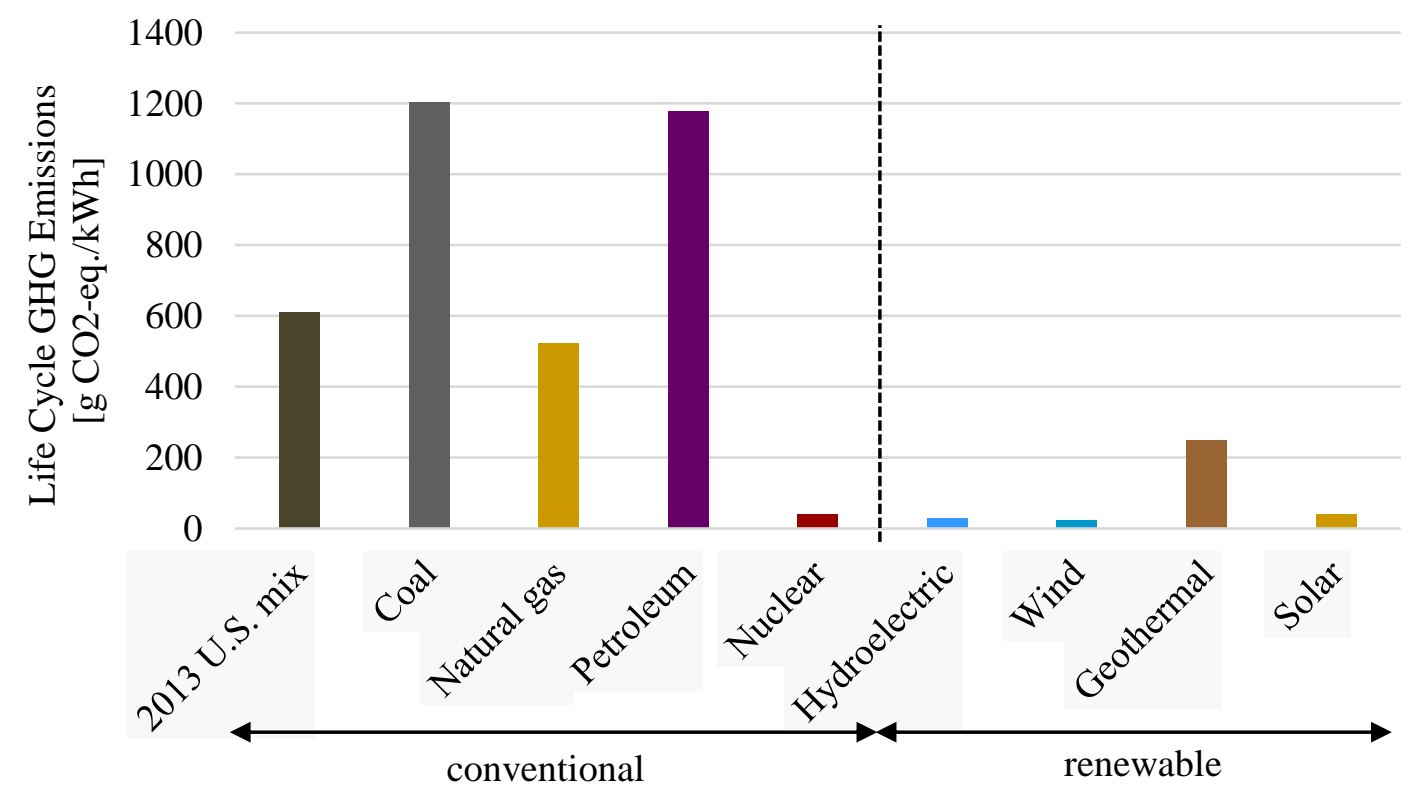

Figure 24: Specific life cycle greenhouse gas emissions of energy sources, conventional and renewable, own figure, data source: Skone $2015^{6}$

Despite the low carbon intensity of nuclear power, past catastrophes like the Fukushima and Chernobyl nuclear meltdowns have exposed the potential risk of using nuclear fission for electricity generation. Based on the half-life period and the amount of emitted radioactive elements, it can take several human generations to safely resettle exposed areas. Both near the Fukushima and the Chernobyl plant site, resettlement is not planned within the next decades ${ }^{67,68}$.

Conventional energies, both nuclear and fossil are not renewable in a time scale that is significant to human generations and are thus considered non-renewable energies. Non-renewable energies rely on limited resources and reserves, which are 
depleted by human consumption and do not replenish. The rate of depletion and the existing reserves and resources define the depletion time. Resources and reserves are distinguished in three ways, namely the accessibility, the feasibility and the geological certainty. Reserves are considered the amount of the total potential, which is validated and feasible to extract with currently available methods. Resources are the amount of the total potential, which are validated with a low degree of geological certainty and are not economically feasible to extract ${ }^{69,70}$. Figure 25 shows the specific depletion times of conventional energy sources, both fossil and nuclear.

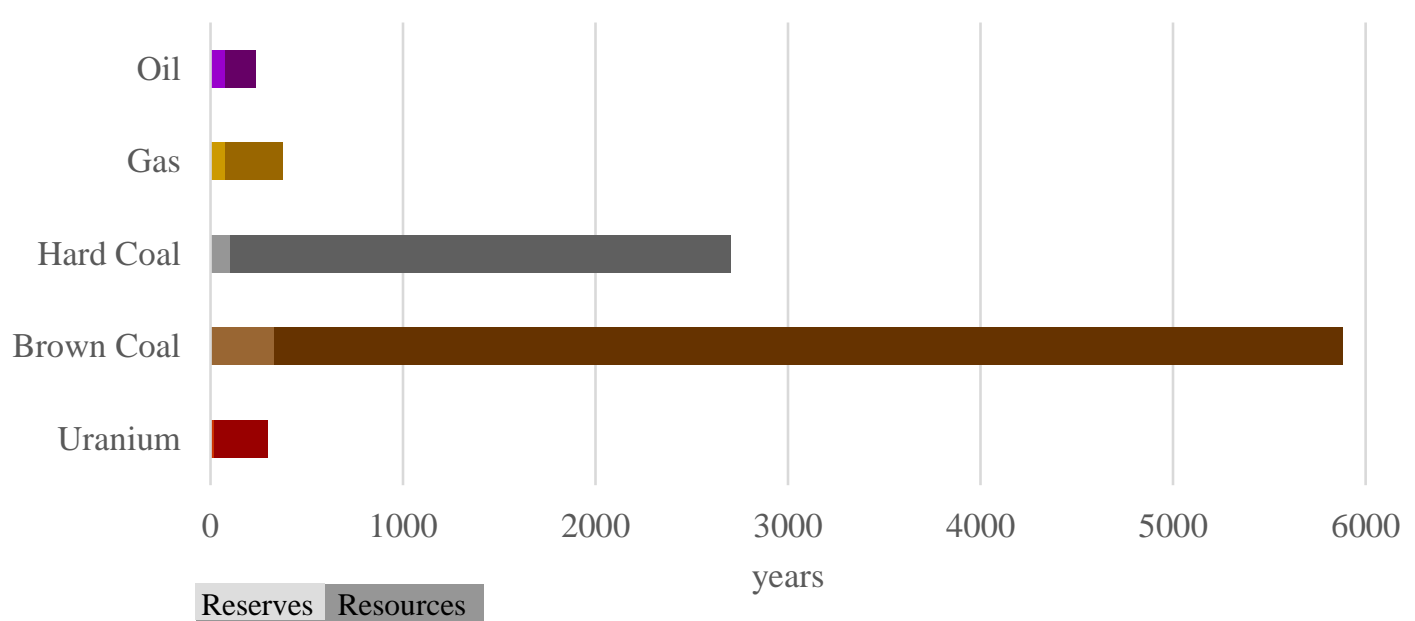

Figure 25: Specific statistical depletion time of conventional energy carriers based on global annual consumption, reserves and resources, own figure, data source: BGR $2016^{71}$

Due to the high carbon intensity, high potential risks and reliance on quickly depleting resources, many countries have set their focus on increasing the share of renewable energies for electricity production. The predominant types of renewable energies will be propounded in section 2.2.1.2. 


\subsubsection{Renewable Energy}

Renewable energies are considered energy sources that replenish in a time scale that is significant to human generations. Compared to non-renewable energies, the stock is not only depleted by human consumption but also regenerated by shortterm physical and biochemical processes. Despite renewable energies with reducible stock, some are considered to have a stock that does not decrease. Solar radiation is one example of a non-reducible energy stock. Biomass on the other hand requires a stock depletion rate below the maximum sustainable yield. If the depletion is larger than the replenishment over a long period of time, the source will eventually lose its capacity to replenish itself ${ }^{33}$.

The predominantly used renewable energy sources are hydroelectric power, solar power, wind power, geothermal and biomass. Besides these market-ready sources, more renewable sources exist such as ocean energy sources like osmosis-, wave-, tidal- and marine current-energy, most of which are still in a scale of research facilities with some grid-integrated power plants in certain regions ${ }^{72}$.

Renewable energies can be further distinguished regarding the form of energy generated, namely mechanical energy, thermal energy and electrical energy. While any renewable source has the ability to generate electrical energy, biomass, solar thermal energy and geothermal energy are predominantly used to generate thermal energy. Direct use of mechanical energy from renewable sources is rarely used except for decentral regions in developing countries ${ }^{73}$. 


\section{Variable Renewable Energy}

Several renewable energy sources can only limitedly be controlled in energy output. Those renewable energies are variable renewable energies (VRE). The predominantly used variable renewable energies are solar energy and wind energy. While measures exist to reduce the power output of both of these systems, the power output can not be increased beyond the available energy provided by the primary energy source, namely wind speed and solar irradiance. This study will focus on variable renewable energies, as they are complex to integrate in the existing energy system.

The conventional energy system is based on consumers demanding a certain amount of power at certain times. Conventional power plants have the ability to react to the demand and increase or reduce their power output. Colloquially, this logic is called supply follows demand. With increasing shares of variable renewable energies, the ability to adapt the energy supply to the demand is limited. The energy supply system is currently experiencing a paradigm shift from supply follows demand towards demand follows supply ${ }^{74}$. As non-variable renewable energies do not pose this challenge to the energy system, they will not be covered in this section. Hereinafter, the variable renewable energy sources wind power and photovoltaic power will be explained briefly.

\section{Wind Power}

Wind power uses air masses as sources of kinetic energy. Those moving air masses are the result of air pressure differences in adjacent areas. The friction of the 
moving air particles creates a rotational movement of the rotors. This rotational kinetic energy is converted into electrical energy using a generator. Power plants can consist of one or more wind turbines at a designated location. The turbines can be distinguished into on- and off-shore turbines, as well as according to their peak power, which can range from below $1 \mathrm{~kW}$ up to more than $10 \mathrm{MW}$. The electrical power output of wind turbines is proportional to the current wind speed cubed ${ }^{75}$. Due to the highly variable nature of wind, the power output of wind turbines is highly variable and only limitedly predictable ${ }^{73}$. The performance of the wind turbine at its location can be calculated using the capacity factor (CF). The capacity factor is the ratio between annual energy generation and the theoretical maximum annual energy generated at peak power.

$$
C F=\frac{E_{\text {annual,produced }}}{P_{\text {Peak }} * 365 \frac{d}{a} * 24 \frac{h}{d}} * 100 \%
$$

The more variable an energy source, the lower is the Capacity factor. The CF can be calculated for any power plant, both renewable and non-renewable. The specific $\mathrm{CF}$ for both conventional and renewable energy sources is shown in Figure 26. 


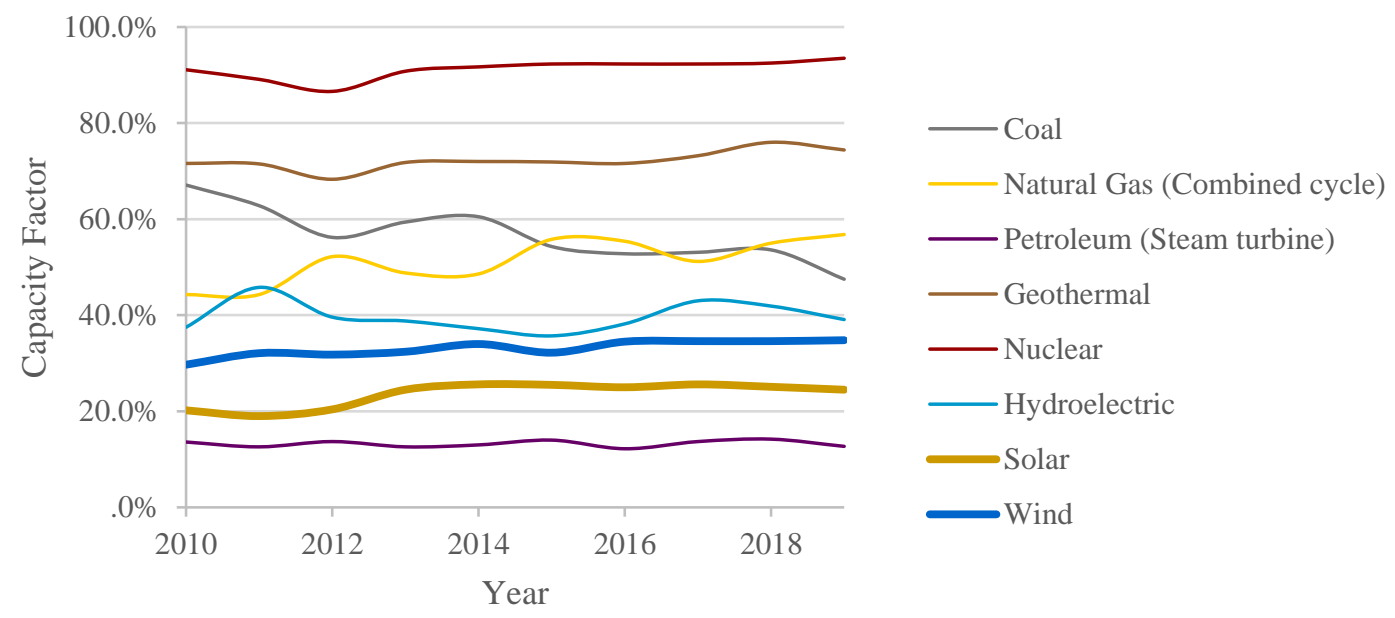

Figure 26: Specific annual capacity factor of energy sources, conventional and renewable energy, own figure, data source: US EIA $2020^{76}$

A low capacity factor can also result from the specific operation schedule of a power plant. With increasing shares of variable renewable energy, conventional power plants will experience lower utilization rates and consequently lower capacity factors.

\section{Photovoltaic Power}

The second predominantly used variable renewable energy source is solar power. Direct solar irradiance can be used to generate electricity using the photovoltaic effect. Photovoltaic panels are combined to a photovoltaic power plant, which can be dimensioned according to the desired peak power and the available space. Thus, photovoltaic energy can be used both on a private, roof-mounted scale and on a utility scale ${ }^{77}$. The dynamic power output of photovoltaic power is determined by the variable solar irradiance. Figure 27 shows the spatial distribution of solar irradiance in the United States. 


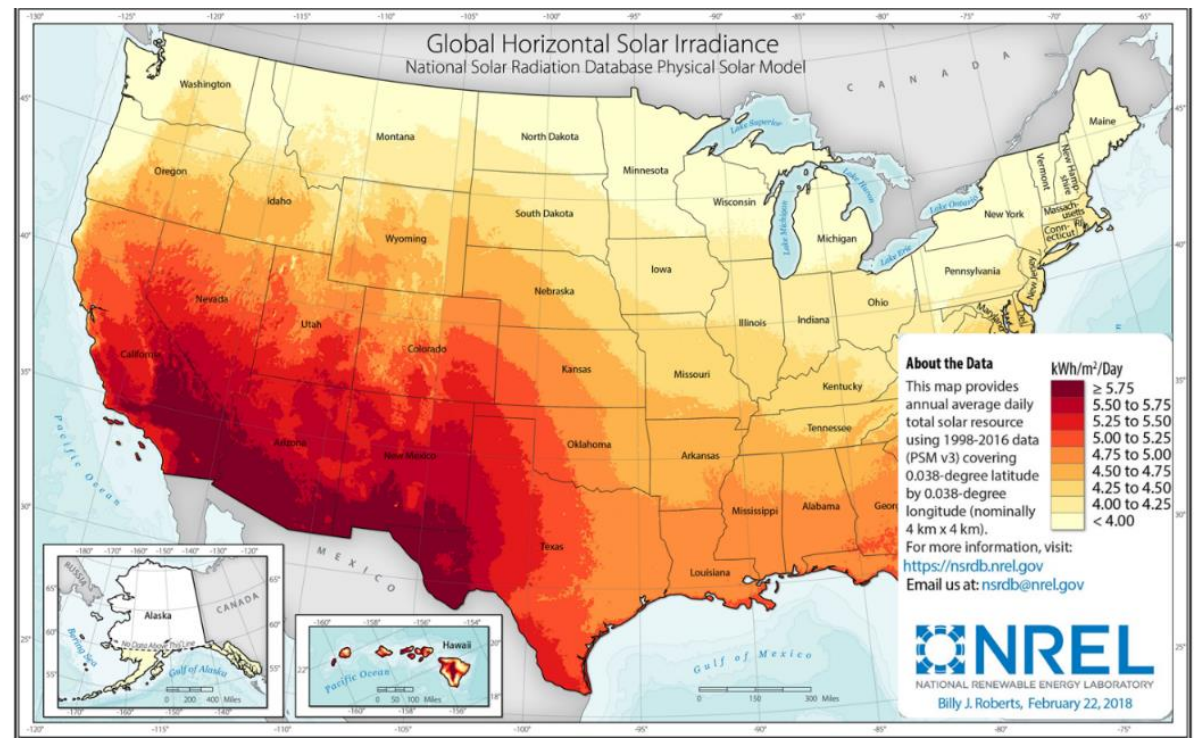

Figure 27: Global horizontal solar irradiance in the US, annual average, source: National Renewable Energy Laboratory $2018^{78}$

The map shows that there is a correlation of solar irradiance and latitude. Despite the latitude, the climate and typical weather of the location determines the potential output of solar power plants. Besides the spatial differences in solar power potential, solar power output is influenced by temporal fluctuations in solar irradiance $^{79}$. Figure 28 shows the daily fluctuations in solar power generation of two different sample days. 
60

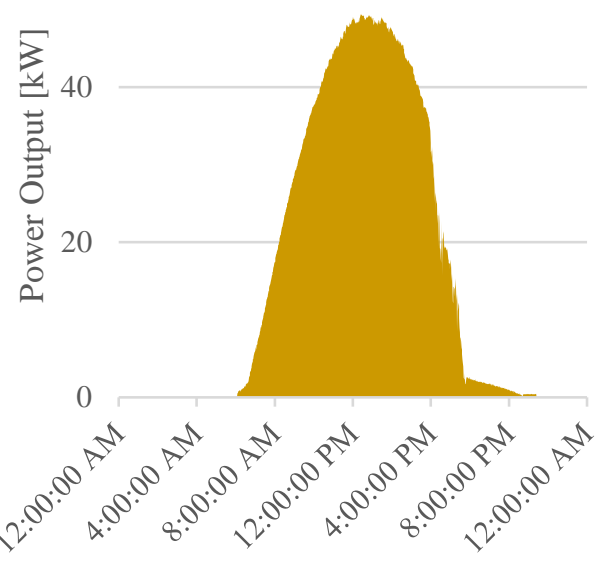

Time [hh:mm:ss]
60

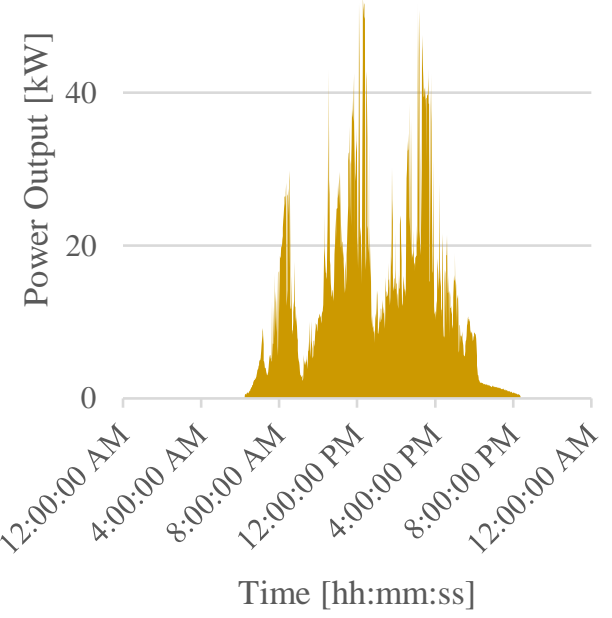

- Sample Day 2

Figure 28: Daily fluctuations and weather influence on solar power output, own figure, data source: IWF TU BS ${ }^{80}$

The power output is directly dependent on the daily course of the sun and thus the angle of the solar irradiance on the photovoltaic panel. The course of the sun creates the characteristic bell-curve of the power output graph shown in Figure 28, sample day 1. If disturbances such as clouds or shade occur, the power output decreases dramatically. The data of sample day 2 shows how the reduction of direct solar irradiance through clouds or shade can negatively influence the power output. The fluctuations may happen on a temporal scale of seconds and pose a great challenge for the successful implementation of high shares of solar power into electricity grids ${ }^{77}$. Due to the seasonal changes of the courses of the sun, the power output of photovoltaic power changes significantly throughout the year. Figure 29 shows the annual variability of the global horizontal irradiance (GHI) of a location on the northern hemisphere. 


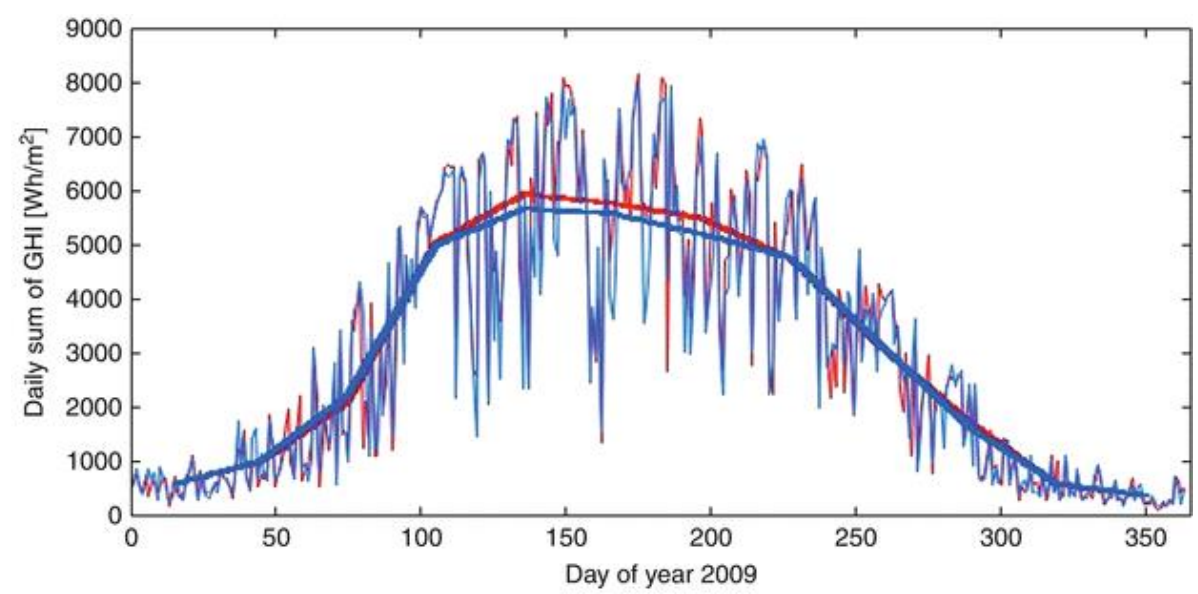

Figure 29: Annual variability of global horizontal irradiance, source: Hammer et al. $2012^{81}$

While the summer months have the highest average GHI, the winter months have the lowest. The temporal variability of solar irradiance determines the temporal variability of solar power output. Together with wind energy, solar energy is the most predominantly used form of variable renewable energy. The variability of these energy forms poses great challenges to the successful integration of large shares of renewable energy $^{81}$

\subsubsection{Rhode Island}

Rhode Island will face a change in the energy supply in the next years. In the year 2018, $93 \%$ of all electricity was generated by natural gas power plants ${ }^{82}$. Rhode Island set incentives to achieve a share of renewable energies of $38.5 \%$ in the year $2035^{83}$. As a reference, Figure 30 shows the global transition from fossil fuels towards an increasing share of renewable energies. 


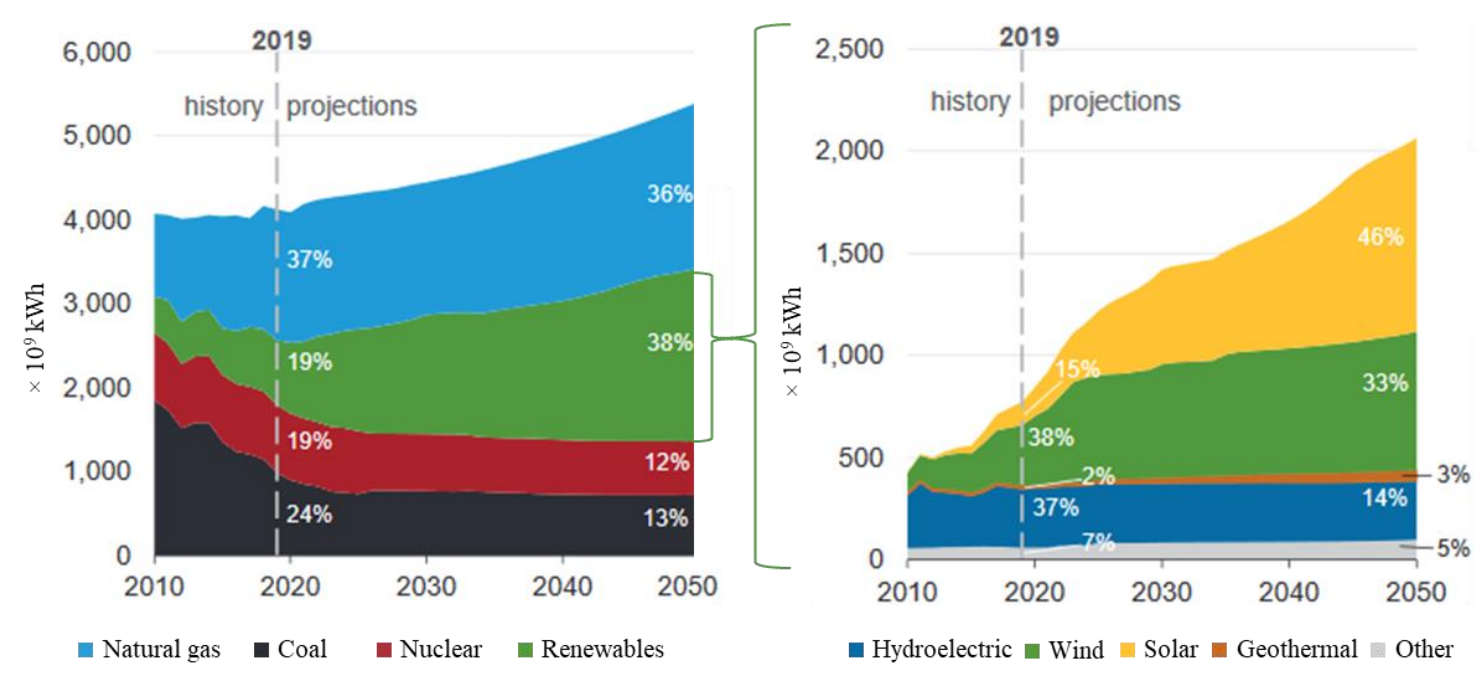

Figure 30: Global conventional and renewable net electricity generation projections, source: US EIA $2020^{84}$

While the overall global electricity generation will increase with a rate of $1 \%$ in the next 30 years, the increase in fossil fuels is mitigated by a growing share of renewable energies. With an average increase of $0.61 \%$ per year, the share of renewable energies for electricity generation is projected to reach almost $38 \%$ in the year 2050. While the development in hydroelectric power is stagnating further (37\% in 2018 to $14 \%$ in 2050), wind and solar power are estimated to account for $79 \%$ of the renewable electricity generation by $2050^{84}$. This development is favorable due to the inexhaustible source of solar and wind energy, but the high shares of solar and wind energy will pose significant challenges to the electricity system, including electricity grids, management and consumers. The global development of wind and solar power further strengthens the need for energy flexibility and demand side management of any electricity consuming entity within the system. As an additional reference to the Rhode Island energy situation, the share of renewable energies of the US net electricity generation is shown in Figure 31. 


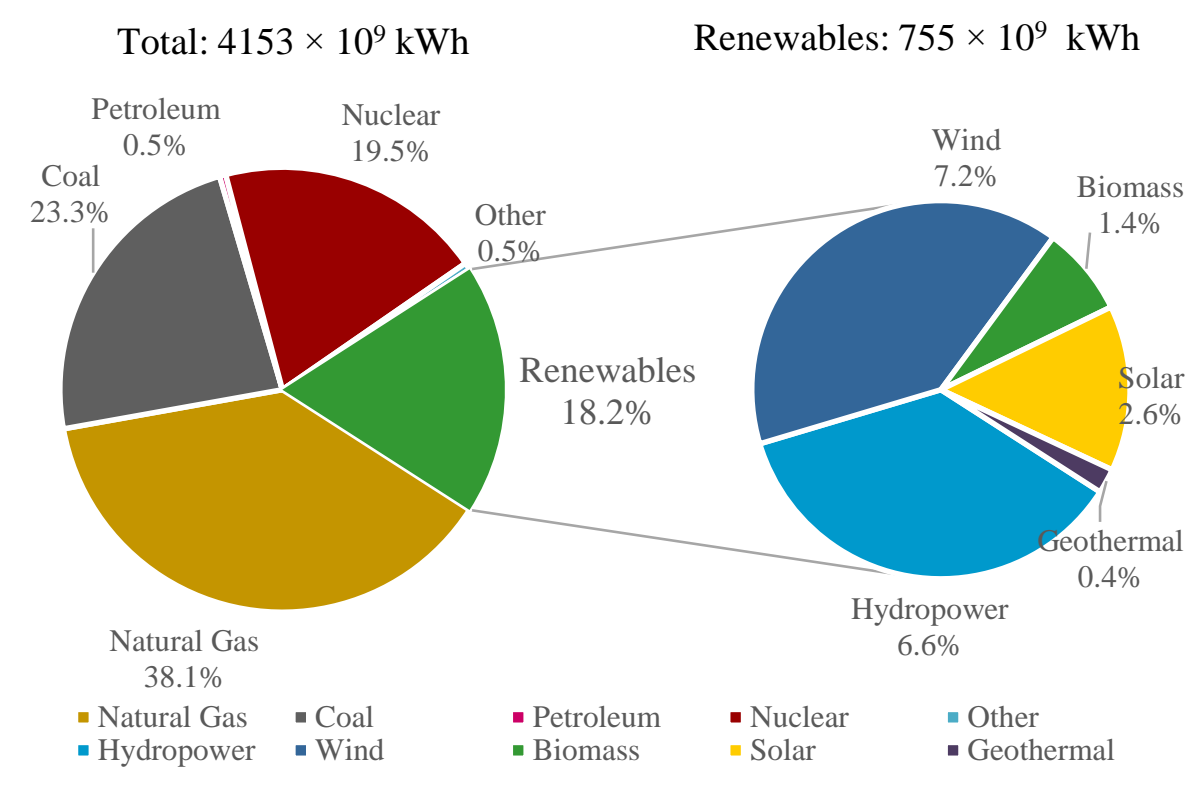

Figure 31: US electricity generation by energy source, own figure, data source: US EIA $2020^{85}$

In the US, the predominantly used renewable energy sources are hydroelectric power and wind power. All renewable energies combined represent a share of $18.2 \%$ of the total net electricity generation.

By the year 2020, Rhode Island aims at a total power of all renewable sources of $1000 \mathrm{MW}$, which is similar to the power of the rejected $900 \mathrm{MW}$ natural gas power plant, that was initially planned in Burriville, $\mathrm{RI}^{86}$. The renewable energy sources include solar energy (both roof-top and large scale), small hydropower, wind energy (both onshore and offshore) as well as anaerobic digestion and landfill gas ${ }^{87}$. Compared to conventional fossil fuel-based energy sources, renewable energies have a significantly smaller carbon footprint. The life-cycle greenhouse gas emissions of wind and solar energy are 11.5 and $44.5 \mathrm{~g}$ co2-eq./ $\mathrm{kWh}$, respectively, whereas for gas and coal, they are 490 and $820 \mathrm{~g}_{\mathrm{Co} 2-\mathrm{eq}} / \mathrm{kWh}$, respectively ${ }^{88}$. Brown University already aims at relying on $100 \%$ renewable energies, which is among others supplied by a 50 
MW solar power farm ${ }^{89}$. The University of Rhode Island has plans to increase the share of renewable energies and thus reduce greenhouse gas emissions. Three solar energy farms are proposed that have a aggregated power of $40 \mathrm{MW}^{90}$.

Rhode Island does not have large amounts of fossil resources, like oil, gas or coal. Still, most of the energy is fossil fuel based. As of 2018, $93 \%$ of all electricity was generated by natural gas power plants, with only $7 \%$ being supplied by renewable energy sources, like wind and solar energy ${ }^{91}$. The required fossil resources for the energy generation in Rhode Island are being imported from other states or even from Canada. This natural gas is being transported to Rhode Island either via pipelines or tanker trucks. The main pipelines are the Algonquin Pipeline and the Tennessee Gas Pipeline, an interstate pipeline that stretches from Texas and its border to Mexico all the way to Rhode Island and Massachusetts $^{92}$. Figure 32 shows the electricity generation in Rhode Island by source from 2001 to 2017.

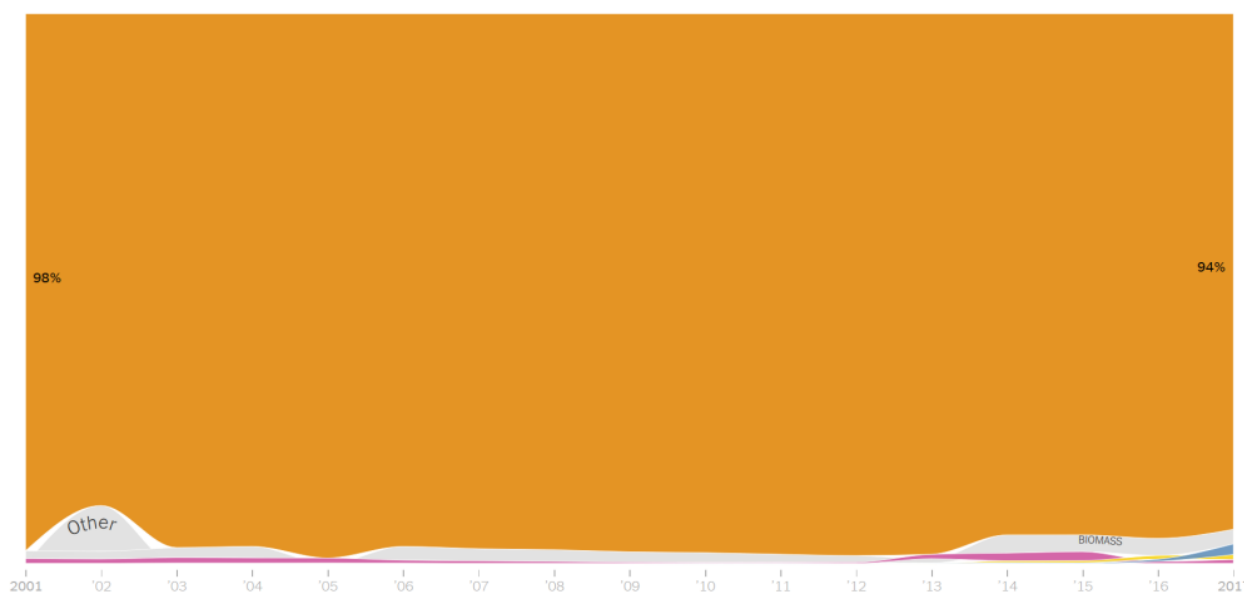

Figure 32: Electricity generation in Rhode Island by Source, $2001-2017$, source: Popovich $2018^{91}$

Figure 32 shows that in the past years no significant reduction in the use of fossil fuels could be achieved. Only from 2015, renewable energies like wind (blue) and solar 
power (yellow) increase with biomass increasing from 2013 to 2014 and stagnating at a share of approximately $4 \%$. The pink line indicates the use of petroleum which still supplies homes on islands like Block Island.

The total energy consumption in Rhode Island can be allocated to four main socioeconomic sectors, namely residential, commercial, transportation and industrial. Combining industrial and commercial, an easy rule can be applied that often represents the energy consumption in economies all over the world. Each sector contributes to approximately a third of all energy consumption. Figure 33 shows the four main energy consuming sectors in Rhode Island, with the total annual energy consumption being 183.8 trillion BTU or $53.86 \mathrm{TWh}^{82}$.

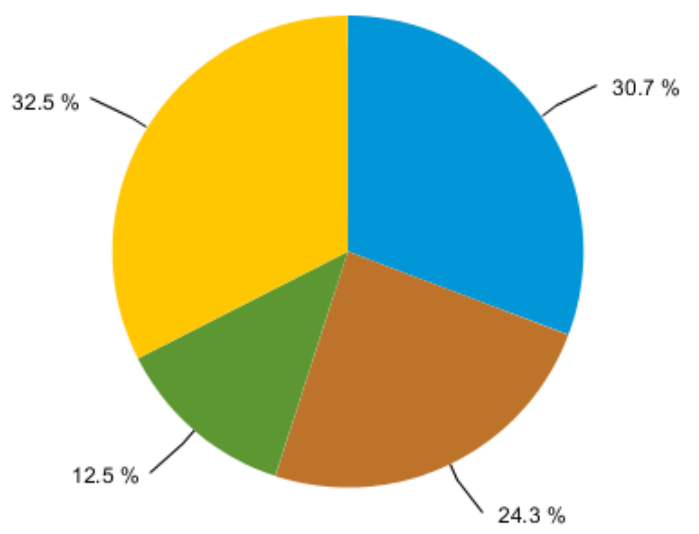

Residential

Commercial

Industrial

Transportation

Figure 33: Rhode Island energy consumption by end-use sector 2017, source: US EIA ${ }^{82}$

From Figure 22 and Figure 33, it can be seen that the biggest overlap with the water consumption is in the residential sector, as transportation and industrial does not consume much water. This indicates that the residential water and energy consumption have a strong relation and is worth investigating. 
The water supply sector energy intensity is not listed but can be approximated. The daily use is $343 \mathrm{MG} / \mathrm{d}$, which is equivalent to $125,195 \mathrm{MG} / \mathrm{a}$. Figure 34 shows the embodied energy of tap water, after it has been conveyed, treated and distributed. The distribution has by far the highest share of the embodied energy, accounting for $84.6 \%$ of all embodied energy. This value depends on the topography in which the water supply system is embedded. In mountainous regions, the energy intensity of the distribution network can increase to maintain the required water pressure in the subsystems. On the other hand, in very flat regions no sub-systems are needed for maintaining pressure levels in the distribution system ${ }^{93}$.

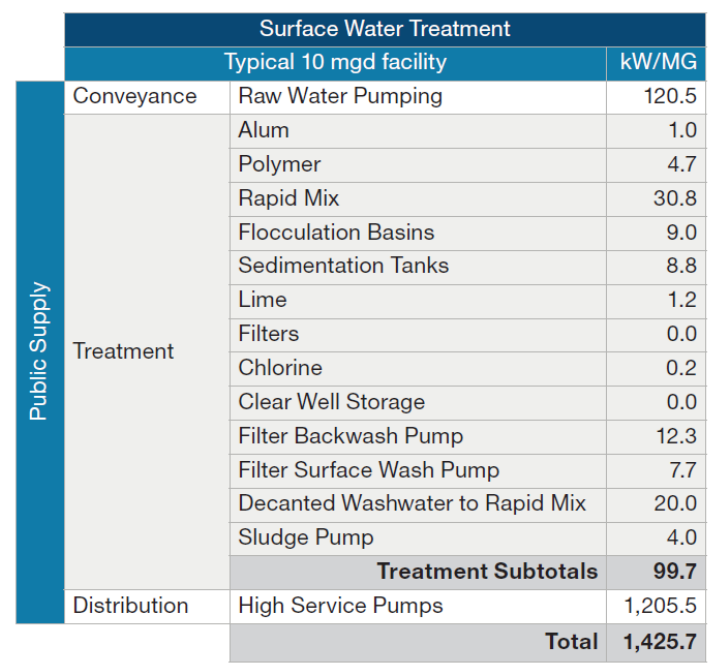

Figure 34: Embodied energy of surface water facilities, source: Water in the West ${ }^{16}$

Using the value for the embodied energy from Figure 34, which is 1,425.7 $\mathrm{kWh} / \mathrm{MG}$, the total annual energy consumption of the water supply sector in Rhode Island can be approximated.

$$
E_{W S, \text { annual }}=Q_{\text {annual }} * E E_{W S}=125,195 \frac{M G}{a} * 1,425.7 \frac{\mathrm{kWh}}{M G}=0.178 \frac{\mathrm{TWh}}{\mathrm{a}}
$$


In relation to the $53.86 \mathrm{TWh}$ of total energy consumption, the water supply sector amounts to a share of $0.33 \%$ of the total energy consumed in Rhode Island. The environmental impact of freshwater supply is thus directly linked to emissions from the energy supply sector. Renewable energies can help to reduce embodied greenhouse gas emissions, as well as further related emissions of the water supply system.

\section{Energy Incentives}

Rhode Island is one of 38 states in the US, that have introduced a renewable energy standard or portfolio to mitigate climate change and to reduce their dependency on non-renewable fossil resources. As Rhode Island has no fossil resources in the state, increasing in-state energy generation from renewable sources could benefit the Rhode Island economy and reduce its dependency on fossil fuel imports from other states. Due to the state's small size, Rhode Island ranks $45^{\text {th }}$ of all states regarding total emissions of carbon dioxide. If calculated per MWh produced, the state now ranks $32^{\text {nd }}$ due to its emission intensive electricity generation using natural gas ${ }^{94}$.

The underlying plans and incentives to introduce more renewable energies are the Rhode Island State Energy Plan for 2035, the Rhode Island Renewable Energy Standard (RIRES) as well as the Renewable Energy Growth Program and Fund (REG and REF). This main goal of the Renewable Energy Standard is to achieve a share of $38.5 \%$ of renewable sources in the electricity generation sector by the year 2035 . This aim is also incorporated in the State Energy Plan. The REG and REF are the main supporting economic programs that carry this development. The first mid-term goal of the Renewable Energy Standard is to increase the in-state capacity of renewable 
energies to 1,000 MW by the year 2020. This number includes already installed plants as well as such, that are in the planning phase. In 2013, the total installed power of renewable energies was only $29 \mathrm{MW}^{92}$. Investments into solar and wind power led to a total installed power of $371 \mathrm{MW}$ in $2019^{95}$, indicating that Rhode Island will not meet its 1,000 MW goal by 2020. Including planned renewable energy plants, The Rhode Island Office of Energy Resources proposes $809 \mathrm{MW}$ of renewable energies by the year 2020, still falling short of the goal ${ }^{87}$.

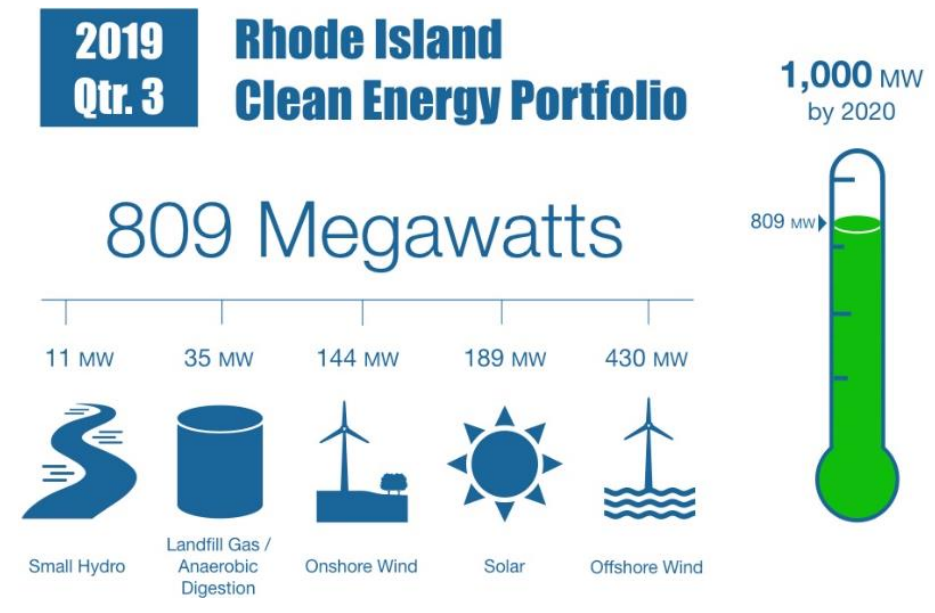

Figure 35: Rhode Island clean energy portfolio - 1,000 MW by 2020, source: RI OER ${ }^{87}$

The major contributor to this goal is the proposed Revolution Wind Farm Project by Deepwater Wind. This Offshore wind project would generate 400 MW of power and benefits from steadier offshore winds and thus a higher capacity factor. Despite that, no land is to be used which would be a big hurdle for on-shore wind farm projects in Rhode Island ${ }^{96}$. Figure 36 shows the revolution wind project and major solar projects in Rhode Island ${ }^{97,98}$. 

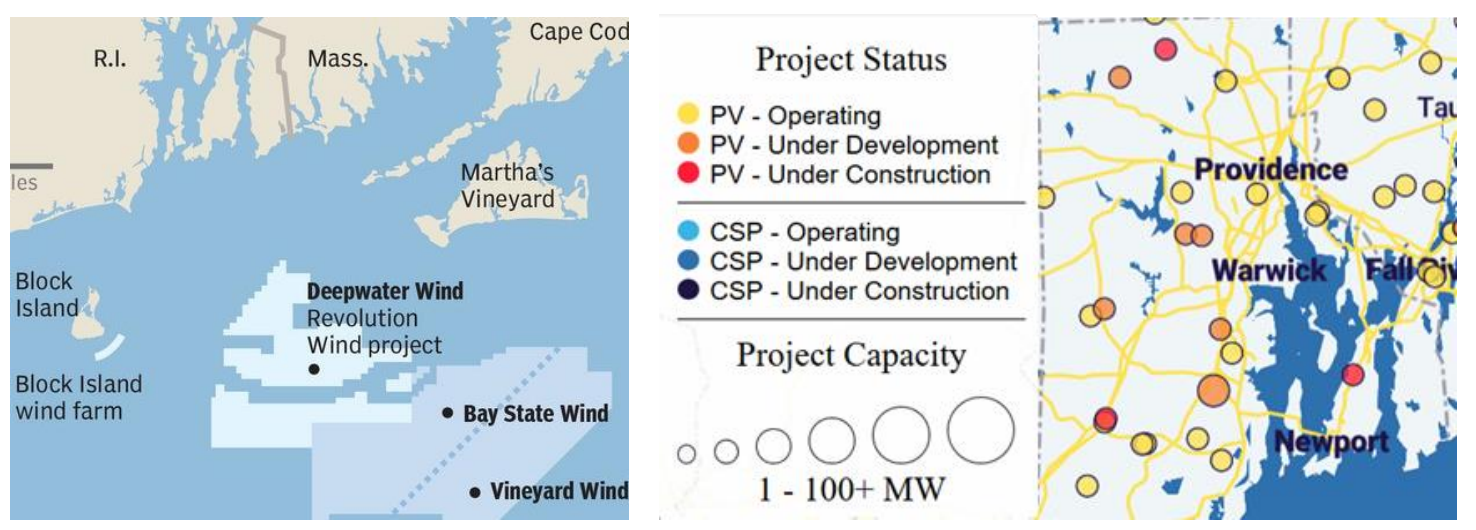

Figure 36: Left: Revolution Wind Project; Right: Solar projects in Rhode Island, source: Kuffner 2018 ${ }^{97}$, SEIA $2019^{98}$

Despite Rhode Island falling short of their first major goal, their future projects indicate the willingness to invest into clean and renewable energy. Besides the environmental savings that would result from renewable energies, the state's economy is likely to profit from energy that is being generated in the state by resources that are available in-state. Every investment into renewable energies also is a preventive step towards potential future national-scale emissions and renewable energies regulations.

\subsection{The Water Energy Nexus}

This section evaluates the current state of research on the water-energy nexus. The first major achievement in the assessment of water for energy and energy for water is Peter H. Gleick's Water and Energy which was published in 1994. It describes the use of energy for water related actions, such as moving of water, groundwater pumping and desalination, as well as the water intensity of various fossil and renewable energy sources. Gleick concludes, that water and energy should not be seen individually and that the interdependencies should be taken into account in any case of water or energy policy. 
Although the word nexus cannot be found in the paper, it marks the beginning of extensive research on the water-energy nexus ${ }^{99}$. As of today, the research about the water-energy nexus has evolved. Further perspectives are also included, extending the water-energy nexus to e.g. the water-energy-health nexus, the water-energy-food nexus and the water-energy-climate nexus.

An extensive literature review does already exist for the water-energy nexus. A very important publication is "Water and Energy Nexus: A Literature Review" from the Stanford Woods Institute for the Environment and the Bill Lane Center for the American West. The report was published in 2013 and evaluates current water and energy nexus research as well as distinguishes the approaches into water for energy and energy for water. The main relevant energy for water aspects of the report are summarized into the conclusions listed in Table 4. 
Table 4: Energy for Water findings summary, source: Water in the West ${ }^{16}$

\begin{tabular}{|c|c|}
\hline 1 & $\begin{array}{l}\text { There is a substantial lack of groundwater data in the US, including the mass } \\
\text { balance of aquifers as well as the energy related to the conveyance of } \\
\text { groundwater and especially the increasing required pumping depth. }\end{array}$ \\
\hline 2 & $\begin{array}{l}\text { Water losses along the supply network must be assessed. This includes not } \\
\text { only the amount of water lost, but also relates to the energy that is embedded } \\
\text { in these losses. }\end{array}$ \\
\hline 3 & $\begin{array}{l}\text { Water treatment practices are not well documented and vary significantly } \\
\text { across the US. There is a need for comparison of the techniques used and the } \\
\text { resulting water quality and energy intensity. }\end{array}$ \\
\hline 4 & $\begin{array}{l}\text { There is a need to assess the embedded energy in the treatment of recycled } \\
\text { water up to drinking water quality and the potential of this practice to reduce } \\
\text { stress on water resources. }\end{array}$ \\
\hline 5 & $\begin{array}{l}\text { The increasing number of new pollutants in water require increased amounts } \\
\text { of energy for their treatment, as well as new treatment technologies. The } \\
\text { energy intensity of both existing technologies and new technologies needs to } \\
\text { be evaluated. Best management practices must be compared to currently used } \\
\text { technologies. }\end{array}$ \\
\hline
\end{tabular}

In the water for energy section, the water needs for different energy sources are assessed. These sources include coal, natural gas, uranium, thermoelectric power generation, oil and transportation biofuels. The main statement is that in every sector there is a lack of data and knowledge about the water use of the specific energy source $^{16}$. This literature review does not include renewable energies and their potential impact on the future water and energy supply system. The author's recommendations 
mostly target the concept of efficiency. This applies for all sectors of both water for energy and energy for water, that were assessed in the report.

Most recommendations point out that more data is required, and technologies have to be made more efficient. The report lacks information about the potentials of system flexibility in both the water and energy supply system. Despite the major findings of the report, some more very relevant information and facts are mentioned. The authors mention the similarity of the water distribution network and electricity distribution networks, as well as the role of the consumer to define the required input from the supply system. Figure 34 shows, that the distribution of water to the customer is by far the most energy intensive part of the water supply system with the intensity depending on the topography, in which the supply system is embedded. The authors argue that assessment of the water demand and the potentials of using storage tanks can help to foster sustainable development in the water supply sector. The authors do not propose any approach to assess the actual potential.

With the current situation of a trend towards renewable energies, the challenge of keeping a balance between demand and supply is intensified, as energy supply is not flexibly adaptable to the energy demand. As this literature review was published in 2013, the main research focus lies on papers that were published in the years 2013 to 2019, unless a major relevancy is assumed, and the paper is not included in the literature review report. Although this literature review is very extensive, it mostly follows the life cycle pathway of energy and water separately. Also, the scope of this study is often limited to the US or even the western part of the US. 
Water-energy nexus research can be distinguished regarding the research approach, which is defined by the investigation scope and the methodologies used. The scope varies from single appliances or entities within the water and energy system to the evaluation of larger supply systems. Methodologies include but are not limited to environmental or life-cycle assessments, simulation modelling and linear and nonlinear programing.

Many approaches focus on islands, as the water energy nexus is an even more crucial due to the limited resources and infrastructure ${ }^{100}$. Current research regarding the energy use in the water supply system includes the relation of water quality to its embodied energy in treatment processes ${ }^{101}$, the assessment of energy efficiency and air emissions of the water supply system ${ }^{102,103}$, the use of water supply networks to increase the use of renewable energies ${ }^{104,105}$ and sea water desalination using renewable energies ${ }^{106}$. Further concepts to address renewable energies in the water sector include the use of aquifer well pumps for energy storage purposes ${ }^{107}$ and the reutilization of old elevated storage tanks for pumped hydro storage ${ }^{108}$.

An increasing share of renewable energies requires the energy-water nexus to not only address the efficiency of single processes, but also the flexibility. Only very few publications can be found on the topic of water supply system flexibility to adapt to an increasing share of renewable energies. Meschede assessed the potential of storage capacities and demand shifting strategies in water supply systems on islands to increase the energy self-sufficiency ${ }^{105}$. Another approach evaluates how the water distribution network can be made flexible to address energy flexibility ${ }^{109}$. Still, these are the few approaches that can be found on flexibility in the water-energy nexus. 


\section{Main Findings}

Although Rhode Island is a state rich in precipitation, the water supply system is experiencing increasing stresses. Efforts towards increasing the share of renewable energies are likely to significantly reduce the use of saline water for cooling purposes in thermoelectric power generation plants. The largest freshwater use sector is the residential and public supply sector. Increasing stresses on the supply system are mainly caused by summer irrigation using tap water. Despite the stress itself, the variety of water supply systems in Rhode Island leads to a lack of data especially for self-supplied homes or smaller communities that rely mostly on groundwater. The embodied energy and related emissions of the Rhode Island water supply can either be mitigated by using water more efficiently or by switching to alternative water sources. Especially for irrigation purposes, alternative approaches like rooftop rainwater harvesting should be implemented to reduce the use of tap water for purposes that do not require that level of quality. This would also reduce the total energy consumption of the water supply sector.

The increasing share of renewable energies has a great potential for Rhode Island's economy. As fossil fuels are currently being imported from other states, Rhode Island can profit from in-state renewable electricity generation and reduce their dependency both on other states and non-renewable fossil resources themselves. Potential future national legislation to reduce greenhouse gas emissions can be preventively addressed by already implementing renewable energies into the Rhode Island electricity grid mix. The main shortcoming of renewable energies like wind and solar power is their volatile and fluctuating power generation behavior. A common 
way to account for that is to use large battery systems that can reduce the deviation of use and supply. The water supply sector has a natural energy storage opportunity in elevated storage tanks. Through flexible planning and control, elevated storage tanks could be an entity that can be used to increase the utilization of renewable energies.

Current scientific literature on water and energy nexus topics indicates that in past years water and energy efficiency were the primary strategies to achieve higher quality and security, while reducing the use of either water for energy or energy for water. In recent years some publications address storage potentials in the water supply sector as well as flexibility potentials that lie in the water supply system. Flexibility has shown great potentials in industrial applications to reduce electricity related greenhouse gas emissions through an increasing utilization of renewable energies. As this novel strategy can be applied to any energy consuming process or entity, the water supply system is likely to have a significant potential for flexibility measures, as storage capacities are already essential elements of water supply systems. In conclusion, three main fields of action are detected in this chapter:

- Increasing shares of renewable energies will reduce the overall Rhode Island water demand.

- The total fresh-water demand, as well as its related embodied energy and emissions can be reduced by decoupling lawn irrigation from the energy intensive, high-quality freshwater supply system using alternative approaches, like rainwater harvesting.

- The water supply system contains naturally existing potentials to increase renewable energy utilization by implementing energy flexibility measures 
through flexible process control and the use of elevated storage tanks as volume buffers and energy storage.

It is recommended, that future research on the water-energy nexus and even the waterenergy-climate nexus should take these aspects into account. These concepts will help the water supply system and the energy supply system to become more sustainable.

\subsection{Demand Side Management}

Demand side management (DSM) has become an increasingly important strategy to cope with increasing shares of fluctuating renewable energies. From the initially economic motivation to adapt to electricity price fluctuation, the concept of demand side management evolved to consider economic and ecological aspects more holistically in the past decades ${ }^{110}$. A first widely accepted definition and framework was introduced by Clark W. Gellings in 1985. According to Gellings, "DSM is the planning, implementation, and monitoring of those utility activities designed to influence customer use of electricity in ways that will produce desired changes in the utility's load shape, i.e., changes in the time pattern and magnitude of a utility's load." $"$ Along with this definition, six categories to apply demand side management were defined, which are shown in Figure 37. 

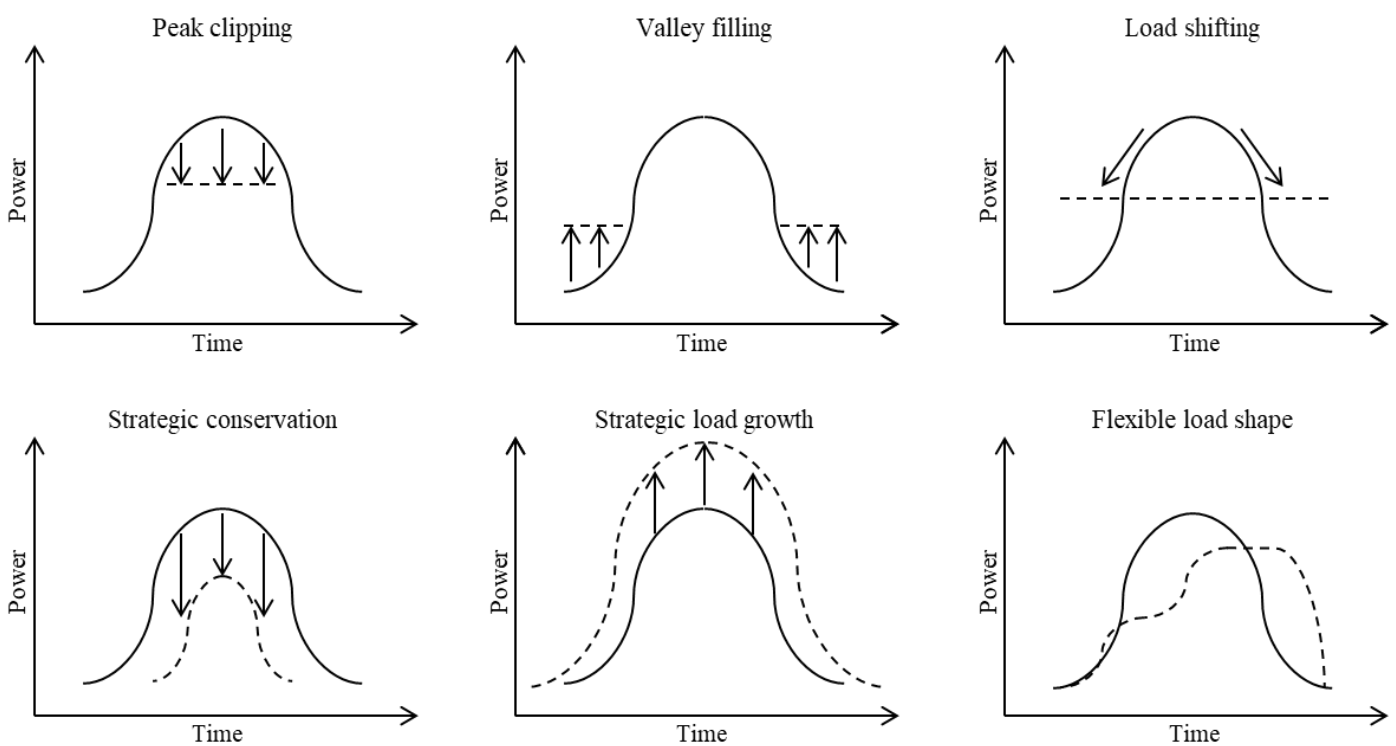

Figure 37: Demand side management strategies, own figure based on Gellings $1985^{111}$

There is no defined range of power of time, which allows these strategies to be applied on different levels of power (single processes up to whole systems) and time periods (seconds up to years).

The proposed change in Rhode Island's electricity mix poses the necessary opportunity to adapt energy consuming entities to fluctuating energy supply. Forecasting of fluctuating renewable energies like wind and solar power plays a significant role in planning dynamic loads ahead ${ }^{112}$. Often, these forecasts mainly address daily to weekly forecasts, though ${ }^{113}$. To adapt to fluctuating energy demands in a minute or even second time frame, demand side management provides tools to flexibly adapt energy demands to the currently available energy supply. This increased productivity of systems needs sufficient downstream storage capacities to act as buffers. Water supply systems have the potential to implement flexibility measures, as storage capacities are already part of the system in the form of elevated storage tanks. 
The potential to implement demand side management measures decentralized water supply systems will be assessed. A case study will be conducted with the object of investigation being the water supply system of the University of Rhode Island, including conveyance, treatment, storage and distribution. The URI elevated storage tank has a capacity of approximately 1 million gallons ${ }^{114}$, which is a promising volume for buffering flexible supply system productivity. As the quality of drinking water is related to the retention time in the system, the measures aim at not affecting the drinking water quality in a negative way.

For the particular case of elevated storage tanks, the underlying concept is the transformation of electrical energy from renewable sources to mechanical energy to run the pumps to hydrostatic energy which is stored in the elevated storage tank. The round-trip efficiency of existing pumped hydro storage plants is $80 \%$, with losses occurring in both the pump and turbine with approximately equal shares. The resulting pump efficiency is calculated as the square root of the round-trip efficiency and is around $89-90 \%{ }^{115}$. The amount of energy stored in the elevated storage tank changes with the fill level of the elevated storage tank. Excess energy from renewable sources can be used to increase the amount of energy stored in the elevated storage tank with a low emission footprint, which eventually allows reductions of electricity demands from sources with a higher emission footprint. 


\section{METHODOLOGY}

This chapter explains the proposed research study on increasing the share of renewable energies using demand side management in water supply systems. The system characteristics are demonstrated from both the water and energy perspective. Data acquisition and treatment as well as the implementation of data and concepts into the simulation modelling process are explained. The reference scenario and the adapted potential future scenario are distinguished. This chapter serves as a profound reference for the scenario comparison and proposed improvement analysis in chapter 4. Figure 38 summarizes the proposed study using a framework drawn from cyberphysical production system approaches ${ }^{116}$.

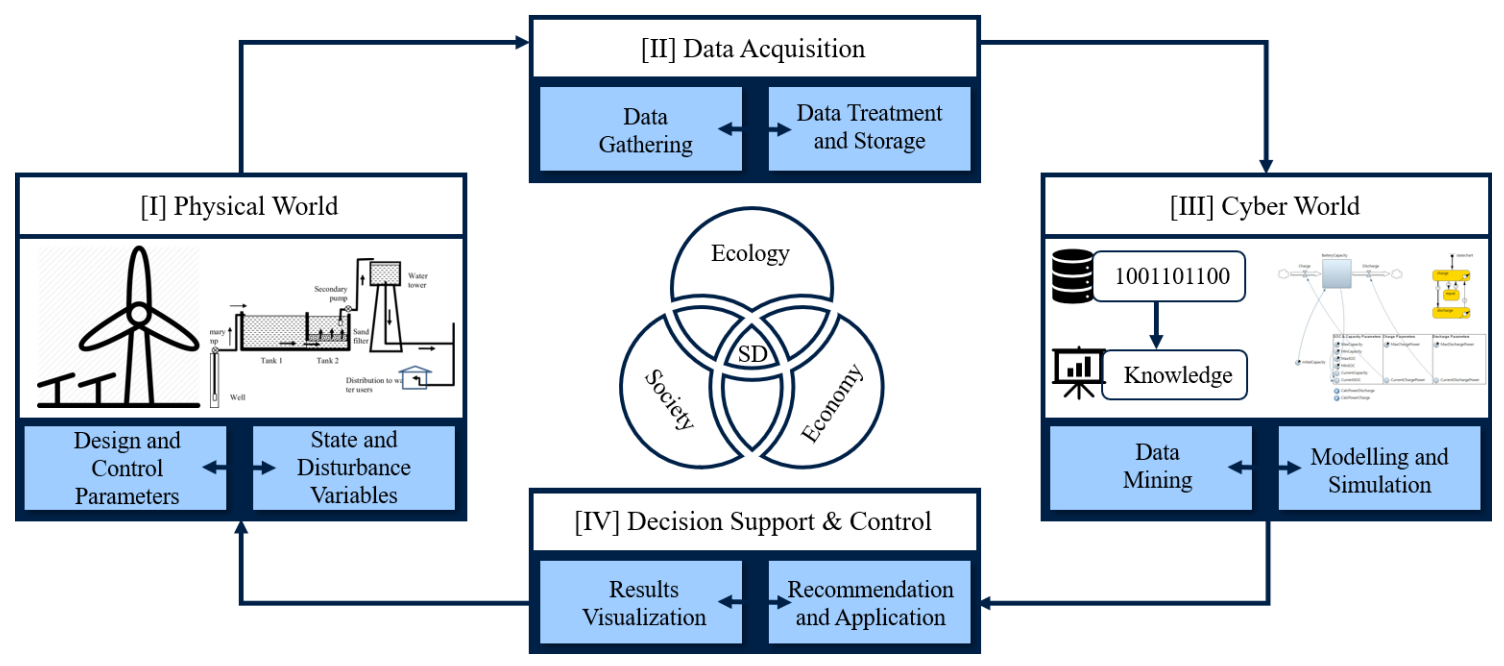

Figure 38: Case study framework, own figure based on Thiede et al. $2016^{116}$

Both the energy system and the water system are assessed regarding their design and control parameters, as well as state and disturbance variables. These parameters and variables serve as the foundation of the operation control loop used in the water supply system. Data from the physical world is acquired from both the water and 
energy system and subsequently treated towards a state that can be used by the simulation model. Data is fed into the model using an application interface, that lets the model draw data from the water and energy system throughout the simulation runs. Key performance indicators are calculated for each scenario during the simulation runs, are then stored in a database and are ultimately exported into static cell-based spreadsheets. From the spreadsheets, the results can be visualized, compared and interpreted to provide a scientific foundation to formulate recommended actions. These recommended actions could potentially be implemented in the physical system within the boundaries of uncertainty and model abstraction. The challenge of implementing measures based on a digital twin model are expounded in chapter 5 .

\subsection{System Characteristics}

The proposed approach assesses the water supply system's ability to be used for flexibility measures along the water's path from conveyance to use. Water supply systems already use means of demand side management. By running booster pumps before the early morning demand peak, the fill level in water storage tanks in the

distribution system is increased. Thus, the system pressure is increased and the reliance on booster pumps during high water demand can be reduced. 


\subsubsection{Water Supply System Characteristics}

The water supply system, which is assessed in this study represents the University of Rhode Island water supply system. The digital twin model will be subject to assumptions that have to be made to efficiently model the system with an adequate level of abstraction.

\subsubsection{Supply}

The University of Rhode Island maintains its own water supply system, the URI Water District. The system is adjacent to the Kingston Water District. For increased reliability, a security connection connects the two comparatively small water districts ${ }^{117}$. Figure 39 shows the spatial extent of the URI Water District, as well as the adjacent supply system, the Kingston Water District. For the modelling of the system, the security connection is neglected to assess the URI water supply system as a decentral and potentially autarchic system.

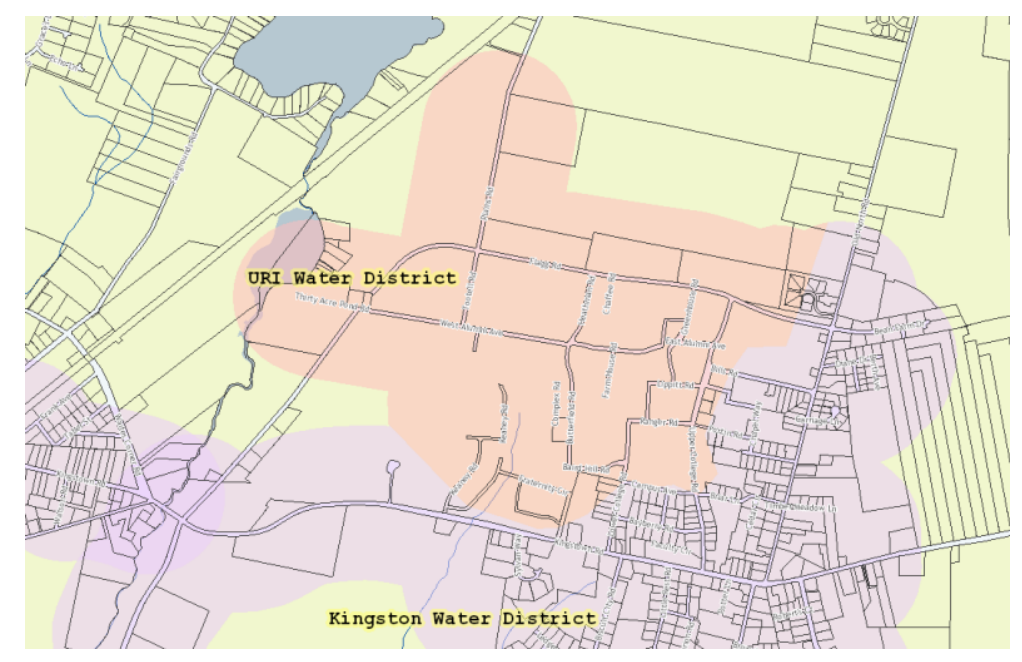

Figure 39: The URI water district and adjacent Kingston water district, source: Town of South Kingstown Web GIS $2020^{118}$ 
The source of water in the URI water supply system is groundwater, which is drawn from the Chipuxet Aquifer using three high volume wells. Figure 40 shows the Kingston area with the University of Rhode Island. The URI is located directly next to the Chipuxet aquifer. An enlarged excerpt of the map is shown in Figure 41 including the three wells and the respective wellhead protection area and the elevated storage tank.

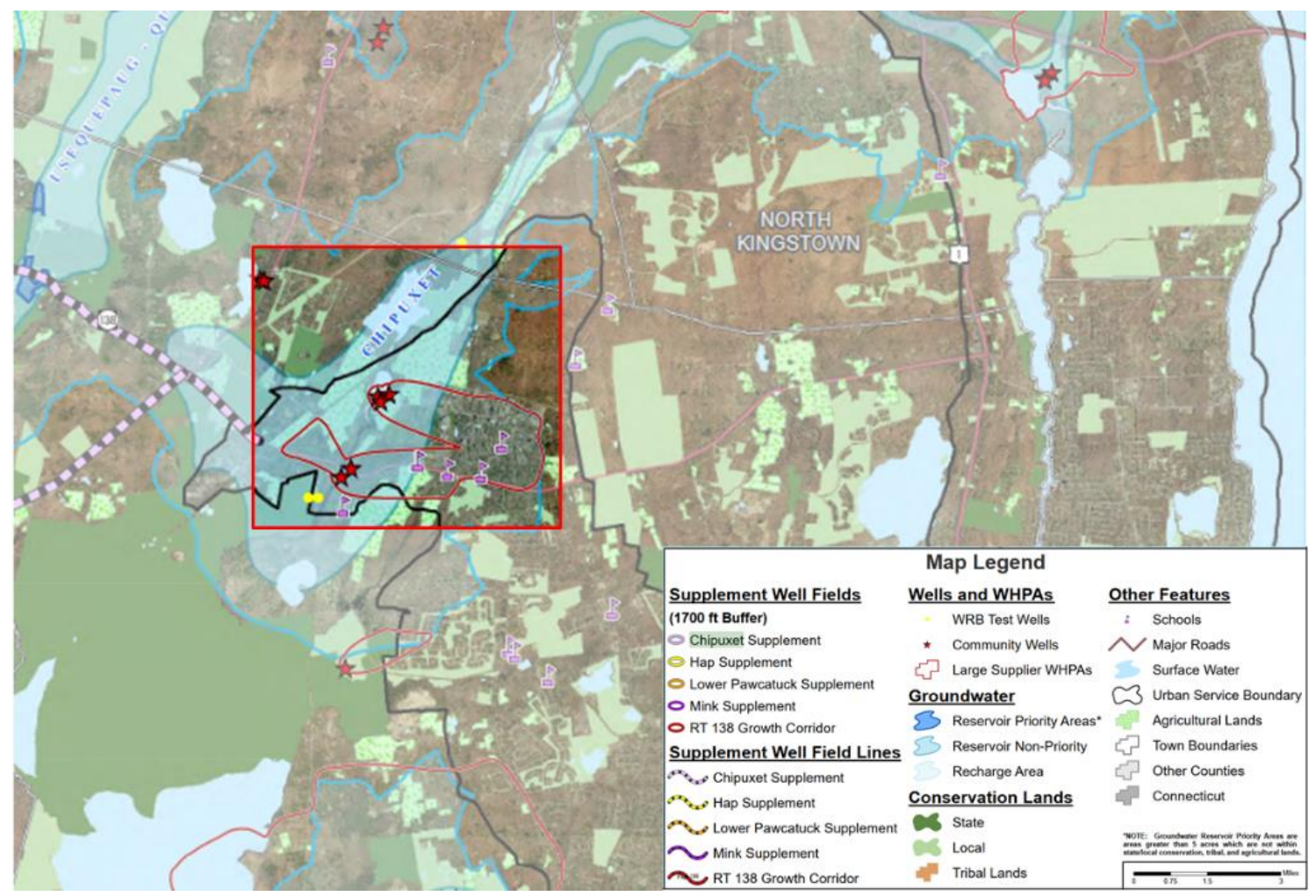

Figure 40: URI freshwater source: The Chipuxet aquifer, source: Rhode Island Water Resources Board $2012^{119}$ 


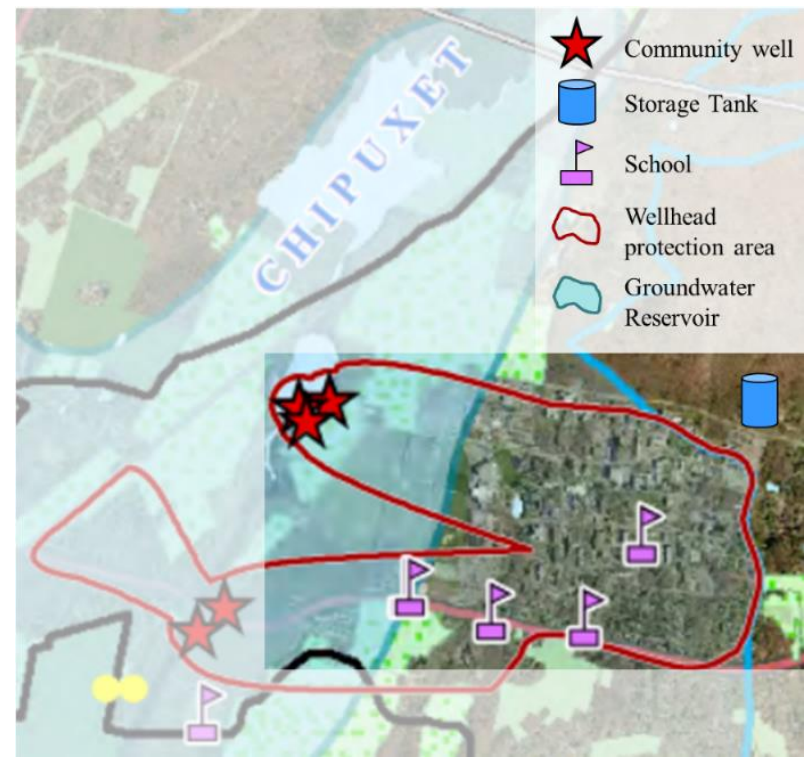

Figure 41: URI freshwater source: Wells and WHPA, source: Rhode Island Water Resources Board $2012^{119}$

The three high volume wells are located on Thirty Acre Pond Rd. on an elevation of 33.5 above sea level. Figure 42 shows a map of the URI campus with $5 \mathrm{ft}$

\section{contour lines.}

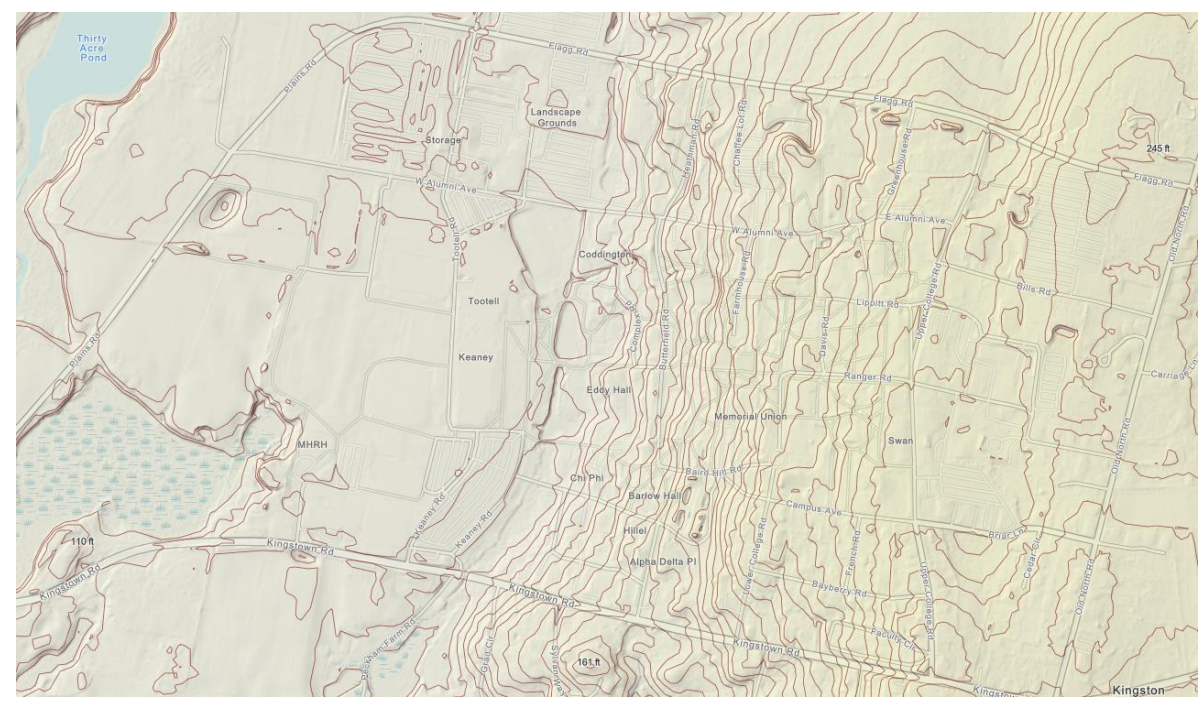

Figure 42: University of Rhode Island topographic map, $5 \mathrm{ft}$ contour lines, own figure based on ESRI ArcGIS $2020^{120}$, University of Rhode Island Environmental Data Center $2020^{121}$, Rhode Island Geographic Information System consortium 2020, US Geological Survey $2020^{122}$ 
Figure 41 and Figure 42 show that the three wells lie at a comparatively low elevation, while the storage tank lies on a high elevation with the distribution system that is spread across the campus being between the wells and the tank.

\subsubsection{Distribution system}

The distribution system for the case study is assumed to be a traditional branch configuration. Although nowadays, grid/loop-networks are more commonly used, the branch network is sufficient for modelling from an energy perspective. The hydraulic complexity of grid networks with multidirectional flows is not appropriate for the purpose of this study. The only bidirectional flow of water is considered at the branch line leading to the elevated storage tank. According to the mass balance of supply and demand, water might flow in the direction of the tank $\left(\mathrm{Q}_{\text {fill,release }}>0\right)$ or back into the system $\left(\mathrm{Q}_{\text {fill,release }}<0\right)$. It should be noted that Bidirectional flow can not exist simultaneously. Water can only flow in either direction at different points of time. Figure 43 illustrates the mass balance of the system and the storage tank. The pipes are assumed to contain no air at any point of time, which implies that the volume of water in the pipes never changes.

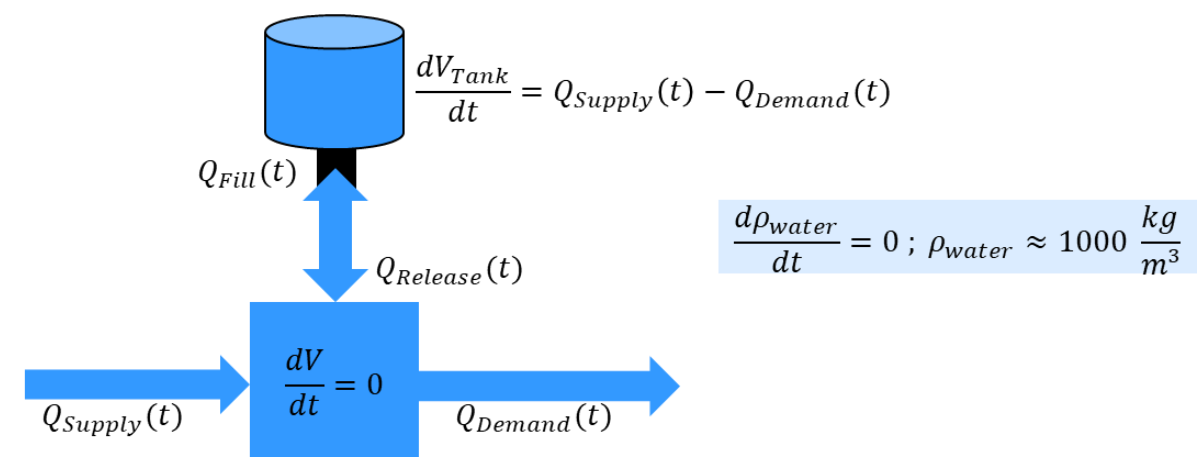

Figure 43: Distribution system volume balance, own figure 


$$
\begin{aligned}
& Q_{\text {Supply }}(t)>Q_{\text {Demand }}(t) \Leftrightarrow Q_{\text {Fill,Release }}(t)>0 \\
& Q_{\text {Supply }}(t)<Q_{\text {Demand }}(t) \Leftrightarrow Q_{\text {Fill,Release }}(t)<0
\end{aligned}
$$

This study assesses a potential future scenario of energy and water supply at the University of Rhode Island. For modelling purposes, a uniform pipe material is assumed in the distribution system. The pipes are assumed to be made out of the most predominantly used material today, which is polyvinyl chloride (PVC) $)^{43,11}$. The absolute pipe roughness of the material PCV is $0.0015 \mathrm{~mm}^{123}$.

Water supply system pipes can be distinguished into transmission pipes, distribution pipes and service lines. Additionally, dual-purpose pipes can be used as both transmission pipe and distribution pipe according to the specific system layout and dimension. The pipes in the distribution system have been dimensioned according to the minimum, maximum and average water demand and the resulting hydraulic variables, such as Reynolds number and velocity. The diameters used in this study range from $12.5 \mathrm{~mm}$ for low demand service lines to $200 \mathrm{~mm}$ for distribution mains. 


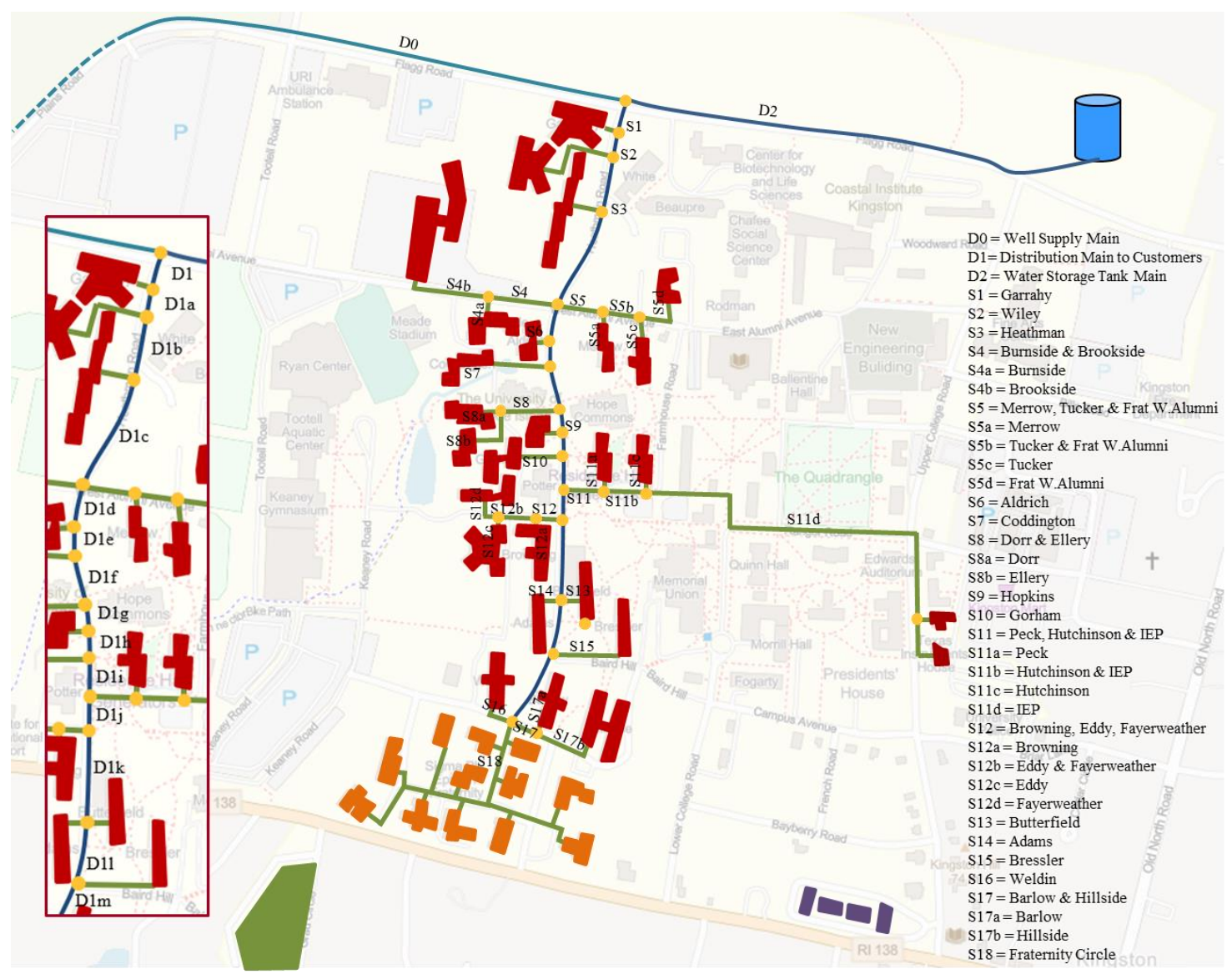

Figure 44: Assumed URI water distribution mains and service lines, own figure based on ESRI ArcGIS $2020^{120}$

All pipe distances are estimated using a branch distribution system and connecting the residence halls and other housing options to the distribution main Du1. The population of Fraternity Circle is seen as a whole. The total distribution network length in the Fraternity Circle is thus divided by the number of houses to calculate the mean service line length from the houses to the distribution main.

For hydraulic calculations, the distribution main D1 has to be recalculated after every junction, as the dynamic flow decreases with every service line. The distribution main D1 is thus cut into 14 single segments, namely D1 - D1m. 


\subsubsection{Storage Tank}

The distribution system is connected to a one million gallon elevated storage tank, which is located at Flagg Rd. on an elevation of $72.2 \mathrm{~m}$ above sea level. The substructure of the tank is assumed to be 18 meters high. Thus, the bottom of the tank itself is at $90.2 \mathrm{ft}$. above sea level. The storage tank is floating on the distribution system. The dynamically changing free surface of the water in the tank marks the highest point of the water within the system. The minimum fill level is determined by the requirement to provide 20 psi pressure at any service connection within the system. The connection with the highest elevation is the IEP / TI house at $70.1 \mathrm{ft}$. For the required pressure, the minimum water level can be calculated.

$$
\begin{gathered}
h_{f i l l, \text { min }}=20 \text { psi } \times 0.703 \frac{\mathrm{m}}{p s i}-\left(\operatorname{elev}_{\text {tank }, \text { bottom }}-\operatorname{elev}_{I E P, T I}\right) \\
h_{\text {fill,min }}=20 \text { psi } x 0.703 \frac{\mathrm{ft}}{p s i}-(90.2 \mathrm{~m}-70.1 \mathrm{~m})=-6.04 \mathrm{~m}
\end{gathered}
$$

Equation (3.1) shows, that even if the tank is empty, the water level in the vertical pipe is enough to supply sufficient pressure to the consumer with the highest elevation. This does not include continuous losses in the distribution system. Continuous losses will be calculated dynamically for each time step in the simulation run. For security reasons, a certain minimum fill level should be determined at a point above the bottom of the tank. Due to the small diameter of the vertical pipe, any demand can reduce the static head drastically and it might fall below the requirement of 20 psi. A minimum fill level of $5 \mathrm{ft}$ is assumed in the storage tank. For modelling purposes, the tank shape is assumed to be cylindrical instead of oval. The changing 
water level (WL) in the tank can then be determined by dividing the current volume in the tank by the circular bottom area.

$$
W L(t)=\frac{V(t)}{A}=\frac{V(t)}{\pi * r^{2}}
$$

A constant water surface area allows for a linear correlation between the current volume in the tank and the water level

\subsubsection{Pumps}

From Figure 41, it can be seen that three wells and thus three pumps are used to supply water to the system. For modelling purposes, it is assumed that these three pumps are used to pump water into the system from an endless source of groundwater. The pumps are dimensioned using the assumed diurnal demand curve. The power that the water needs to be pumped into the system with (water power) can be calculated:

$$
P_{w}[k W]=\frac{\rho * g * Q * T D H[m]}{1000 * \eta}
$$

The height $\mathrm{h}$ is the sum of all heads within the distribution system, namely the static head, the pressure head, the volume head and the friction head. The consideration of the pump head will be explained further in section 3.2.2.4.

$$
T D H(t)=S H(t)+P H(t)+V H(t)+F H(t)
$$

Based on literature references, the efficiency of the pump is assumed to be $70 \%$, including both motor and pump efficiency ${ }^{49,124}$. 


\subsubsection{Population served}

Population data from URI was acquired from information websites of the University of Rhode Island. According to URI, approximately 5600 undergraduate students live in 25 residence halls ${ }^{125}$. Data from the individual websites of the residence halls was not always available but was provided by the URI Housing and Residential Life Customer Service via email. The total number of undergraduate students in residence halls was aggregated from the data sources and is a total of 5999 residents. Additionally, approximately 700 students live in the 15 sororities and fraternities. 13 of these are located on campus and thus supplied through the URI water district ${ }^{126}$. It is assumed that the population in the sororities and fraternities is equally distributed between the houses, resulting in an estimated population of 606 students living on-campus. An additional 75 residents live in the International Engineering Program House and the Texas Instruments House ${ }^{127}$.

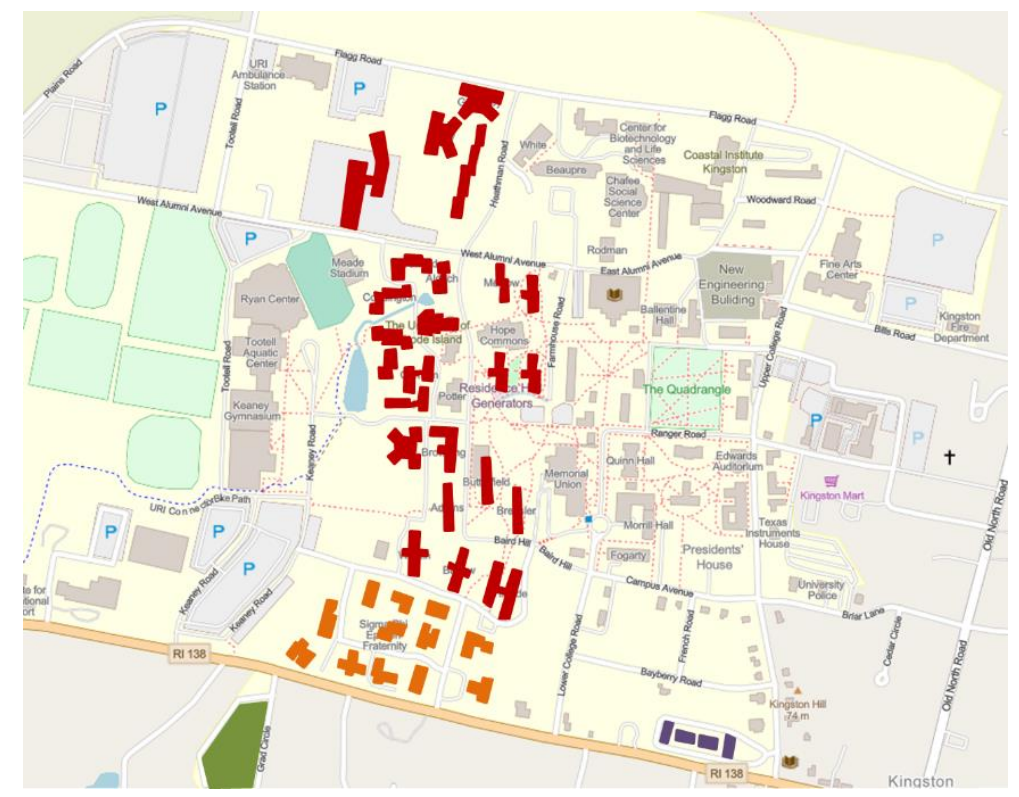

Figure 45: Life on campus - Residence halls, fraternity circle and other, own figure based on ESRI ArcGIS $2020^{120}$ 


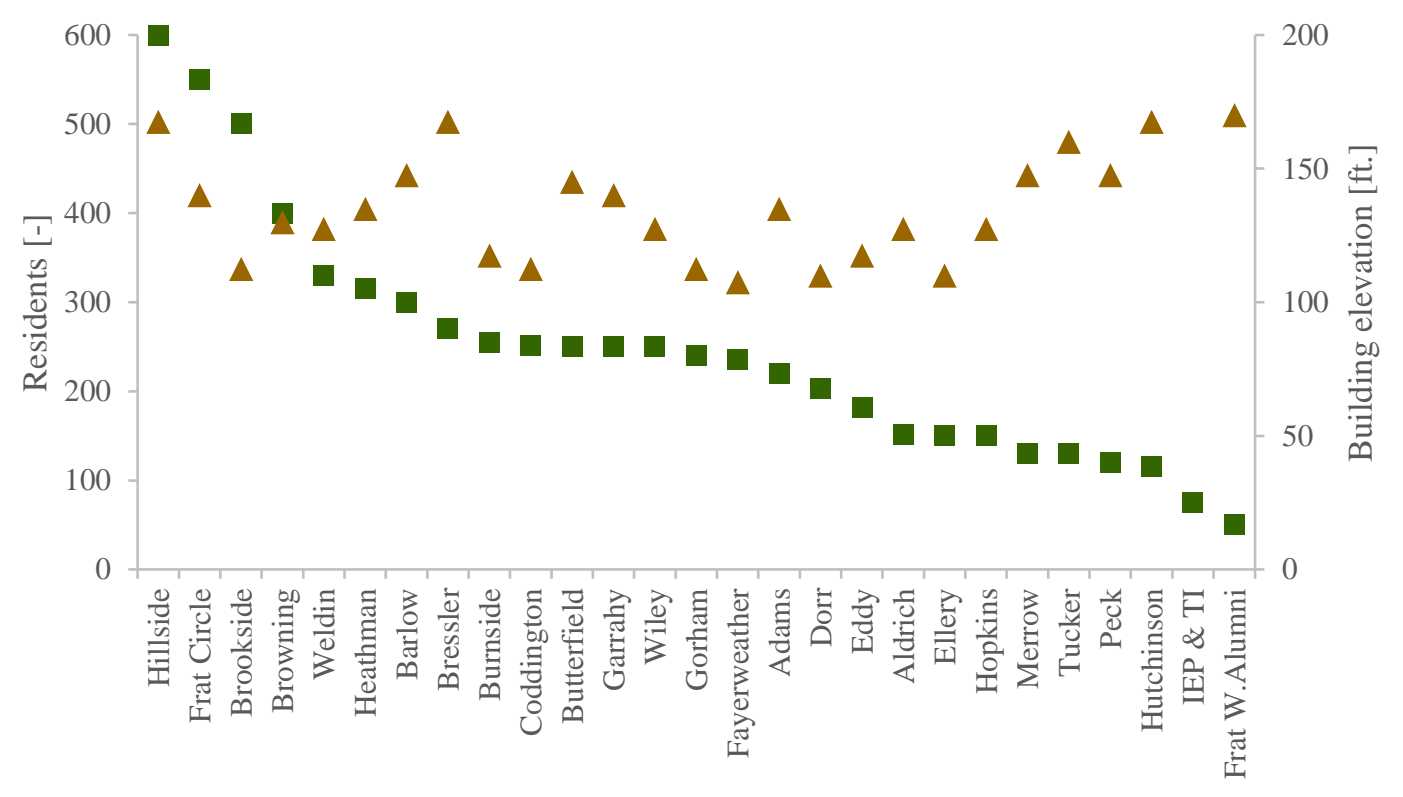

Figure 46: Life on campus - Number of residents and building elevation of on-campus housing, own figure, based on ESRI ArcGIS $2020^{120}$, University of Rhode Island $2020^{128}$

According to Figure 39, the University Gateway Apartments and the Graduate Village are not located within the URI water supply system and will thus not be included in this study. The total population served by the URI water district is assumed to be the sum of all residence halls, sororities and fraternities and other housing options on campus and is 6674. Although there are many more demand ends to the water supply system, this study aims at evaluating the potential of energy flexibility for domestic water supply systems and does not consider any further irregular water use on campus for i.e. laboratories, dining halls, gardens, etc.

Water demand data is estimated using the mean water usage in Rhode Island of $58-72 \mathrm{gal} / \mathrm{p}^{*} \mathrm{day}^{57}$. The total water demand can be calculated by multiplying the mean demand of $65 \mathrm{gal} / \mathrm{p}^{*}$ day with the population and results in a daily demand of $433,810 \mathrm{gal} / \mathrm{day}$ or $1641.97 \mathrm{~m}^{3} /$ day. No data was available to display any diurnal patterns of the water demand. The dynamic demand curve was aggregated based on 
the assumption of two major peaks in the morning and in the evening as well as an additional, slightly lower peak at lunchtime. While different diurnal patterns may exist, this pattern is based on past studies about water demand forecasting ${ }^{129}$. The daily demand is allocated to the characteristic pattern, maintaining the average demand of $65 \mathrm{gal} / \mathrm{p} *$ day.

$$
\int_{0}^{t=24 h} Q_{\text {demand }} d t=65 \frac{g a l}{p * d a y}
$$

The assumed diurnal demand curve is shown in Figure 47.

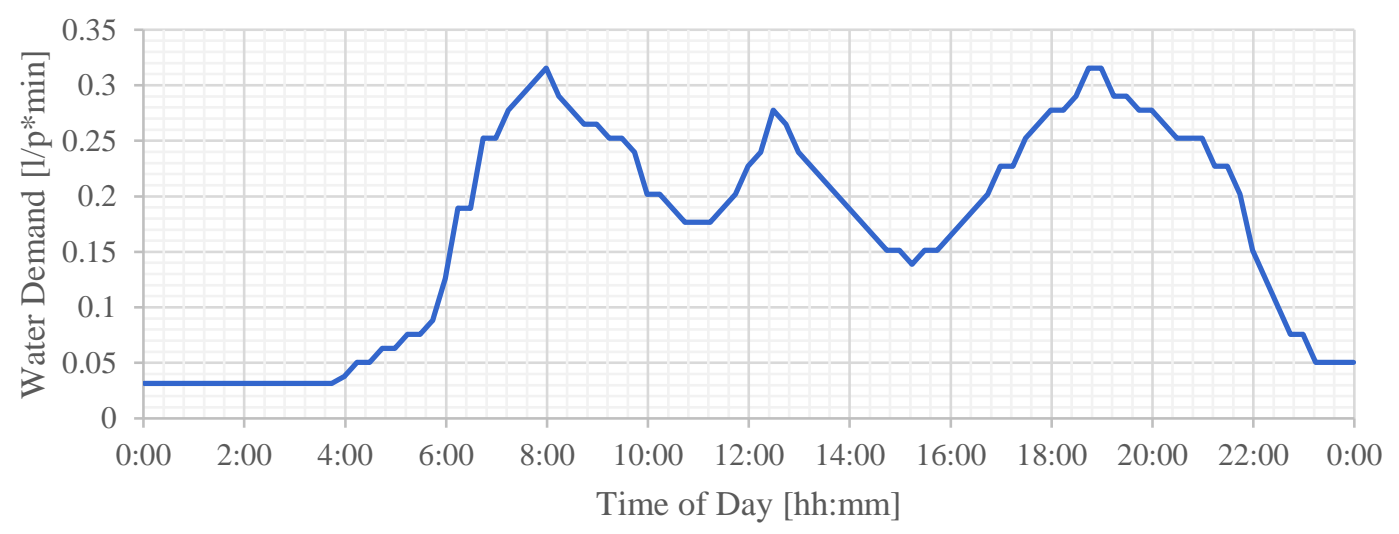

Figure 47: Assumed diurnal water demand curve, own figure based on Alvisi et al. $2007^{129}$

To add potential variations to the curve, each day's data is fed into a normal distribution tool, which alters each value slightly to represent daily differences in water use. The tool assumes a normal distribution with a mean of $65 \mathrm{gal} / \mathrm{p} *$ day and a double sigma of $2 \sigma=7 \mathrm{gal} / \mathrm{p}^{*}$ day. Accordingly $95.45 \%$ of the values created by the tool then fall into the range of $58-72 \mathrm{gal} / \mathrm{p}^{*}$ day, representing the range of water consumption data for the state of Rhode Island ${ }^{57}$. 


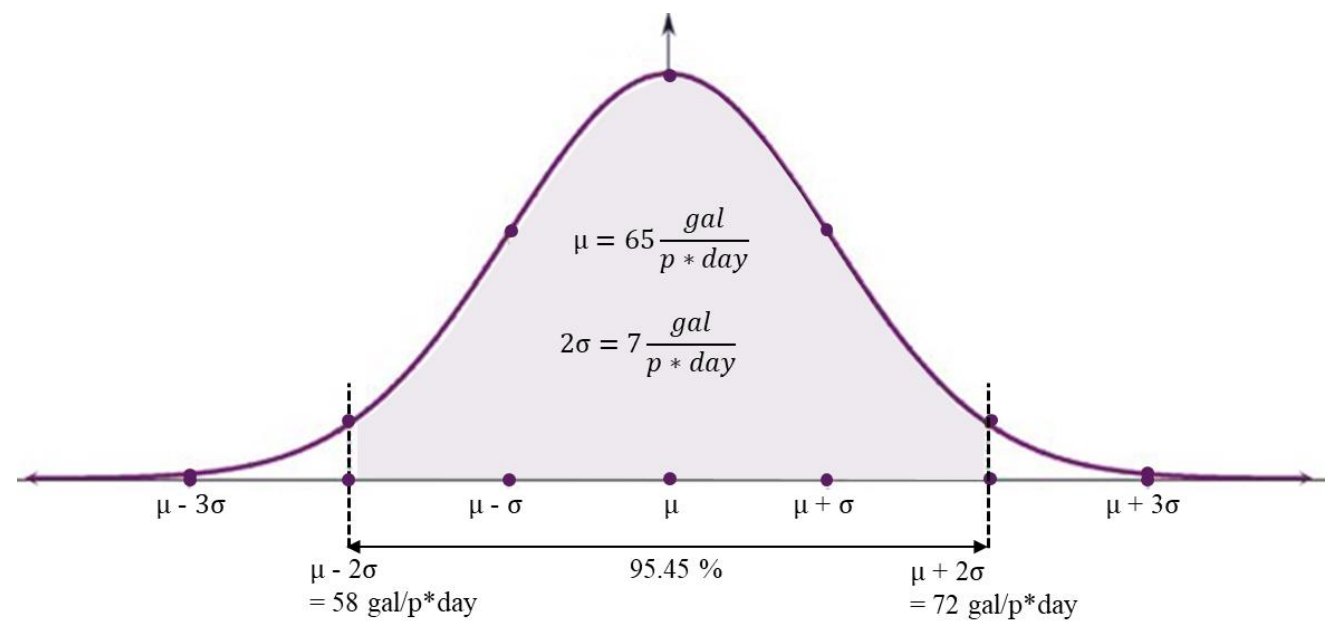

Figure 48: Assumed normal distribution of individual water demand data, own figure based on Wang et al. $2015^{130}$

\subsubsection{Energy Supply System Characteristics}

The energy supply for this study consists of two major systems. Initially, electricity is supplied through the physically existing connection to the Rhode Island electricity grid. Furthermore, a scenario will be simulated in which renewable energy is provided by photovoltaic and wind energy.

\subsubsection{Grid Electricity}

Grid electricity is assumed to be available without limitations. The University of Rhode Island is connected to the interconnected New England-wide electricity grid. Electricity market participants in the six states of New England are members of the New England Power Pool (NEPOOL) $)^{131}$. For Rhode Island, National Grid is the

provider of the transmission system and contractor of supplying the University of Rhode Island with electricity. Despite the high share of natural gas in the Rhode Island electricity generation, the same does not apply for the grid mix due to the connection 
to the New England-wide integrated electricity grid. The grid mix of the system is shown in Figure 49.

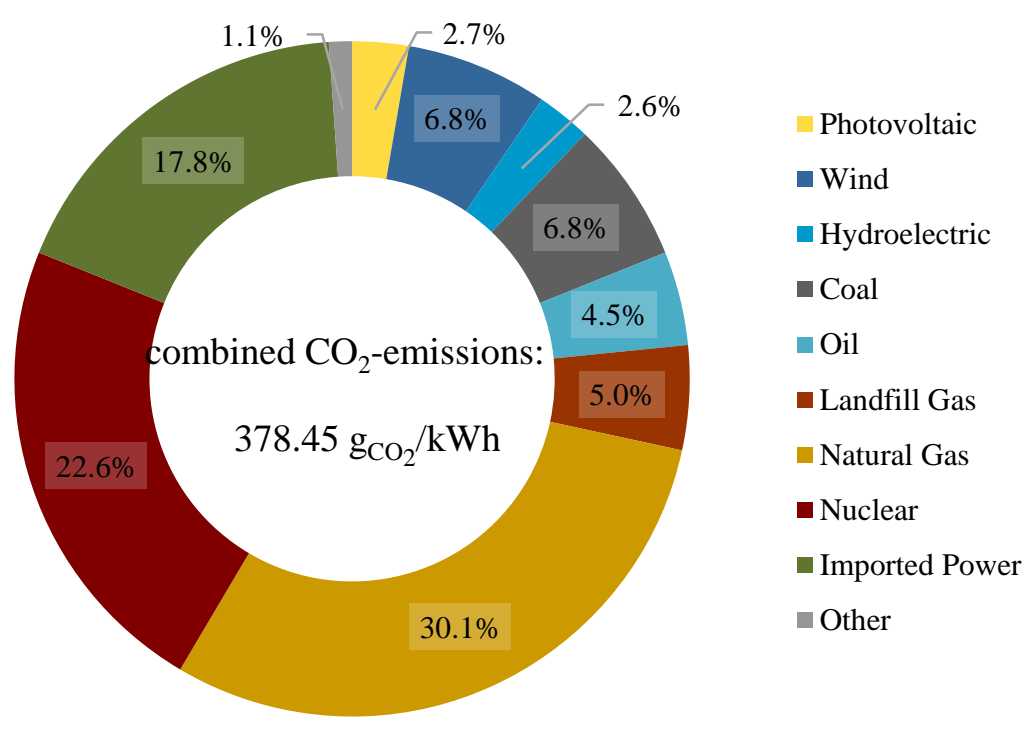

Figure 49: Electricity grid mix, standard offer service in Rhode Island for National Grid customers, own figure, data source: National Grid $2020^{132} /$ NEPOOL $2019^{133}$

The combined $\mathrm{CO}_{2}$-emissions of $378.45 \mathrm{~g}_{\mathrm{CO} 2} / \mathrm{kWh}$ will be used to determine the carbon intensity of the reference scenario.

\subsubsection{Renewable Energy}

Any additional scenarios in this study will assess the potential integration of renewable energies to supply the URI water supply system with electricity. The main focus of this study lies on the fluctuating renewable energy carriers. Therefore, wind power and photovoltaic power are chosen as renewable energies. Although a photovoltaic plant already exists near the University and a Wind farm exists off the shore of Block Island, the installed power of the renewable energies is designed and dimensioned according to the energy demand of the water supply system for modelling and evaluation purposes. 
Data for the renewable energies is acquired from a small-scale photovoltaic and wind power plant, that is mainly used for research purposes on renewable energies in a manufacturing environment. The system is located on the roof of the Institute of Machine Tools and Production Technology (IWF) of the Technical University of Braunschweig, Germany.

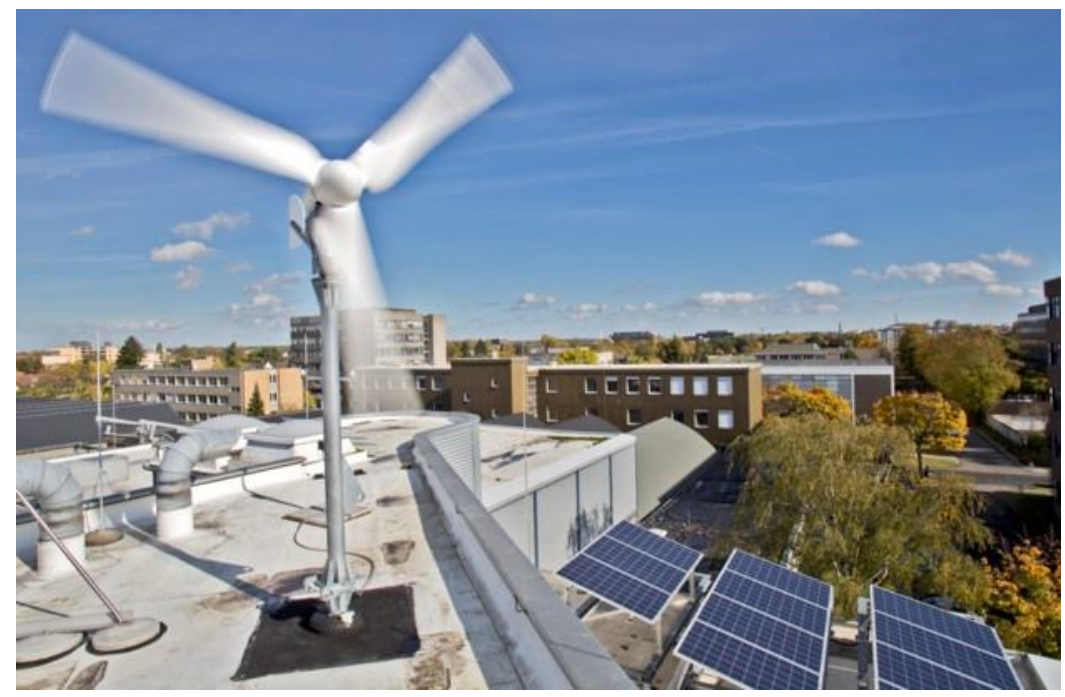

Figure 50: Roof-mounted wind turbine and photovoltaic system on the Institute of Machine Tools and Production Technology, source: IWF TU BS $2017^{80}$

The installed peak power of the Photovoltaic and Wind turbine is $2.94 \mathrm{~kW}$ and $2.7 \mathrm{~kW}$, respectively ${ }^{134}$. Generation data of both wind and photovoltaic power are continuously monitored in a very detailed temporal data resolution of one second. Data collected from the wind turbine will not be altered due to the highly fluctuating nature of wind power.

\section{Relocation coefficient and power scaling}

Data from the photovoltaic (PV) system is fit to the Rhode Island scenario using a relocation coefficient, which considers the location of the PV system and 
adjusts the data points accordingly. The proportion of the PV system output is calculated using the European Commission Photovoltaic Geographical Information System (PV-GIS).

Table 5: Calculation of a relocation coefficient for photovoltaic power data, data source: European Commission PVGIS $2020^{135}$

\begin{tabular}{l|l|l} 
Location & $\begin{array}{c}\text { Annual in-plane irradiance } \\
{\left[\mathrm{kWh} / \mathrm{m}^{2 *} \mathrm{a}\right]}\end{array}$ & $\begin{array}{c}\text { Annual photovoltaic energy } \\
\text { generation } \\
{[\mathrm{kWh} / \mathrm{a}]}\end{array}$ \\
\hline IWF, Braunschweig, Germany & 1240.11 & 2928.2 \\
\hline URI, Kingston, Rhode Island & 1721.27 & 4131.44 \\
\hline \hline Relocation coefficient [ - ] & & 1.411
\end{tabular}

Due to the higher in-plane irradiance in Rhode Island, the annual energy output of the same system at URI is $4131.44 \mathrm{kWh}$ compared to $2928.2 \mathrm{kWh}$ for the Braunschweig location, resulting in a relocation coefficient of 1.411 for all PV datapoints ${ }^{135}$. The calculation considers an identical photovoltaic system with the same peak power of $2.94 \mathrm{~kW}$.

The wind turbine data is adapted to the area of the University of Rhode Island using the Global Wind Atlas 3.0 (GWA 3.0), developed by the Technical University of Denmark and the World Bank Group. The relocation coefficient is calculated using the mean power density for the $10 \%$ windiest area in the selected region at a height of 100 meters $^{136}$. 
Table 6: Calculation of a relocation coefficient for wind turbine power data, data source: GWA 3.0, DTU $2020^{136}$

\begin{tabular}{l|l|l}
\multicolumn{1}{c|}{ Location } & \multicolumn{1}{|c|}{$\begin{array}{c}\text { Mean wind speed } \\
{[\mathrm{m} / \mathrm{s}]}\end{array}$} & \multicolumn{1}{c}{$\begin{array}{c}\text { Mean power density } \\
{\left[\mathrm{W} / \mathrm{m}^{2}\right]}\end{array}$} \\
\hline IWF, Braunschweig, Germany & 6.84 & 341 \\
\hline URI, Kingston, Rhode Island & 6.69 & 322 \\
\hline \hline
\end{tabular}

Due to the lower mean wind speed, the mean power density on the site of the University of Rhode Island is $94.4 \%$ of the mean power density on the site of the actual wind turbine in Braunschweig, Germany. The resulting relocation coefficient is 0.944. Every data point of the wind turbine power data series is multiplied with the coefficient to recognize the study location.

The scale of the renewable energy supply is then set to potentially meet the electricity demand of the water supply system. While the energy supplied might be equal to the energy required over a set time period, it does not necessarily imply that the renewable power is enough to meet the demand at any given point of time. After assessing the reference scenario, the water supply system (WSS) operating schedule is altered in a way, that tries to synchronize the energy demand to match the supply. Demand side management measures are used to shift power from periods of low renewable energy availability to periods of high renewable energy availability. The goal is to create a balanced energy self-sufficient scenario as a starting point which will then be improved towards real energy self-sufficiency ${ }^{134}$. In a balanced energy self-sufficient system, the input energy over a defined time period equals the output energy. 


$$
E_{S u p p l y, R E, t}-E_{\text {demand }, W S S, t}=\sum_{0}^{t} P_{S u p p l y, R E, t}-\sum_{0}^{t} P_{\text {demand }, W S S, t}=0
$$

While the energy is equal, real energy self-sufficiency ensures that the demand matches the supply so well, that the dynamic curve is synchronized perfectly.

The total energy demand of the water supply system will be computed in a simulation run with reference scenario operation. The resulting total energy demand is

$$
E_{\text {demand,WSS,t }}=2647.86 \mathrm{kWh}
$$

While the total energy supply from the two renewable energy sources is

$$
E_{\text {Supply,RE,t }}=62.27 \mathrm{kWh}
$$

All renewable energy datapoints are multiplied with a power scaling coefficient to create a balanced self-sufficiency scenario.

$$
f_{P S}=\frac{E_{\text {demand }, W S S, t}}{E_{\text {Supply }, R E, t}}=42.52
$$

The resulting photovoltaic and wind power curve for one week is shown in Figure 51. 


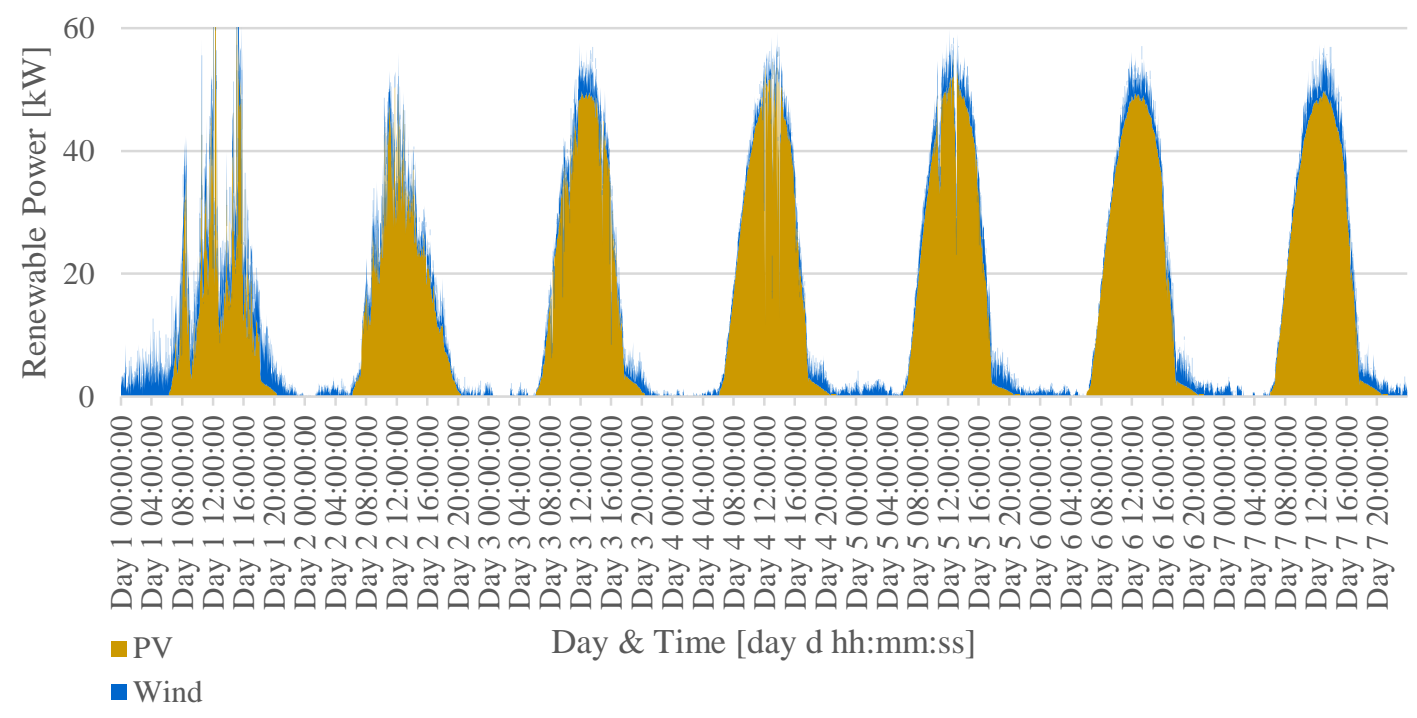

Figure 51: PV and wind power output, relocation considered, power scaled, own figure, data source: IWF TU BS $2017^{80}$

The curve shows that most days are almost cloud free with slight wind in the evenings. Day 1 represents an overcast day with slightly more wind than on the following days.

\section{Specific carbon intensity}

The specific carbon intensity of both wind and solar power are shown in Figure 52. While for the NEPOOL grid mix the carbon emissions consider only $\mathrm{CO}_{2}$, the data from the Intergovernmental Panel on Climate Change includes the life-cycle emissions of both solar and wind energy, as well as other emissions contributing to the impact category global warming. A direct comparison of $\mathrm{CO}_{2}$ solely would thus be even less favorable for the NEPOOL grid mix. According to that, any results from emission calculations in this study are subject to a conservative assumption. 


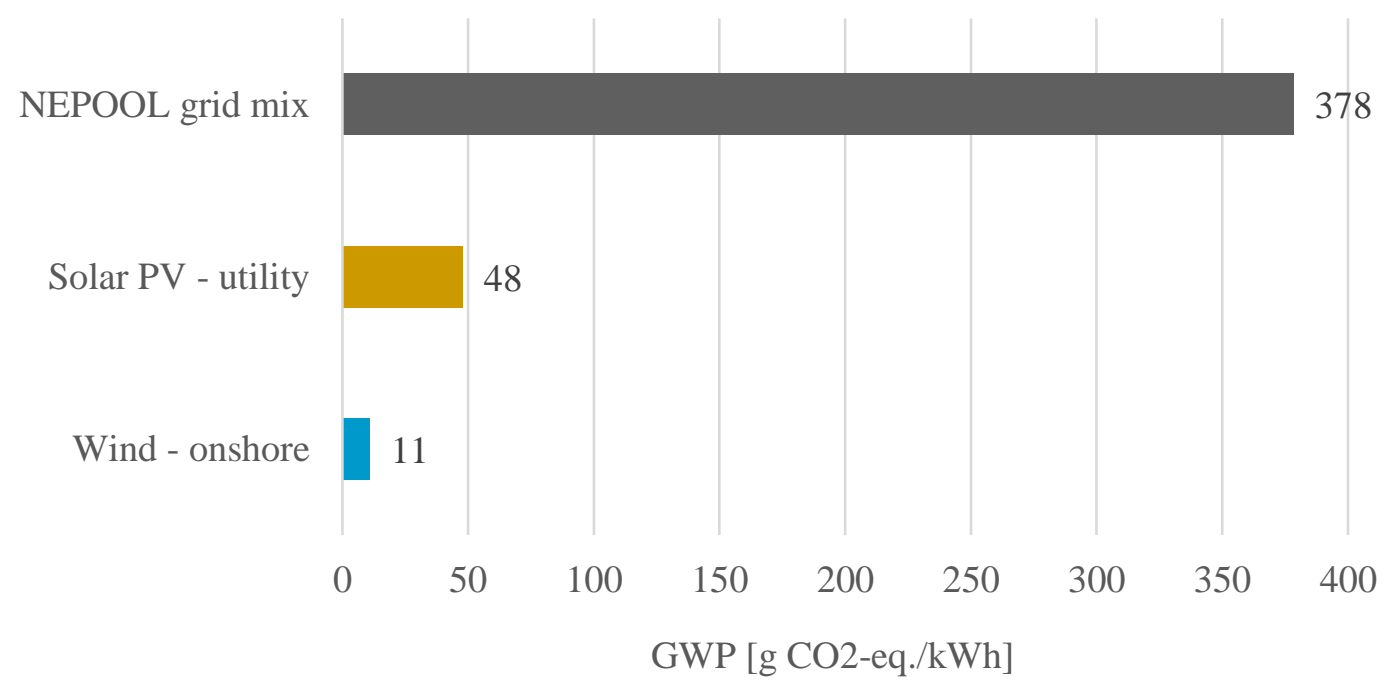

Figure 52: Specific global warming potential of selected electricity supply sources, own figure, data source: IPCC $2014^{137}$, NEPOOL 2019 ${ }^{133}$, National Grid 2020 132

The carbon intensity of the renewable energy data is calculated according to dynamic share of wind and photovoltaic power throughout the simulation run.

$$
C_{R E, t}=\frac{P_{P V, t}}{P_{R E, t}} * C_{P V}+\frac{P_{\text {Wind }, t}}{P_{R E, t}} * C_{\text {Wind }}
$$

\subsection{Modelling and Simulation}

This section explains the modelling approach used for this study. After an introduction to the software used, the modelling steps are described for the single agents and agent populations used in this study. The explanation of the agents refers to the reference scenario. Furthermore, the differences between the proposed future scenario and the reference scenario are described in section 3.2.3. 


\subsubsection{Software}

The Software used to model the digital twin of the physical system is Anylogic ${ }^{\circledR}$. Anylogic ${ }^{\circledR}$ is a multimethod simulation software that allows users to combine various simulation paradigms, like system dynamics modelling, agent based modelling and discrete event modelling. The modelling language used in Anylogic ${ }^{\circledR}$ is the Java Modelling Language (JML). In Anylogic ${ }^{\circledR}$, predefined libraries exist for modelling different systems. These libraries include but are not limited to the process modelling library, the material handling library, the pedestrian, road and railroad library, the fluid library and the system dynamics library.

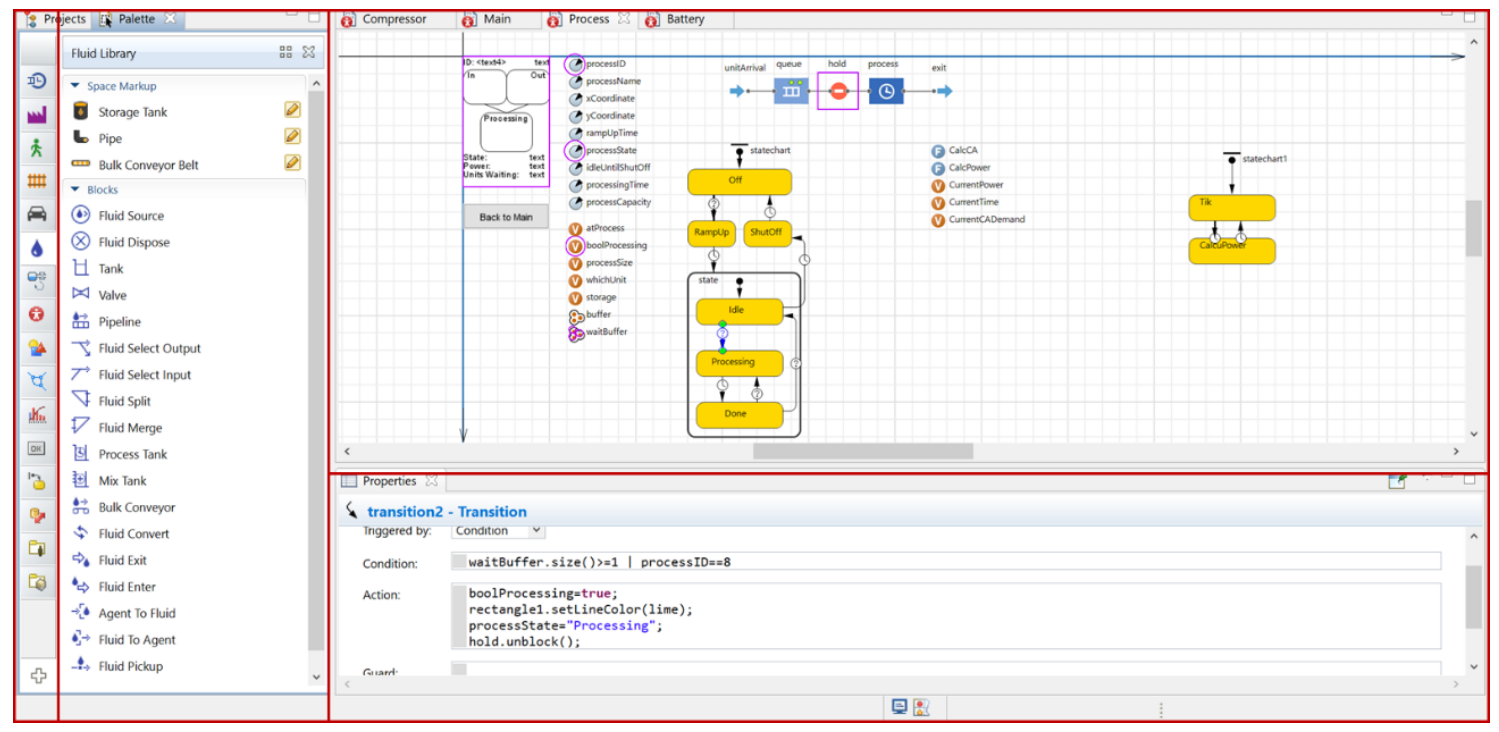

Figure 53: Overview of the Anylogic simulation software including palettes, elements, canvas and property editor, source: Anylogic 2020 ${ }^{138}$

Elements from the palette can be dragged and dropped onto the main canvas. Agents or populations of agents can be created with each agent having its own canvas. The modelling elements can be characterized using individual parameters of different types (boolean, integer, double, string, ...) that are already predefined by the specific 
element. For example, a storage tank can be assigned a capacity, an initial amount (int), a name (string) and behavioral aspects, such as if it has a limited output rate (boolean). Furthermore, many elements have boxes to enter JML code, if a certain event is triggered (i.e. tank is empty, rate change, tank is full). Anylogic ${ }^{\circledR}$ allows users to connect the model to data sources, such as .csv or .xlsx files to both acquire input data for the model as well as to write output data after a simulation run.

\subsubsection{System Modelling}

For this study, no case-specific predefined library was used. Instead, the modelling was done using the agent palette and system dynamics palette. Additional elements are used from the state chart-, connectivity-, space markup- and analysis palette. Empty populations of agents were created for the agent types pump, pipe and consumer. These empty populations were filled using a function that allocates specific parameters to each individual agent of an agent type. While a whole population of agents has the same type of parameters, the values differ according to individual data. Furthermore, state charts were used to model both the generic behavior of an agent type, while also allowing for individual behavior based on the linked parameters.

While one agent of the type pump may follow the same logic as another, they can be activated or shut down based on the individual agent's parameters. The energy supply and the storage tank are modelled directly onto the main canvas, as they are single entities. The simulation time is set to 10080 minutes, which is equivalent to one week. This duration was chosen to focus on the ability of the system to flexibly adapt to changes in VRE availability at a high temporal resolution. Seasonal variability of 
renewable energy production is not yet considered in this study. After this time has elapsed, the simulation is finished, and all results are written into a connected .xlsx-file as a data series. In the following sections, the main modelling aspects of each agent or agent type are explained.

\subsubsection{Agent Main}

The Agent Main is both used as the super-agent for all agent populations and agents, as well as for the visualization of the dynamic system behavior. Input data files and the required functions to load the data into the model are built on the main canvas. All agents and agent populations are initially empty and are characterized and quantified using a function that is called upon model start-up. This includes the creation of 3 agents of the type pump, 27 agents of the type consumer and 52 agents of the type pipe. Using spreadsheets, each individual agent can be characterized using specific data, which is linked to the agent's ID number. Furthermore, two single agents exist for the storage tank and the energy supply. The main canvas is used to import, store and visualize the dynamic data series for both the water consumption and energy

supply. Furthermore, functions to calculate total values of agent populations are modelled on the main canvas. While for example, each individual consumer has its water demand based on the population, the functions on the main canvas calculate the total demand of all agents of the type consumer.

Helpful charts and plots are visualized on the main agent during simulation runs. This includes time plots of water system data, such as the current water demand, water supply and differential volume, the tank fill level and each residence hall's 
current pressure. All pipes and consumers and pumps are additionally displayed on the main canvas as agent presentations along with the most important parameters. The presentations can change in color or size to highlight parameter values (i.e. pump is active or pressure is too low at a service line). Energy data is visualized in a time plot, which displays wind power, solar power, the current energy demand as well as the energy balance.

\subsubsection{Agent population Pipes}

The agent population pipes consists of 52 agents of the type pipe. Each agent is assigned an individual value for the parameters ID, length, diameter, roughness and population served. A state chart is used to calculate necessary dynamic variables for each time step. This includes the calculation of the current flow, velocity, Reynoldsnumber, flow regime, friction coefficient and resulting continuous pipe losses. Depending on the location of the pipe in the system and individual agent ID, the dynamic variables are calculated accordingly. For the pipe from the wells to the first junction (D0) for example, the current flow is calculated based on the water supply by the pumps. For a service line on the other hand, the flow is calculated by the current demand and the population served by that line. The friction coefficient for the critical and turbulent regime is approximated using the Blasius equation, while for the laminar regime the law of Hagen-Poiseuille is used. The agent presentation on the main canvas indicates the current flow regime, Reynolds-number, continuous losses and flow. 


\subsubsection{Agent population Consumers}

The agent population consumers consists of 27 agents of the type consumer. The agent population consumer represents the 27 residence halls and other housing option on the URI campus. The individual parameters include ID, elevation, name and number of residents. A state chart is used to calculate the individual dynamic variables of each consumer. The dynamic variables include the continuous pipe losses, the dynamic head difference and the resulting pressure. At this point, one important assumption is made. The pressure head is calculated based on the energy balance between the storage tank and each individual consumer. The water supply system is thus split into two parts from an energy perspective, namely the supply-side system and the demand side system.

The water supply by the wells is part of the supply-side system and can thus be excluded in the pressure head calculation. As the dynamic water level in the tank is calculated based on the energy balance in the supply-side system, the water supply from the wells is still accounted for in the pressure head calculations. The current pressure head is calculated using the Bernoulli equation.

$$
h_{E, \text { Tank }}=\frac{p_{\text {tank }}}{\rho * g}+\frac{v_{\text {tank }}{ }^{2}}{2 * g}+h_{\text {waterlevel }}=h_{E, \text { cons }}=\frac{p_{\text {cons }}}{\rho * g}+\frac{v_{\text {cons }}{ }^{2}}{2 * g}+h_{\text {cons }}+\sum h_{\text {losses }}
$$

As the pressure and the velocity on the water surface in the tank can be assumed to be zero, the left term is only defined by the water level height in the tank, representing the static head. The dynamic velocity is calculated based on the dynamic flow and pipe cross section area and the elevation of each consumer is known from 
Figure 46. The head loss is calculated as the sum of continuous losses of those pipes that connect the consumer to the storage tank. The resulting equation is

$$
h_{\text {pressure }}=\frac{p_{\text {cons }}}{\rho * g}=h_{\text {waterlevel }}-\frac{v_{\text {cons }}^{2}}{2 * g}-h_{\text {cons }}-\sum h_{\text {losses }}
$$

The pressure head is converted into pressure [psi] using the conversion factor below.

$$
1 \text { psi }=0.7031 \mathrm{~m} \text { of head }
$$

The pressure is one key performance indicator that has to be kept in a range of 20 psi to 125 psi, as defined by RI Division of Public Utilities and Carriers ${ }^{48}$. The pressure at each service connection is included in the agent presentation on the main canvas, along with the current demand, name of the housing option and number of residents.

\subsubsection{Agent population Pumps}

The agent population pumps consists of three agents of the type pump. The pumps are characterized by the static parameters ID, elevation, total efficiency and minimum time active until shut-off. Based on literature references the total efficiency of the pumps is assumed to be $70 \%$ for all three pumps ${ }^{49,124}$. During the simulation run, dynamic variables are calculated, including the current flow, a Boolean value that indicates if the pump is active or inactive, the number of (on-)switches of the pump, as well as the dynamic pump head and resulting power. The pumps were dimensioned to meet the specific demand of the modelled system in this case study. The flow of each 
pump in the active state is set to $800 \mathrm{l} / \mathrm{min}$. The flow value is based on the ability of the pumping station to potentially meet the maximum daily demand. The minimum time active until shut-off is set to 60 minutes to reduce mechanical stress and the amount of load peaks in the electricity system. The 60-minute duration was determined through an iterative process $(1,15,30,60,120$ minutes $)$, which is based on the balance of further improvements on the energy self-sufficiency versus the increased number of pump switches. Below 60 minutes, no significant improvements on self-sufficiency could be achieved, while the number of pump switches increased drastically. From an energy perspective, the pumps along with the storage tank are part of the supply-side of the system. Using the Bernoulli equation, the required pump head can be calculated.

$$
\frac{p_{\text {pump }}}{\rho * g}+\frac{v_{\text {pump }}{ }^{2}}{2 * g}+h_{\text {pump }}=\frac{p_{\text {tank }}}{\rho * g}+\frac{v_{\text {tank }}^{2}}{2 * g}+h_{\text {waterlevel }}+\sum h_{\text {losses }}+\Delta h_{\text {waterlevel }, t-1}
$$

The velocity in the pump is calculated based on the flow and cross-sectional area of pipe D0. The continuous losses that are considered in this equation are the losses of pipes D0 and D2. To account for the additional or reduced energy required to change the water level in the tank, a head differential term was added. If the water level in the tank increases, additional energy has to be fed into the system to reach that level. Due to the complexity of non-stationary hydraulic modelling, inertia losses due to the acceleration of the moved fluid are not considered in this study. The pressure and the velocity in the storage tank are assumed to be zero. The dynamic pump head can thus be calculated as 


$$
h_{\text {Pumphead }}=\frac{p_{\text {pump }}}{\rho * g}=h_{\text {waterlevel }}+\sum h_{\text {losses }}+\Delta h_{\text {waterlevel }, t-1}-\frac{v_{\text {pump }}{ }^{2}}{2 * g}-h_{\text {pump }}
$$

The required electrical power that the pump needs to supply the set flow at the current pump head can be calculated

$$
P_{\text {Pump }, \text { elec }}=\frac{\rho * g * Q * h_{\text {pumphead }}}{1000 \frac{W}{k W} * \eta_{\text {total }, \text { pump }}}
$$

Each of the three pumps is designed and dimensioned similar but the individual behavior differs based on the fill level in the water storage tank. Figure 54 shows the behavior of the individual pumps according to the fill level in the water storage tank.

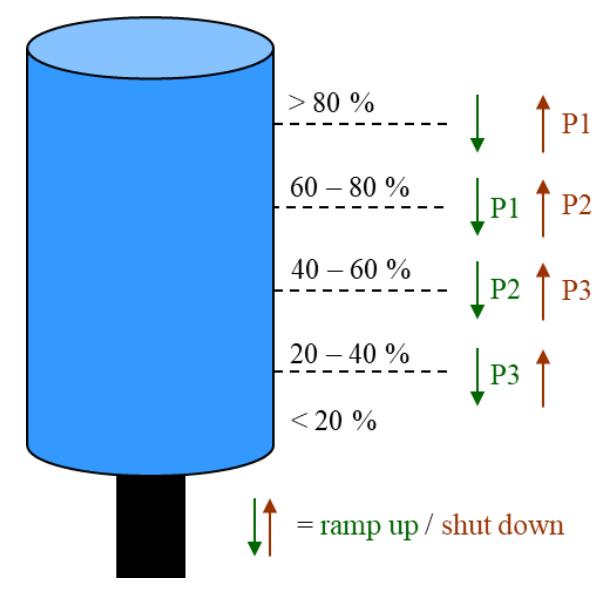

Figure 54: Pump scheduling according to storage tank fill level, own figure

The three pumps along with the most important variables power, flow and pump head are included in an agent presentation on the main canvas. Additionally, the aggregated flow of all three pumps is included in the water supply and demand balance time plot and the power of the pumps is included in the energy supply and demand time plot. The pump schedule is changed in the adapted operation scenario to 
enable demand side management measures. The adapted pump behavior will be explained in section 3.2.3.2.

\subsubsection{Agent population Batches}

To assess the impact of the introduction of demand side management measures into the water supply system operation, batches have been modelled representing water molecules travelling through the supply system. The agent population grows with the simulation time, as every 60 minutes, a new sample batch is created. The batch then travels through the distribution system following a first in first out (FIFO) logic.

One residence hall has been chosen to create a sample path from water source (pumps) to water sink (service line). Hillside Hall is a service connection that uses a high share of the total distribution system length. The water at Hillside Hall is supplied through the pipes D0 and D2, the elevated storage tank, the pipes D1-D1m, as well as the connection S17 and S17b. The location and connection of Hillside Hall to the distribution system is shown in Figure 44. The FIFO flow logic deviates slightly from the actual supply system operation. At the first junction, any water molecule usually decides whether it moves towards the storage tank or towards the demand side system.

According to the applied FIFO logic, the water molecule that enters the distribution system first is the molecule that will exit the system first. Thus, every molecule is assumed to travel through the cumulated volume of all pipes of the chosen connection from source to Hillside Hall, as well as through the current volume of the elevated storage tank. For every second, the molecule is assigned a distance travelled 
according to the current location in the system and the specific flow velocity in the pipe, that currently contains the molecule. Once the distance travelled exceeds the total pipe length, the molecule moves to the next pipe and the calculation start again for the new pipe.

For the integration of the FIFO logic, the molecule travels through pipe D2 towards the storage tank, then travels through the current volume of the storage tank and ultimately flows through an assumed parallel pipe D2* back towards the demand side system. The velocity in pipe D2 on the way to the tank is based on the water supply of the pumps. Similarly, the velocity in the storage tank and in pipe D2* is based on the dynamic water demand. Due to the changing water volume in the storage tank, the total volume that the molecule has to travel through has to be set for every molecule at the time that it arrives at the tank.

Once the molecule enters the system, the current simulation time is set as the starting time. When the molecule leaves the distribution system, the retention time is calculated based on the arrival time and the start time.

\subsubsection{Single agent Storage Tank}

As only one storage tank exists in the water supply system, no agent population needs to be created. The storage tank is characterized by the static parameters diameter, height, elevation, minimum fill level and maximum fill level. The dynamic water fill level in the tank is computed using flow and stock elements from the system dynamics palette. Depending on the balance of water supply and water demand, the differential flow towards the storage tank is positive or negative, resulting in a positive 
or negative change of the current volume of water inside the tank. The dynamic water level height is calculated using the current volume and the cross-section area of the cylindrical tank. The change of water level is calculated by subtracting the current value from the water level at the time t-1. A state chart is used to define the current fill status of the storage tank. The fill level is categorized according to Figure 54.

\subsubsection{Single agent Energy Supply}

For the reference scenario, only grid electricity is considered. The source of energy is assumed to be infinite and any energy demand by the pumps is directly translated to the energy supply from the grid. An additional parameter that characterizes the grid electricity is the specific greenhouse gas emissions, as shown in Figure 52. The temporal resolution of the simulation is one minute. The conversion from kilowatt-hours to kilowatt-minutes is considered in the calculation of the total carbon emissions of the water supply system operation.

For the adapted scenario, renewable energy data is imported into the model. The data is scaled to potentially meet the demand of the water supply system, as mentioned in 3.1.2.2. the specific carbon emission of the renewable energy sources are defined as static parameters in the model. The dynamic total carbon emissions from the renewable energies are calculated using the dynamic supply of each source multiplied with the specific carbon emissions parameter.

\subsubsection{Simulation Scenarios}

This study includes three scenarios. The scenarios are different regarding the operation of the water supply system as well as the energy supply option to meet the 
demand of the water supply system. After each simulation run, datasets will be written into spreadsheets. The datasets will include the key performance indicators (KPI) total energy consumption, total carbon emissions, degree of self-sufficiency, dynamic storage tank fill level, number of pump switches, water renewal rate and mean system pressure. In the simulation initialization, checkboxes are used to allow the user to decide whether VRE should be included and DSM measures should be activated to choose between the scenarios.

\subsubsection{Sc. 1: Reference Scenario}

Scenario Sc. 1 is the reference scenario for this study. Any improvements and implications of the proposed idea of integrating renewable energies and adapting the operation schedule will be compared to the reference scenario. The reference scenario Sc. 1 can be further distinguished into Sc 1a and Sc $1 \mathrm{~b}$.

\section{Sc 1a - Reference Scenario without Integration of VRE}

Scenario Sc 1a is defined by the water supply system operation schedule mentioned in section 3.2.2 and does not consider the integration of variable renewable energy as a source of electricity. The behavior of the system entities, namely main, pumps, pipes, consumer, storage tank and energy supply is explained in section 3.2.2.1 to section 3.2.2.7. No additional information is required for this scenario.

\section{Sc 1b - Reference Scenario with Integration of VRE}

Scenario Sc $1 \mathrm{~b}$ is identical to Sc 1a regarding the operation schedule of the water supply system. The only change made is that the potential of integrating variable 
renewable energy is included into the assessment. If available, electricity is supplied by the renewable energy sources. If the demand exceeds the supply from renewable energies, electricity will be supplied by the electricity grid. By integrating renewable energies into the water supply system, the carbon emissions are expected to decrease. Another key indicator is excess renewable energy. If the renewable energy supply exceeds the demand, the water supply system in Sc $1 \mathrm{~b}$ has no option to adapt the operation schedule of the pumps to unlock the potential of the excess energy. The energy balance from scenario Sc $1 \mathrm{~b}$ will be compared to both scenario Sc 1a and Sc 2 regarding the carbon savings from the integration of VRE as well as the ability to use excess renewable energy.

\subsubsection{Sc. 2: Integration of VRE and DSM Measures}

Scenario Sc 2 represents the proposed future scenario of integrating variable renewable energy and adapting the operation schedule of energy consuming entities towards matching the energy demand to the energy supply. Besides the ability to use VRE as already covered by Scenario Sc $1 \mathrm{~b}$, Scenario Sc 2 will include an energy flexible operation schedule of the water supply system. The water demand of the residents will not be changed to ensure the comparability of the scenarios. To adapt the operation schedule towards increasing the utilization of variable renewable energy, the following adjustments are made to the water supply system operation.

The pumps define the energy demand of the water supply system. Based on the demand and the current supply from VRE, the energy balance of the system will be positive or negative. If the power from renewable energies exceeds the demand to 
potentially power an additional pump, the pump will be turned on. If the power falls short of the demand to run the pumps that are currently active, the pumps will turn off successively. If the supply exceeds the current demand for a period of less than 15 minutes, any pumps switched on will not be turned off before the 15 minutes have elapsed. This ensures the comparability to the reference scenarios Sc 1a and Sc $1 \mathrm{~b}$. Due to the adapted operation, additional security operation has to be added to the schedule. The pumps P1, P2 and P3 are successively turned on, if the water level falls below $40 \%, 30 \%$ and $20 \%$ fill level, respectively. To avoid overflow of the tank, all pumps are shut off if the water fill level exceeds $80 \%$. Figure 55 summarizes the combined operation based on storage tank fill level and variable renewable energy availability.

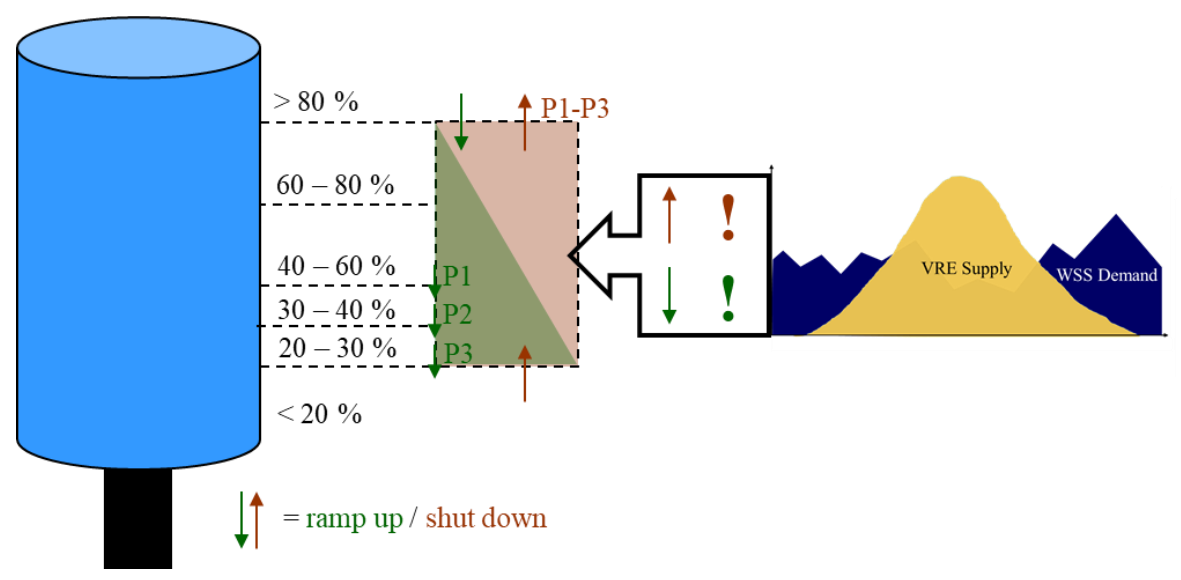

Figure 55: Adapted pump operation based on storage tank fill level and VRE availability, own figure

Scenario Sc 2 uses the concepts of load shifting, peak clipping and valley filling, three key elements of demand side management, as explained in Figure 37. The proposed improvements are a lower carbon intensity compared to scenario Sc 1a by increasing the degree of self-sufficiency using VRE. Furthermore, the synchronization 
of energy demand and energy supply is expected to increase the utilization of renewable energies regarding the reduction of excess energy from VRE. The adapted operation schedule is likely to cause an increased total energy consumption of the system. The potential impacts on the water supply system include an increased retention time of the water in the system, increased wear of the pumps due to a higher number of switches and a higher pressure in the distribution system, which may cause more leakage. Each scenario will produce unique results regarding the key performance indicators. The KPIs are exported into spreadsheets and are then evaluated and compared. In chapter 4 , a thorough assessment of the results are conducted. 


\section{FINDINGS}

In this chapter, the results from the simulation runs of all three scenarios are evaluated and compared. The reference scenario Sc 1a is visualized and interpreted first, followed by Scenario Sc 1b, which includes the integration of variable renewable energies. Lastly, the results from the proposed scenario Sc 2 are evaluated, including the integration of variable renewable energy as well as demand side management measures. Additionally, the three scenarios are compared side by side for each key performance indicator to allow for a meaningful assessment of the proposed improvement towards scenario Sc 2. The key performance indicator included in this assessment are shown in Table 7.

Table 7: Key performance indicators for the evaluation of the simulation scenarios

\begin{tabular}{c|c|c}
\multicolumn{1}{c|}{ Type } & KPI & Unit \\
\hline \hline \multirow{3}{*}{ Energy related } & Total energy demand & {$[\mathrm{kWh}]$} \\
\cline { 2 - 3 } & Total excess VRE energy & {$[\mathrm{kWh}]$} \\
\cline { 2 - 3 } & Degree of energy self-sufficiency & {$[\%]$} \\
\hline \multirow{3}{*}{ Water related } & Total CO -emissions $^{2}$ & {$[\mathrm{~kg}]$} \\
\cline { 2 - 3 } & Mean system pressure (Hillside residence hall) & {$[\mathrm{psi}]$} \\
\cline { 2 - 3 } & Total number of pump switches (Pump I / II / III) & {$[-]$} \\
\cline { 2 - 3 } & Mean storage tank fill level & {$[\%]$} \\
\cline { 2 - 3 } & Mean water retention time & {$[\mathrm{h}]$}
\end{tabular}




\subsection{Scenario Sc 1a results}

The results of the simulation run of scenario Sc 1a are visualized in this section. scenario Sc 1a is the reference scenario of this study. All improvements or implications of scenario Sc 2 are compared to this reference scenario. This will allow to compare the proposed integration of VRE and DSM measures to the current state of the system.

The results are distinguished into energy related and water related results. $\mathrm{As}^{\mathrm{CO}_{2}-}$ emissions are strongly related to the energy demand and the type of energy source, the results are included in the energy results evaluation.

\subsubsection{Sc 1a - Energy related results}

The energy demand in scenario Sc 1a is solely covered by grid electricity. Thus, the grid electricity supply is equal to the power demand at every time step. Based on the pump schedule explained in section 3.2.2.4, the dynamic power demand of scenario Sc 1a is visualized in Figure 56.

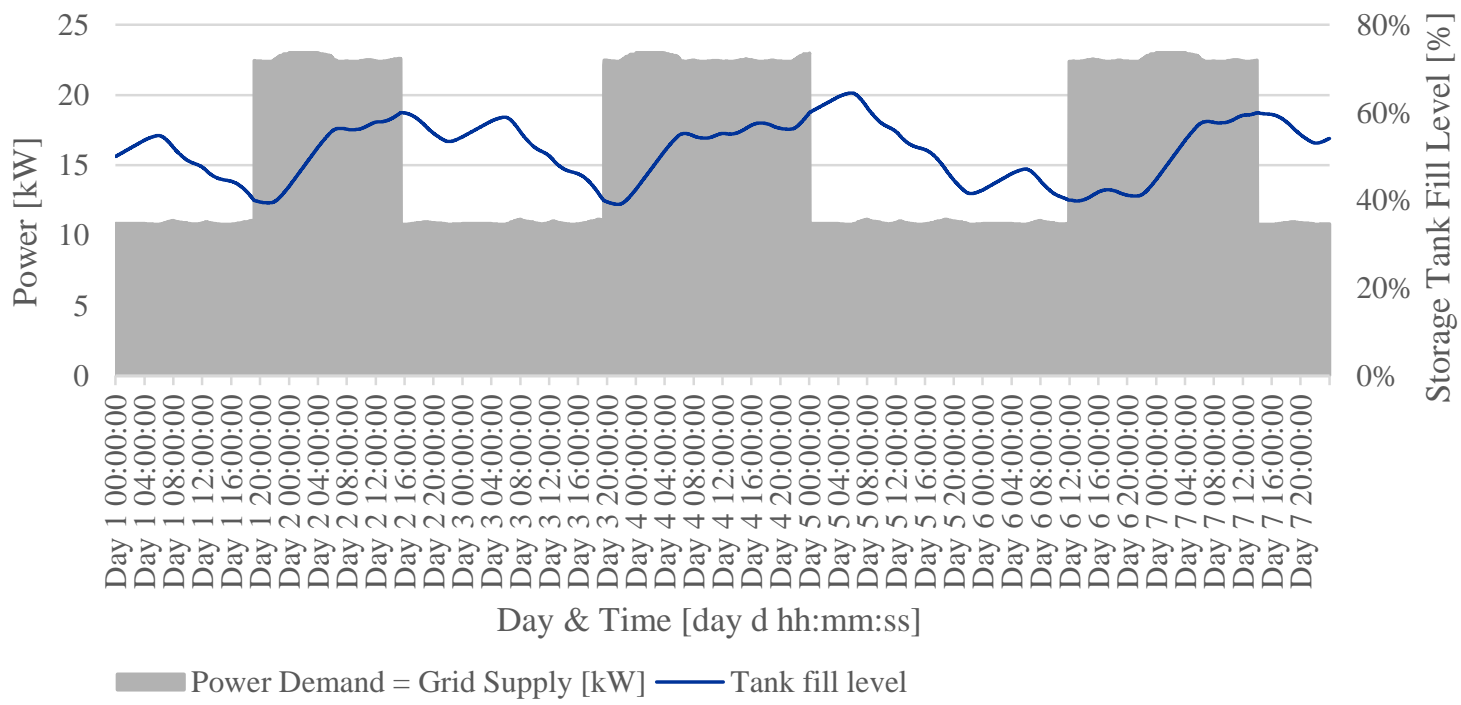

Figure 56: Sc 1a - Dynamic power demand and storage tank fill level, own figure 
Additionally, the storage tank fill level is included in the figure. Although the pump schedule of scenario Sc 1a can be recognized, the storage tank fill level deviates slightly from the trigger points at which the pumps are switched on and turned off. Due to high water demand, the tank fill level may still fall, after an additional pump is being turned on. Similarly, the fill level may rise even further, if a pump is turned off due to very low demand. In the reference scenario Sc 1a, only pump I and pump II are used to supply water to the distribution system. This represents that there is still potential to increase the water supply, if needed. The safety margin can ensure adequate fire flow potential as well as water supply in the case of an excessively high demand. The minimum, maximum and mean power during the simulation run are $10.48 \mathrm{~kW}, 23.03 \mathrm{~kW}$ and $16.10 \mathrm{~kW}$ respectively. The cumulated energy demand and resulting $\mathrm{CO}_{2}$-emissions during the simulation run of scenario $\mathrm{Sc} 1 \mathrm{a}$ is shown in Figure 57.

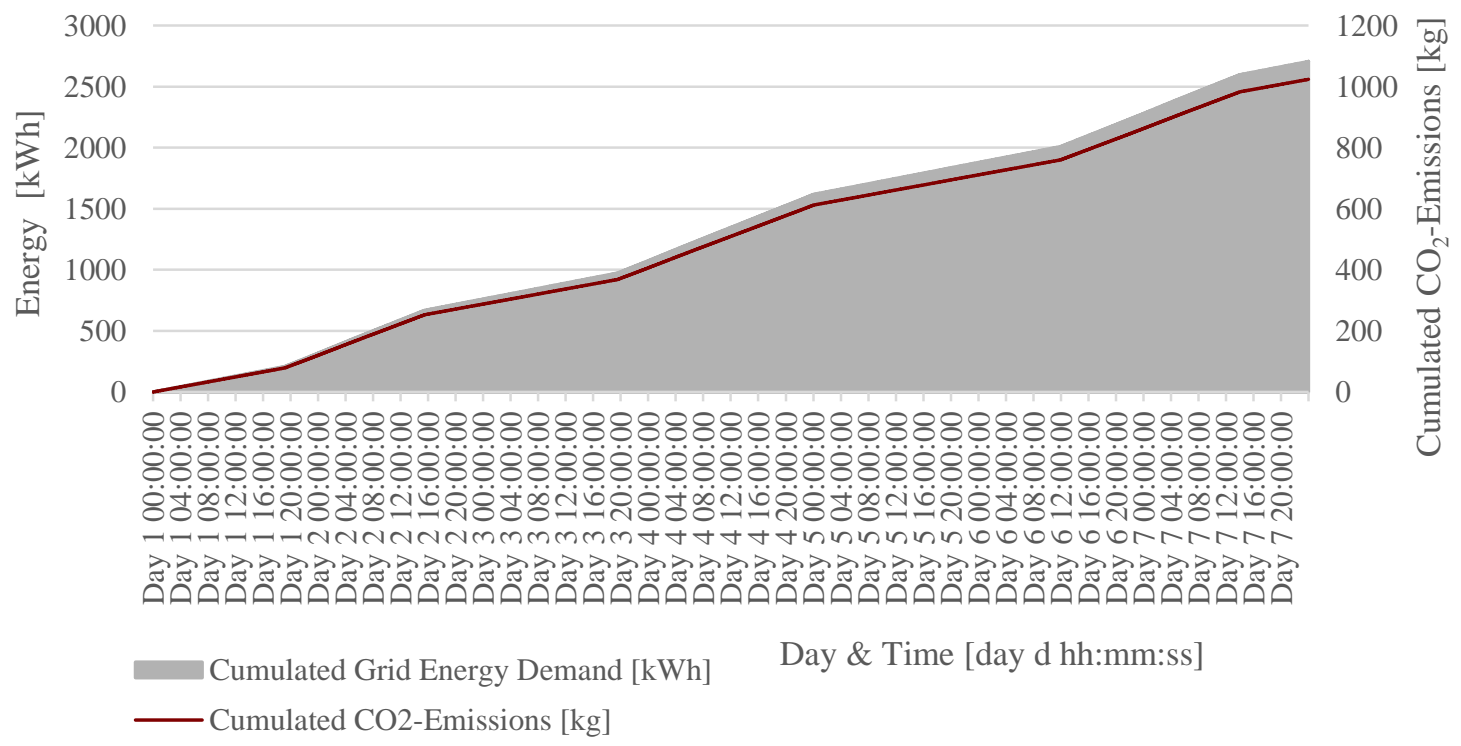

Figure 57: Sc 1a - Cumulated energy demand and resulting $\mathrm{CO}_{2}$-emissions, own figure 
The slope of the curve is proportional to the current power demand with a steep slope representing a high power demand and a gentle slope representing a low power demand. The total energy demand in scenario Sc 1a is $2705.27 \mathrm{kWh}$. Energy is solely supplied by the electricity grid resulting in a degree of energy self-sufficiency of $0 \%$. The specific $\mathrm{CO}_{2}$-emissions of the grid electricity supply are a static value, resulting in directly proportion to the energy demand. The deviation of the line from the shaded line plot is solely a result of the secondary axis range. The total $\mathrm{CO}_{2}$-emissions in scenario Sc 1a are $1023.80 \mathrm{~kg}$.

\subsubsection{Sc 1a - Water related results}

The water related results of simulation scenario Sc 1a are visualized and interpreted in this section. The water demand is set to be identical in all three scenarios. As a reference, it is still included in the Figure 58.

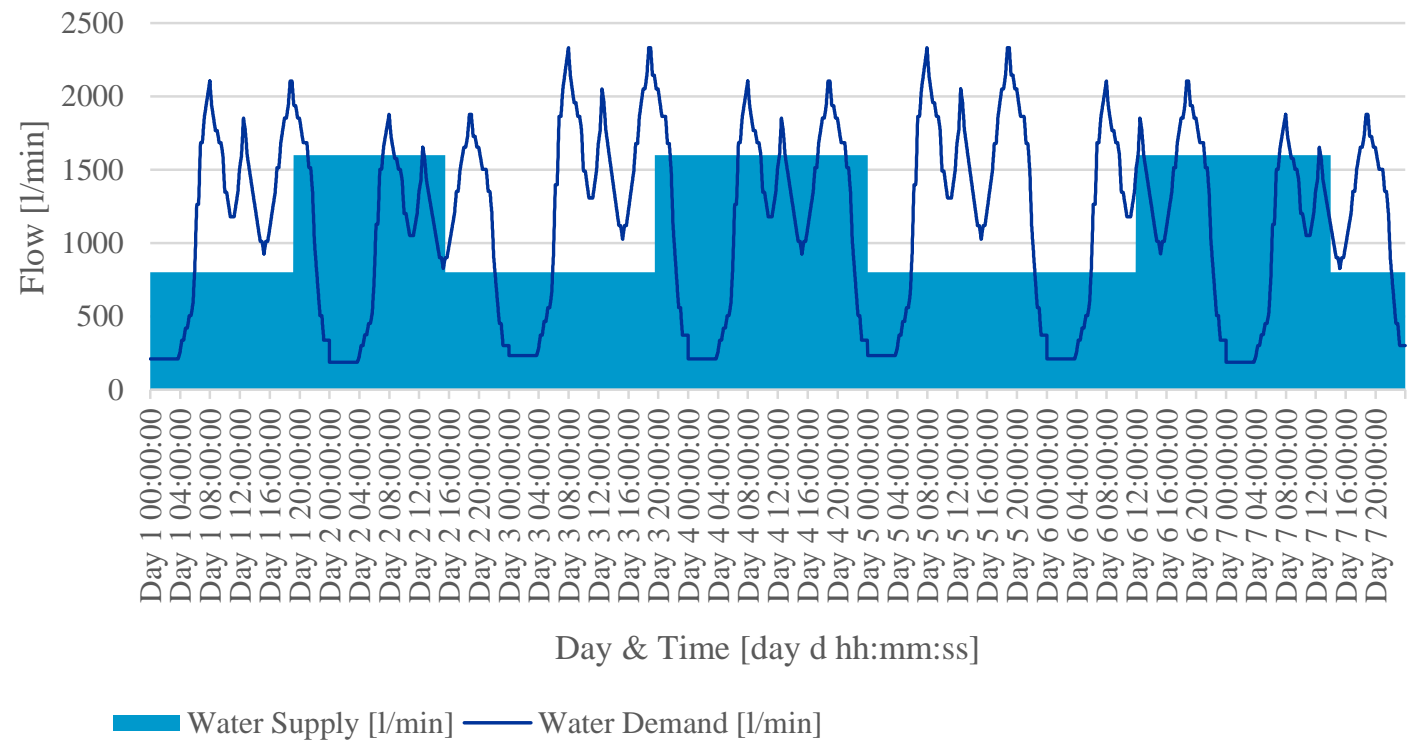

Figure 58: Sc 1a - Dynamic water demand and water supply, own figure 
The water demand is included to visualize the differential flow, which flows towards or from the storage tank. If the water supply exceeds the demand, water is fed into the storage tank and the water level increases. Similarly, if the supply does not meet the demand, additional water is drawn from the storage tank and the water level decreases. Figure 59 shows the differential flow and the resulting change in storage tank fill level
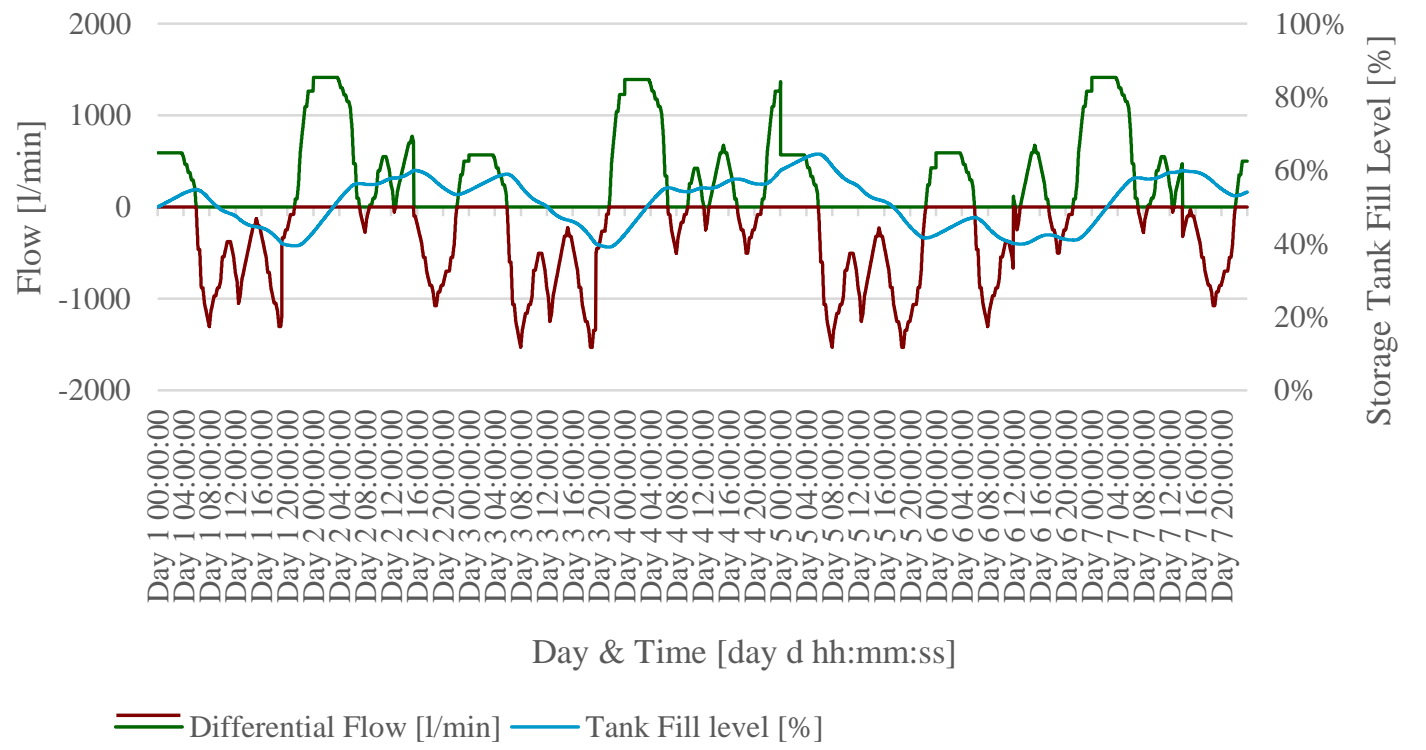

Figure 59: Sc 1a - Differential flow and storage tank fill level, own figure

The differential flow is colored in green, if the value is positive and the resulting change is the storage tank fill level is positive and in red, if the value is negative and the resulting change in the storage tank fill level is negative. The storage tank fill level at the end of the simulation run is $54.10 \%$. The minimum, maximum and mean fill level of the storage tank are $36.06 \%, 64.49 \%$ and $51.31 \%$, respectively.

To evaluate the pressure in the distribution system throughout the simulation run, one service connection is chosen as an indicator and to eventually compare the 
simulation scenarios. All continuous pipe losses are included in the evaluation. The chosen service connection is Hillside Hall. According to Figure 44, Hillside hall is supplied by the Pipes D0, D2 (storage tank) and D1-D1m as well as S17 and S17b and thus represents a service line with very high pipe loses. Figure 60 shows the pressure level at Hillside Hall throughout the simulation run.

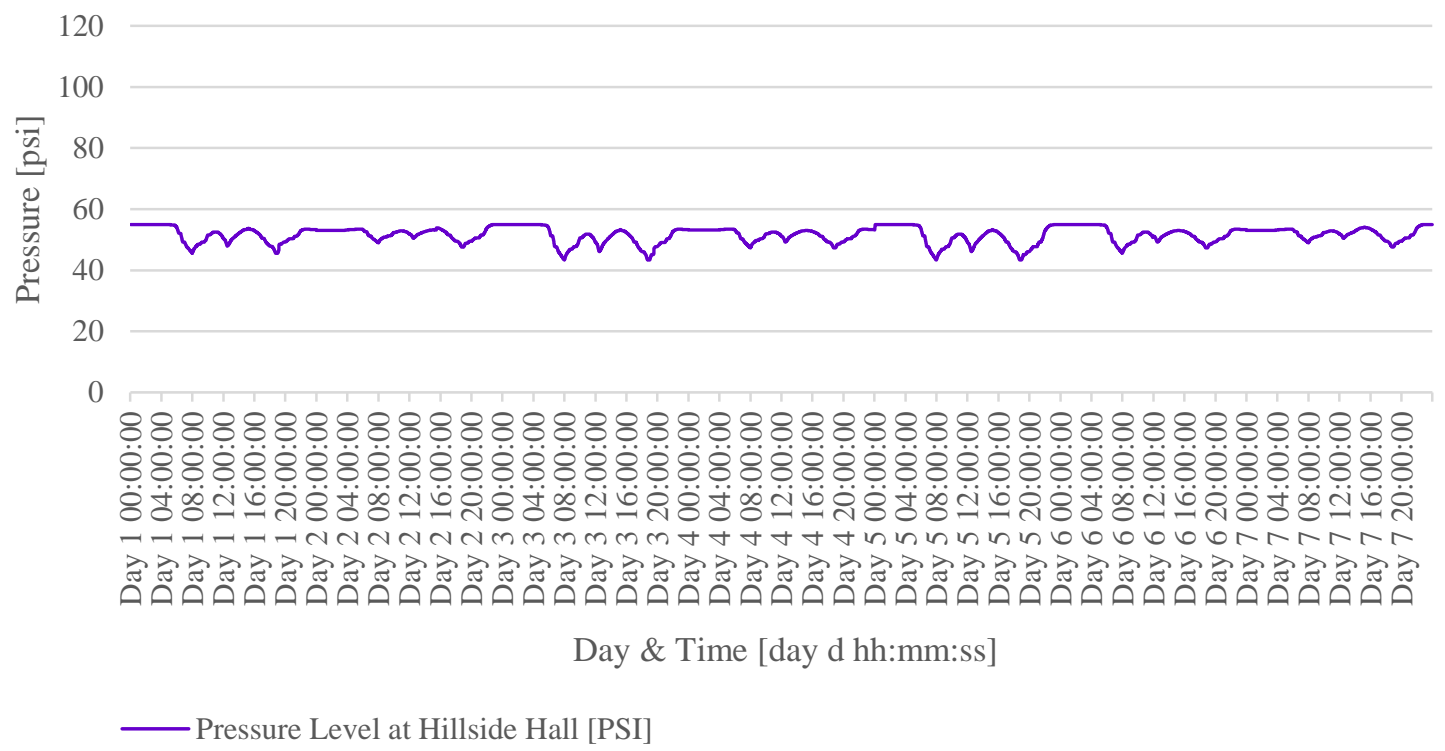

Figure 60: Sc 1a - Dynamic pressure level at Hillside Hall, own figure

Due to the relatively low fluctuations of the storage tank fill level, the pressure does not change significantly. Additionally, changes in pressure are a result of the current water demand, which influences the flow in the demand side system pipes and thus the continuous losses. The minimum, maximum and mean pressure levels during the simulation run are $43.29 \mathrm{psi}, 55.02 \mathrm{psi}$ and $51.58 \mathrm{psi}$, respectively.

The water retention time in the distribution system is calculated using sample batches that flow through the distribution system on a designated path from source to sink. The source is pipe D0 at its interface with the pumps and the sink is assumed to 
be the residence hall Hillside Hall. The retention time depends on the dynamic water demand as well as on the operation schedule of the distribution system. The retention time of the sample batches is visualized in Figure 61.

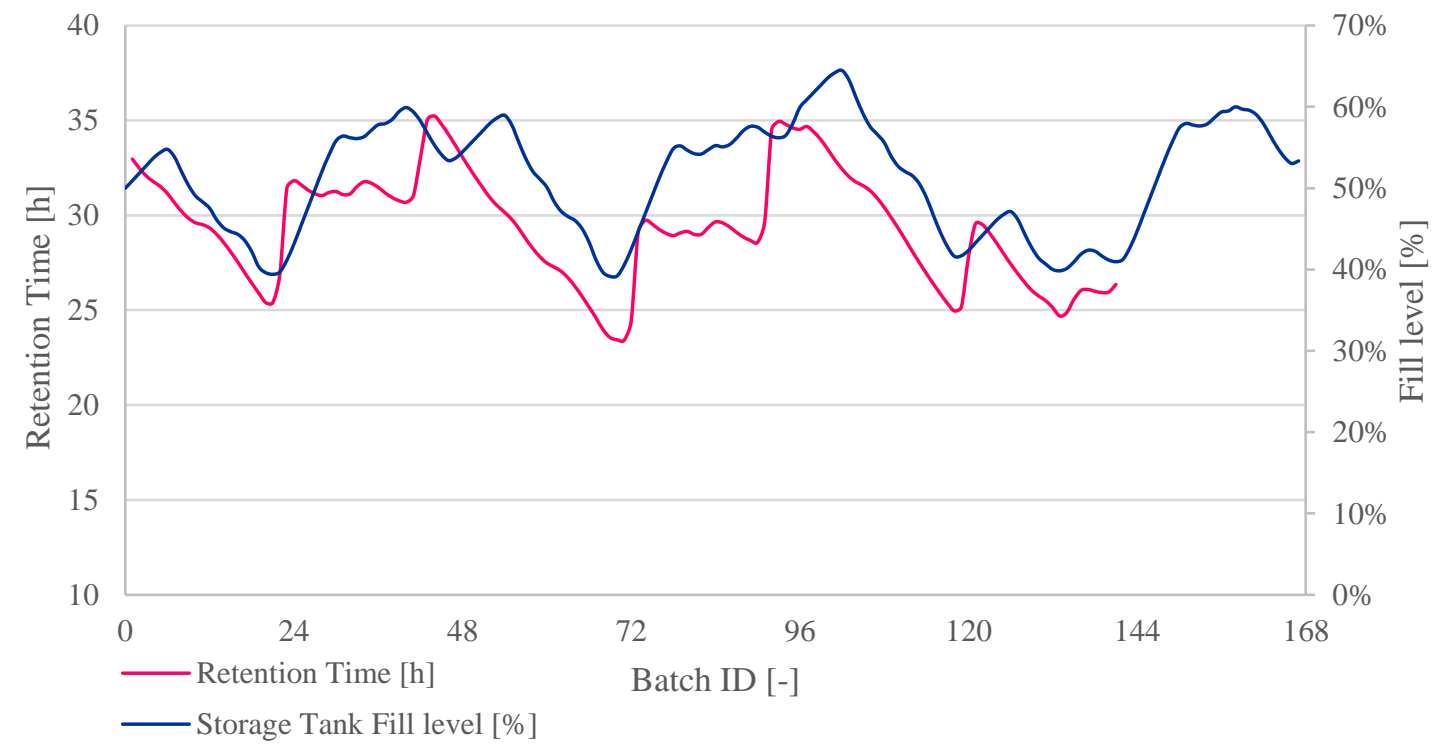

Figure 61: Sc 1a - Retention time of sample water batches and tank fill level, total batches arrived at simulation end $=141$, own figure

At the end of the simulation, not all batches have travelled through the entire system. The last batch to arrive before the stop of the simulation is batch number 141 . As the interval of the samples is one hour, the $\mathrm{x}$-axis is stretched to represent to total simulation time of one week. Due to the first-in-first-out logic, the storage tank has the greatest influence on the retention time. The dynamic fill level in the tank is included into the figure. The graphs show a clear delayed correlation between the storage tank fill level and the sample batch retention time. Additionally, the retention time is highly dependent on the dynamic water demand, which determines the height differential in the storage tank. The minimum, maximum and mean water retention time in scenario Sc $1 \mathrm{a}$ is $23.42 \mathrm{~h}, 35.23 \mathrm{~h}$ and $29.35 \mathrm{~h}$, respectively. 
Pump I is running throughout the whole duration of the simulation, while pump II is turned three times as a reaction to storage tank fill level decrease caused by large negative differential flows (high demand, insufficient supply). As the storage tank fill level does not drop significantly, pump III is not required and thus not switched on during the reference scenario.

\subsection{Scenario Sc $1 \mathrm{~b}$ results}

Scenario Sc 1b represents the same case as the reference scenario Sc 1a, but includes the potential of integrating variable renewable energy as an electricity source. No changes are made to the water supply system operation schedule. The demand, the supply, the pump schedule and resulting KPIs differential flow, storage tank fill level, pressure level, retention time are thus equal to scenario Sc 1a and will not be discussed further. The energy related results of scenario Sc $1 \mathrm{~b}$ are visualized and interpreted in section 4.2.1.

\subsubsection{Sc 1b - Energy related results}

The major difference between scenario Sc 1a and Sc $1 \mathrm{~b}$ is the consideration of the variable renewable energy potential and thus the potential self-sufficiency and $\mathrm{CO}_{2}$-emissions. While in this section, the results of scenario $\mathrm{Sc} 1 \mathrm{~b}$ are visualized and interpreted, the results of all three scenarios will be compared and evaluated in section 4.4. Figure 62 shows the water supply system power demand, which is identical to the power demand in scenario Sc 1a. Additionally, the variable renewable energy supply is shown. 


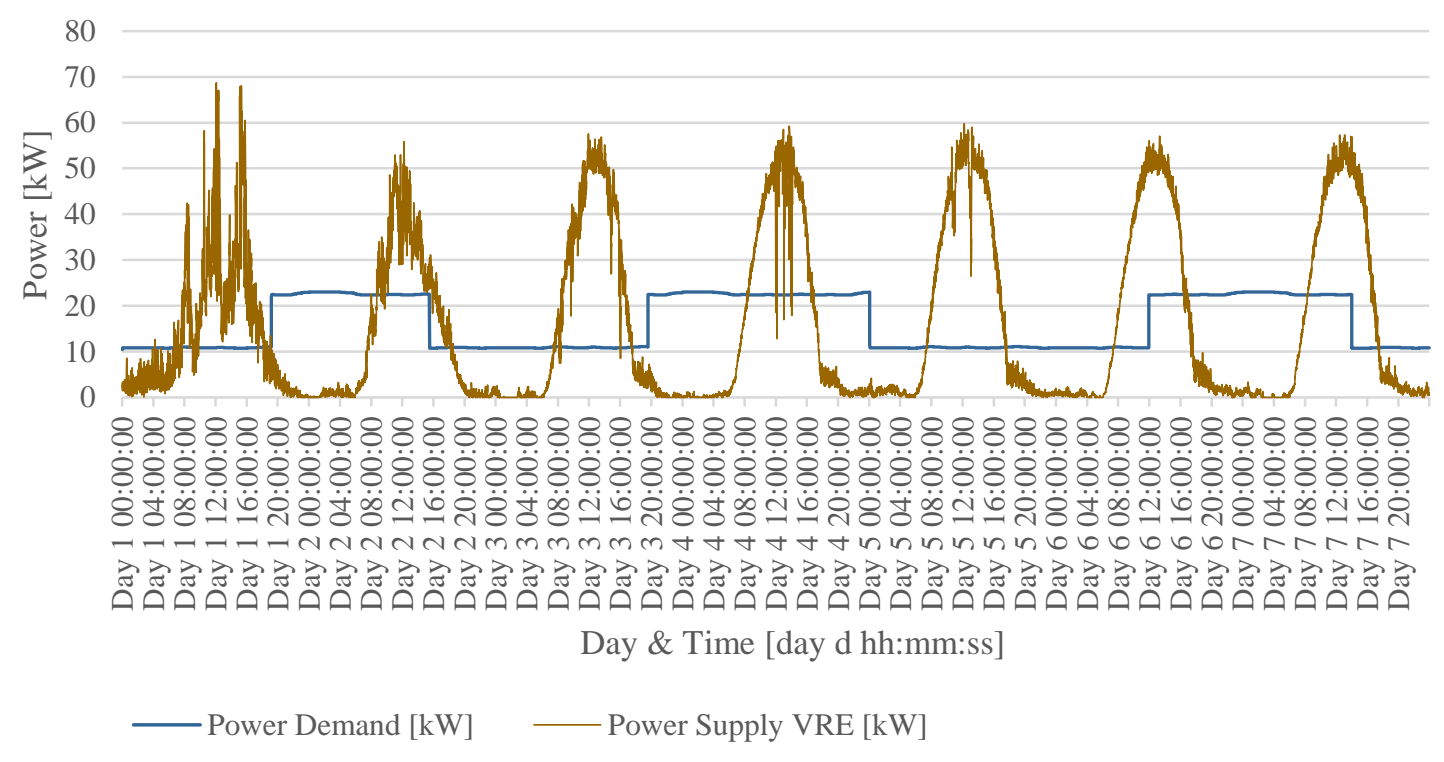

Figure 62: Sc 1b - VRE power supply and water supply system power demand, own figure

The VRE supply is scaled to potentially meet the energy demand of the water supply system. The cumulated energy demand is thus identical to the cumulated energy supply. Still, there are both time periods, in which the VRE supply can power the water supply system entirely and time periods in which the VRE supply is not enough to meet the power demand. In case of a lack of power, the required additional power is supplied by the electricity grid. Especially at night, where solar energy is not available and wind energy is relatively low (in this VRE supply data sample), almost all power needs to be supplied by grid electricity. On the other hand, during high VRE power availability, there is a large amount of excess energy.

Figure 63 shows the power demand including the time periods that the VRE power supply is sufficient to meet the demand and the time periods that grid electricity has to be added to meet the power demand. Additionally, the excess power of the 
variable renewable energies is shown in the transparent dark-yellow color. The total excess VRE energy during the simulation run is $1400.60 \mathrm{kWh}$.

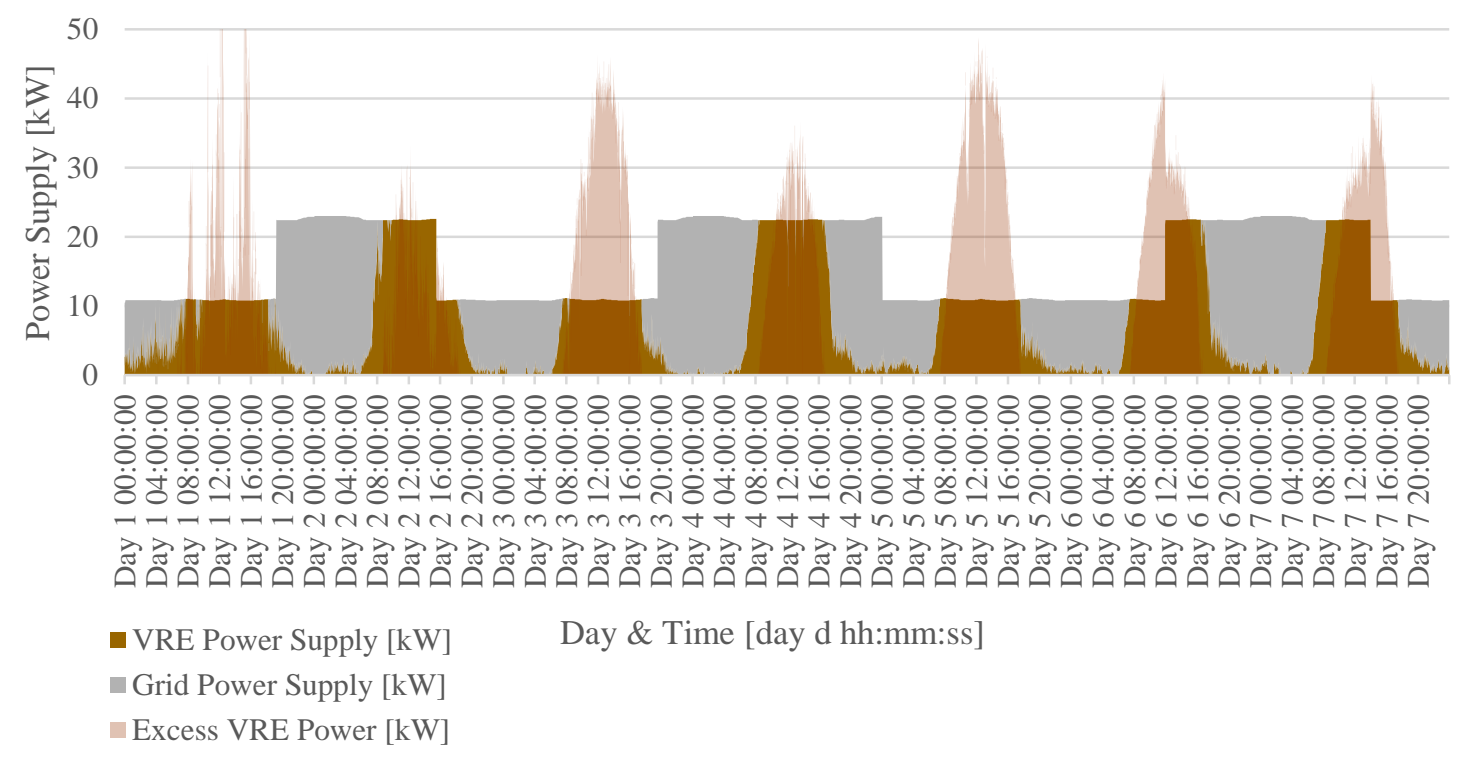

Figure 63: Sc 1b - VRE power supply and grid power supply to meet the WSS power demand including excess VRE power, own figure

At every time step, the VRE supply meets a share between $0 \%$ to $100 \%$ of the power demand. This share is considered the degree of power self-sufficiency. If the VRE power supply is VRE $=0$, all power has to be supplied by grid electricity and the power self-sufficiency is $0 \%$. If the VRE power is equal or exceeds the power demand of the water supply system, the power self-sufficiency is $100 \%$. As the total energy demand is represented as the integral under the demand curve, the degree of energy self-sufficiency can be calculated. Figure 64 shows the cumulated energy demand and the supply by variable renewable energies and grid electricity. 


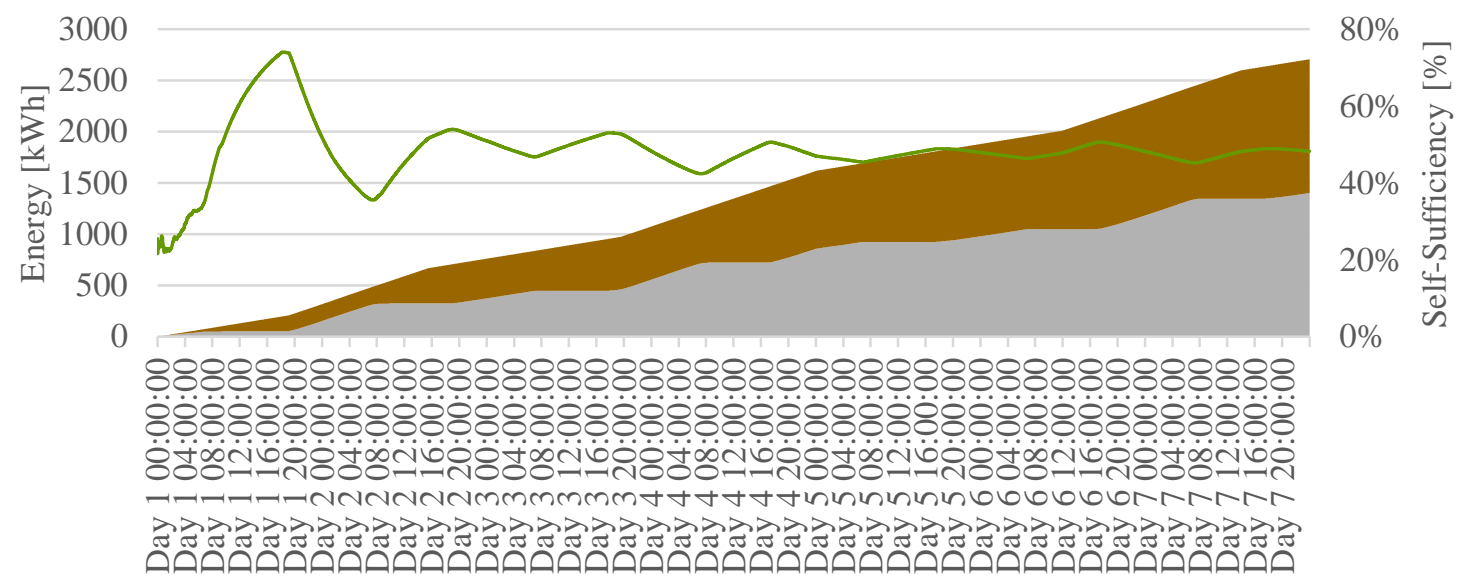

Day \& Time [ day d hh:mm:ss]

Cumulated Energy Grid [kWh]

Cumulated Energy VRE [kWh]

- Energy Self Sufficiency [\%]

Figure 64: Sc 1b - Energy demand and supply by VRE and grid electricity and degree of self-sufficiency (floating mean), own figure

The total energy demand of the water supply system is identical to the demand in scenario Sc 1a. Despite the shared supply by VRE and grid electricity, the graph looks similar to the cumulated energy demand in Figure 57. Included in the figure is the floating mean of the degree of energy self-sufficiency. At the end of the simulation run, the degree of energy self-sufficiency is $48.21 \%$.

Compared to scenario Sc $1 \mathrm{a}$, the $\mathrm{CO}_{2}$-emissions are calculated as the product of the current power supply of both VRE and grid electricity and their specific $\mathrm{CO}_{2}-$ emission coefficients. The different specific $\mathrm{CO}_{2}$-emission coefficients of photovoltaic power and wind power are considered using the current ratio of each source and the total VRE power at each time step. The cumulated $\mathrm{CO}_{2}$-emissions during the simulation run are visualized in Figure 65. 


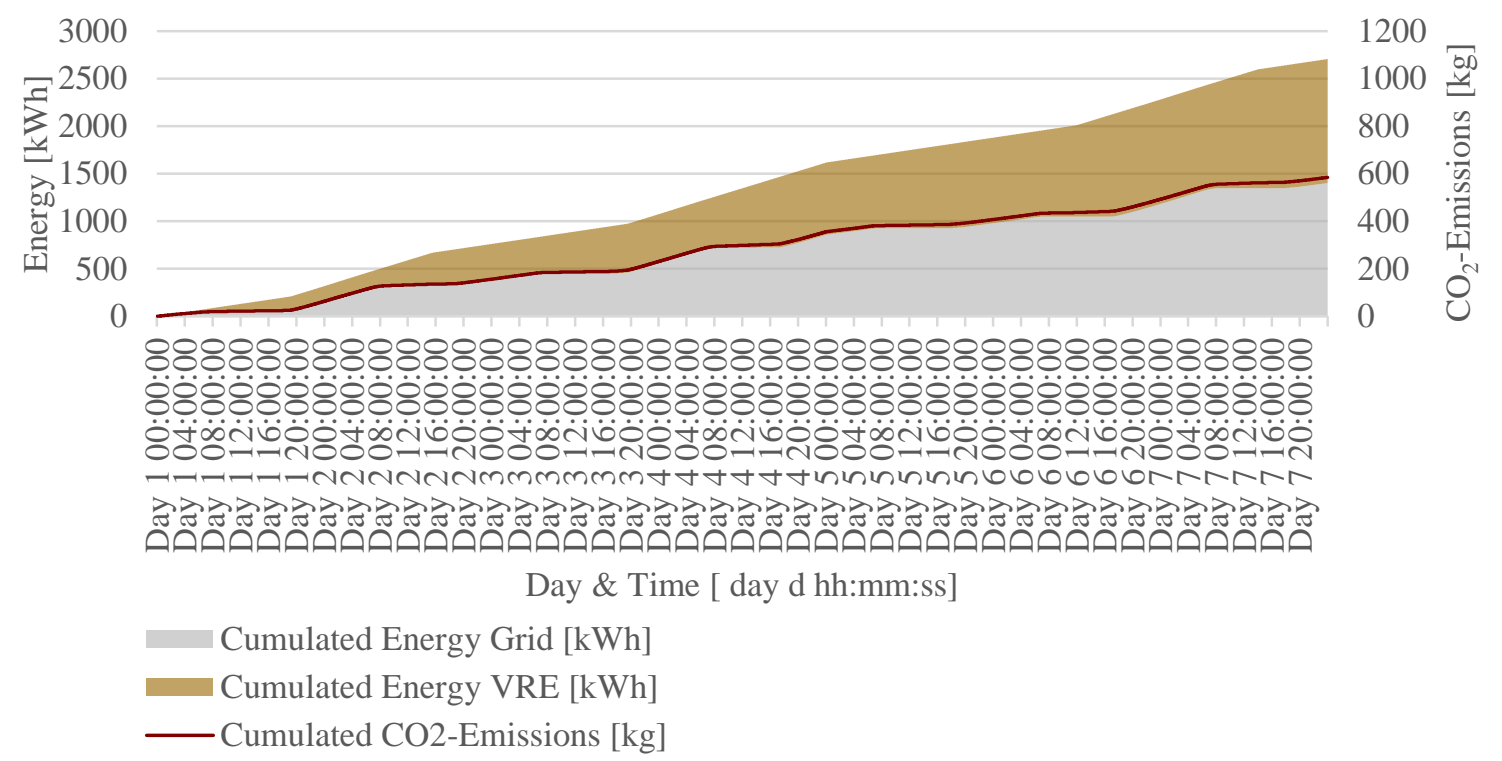

Figure 65: $\mathrm{Sc} 1 \mathrm{~b}$ - Cumulated $\mathrm{CO}_{2}$-emissions and cumulated energy supply, own figure

The cumulated energy supply by VRE and grid electricity are included to allow for comparison of scenario Sc $1 \mathrm{~b}$ and Sc 1a. The vertical axis range is kept identical to visualize the different results. The total cumulated $\mathrm{CO}_{2}$-emissions in scenario $\mathrm{Sc} 1 \mathrm{~b}$ are $584.31 \mathrm{~kg}$.

\subsection{Scenario Sc 2}

In this section, the results from simulation scenario Sc 2 will be visualized and interpreted. Scenario Sc 2 represents the proposed potential future scenario with integrated variable renewable energy supply and the implementation of demand side management measures into the water supply system operation. The results are distinguished into energy related and water related results. Beginning with the energyrelated results, the focus will be on the total energy demand, excess VRE power, degree of self-sufficiency and resulting $\mathrm{CO}_{2}$-emissions. 


\subsubsection{Sc 2 - Energy related results}

In this section, the energy related results of simulation scenario Sc 2 are visualized and interpreted. The style of the graphs will be kept similar to the results sections of simulation scenarios $\mathrm{Sc} 1 \mathrm{a}$ and $\mathrm{Sc} 1 \mathrm{~b}$ to allow comparison of the scenarios. Nevertheless, section 4.4 will aggregate and visualize the results of all three scenarios side-by-side to show the improvements and draw-backs of the integration of VRE and DSM measures. The dynamic power demand of the water supply system has changed significantly in scenario Sc 2 . The VRE supply and WSS power demand are shown in Figure 66.

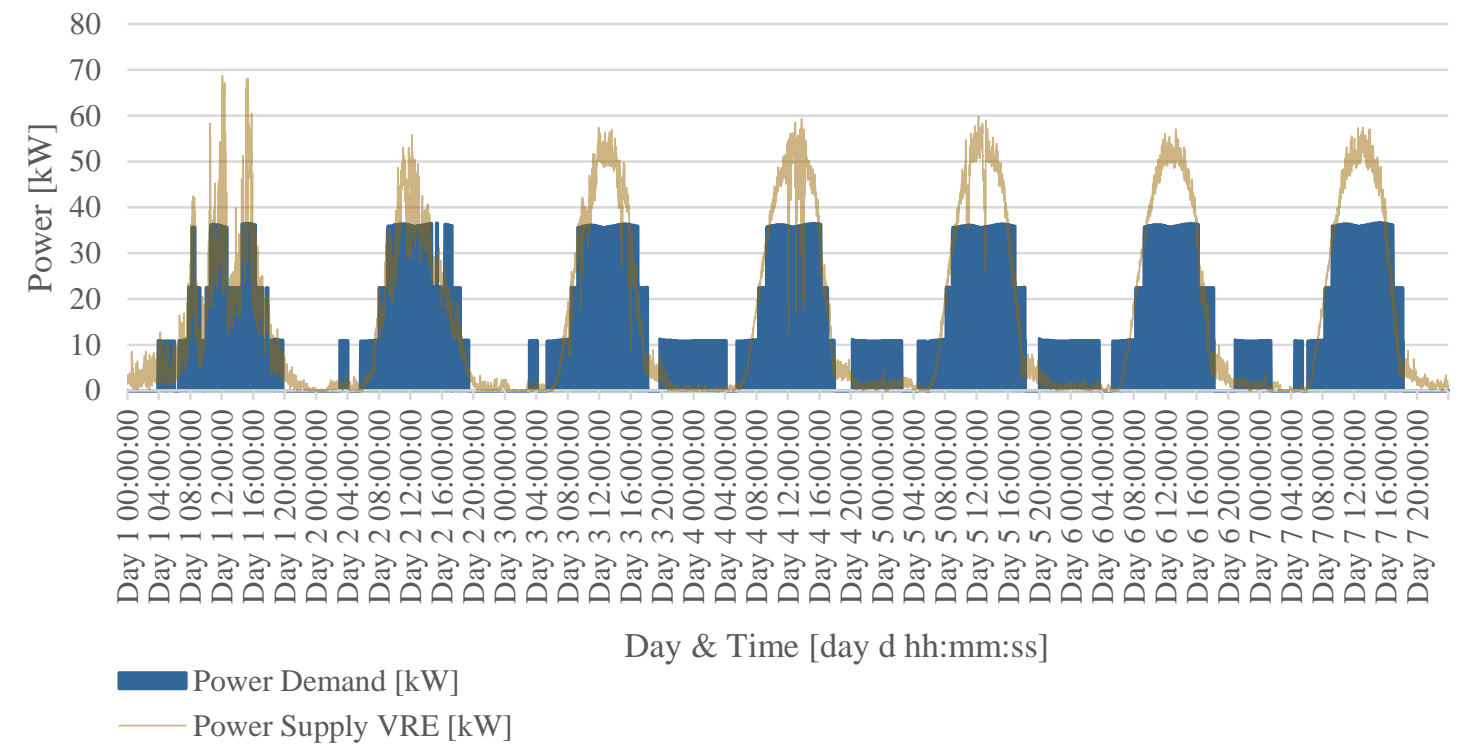

Figure 66: Sc 2 - VRE power supply and water supply system power demand, own figure

The VRE power supply graph is set transparent and the power demand curve is filled to highlight the adapted water supply system power demand. Due to the variable renewable energy-adapted operation schedule of the water supply system, the pumps 
are operated more dynamically with the goal to synchronize the power demand with the available VRE power supply.

At low VRE availability, the water supply system is run on minimum power within the required boundaries of ensuring good physical water quality in form of sufficient pressure and flow. At high VRE availability, the water supply system runs on maximum flow within the limits of maximum pressure requirements in the water supply system. The minimum, maximum and mean power during the simulation run are $0.00 \mathrm{~kW}, 36.60 \mathrm{~kW}$ and $16.05 \mathrm{~kW}$ respectively. The resulting share of VRE and grid electricity to meet the power demand is shown in Figure 67.

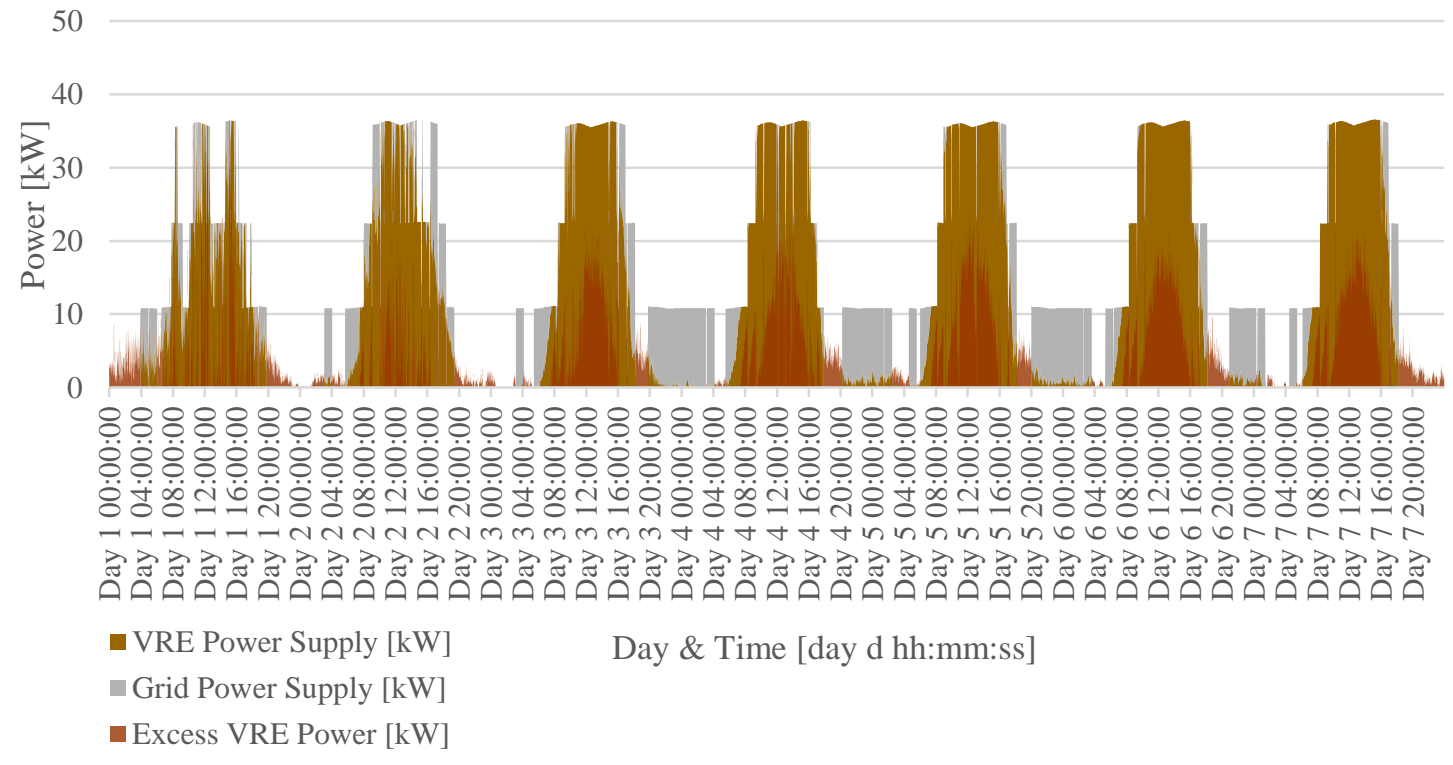

Figure 67: Sc 2 - VRE power supply and grid power supply to meet the WSS power demand including excess VRE power, own figure

Due to the combined power demand of the three running pumps at high VRE availability, the excess VRE power is comparatively low. The cumulated excess energy is $581.18 \mathrm{kWh}$. 
The visible area of both VRE power supply and grid power supply represents the share of each power source to meet the power demand. The high share of VRE power supply is clearly visible during most days. To maintain the physical water quality, pumps are sometimes turned on at night to keep the fill level in the storage tank at a sufficient height and to maintain the minimum pressure in the water supply system. The resulting energy self-sufficiency is shown in Figure 68 along with the cumulated energy supply from both VRE and grid supply.

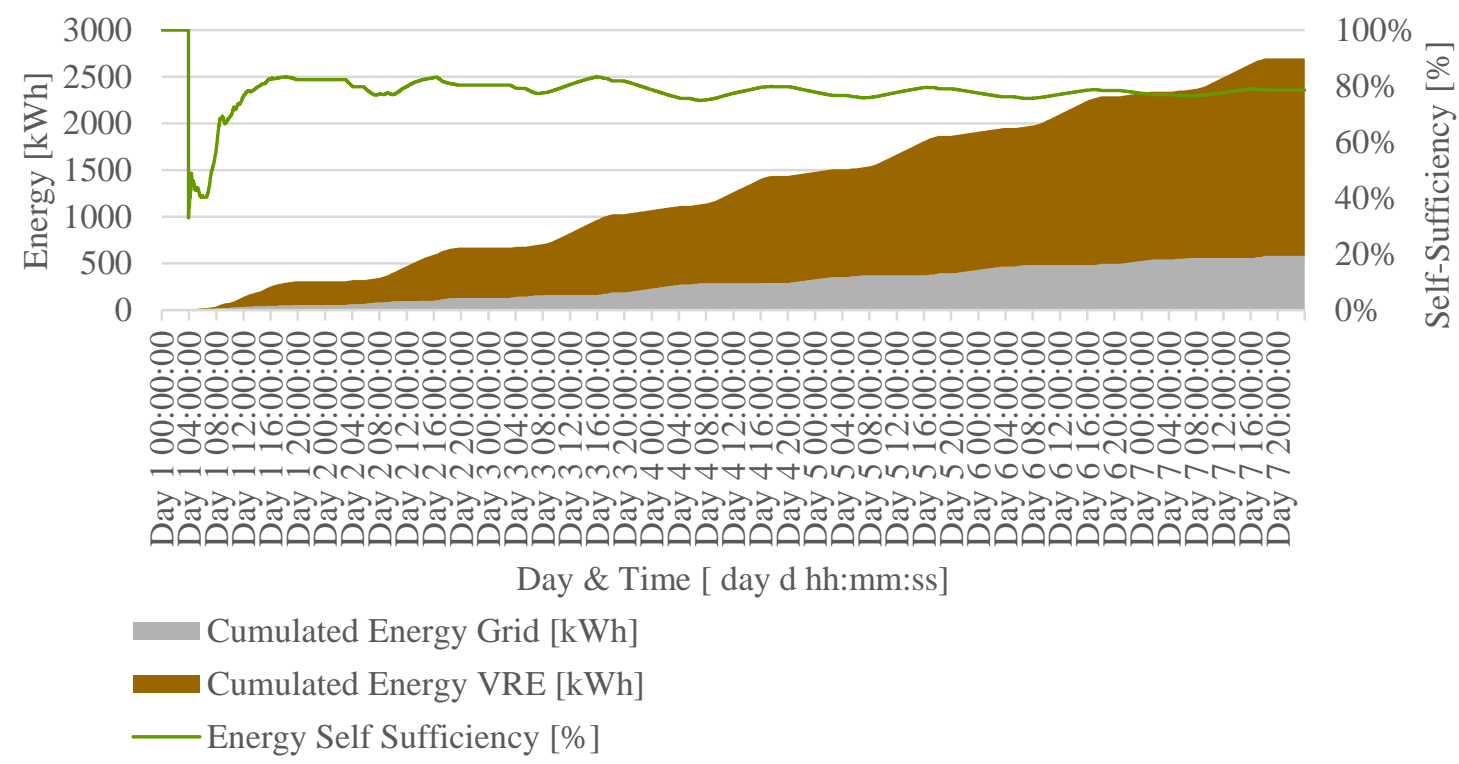

Figure 68: Sc 2 - Energy demand and supply by VRE and grid electricity and degree of self-sufficiency (floating mean), own figure

Due to the adapted operation of the water supply system, the cumulated energy demand is $2697.20 \mathrm{kWh}$. The energy self-sufficiency reaches a value of $78.48 \%$ at the end of the simulation run. The high share of renewable energies results in a reduction of total $\mathrm{CO}_{2}$-emissions. The cumulated emissions compared to the total energy demand supplied by both VRE and grid electricity are shown in Figure 69. 


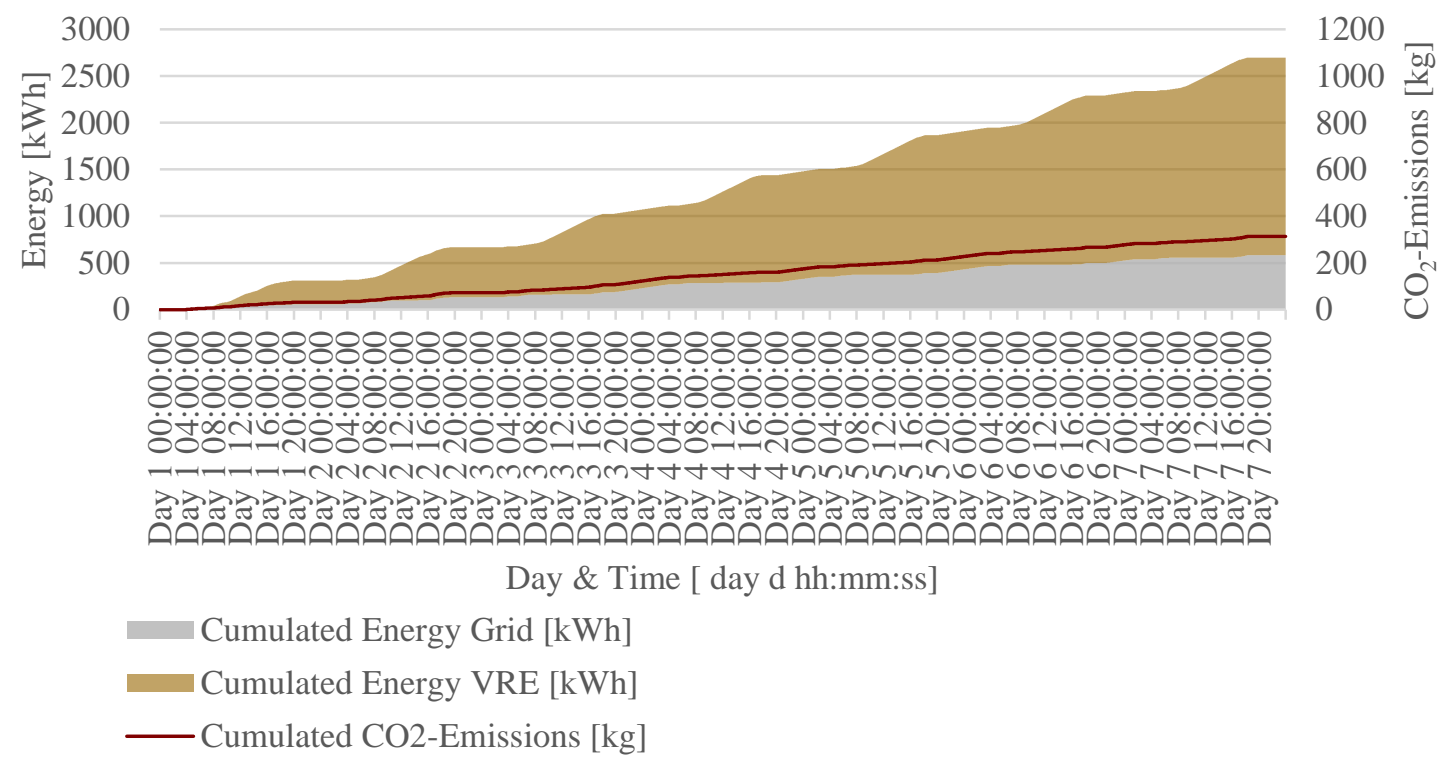

Figure 69: Sc 2 - Cumulated $\mathrm{CO}_{2}$-emissions and cumulated energy supply, own figure

The results of the proposed future scenario Sc 2 are promising regarding the energy related KPIs. After visualizing and interpreting the water related results, all KPIs are compared in section 4.4.

\subsubsection{Sc 2 - Water related results}

In this section, the water related results of simulation scenario Sc 2 are visualized and interpreted. Due to the adapted operation schedule, changes in pump switches, dynamic water supply, system pressure, storage tank fill level and retention time are expected. The water demand is identical in all three simulation scenarios. The water supply and water demand are shown in Figure 70. 


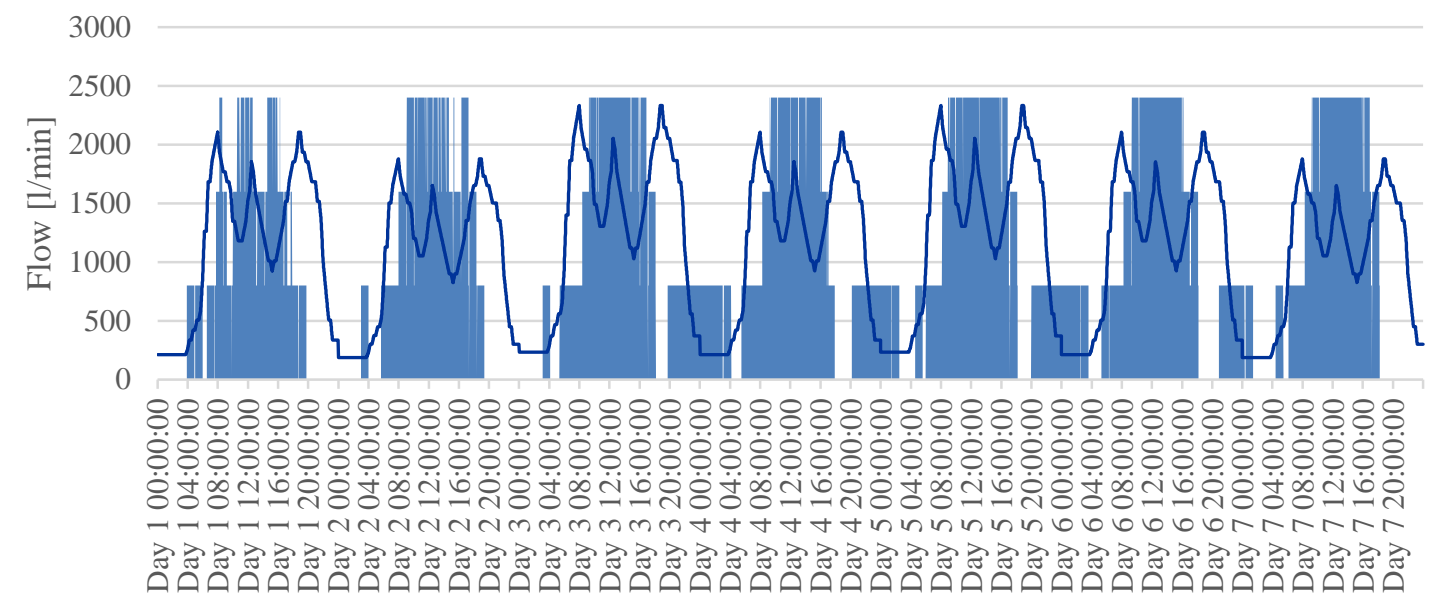

Water Supply $[1 / \mathrm{min}]$

Day \& Time [day d hh:mm:ss]

Water Demand [1/min]

Figure 70: Sc 2 - Dynamic water demand and water supply, own figure

In the water supply graph, the current states of the three pumps can be identified clearly. The supply matches the demand very well at around noon but falls short of it during the mornings and evenings, where pump supply is reduced due a lower availability of variable renewable energy. The adapted pump schedule effects the differential flow towards and from the storage tank and thus the water fill level in the tank. Both variables are visualized in Figure 71. 


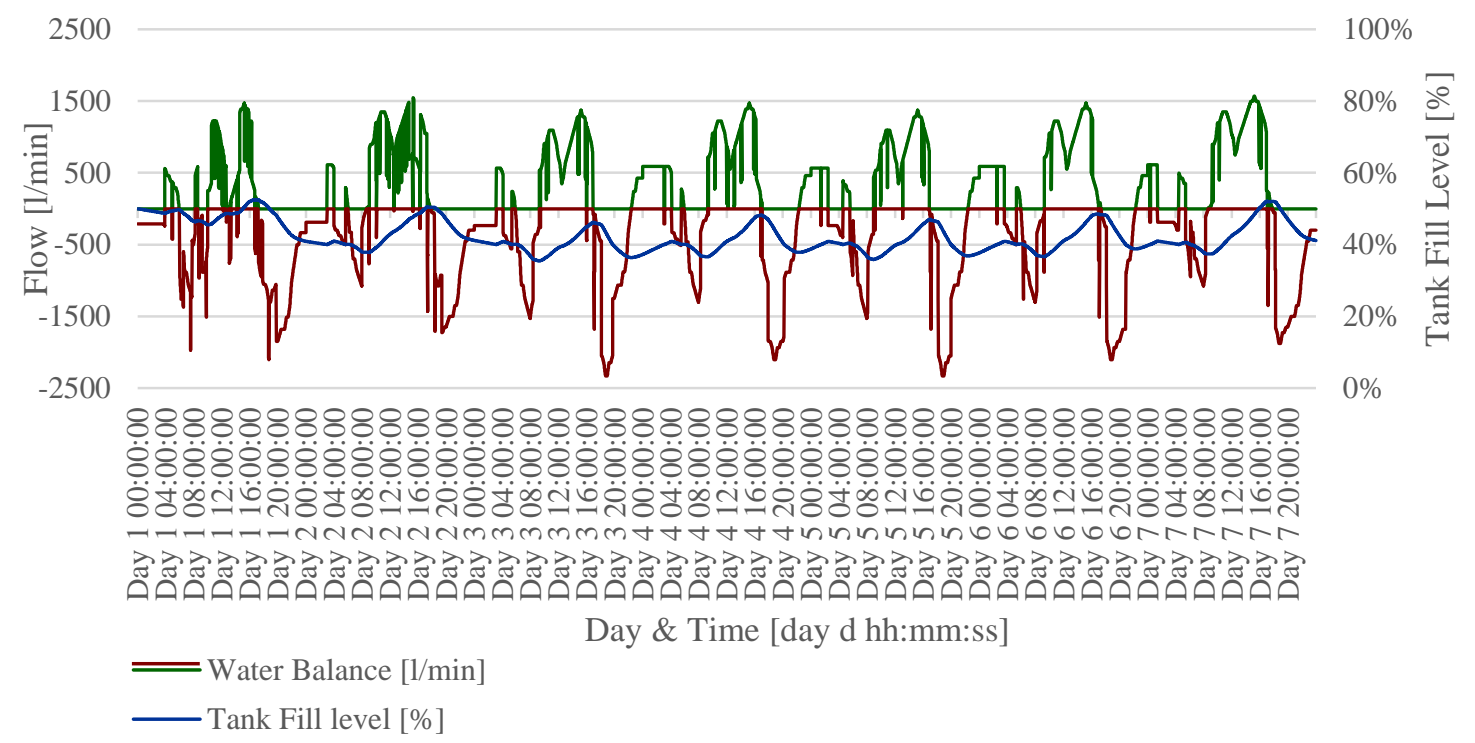

Figure 71: Sc 2 - Differential flow and storage tank fill level, own figure

The water balance (differential volume) shows much larger fluctuations than in scenarios Sc 1a and Sc 1b. Again, it is evident that the water balance relates directly to the change in the storage tank fill level. The amplitude of both the negative water balance and positive water balance values is much higher than in the previous scenarios, indicating that the pumps are run at either very high or very low or sometimes zero supply. During the time that the pumps are shut off completely, the storage tank and thus the water balance meets the total demand of the consumers. The minimum, maximum and mean storage tank fill levels are $35.43 \%, 52.52 \%$ and $42.36 \%$, respectively. The fill level at the end of the simulation is $41.13 \%$.

Due to the lower mean water storage tank fill level, the pressure within the distribution system is expected to be lower on average. The dynamic pressure at Hillside Hall during the simulation run is shown in Figure 72. 


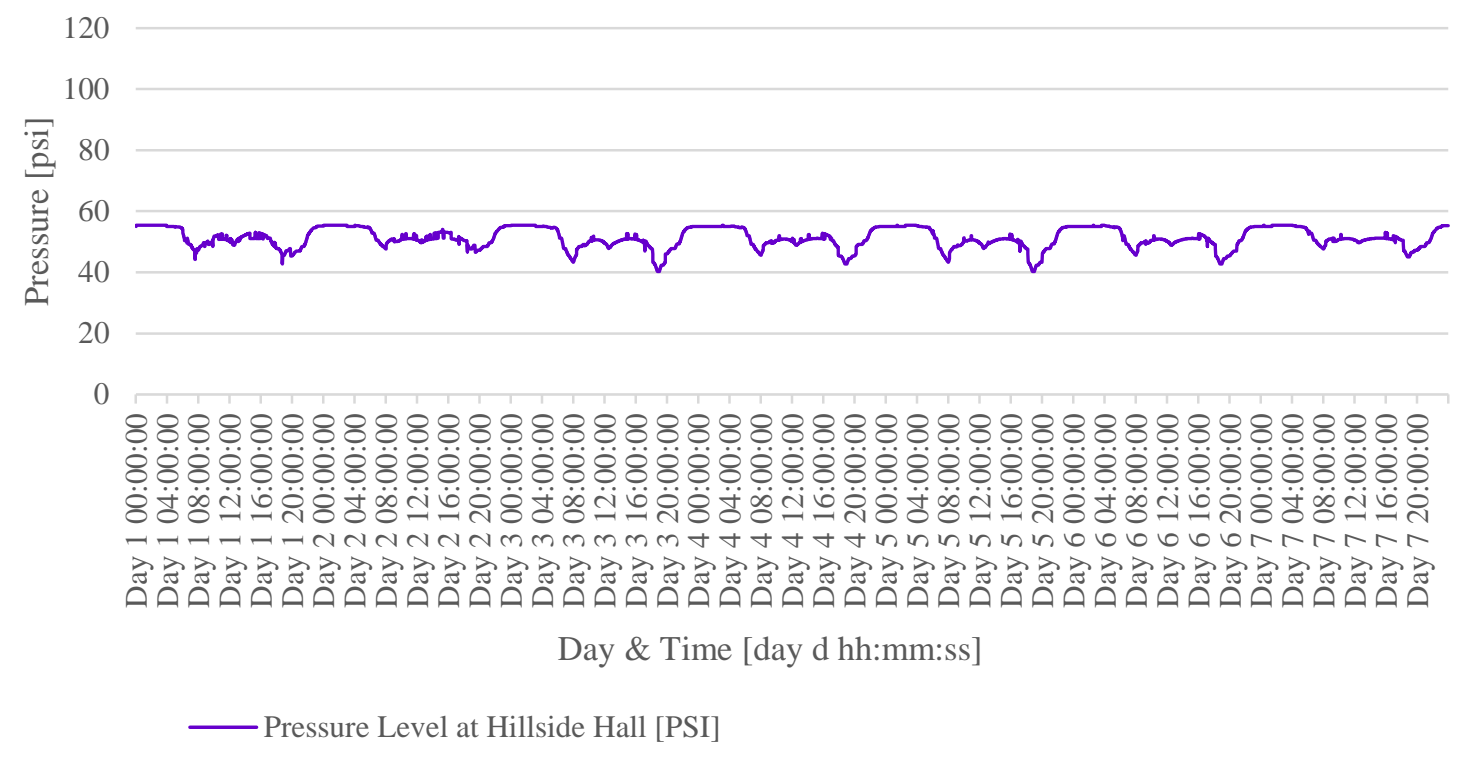

Figure 72: Sc 2 - Dynamic pressure level at Hillside Hall, own figure

The minimum, maximum and mean pressure at Hillside Hall during the simulation are $40.22 \mathrm{psi}, 55.49$ psi and 51.25 psi, respectively. The expectation, that due to the adapted pump schedule, pressure problems would occur, is thus falsified. Contrary to the expectation, the pressure in the water distribution system is lower on average than in the scenarios Sc 1a and Sc 1b.

The water retention time in scenario has changed significantly. Due to the integration of demand side management measures into the water supply system operation, the water supply and thus the dynamic fill level in the tank have changed compared to scenario Sc 1 . The retention time with both the integration of VRE and DSM measures is shown in Figure 73, including the storage tank fill level as a reference. 


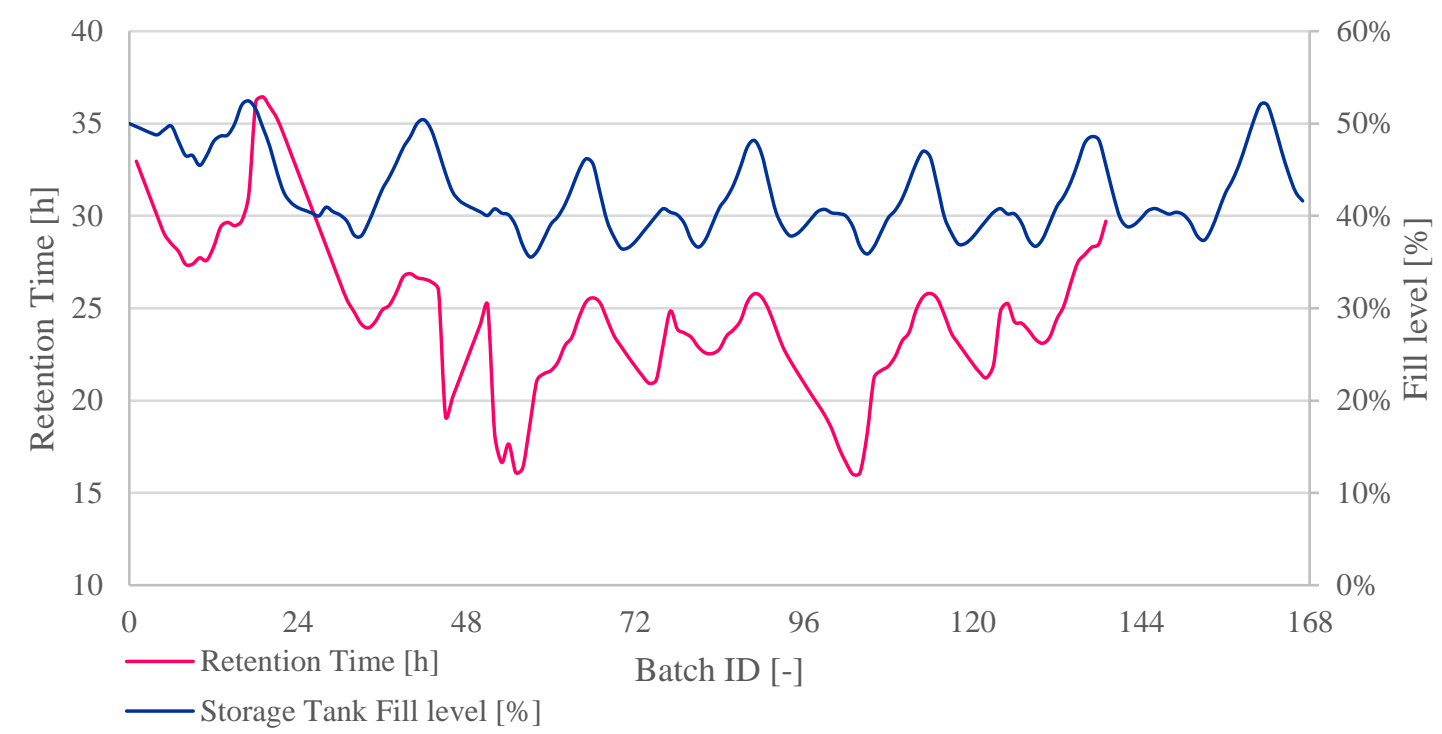

Figure 73: Sc 2 - Retention time of sample water batches and tank fill level, total batches arrived at simulation end $=139$, own figure

The water retention time is both dependent on the storage tank fill level and the water demand. Additionally, the retention time in pipe D0 is solely dependent on the water supply. Due to the potential of the improved operation schedule to increase the water supply at times of high VRE availability, the retention time during those time periods is comparatively low, reaching a minimum of 16.01 hours. Even though the pumps are shut off during long periods of low water demand and low VRE availability, the maximum retention time during the simulation run is kept low at 36.45 hours. The mean retention time of all sample batches in scenario Sc 2 is 24.66 hours.

The pumps I, II and III are turned on and off very often. To avoid unnecessary switches, a pump stays on for 60 minutes, before it can turn off again. Due to the significant fluctuations of the variable renewable energy supply, sudden but short supply peaks drive the operation control towards switching on a pump. This pump is then kept on for 60 minutes. This security and wear-reducing measure potentially 
increases the dependence on grid electricity but is required to successfully operate the water supply system using variable renewable energy. The pumps I, II and III are switched on 47 times, 42 times and 32 times respectively.

Overall, the water related results are promising and below the expectations of potential threats due to extremely low or high pressures. It is important to mention, that measures towards maintaining the physical water quality, such as pressure and flow have been implemented to reduce the potential of threats that may affect the physical water quality. An operation schedule based solely on renewable energy availability may lead to very high and low storage tank water fill levels or distribution system pressures, potentially causing physical harm to the system and reducing the physical water quality.

\subsection{Comparative Evaluation}

In this section, the three scenarios Sc 1a, Sc $1 \mathrm{~b}$ and Sc 2 are compared based on the key performance indicators mentioned in Table 7. The KPIs are distinguished into energy related results and water related results, which will be interpreted and analyzed in the sections 4.4.1 and 4.4.2, respectively. 


\subsubsection{Comparative Evaluation - Energy related results}

In this section, the energy related results from the simulation scenarios Sc 1a, $\mathrm{Sc} 1 \mathrm{~b}$ and Sc 2 are compared. The first aspect is to compare the power demand of the water supply system. As in scenario Sc 2, the operation schedule is changed significantly, a comparison will reveal the main aspects of the adapted operation compared to the initial schedule. Figure 74 shows the power demand of both Sc 1a and Sc $1 b$ (identical demand) and Sc 2 .

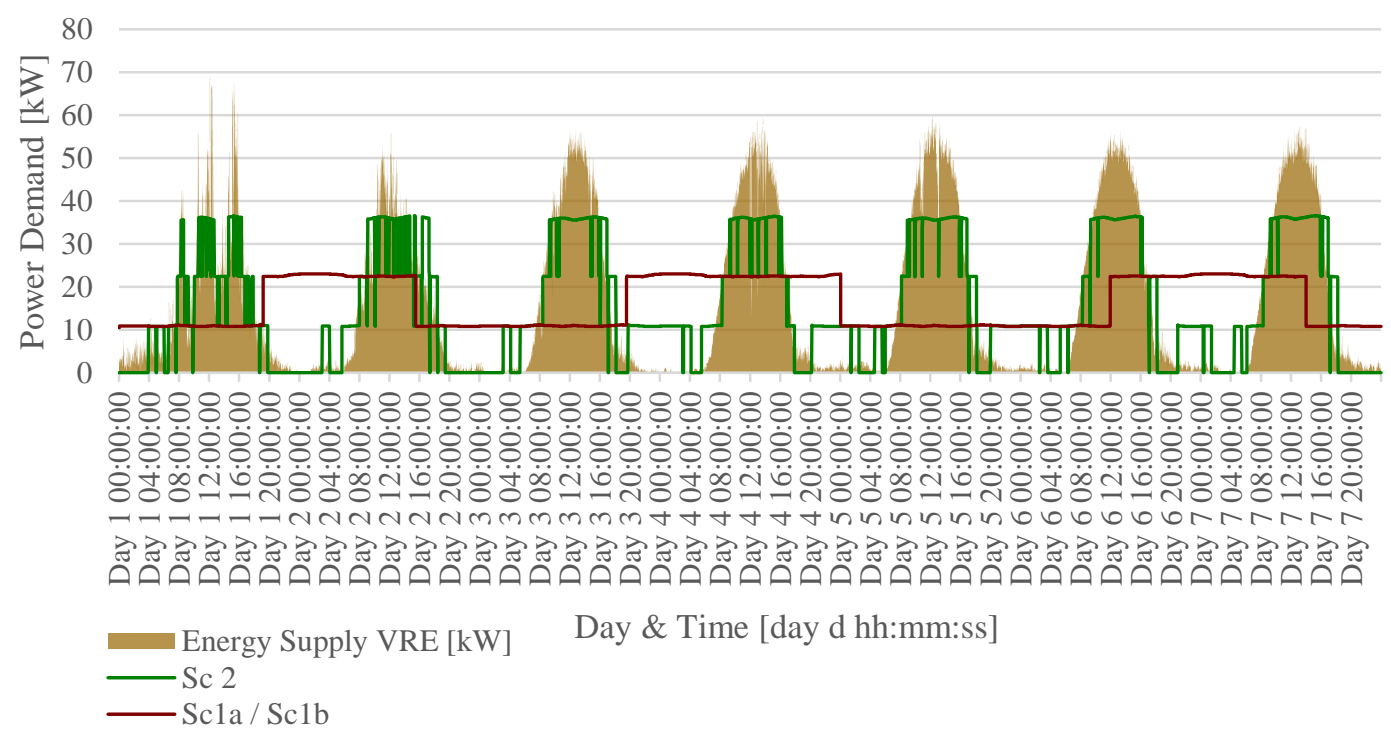

Figure 74: Comparative evaluation - Power demand and VRE supply, own figure

The red line represents the power demand according to the initial operation schedule. The operation schedule does not consider the availability of renewable energy and thus operates solely based on the fill level in the storage tank. While at some time periods, the initial schedule overlaps well with high availability of renewable energy (e.g. Day 4, 08:00 to 18:00), a lot of energy needs to be supplied by the electricity grid at times of high power demand and low or even no availability of 
VRE (e.g. Day 6, 20:00 - Day 7, 08:00). Besides that, high VRE availability can't be made any use of due to the inability to synchronize the power demand to the VRE supply, leading to a high amount of excess renewable energy (e.g. Day 5, 08:00 18:00).

The ability of the optimized schedule to adapt to high or low VRE availability allows the water supply system to reduce or increase its current power demand by switching pumps on or off. Two improvements can be achieved by doing so. Most importantly, the utilization of variable renewable energy can be increased by increasing the power demand during high VRE availability. Besides that, grid electricity can be avoided during time periods of low VRE availability. These two improvements go hand in hand, as shutting down pumps is only possible if they have been running at a higher flow rate before.

Despite the good fit of the power demand to the VRE supply, the water supply system is still not capable of using all the available renewable energy, as the power demand of the system is limited (Day 3, 08:00 - 16:00). The load-shifting approach can thus not be used to its full potential, which eventually causes the storage tank water level to trigger pumps to be switched on to maintain the physical integrity of the water (Day 5, 20:00 - Day 6, 04:00). Additional pumps, that are off or idle most of the time could add even more potential to utilize the available renewable energy and reduce the dependency on grid electricity. The integration of such a number of overdimensioned pumps needs to be assessed in future studies regarding the feasibility and higher initial environmental impacts due to the added entity. 
Despite the very differently distributed power demand, the energy demand throughout the sample week simulation of scenario Sc 2 is very similar to Sc 1a and Sc 1b. Figure 75 shows the total energy demand of both scenario Sc $1 \mathrm{~b}$ and Sc 2 .

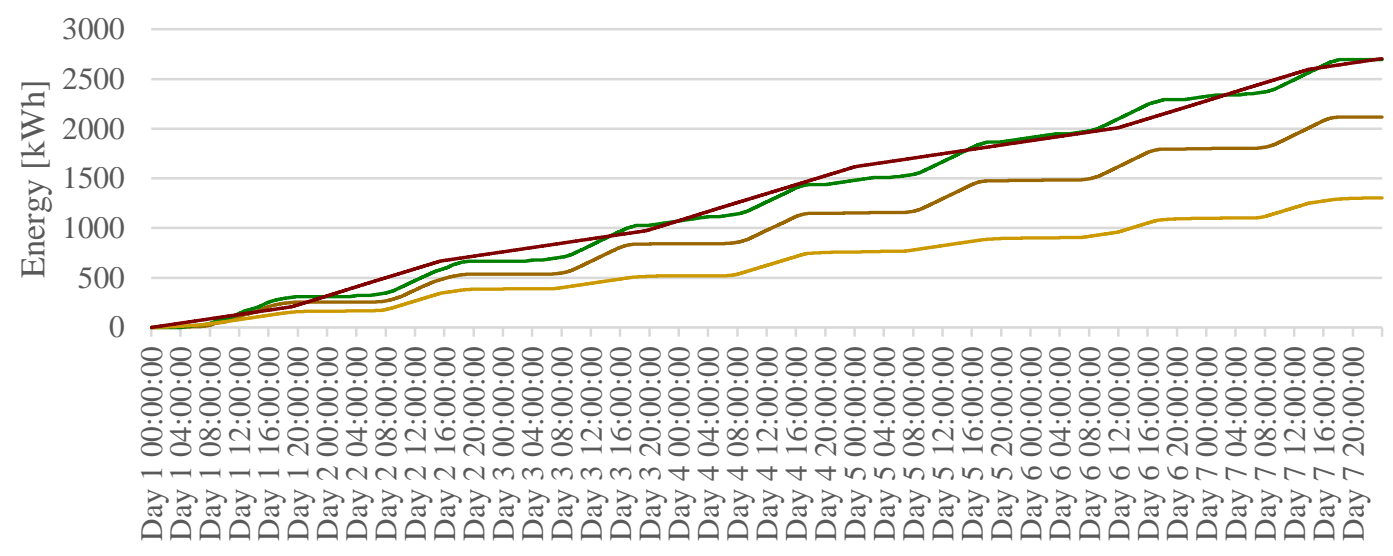

- Sc 2 - Cumulated Energy VRE [kWh]

- Sc 2 - Cumulated Energy Total [kWh]

Day \& Time [Day d hh:mm:ss]

Sc $1 \mathrm{~b}$ - Cumulated Energy VRE [kWh]

Sc $1 \mathrm{~b}$ - Cumulated Energy Total [kWh]

Figure 75: Comparative evaluation - Total energy demand and VRE supply share, own figure

The total energy demand of both scenarios is almost identical. While in scenario Sc 1b, $2705.27 \mathrm{kWh}$ are consumed, in scenario Sc 2, $2697.20 \mathrm{kWh}$ are consumed. The difference is likely to be the result of the slightly lower storage tank fill level at the end of the simulation in scenario Sc 2. The major difference between Sc $1 \mathrm{~b}$ and Sc 2 is the share of VRE supply. Figure 75 shows, that in scenario Sc 2, the system is able to utilize more renewable energy at a similar total energy demand. The graphs Cumulated Energy VRE of Sc $1 \mathrm{~b}$ and Sc 2 result in a degree of energy self-sufficiency at the end of the simulation of $48.21 \%$ and $78.48 \%$, respectively. The high degree of energy self-sufficiency reduces the dependency on carbon-intensive grid electricity. The energy self-sufficiency and the $\mathrm{CO}_{2}$-emissions are shown in Figure 76. 

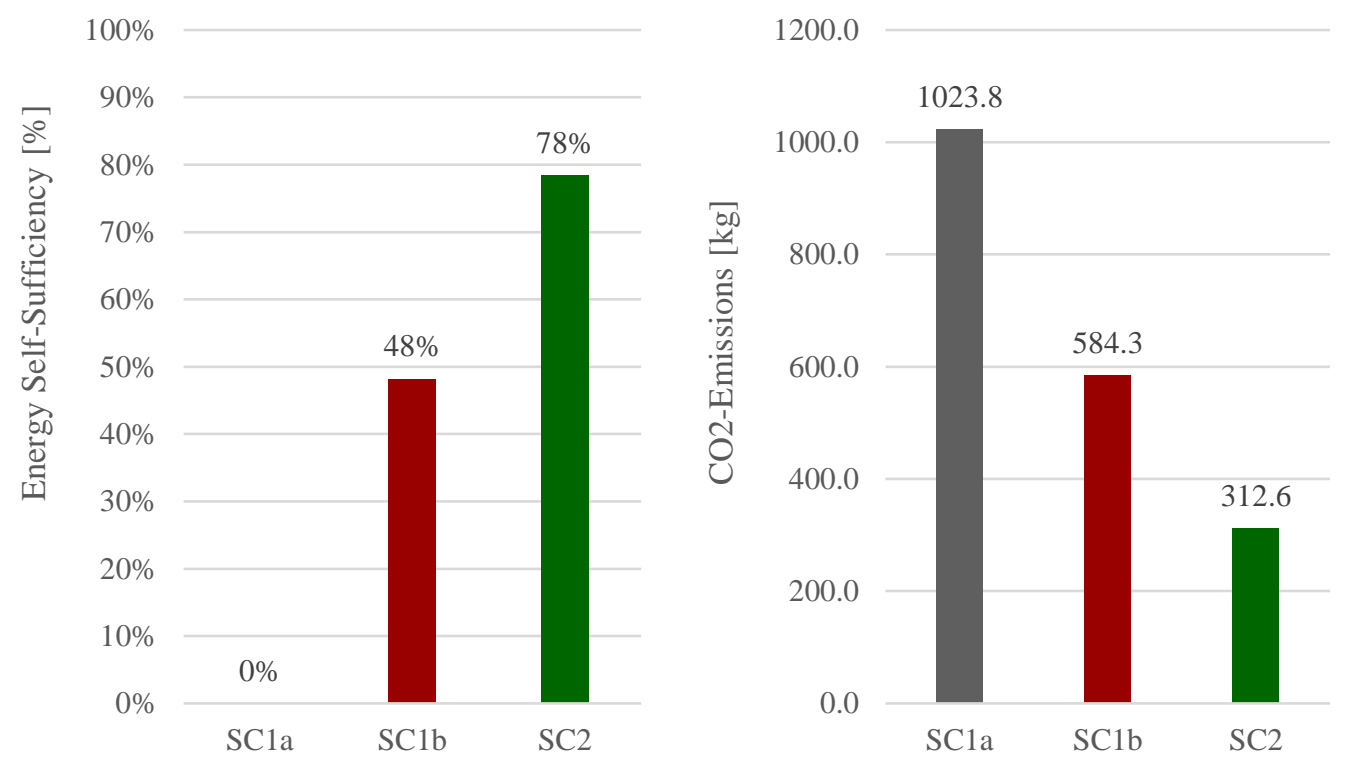

Figure 76: Comparative evaluation - Energy self-sufficiency and $\mathrm{CO}_{2}$-emissions, own figure

From Scenario Sc 1a, the energy self-sufficiency could be increased from $0 \%$ to $48 \%$ solely by the integration of variable renewable energies, resulting in a decrease in $\mathrm{CO}_{2}$-emissions of $42.92 \%$. The additional implementation of demand side management measures to increase the utilization of renewable energies led to a further increase of energy self-sufficiency by $30 \%$ while cutting the carbon-intensity by an additional $46.5 \%$ compared to scenario $\mathrm{Sc} 1 \mathrm{~b}$. The total cut of $\mathrm{CO}_{2}$-emissions that could be achieved in scenario Sc 2 compared to the reference scenario Sc 1a is $69.4 \%$.

Due to the improved operation schedule and resulting improvement regarding the utilization of the available renewable energy, the excess renewable energy was reduced from scenario Sc $1 \mathrm{~b}$ to Sc 2 . The cumulated excess renewable energy in scenario S $1 b$ and S 2 are shown in Figure 77. For reference, the cumulated VRE supply is added. 


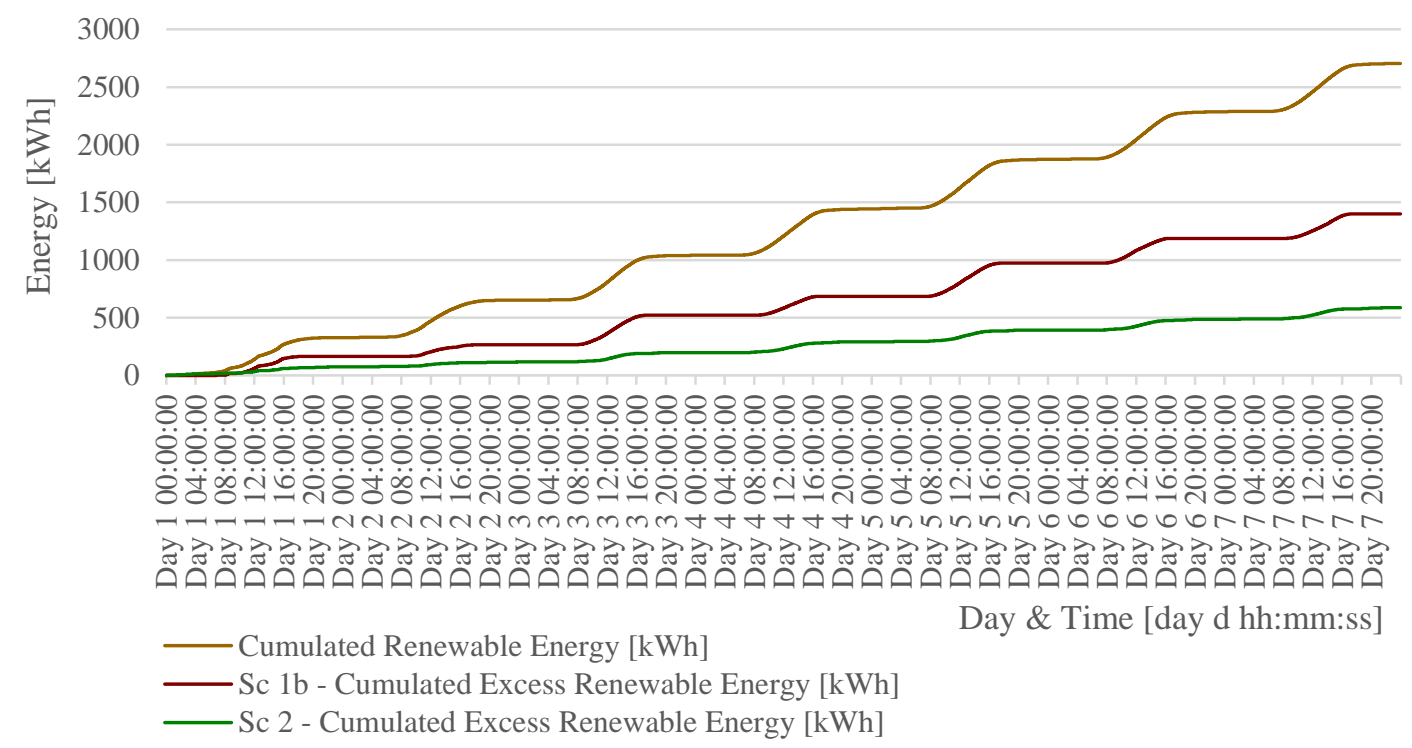

Figure 77: Comparative evaluation - Cumulated VRE supply and excess renewable energy, own figure

Figure 77 shows clearly, that the total renewable energy cumulates throughout the day, when the VRE supply is very high. The flat segments represent the night, in which not much renewable energy is generated. Photovoltaic power is not available during the night and in the week of the specific sample data, wind energy is very low during most nights. The excess energy graphs for $\mathrm{Sc} 1 \mathrm{~b}$ and $\mathrm{Sc} 2$ show that in $\mathrm{Sc} 2$, the water supply system can use most of the available renewable energy, while in Sc 1, the excess energy can't be used due to the inability to run the energy intensive pumps accordingly. The total excess energy in the scenarios Sc $1 \mathrm{~b}$ and Sc 2 is $1400,60 \mathrm{kWh}$ and $588.15 \mathrm{kWh}$, respectively, resulting in a reduction of excess renewable energy by $58.0 \%$.

A summary of the scenario comparison of the energy related is provided in Table 8. If the desired value of a KPI is low, reductions in value compared to previous 
scenarios are marked in green and increases are marked in red. Similarly, if the desired value of a KPI is high, increases are marked red and reductions are marked green.

Table 8: Comparative evaluation - Summary of energy related results

\begin{tabular}{|c|c|c|c|c|c|c|c|}
\hline KPI & Unit & Sc $1 \mathrm{a}$ & Sc $1 b$ & $\Delta$ to $S c 1 a$ & Sc 2 & $\Delta$ to $S c 1 a$ & $\Delta$ to $S c 1 b$ \\
\hline Energy demand & {$[\mathrm{kWh}]$} & 2705.3 & 2705.3 & $+-0 \%$ & 2697.2 & $-0.3 \%$ & $-0.3 \%$ \\
\hline $\begin{array}{c}\text { Minimum } \\
\text { power demand }\end{array}$ & {$[\mathrm{kW}]$} & 10.5 & 10.5 & $+-0 \%$ & 0 & $-\infty \%$ & $-\infty \%$ \\
\hline $\begin{array}{c}\text { peak power } \\
\text { demand }\end{array}$ & {$[\mathrm{kW}]$} & 23.0 & 23.0 & $+-0 \%$ & 36.6 & $+59.1 \%$ & $+59.1 \%$ \\
\hline $\begin{array}{c}\text { Mean power } \\
\text { demand }\end{array}$ & {$[\mathrm{kW}]$} & 16.1 & 16.1 & $+-0 \%$ & 16.05 & $-0.3 \%$ & $-0.3 \%$ \\
\hline $\begin{array}{l}\text { Degree of } \\
\text { energy self- } \\
\text { sufficiency }\end{array}$ & {$[\%]$} & 0 & 48.2 & $+48.2 \%$ & 78.5 & $+78.5 \%$ & $+30.3 \%$ \\
\hline $\begin{array}{c}\text { Cumulated } \\
\mathrm{CO}_{2} \text {-emissions }\end{array}$ & {$[\mathrm{kg}]$} & 1023.8 & 584.3 & $-42.9 \%$ & 312.6 & $-69.4 \%$ & $-46.5 \%$ \\
\hline $\begin{array}{c}\text { Excess } \\
\text { renewable } \\
\text { energy }\end{array}$ & {$[\mathrm{kWh}]$} & - & 1400.6 & - & 588.2 & - & $-58.0 \%$ \\
\hline
\end{tabular}




\subsubsection{Comparative Evaluation - Water related Results}

In this section, the water related results of the simulation scenarios Sc 1a and $\mathrm{Sc} 1 \mathrm{~b}$ are compared to the results of simulation scenario Sc 2 . As mentioned in section 4.2, Scenario Sc 1a and $\mathrm{Sc} 1 \mathrm{~b}$ are identical regarding the operation of the water supply system. The pump schedule is solely depended on the control variable storage tank fill level. In Scenario Sc 2, the pump schedule is additionally dependent on the currently available renewable energy. The specific system operation can be found in chapter 3 in the sections 3.1.1.4, 3.2.2.4 and 3.2.3.2.

For this comparison, scenario $\mathrm{Sc} 1 \mathrm{a}$ and $\mathrm{Sc} 1 \mathrm{~b}$ will be referred to as $\mathrm{Sc} 1$. The scenarios will be compared using the key performance indicators mentioned in Table 7. A first overview is visualized in Figure 78, which shows the dynamic water demand and the water supply in both the scenario Sc 1 and Sc 2.

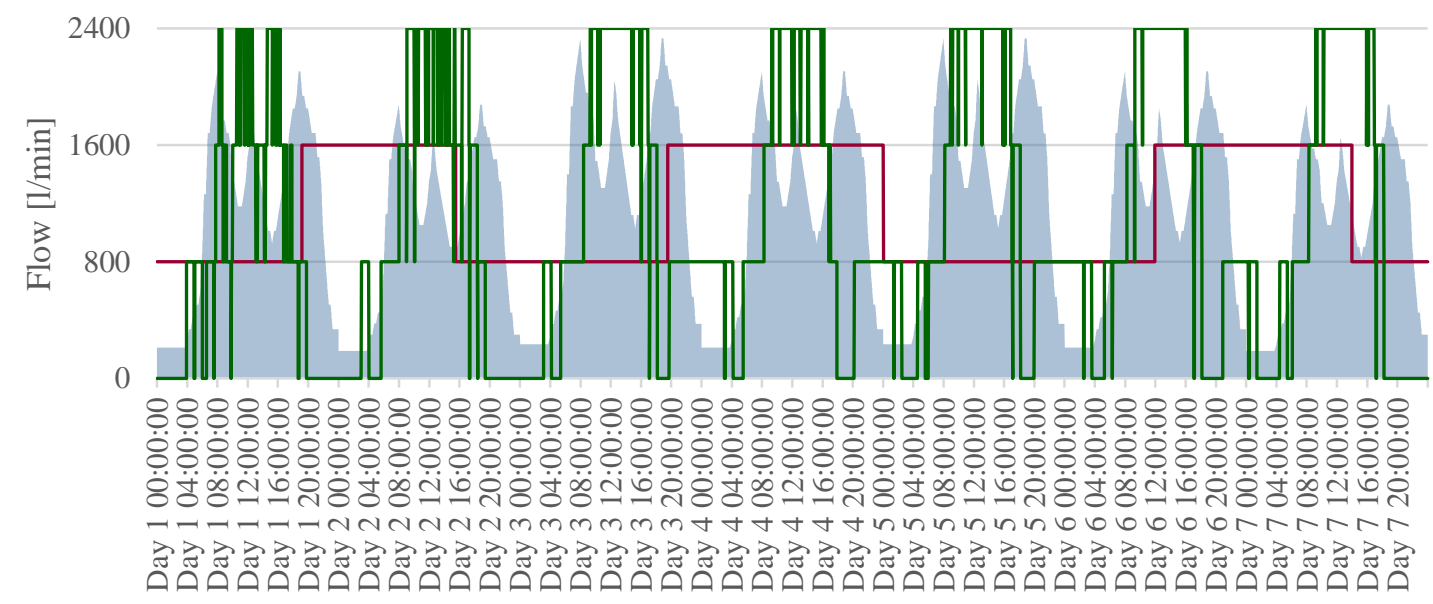

\footnotetext{
Water Demand

Water Supply Sc 1

Day \& Time [day d hh:mm:ss]
}

Figure 78: Comparative evaluation - Dynamic water demand and water supply, own figure 
The water demand is identical in both scenarios, but the water supply differs significantly. The water supply, by design, is determined by the pump operation. If one pump is active, the water supply is $800 \mathrm{l} / \mathrm{min}$. If two or three pumps are active, the water supply is $1600 \mathrm{l} / \mathrm{min}$ and $2400 \mathrm{l} / \mathrm{min}$, respectively. The water supply correlates directly with the power demand. The graphs thus look very similar to the power demand graphs in Figure 74. In Figure 74, the power demand of Sc 1 does not match the variable energy supply well, while the power demand of Sc 2 increases the synchronization of demand and supply. Interestingly, a similar pattern can be detected regarding the water supply in the scenarios Sc 1 and Sc 2 and the dynamic water demand. But although it seems that the water supply in scenario Sc 2 matches the water demand much better than the supply in scenario Sc 1, a closer look reveals that the VRE supply alone is not sufficient to run the pumps during the very high morning and evening water demand peaks. The water balance changes significantly from scenario Sc 1 to Sc 2. In Figure 79, the two scenarios are compared side-by-side.

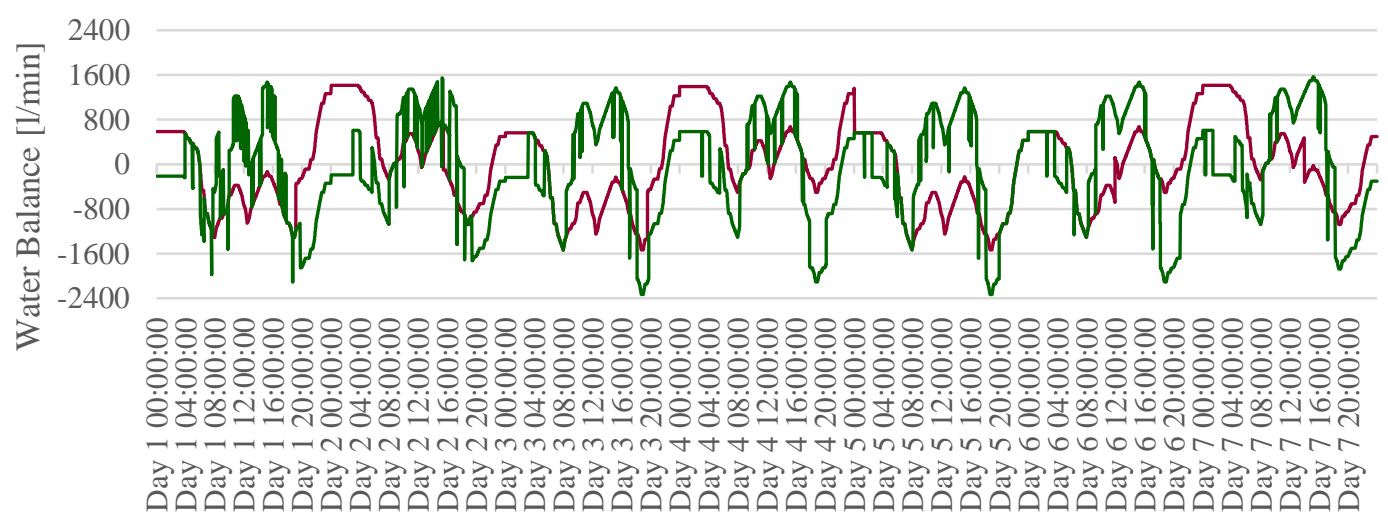

W Water Balance Sc 1

Day \& Time [day d hh:mm:ss]

Figure 79: Comparative evaluation - Water balance, own figure 
If the water balance is below zero, the water supply will not be enough to meet the demand and additional volumes have to be drawn from the storage tank. If the water supply matches the demand exactly, the water balance is zero and no water is fed into or drawn from the tank. If the supply exceeds the demand, the excess water is fed into the storage tank. Figure 59 and Figure 71 have shown the direct correlation between water balance and storage tank fill level.

In both scenarios, reoccurring patterns can be detected. Scenario Sc 1 is shaped by continuous high positive water balances at night and negative water balances during the daily demand peaks in the morning, at lunch and in the evening. Scenario Sc 2 on the other hand shows opposing water balances during many periods. During high VRE availability, the water supply is very high and sometimes even exceeds the demand peaks during the day while at night, the pumps are shut-off to conserve energy and the low nightly water demand is met entirely by the storage tank.

If the fill level in the tank decreases too much, pumps are run based on the initial operation schedule, even if no VRE is available. On day 6 at night, the water balances match due to the security-oriented operation in scenario Sc 2 . Figure 80 shows the resulting changes in the dynamic fill level of the storage tank. 


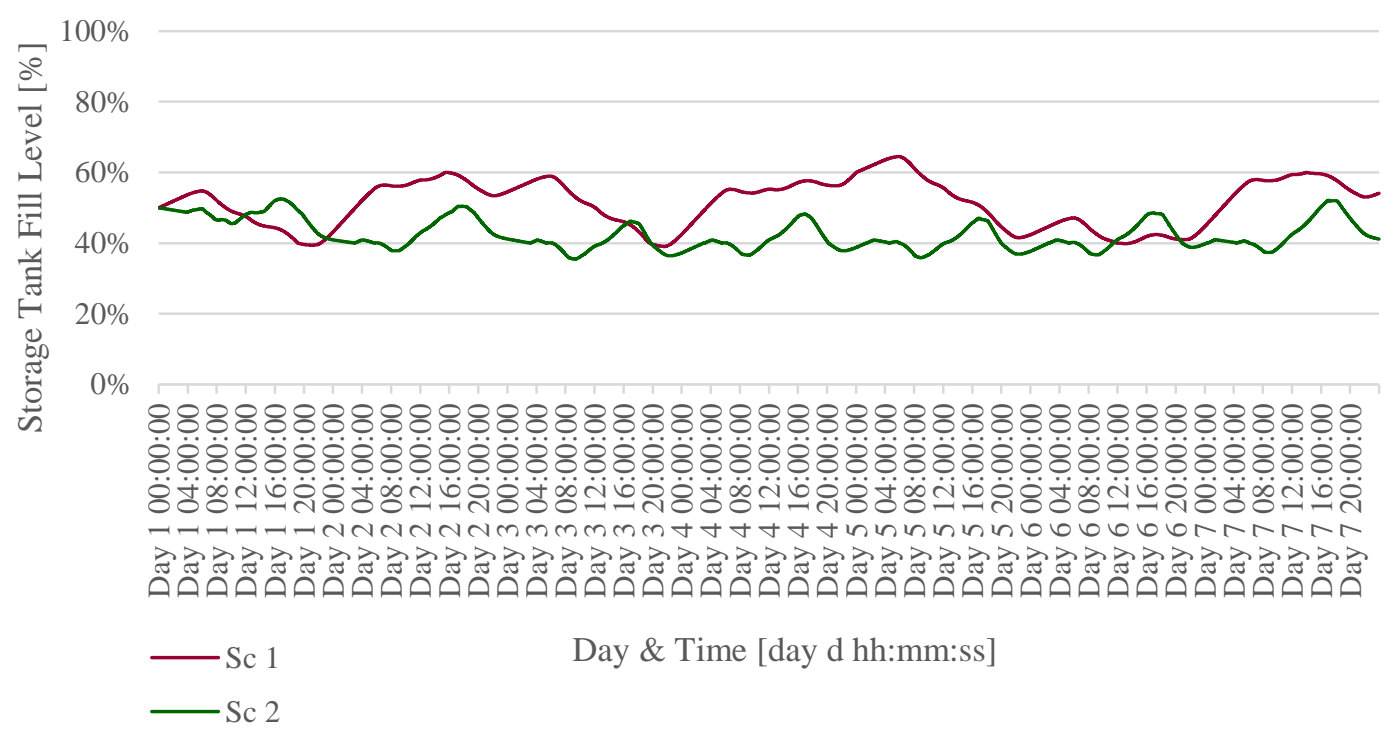

Figure 80: Comparative evaluation - Storage tank fill level, own figure

Due to the more flexible operation schedule in scenario Sc 2, the storage tank fill level can be kept in a narrower range than in the reference scenario. The difference between the highest and lowest fill level for scenario Sc 1 and Sc 2 is $25.43 \%$ and $17.10 \%$, respectively.

While this outcome was not expected, it is favorable for scenario Sc 2 and indicates are more constant pressure in the distribution system. Despite the narrower range, the mean fill level in the storage tank is lower in total. This reduces the overall pressure in the distribution system and thus reduces the potential for cracks and leakages. Figure 81 shows the pressure level at Hillside Hall during the simulation run. 


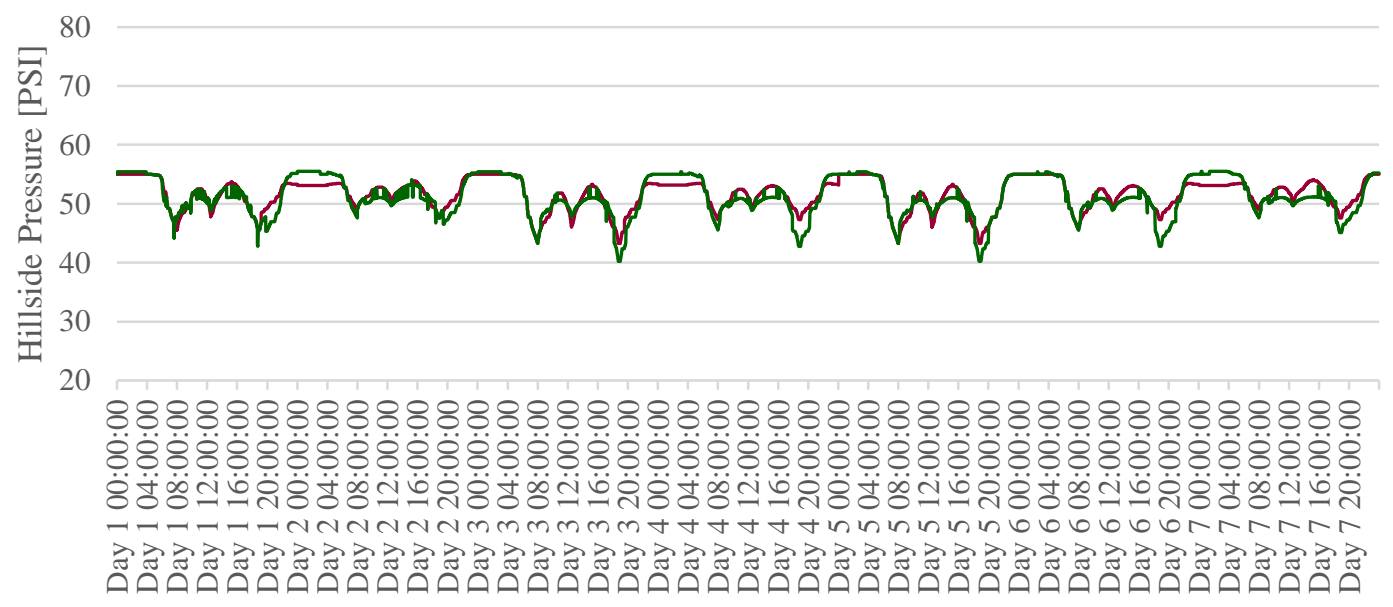

$-\operatorname{Sc} 1$

Day \& Time [day d hh:mm:ss]

Figure 81: Comparative evaluation - Pressure level at Hillside Hall, own figure

As mentioned above, the pressure level is dependent on the storage tank fill level. Figure 81 shows, that the pressure in scenario Sc 2 is mostly below the pressure in scenario Sc 1, confirming the interpretation of the storage tank fill level. Still, it does exceed the pressure level of Sc 1 during several shorter periods. The mean pressure level in scenario Sc 1 and scenario Sc 2 are 51.58 psi and 51.25 psi, respectively. The change of the pressure level through the implementation of demand side management measures is marginal and can thus be considered insignificant.

Despite the pressure level and the flow rate, the third important parameter to evaluate the physical water integrity is the water retention time. A sample residence hall is chosen to represent the retention time in the system. As the water demand is not changed from scenario Sc 1 to scenario Sc 2, one sample residence hall can be used to evaluate and compare the retention time. The behavior of the sample batches or 
molecules is explained in section 3.2.2.5, including the FIFO approach to evaluate the retention time. The retention time of both scenarios is visualized in Figure 82.

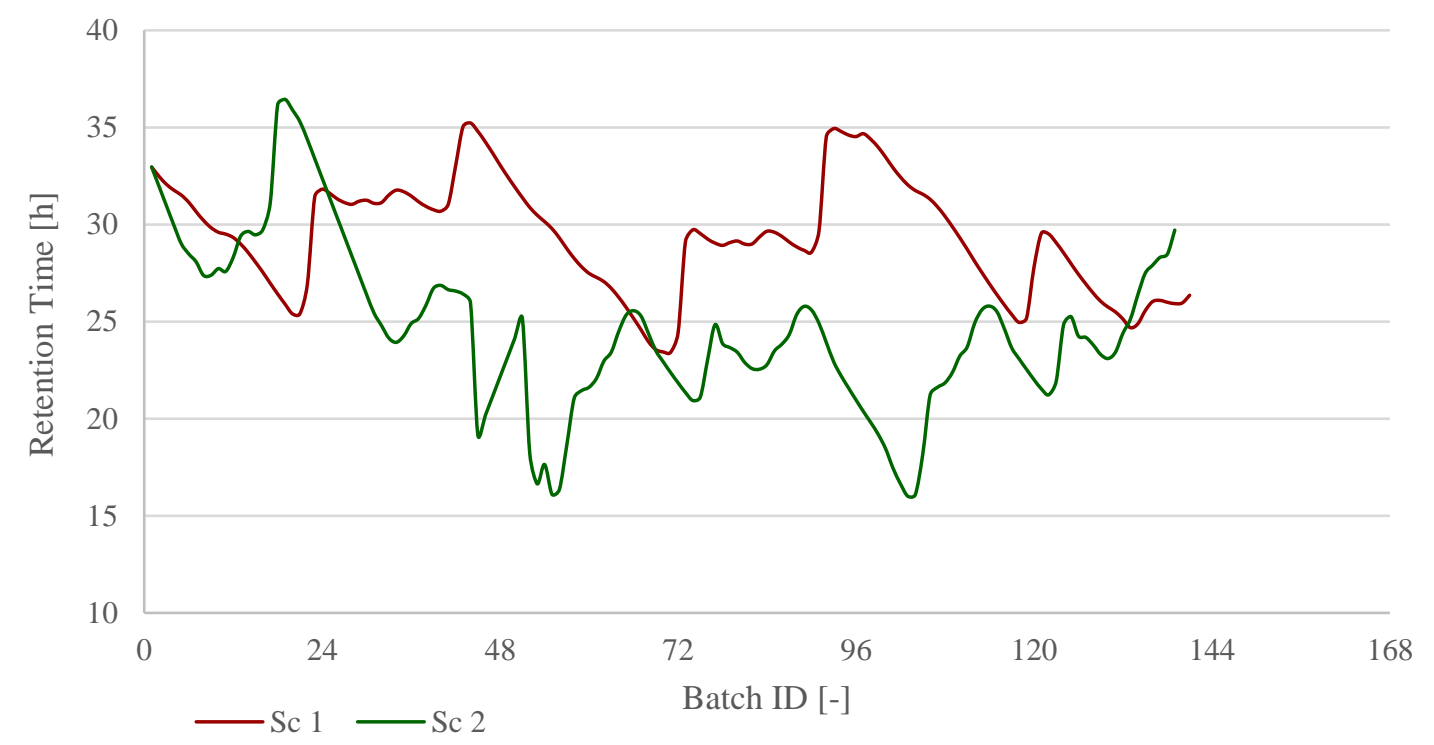

Figure 82: Comparative evaluation - Retention time of sample water batches, own figure

Scenario Sc 2 shows a lower retention time in the water system on average. The shape of the graphs depends on the specific and dynamic velocity of both all pipes that connect the water source and sink as well as the discharge rate of the storage tank. High retention times usually occur during night, when the demand and thus the discharge rate in the storage tank are very low. The next batch is already closer to the morning peak and takes less time to travel through the system. This explains the graph shape at e.g. batch 90 - batch 103, Sc 2 .

Due to the high volume of the storage tank, most of the retention time occurs during the FIFO-based flow through the storage tank. In scenario Sc 1, the share of the time spent in the storage tank compared to the total time spent in the system is $93.7 \%$. The lower average fill level of the storage tank in scenario Sc 2 reduce the time that 
the sample batches spend in the storage tank. The share of the time spent in the tank compared to the total retention time in scenario Sc 2 is $88.3 \%$. The average retention time in the distribution system in the scenarios Sc 1 and Sc 2 are 29.35 hours and 24.66 hours, respectively.

Contrary to the apprehension that the DSM measures would lead to a significant increase of the retention time, this result shows that the implementation of a variable renewable energy oriented, flexible operation schedule might actually be favorable regarding physical water integrity parameters.

The final water related key performance indicator is the number of switches of the three water pumps. Figure 74 and Figure 78 have already included the number of pump switches translated into a power demand and water supply graph, respectively. While the figures show more flexible behavior of the operation schedule in scenario Sc 2, they do not include the total number of switches of the three water pumps. Figure 83 shows the total number of pump switches for all three pumps and the two scenarios. 


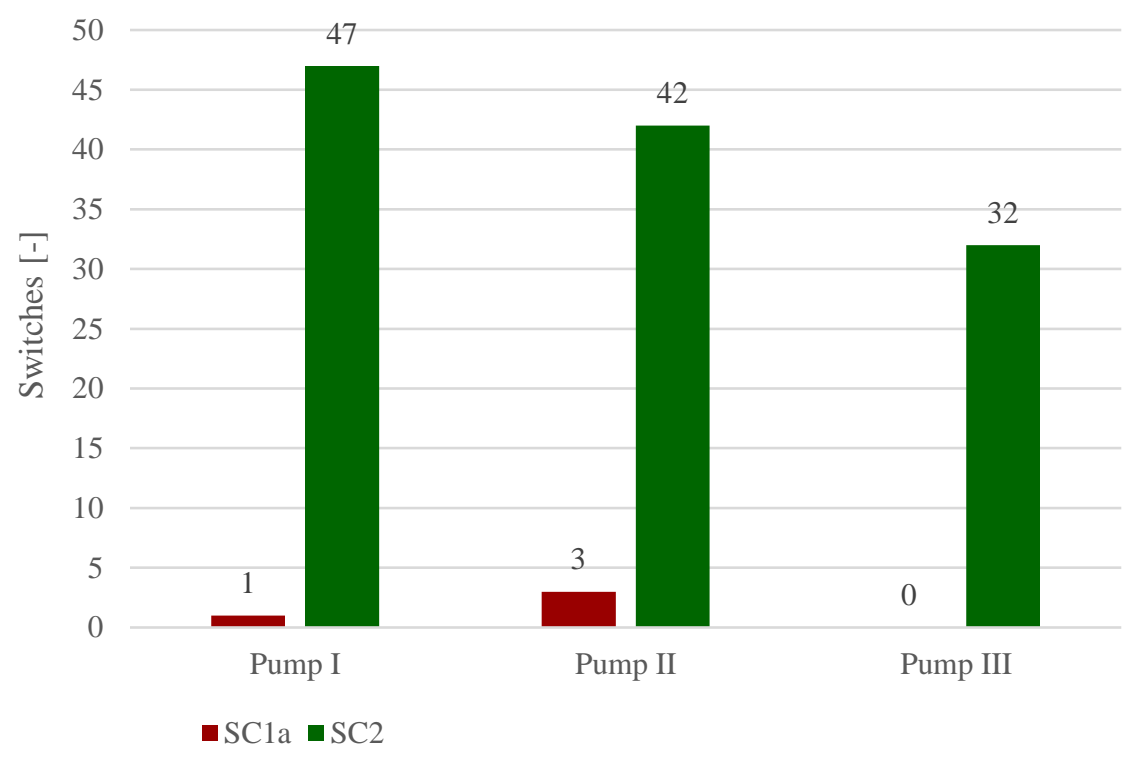

Figure 83: Comparative evaluation - Total number of pump switches, own figure

The number of switches increases dramatically. With an average increase of 39 switches, the pumps are activated approximately 30 times more often than in scenario Sc 1. This may cause significant mechanical wear of the pumps as well as impacts on the pressure in the water system. Due to the hydraulic complexity of non-stationary flow and implicit calculations, the impact of sudden increases or reductions in water pressure caused by shutting off or switching on the pumps could not be considered in this study. Additionally, the process stages of the pumps are solely distinguished into the states off and on. Potential power peaks during the ramp-up of the pumps are not considered. The summary of the water related results of the scenario comparison is provided in Table 9. 
Table 9: Comparative evaluation - Summary of water related results

\begin{tabular}{c|c|c|c|c} 
KPI & Unit & Sc 1 & Sc 2 & $\Delta$ to Sc 1b \\
\hline Min storage tank fill level & {$[\%]$} & 39.06 & 35.43 & $-9.3 \%$ \\
\hline Mean storage tank fill level & {$[\%]$} & 51.31 & 42.36 & $-17.4 \&$ \\
\hline Max storage tank fill level & {$[\%]$} & 64.49 & 52.52 & $-18.6 \%$ \\
\hline Min pressure & {$[\mathrm{psi}]$} & 43.29 & 40.22 & $-7.1 \%$ \\
\hline Mean pressure & {$[\mathrm{psi}]$} & 51.58 & 51.25 & $-0.6 \%$ \\
\hline Max pressure & {$[\mathrm{psi}]$} & 55.02 & 55.48 & $+0.8 \%$ \\
\hline Min water retention time & {$[\mathrm{h}]$} & 23.42 & 16.00 & $-31.7 \%$ \\
\hline Mean water retention time & {$[\mathrm{h}]$} & 29.35 & 24.66 & $-15.98 \%$ \\
\hline Max water retention time & {$[\mathrm{h}]$} & 35.23 & 36.45 & $-3.3 \%$ \\
\hline Total number of pump \\
switches
\end{tabular}

While most of the key performance indicators could be improved in scenario Sc 2 compared to Sc 1, the maximum pressure in the system was increased slightly. The most negative, but also a predicted effect is the significant increase in the total number of pump switches. Interestingly, he KPI categories mean water retention time, mean storage tank fill level and mean system pressure could be improved by introducing variable renewable energies and an energy flexible operation schedule. 


\section{CONCLUSION}

In this chapter, the results of this study are summarized and discussed. The major findings from the comparative evaluation of the proposed future scenario and the reference scenario are the focus of the discussion. In section 5.2, the limitation of the study are propounded with a focus on the level of abstraction of the simulation model and resulting assumptions that were made to successfully model the case study. Finally, an outlook is given towards how the results of this study can be used in the physical system and how the research in the field of energy flexibility in water supply systems can be continued.

\subsection{Summary and Discussion}

In this study, the potential of a water supply system to increase the utilization of variable renewable energy was assessed. The objective was to reduce the carbonintensity of the water supply and to reduce the dependency on grid electricity, while maintaining the physical integrity of the water within the system. Three scenarios were evaluated regarding their energy related and water related key performance indicators. The comparative study included the scenarios

Sc 1a, a reference scenario, which represents an abstracted version of the currently existing water supply system at the University of Rhode Island,

Sc $1 b$, the reference scenario including the potential of integrating on-site variable renewable energy and 
Sc 2, a potential future scenario including the integration of on-site variable renewable energy as well as an adapted energy-flexible operation schedule of the water supply system using demand side management measures.

The scenarios were modelled and continuously refined to provide an adequate level of modelling abstraction. Subsequently, the simulation runs were conducted, and the results were visualized and interpreted. The integration of renewable energy alone enabled the water supply system to operate at a degree of energy self-sufficiency of 48 $\%$, resulting in a reduction of $43 \%$ in $\mathrm{CO}_{2}$-emissions. By introducing an energyflexible operation schedule of the water supply system, the utilization of currently available renewable energy could be increased further. The degree of energy selfsufficiency could be increased to $78.5 \%$, cutting carbon emissions by more than two thirds compared to the reference scenario.

Included in the hypothesis of this study was the objective to keep the negative impacts on the physical water integrity to a minimum. The apprehensions, that the novel operating schedule might result in an increased average system pressure and increased retention time of the water within the distribution system have been confounded. The average system pressure did not change significantly (-0.6\%) and the water retention time could be reduced by $16 \%$. The major negative impact resulting from the adapted operation schedule was the increased total number of pump switches. While in the reference scenario, the total number of switches was four, it was 121 in the proposed future scenario. 
This study shows the potential of energy flexibility measures to increase the utilization of variable renewable energies. Applying these measures to a water supply system adds more load shifting potential within energy systems with high shares of fluctuating renewable energy. Overcoming the hurdle to adapt energy demand to a fluctuating energy supply, the potential of this study can be applied on different scales from decentralized, energy self-sufficient communities to large interconnected energy and water supply systems.

\subsection{Limitations of the Study}

The results of this study are not based on physical experiments or the application of the DSM measures and integration of variable renewable energy into the physically existing system. The study assesses a digital twin model of the physical twin model and is thus subject to a certain degree of modelling abstraction. The temporal resolution of one minute of the simulation model is comparatively high, but the simulation duration is limited to one week. Especially regarding the dimensioning of variable renewable energy supply, seasonal fluctuation has an important impact on the performance of the proposed measures and is likely to negatively influence the study results.

Additionally, this study is based on the campus layout, resident populations and water supply system data of the University of Rhode Island but it does not necessarily represent the physical water supply system of the URI water district. Instead, the model represents a potential community, which is based on the available data about the University of Rhode Island campus. The water demand is characterized by a typical 
daily routine of campus residents and does not include additional water use for laboratory facilities, dining halls, swimming halls and additional entities based on campus.

The study includes hydraulic modelling of non-stationary incompressible pipe flows. Due to the computation complexity of implicit equations, the hydraulic model on which this study is based includes approximations commonly used to avoid solving implicit equations. The level of abstraction of the study includes hydraulic and energetic aspects that have been considered insignificant for the comparison of the scenarios, such as minor head losses in the supply system and short-term power demand peaks due to pump ramp-ups.

\subsection{Outlook}

The comparative study of the utilization of renewable energies using energy flexibility measures in water supply system builds a foundation for potentially significant future water-energy nexus research. Contrary to the traditional approach to increase the efficiency of energy consuming entities, this study focuses on the potential of flexibility, which can only be achieved by allowing system entities to react to both lack of power and excess power.

The simulation model was purposely built to allow a user to change the simulation scenarios easily. Data from other cases can be connected to the simulation model with minor data preparation needed. One potential future focus will be to assess the seasonal variability of renewable energy generation and the resulting impacts on the performance of the proposed approach. This could be achieved by using the same 
temporal resolution with sample data from different seasons or by reducing the temporal resolution of the simulation steps and thus enable the model to simulate the time frame of a whole year or for a climatological monthly scenario. The latter is assumed to be unfavorable, as the system operates at a very high temporal resolution, which would reduce the accuracy and increase the level of abstraction of the simulation model. The model will be continuously refined to make it more userfriendly and interactive. Due to data acquisition restriction from the URI water supply system, a future focus based on this study should be to continuously gain more valid information and data about the distribution system of the URI water district.

This study focusses on the environmental assessment of the proposed approach. Future studies on energy flexibility in water supply systems should provide a holistic perspective, including an economic assessment, the assessment of more environmental impact categories, including carbon emission footprints, and the evaluation of the long-term performance of the proposed approach.

Lastly, one proposed outcome of the continuous work on the study subject is to create a simulation model which is connected to a live database. Live renewable energy power generation data and live water demand data could be used as a data source to continuously feed the simulation model. During the simulation, the model can be used as a graphical user interface to trigger actions as well as to visualize and evaluate the current performance and to compare different operation and energy supply scenarios and encourage improvement practices. 


\section{LIST OF REFERENCES}

(1) United Nations. Global Issues - Climate Change https://www.un.org/en/sections/issues-depth/climate-change/ (accessed Jul 10, 2020).

(2) IPCC. Summary for Policymakers. Global Warming of $1.5^{\circ}$ C. An IPCC Special Report on the Impacts of Global Warming of $1.5{ }^{\circ} \mathrm{C}$ above Pre-Industrial Levels.; 2018. https://doi.org/10.1017/CBO9781107415324.

(3) Lindsey, R.; Climate.gov; NOAA National Centers for Environmental information; ESCI. Understanding Climate - Climate Change: Atmospheric Carbon Dioxide https://www.climate.gov/news-features/understandingclimate/climate-change-atmospheric-carbon-dioxide (accessed Oct 7, 2020).

(4) Simmon, R.; NASA Goddard Institue for Space Studies; NOAA National Climatic Data Center; Met Office Hadley Centre/Climatic Research Unit; Japanses Metorologic Agency. Global Temperature Anomaly, 1880-2013 https://earthobservatory.nasa.gov/images/82908/global-temperature-anomaly18802013 (accessed Jul 10, 2020).

(5) Center For Climate and Energy Solutions; World Resources Institute. Climate Basics, Energy/Emission Data - Global Emissions https://www.c2es.org/content/international-emissions/ (accessed Jul 10, 2020).

(6) Skone, T. J.; U.S. Energy Information Administration. Life Cycle Greenhouse 
Gas Emissions: Natural Gas and Power Production. In Proceedings of the 2015 EIA Energy Conference, Washington, D.C.; 2015.

(7) Spiecker, S.; Weber, C. The Future of the European Electricity System and the Impact of Fluctuating Renewable Energy - A Scenario Analysis. Energy Policy 2014. https://doi.org/10.1016/j.enpol.2013.10.032.

(8) United Nations. UN Sustainable Development Goals - Goal 7: Ensure access to affordable, reliable, sustainable and modern energy https://www.un.org/sustainabledevelopment/energy/ (accessed Oct 11, 2019).

(9) United Nations. UN Sustainable Development Goals: Goal 13 - Take urgent action to combat climate change and its impacts https://www.un.org/sustainabledevelopment/climate-change/ (accessed Oct 11, 2019).

(10) Hanke, S. H. Pricing Urban Water. Public Prices Public Prod. 1972, Washinton.

(11) National Research Council. Drinking Water Distribution Systems: Assessing and Reducing Risks; 2007. https://doi.org/10.17226/11728.

(12) US Environmental Protection Agency. Summary of the Clean Water Act. United States Envitonmental Protection Agency. 1972.

(13) Robbins, P. Safe Drinking Water Act (SDWA). In Encyclopedia of Environment and Society; 2014. https://doi.org/10.4135/9781412953924.n941.

(14) US Environmental Protection Agency. Water Sense - An EPA Partnership Program - Our Water - Tomorrow and Beyond 
https://19january2017snapshot.epa.gov/www3/watersense/our_water/tomorrow _beyond.html (accessed Nov 18, 2019).

(15) US Environmental Protection Agency. The Clean Water and Drinking Water Infrastructure Gap Analysis. EPA-816-R-02-020. EPA816R02020. 2002.

(16) Water in the West. Water Energy Nexus: Literature Review; 2008.

(17) U.S. Energy Information Administration. Renewable energy explained https://www.eia.gov/energyexplained/renewable-sources/ (accessed Mar 4, 2020).

(18) WCED. Our Common Future (The Brundtland Report); 1987. https://doi.org/10.1080/07488008808408783.

(19) Purvis, B.; Mao, Y.; Robinson, D. Three Pillars of Sustainability: In Search of Conceptual Origins. Sustain. Sci. 2019. https://doi.org/10.1007/s11625-0180627-5.

(20) O’Neill, D. W.; Fanning, A. L.; Lamb, W. F.; Steinberger, J. K.; Rockström, J. Bounding the Planetary Future: Why We Need a Great Transition. https://doi.org/10.1038/s41893-018-0021-4.

(21) Metzner-Szigeth, A. Strategies for Eco-Social Transformation: Comparing Efficiency, Sufficiency and Consistency. In Proceedings of the LeNS Conference; 2019.

(22) Huber, J. Towards Industrial Ecology: Sustainable Development as a Concept of Ecological Modernization. J. Environ. Policy Plan. 2000. 
https://doi.org/10.1080/714038561.

(23) Figge, F.; Young, W.; Barkemeyer, R. Sufficiency or Efficiency to Achieve Lower Resource Consumption and Emissions? The Role of the Rebound Effect. J. Clean. Prod. 2014. https://doi.org/10.1016/j.jclepro.2014.01.031.

(24) Lamberton, G. Sustainable Sufficiency - An Internally Consistent Version of Sustainability. Sustain. Dev. 2005. https://doi.org/10.1002/sd.245.

(25) Shaheen, S.; Cohen, A.; Farrar, E. Carsharing's Impact and Future. In Advances in Transport Policy and Planning; 2019. https://doi.org/10.1016/bs.atpp.2019.09.002.

(26) Fraiberger, S. P.; Sundararajan, A. Peer-to-Peer Rental Markets in the Sharing Economy. SSRN Electron. J. 2015. https://doi.org/10.2139/ssrn.2574337.

(27) Hauschild, M. Z.; Rosenbaum, R. K.; Olsen, S. I. Life Cycle Assessment: Theory and Practice; 2017. https://doi.org/10.1007/978-3-319-56475-3.

(28) European Commission -- Joint Research Centre -- Institute for Environment and Sustainability. International Reference Life Cycle Data System (ILCD) Handbook -- General Guide for Life Cycle Assessment -- Detailed Guidance; 2010. https://doi.org/10.2788/38479.

(29) Holdren, J. P.; Ehrlich, P. R. Human Population and the Global Environment. Am. Sci. 1974.

(30) Commoner, B. Economic Growth and Ecology - a Biologist's View. Popul. Resour. Evironment 1972, 94 (11), 3-13. 
(31) Kaya, Y.; Yokobori, K. Environment, Energy, and Economy: Strategies for Sustainability; United Nations University Press: New York, 1997.

(32) US Geological Survey; Perlman, H.; Evans, J. The Water Cycle (Natural water cycle) https://www.usgs.gov/media/images/water-cycle-natural-water-cycle (accessed Jul 13, 2020).

(33) Hilborn, R.; Walters, C. J.; Ludwig, D. Sustainable Exploitation of Renewable Resources. Annual Review of Ecology and Systematics. 1995. https://doi.org/10.1146/annurev.es.26.110195.000401.

(34) von Carlowitz, H. C. Sylvicultura Oeconomica; Leipzig, 1732.

(35) Winter, T. C.; Harvey, J. W.; Franke, O. L.; Alley, W. M. Ground Water Surface Water and A Single Resource; 1998.

(36) Alley, William M.; Reilly, Thomas E.; Franke, O. L.; U.S. Geological Survey. Sustainability of Ground-Water Resources, U.S. Geological Survey Circular $1186 ; 1999$.

US Geological Survey. Total Water Use in the United States https://www.usgs.gov/special-topic/water-science-school/science/total-wateruse-united-states?qt-science_center_objects=0\#qt-science_center_objects (accessed Dec 12, 2019).

(38) Zhao, G.; Gao, H. Estimating Reservoir Evaporation Losses for the United States: Fusing Remote Sensing and Modeling Approaches. Remote Sens. Environ. 2019. https://doi.org/10.1016/j.rse.2019.03.015. 
(39) Eker, I.; Kara, T. Operation and Control of a Water Supply System. ISA Trans. 2003. https://doi.org/10.1016/S0019-0578(07)60147-5.

(40) Walski, Thomas M.; Chase, Donald V.; Savic, D. A. Water Distribution Modeling; Haestad Press: Waterbury, CT, 2001.

(41) Mazumder, R. K.; Salman, A. M.; Li, Y.; Yu, X. Performance Evaluation of Water Distribution Systems and Asset Management. Journal of Infrastructure Systems. 2018. https://doi.org/10.1061/ (ASCE)IS.1943-555X.0000426.

(42) Public Water Corporation; Ministry of Irrigation and Water Resources of Sudan. Technical Guidelines for the Construction and Management of Drinking Water Distribution Networks - A Manual for Field Staff and Praticioners; 2009. van Zyl, J. Introduction to Operation and Maintenance of Water Distribution Systems; 2014.

(44) Parrondo, J. L.; Velarde, S.; Santolaria, C. Development of a Predictive Maintenance System for a Centrifugal Pump. J. Qual. Maint. Eng. 1998. https://doi.org/10.1108/13552519810223490.

(45) Dyckhoff, H. Betriebliche Produktion - Theoretische Grundlagen Einer Umweltorientierten Produktionswirtschaft; Springer-Verlag berlin Heidelberg, 1994. https://doi.org/10.1007/978-3-642-57959-2.

(46) Stokes, C. S.; Simpson, A. R.; Maier, H. R. A Computational Software Tool for the Minimization of Costs and Greenhouse Gas Emissions Associated with Water Distribution Systems. Environ. Model. Softw. 2015. 
https://doi.org/10.1016/j.envsoft.2014.11.004.

(47) Walski, T. M.; Chase, D. V.; Savic, D. A.; Grayman, W.; Beckwith, S.; Koelle, E. Advanced Water Distribution Modeling and Management. Methods 2003. https://doi.org/10.3844/ajassp.2012.1974.1978.

(48) State of Rhode Island Division of Public Utilities and Carriers. Rules as Regulations Prescribing Standards for Water Utilities; 2008.

(49) Volk, M. Pump Characteristics and Applications; 2013. https://doi.org/10.1201/b15559.

(50) Brown, G. O. The History of the Darcy-Weisbach Equation for Pipe Flow Resistance. In Proceedings of the Environmental and Water Resources History; 2002. https://doi.org/10.1061/40650(2003)4.

(51) Ferro, M. Experimental Study on Turbulent Pipe Flow, KTH Mechanics, Royal Institute of Technology Stockholm, 2012.

(52) Lang, Cornelia; Stache, N. Hydraulik von Rohrsystemen, Karlsruher Intitut für Technologie, 2010.

(53) Surek, D.; Stempin, S. Technische Strömungsmechanik; 2014. https://doi.org/10.1007/978-3-658-06062-6.

(54) Stewart, M.; Arnold, K. Surface Production Operations. Volume III, Facility Piping and Pipeline Systems; 2015.

Menon, E. S. Liquid Pipeline Hydraulics; 2004. https://doi.org/10.1201/9780203021385. 
(56)

WorldAtlas. $\quad$ Rhode $\quad$ Island Precipitation $\quad$ Map https://www.worldatlas.com/webimage/countrys/namerica/usstates/weathermap s/riprecip.htm (accessed Nov 19, 2019).

(57) Rhode Island Department of Administration, D. of P. Rhode Island Water 2030 Management of Drinking Water Supply Resources in the State of Rhode Island; 2012.

(58) Rhode Island Water Resources Board. Water Suppliers - District Maps http://www.wrb.ri.gov/data_watersuppliers.html (accessed Jul 5, 2020).

(59) U.S. Department of Commerce; Economics and Statistics Administration; U.S. Census Bureau. 2010 Census: Rhode Island Profile - Population Density by Census Tract; 2019.

(60) Rhode Island Department of Administration; Division of Planning. Water Quality 2035 - Rhode Island Water Quality Management Plan; 2016.

(61) United States Geological Survey; United States Department of the Interior. Water Availability and Use Science Program - Estimated Use of Water in the United States in 2015; 2015.

(62) Kenway, S. J.; Lam, K. L. Quantifying and Managing Urban Water-Related Energy Use Systemically: Case Study Lessons from Australia. Int. J. Water Resour. Dev. 2016. https://doi.org/10.1080/07900627.2015.1132195.

(63) Wakeel, M.; Chen, B.; Hayat, T.; Alsaedi, A.; Ahmad, B. Energy Consumption for Water Use Cycles in Different Countries: A Review. Applied Energy. 2016. 
https://doi.org/10.1016/j.apenergy.2016.06.114.

(64) Schwarzwald Energy. Stromerzeugung - Kohlekraftwerk https://www.schwarzwald-energy.de/kohlekraftwerke.html (accessed May 7, 2020).

(65) Umweltbundesamt. Konventionelle Kraftwerke und Erneuerbare Energien https://www.umweltbundesamt.de/daten/energiebereitstellungverbrauch/konventionelle-kraftwerke-erneuerbare-energien\#textpart-2 (accessed May 7, 2020).

(66) U.S. Energy Information Administration. Nuclear explained - Nuclear power plants https://www.eia.gov/energyexplained/nuclear/nuclear-power-plants.php (accessed May 7, 2020).

(67) Japan Ministry of the Environment. Progress on Off-Site Clean up Efforts in Japan; 2013.

(68) Kiefer, H.; Koelzer, W. Strahlen Und Strahlenschutz - Vom Verantwortungsbewussten Umgang Mit Dem Unsichtbaren, 2nd ed.; Springer, Berlin / Heidelberg, 1987.

(69) BGS Minerals UK; Centre for sustainable mineral development. What is the $\begin{array}{llll}\text { difference between } & \text { resources and reserves? }\end{array}$ https://www.bgs.ac.uk/mineralsuk/mineralsYou/resourcesReserves.html (accessed May 7, 2020).

(70) Bundesverband Erdgas Erdöl und Geoenergy e.V. Reichweite fossiler Rohstoffe 
https://www.bveg.de/Erdgas/Rohstoffe/Reichweite-fossiler-Rohstoffe (accessed May 7, 2020).

(71) Bundesanstalt für Geowissenschaften und Rohstoffe. Energy Study 2016. Reserves, Resources and Availability of Energy Resources. Reserv. Resour. Availab. Energy Resour. 2016.

(72) Dincer, I. Comprehensive Energy Systems; Oliver Walter, 2018.

(73) Edenhofer, O.; Pichs-Madruga, R.; Sokona, Y.; Seyboth, K.; Eickemeier, P.; Matschoss, P.; Hansen, G.; Kadner, S.; Schlömer, S.; Zwickel, T.; et al. IPCC, 2011: Summary for Policymakers. In: IPCC Special Report on Renewable Energy Sources and Climate Change Mitigation; 2011. https://doi.org/10.5860/CHOICE.49-6309.

(74) Deconinck, G.; Thoelen, K. Lessons From 10 Years of Demand Response Research: Smart Energy for Customers? IEEE Syst. Man, Cybern. Mag. 2019, 5 (3), 21-30. https://doi.org/10.1109/MSMC.2019.2920160.

(75) Snurr, R.; Freude, D. Energy Fundamentals - Physics of Wind Turbines https://home.uni-leipzig.de/energy/energy-fundamentals/15.htm (accessed May 7, 2020).

(76) US Energy Information Administration. Electric Power Monthly, Data for April 2020 https://www.eia.gov/electricity/monthly/ (accessed May 7, 2020).

(77) Arvizu, D.; Balaya, P.; Cabeza, L.; Hollands, T.; Jäger-Waldau, A.; Kondo, M.; Konseibo, C.; Meleshko, V.; Stein, W.; Tamaura, Y.; et al. Direct Solar Energy. 
In IPCC Special Report on Renewable Energy Sources and Climate Change Mitigation; Edenhofer, O., Pichs-Madruga, R., Sokona, Y., Seyboth, K., Matschoss, P., Kadner, S., Zwickel, T., Eickemeier, P., Hansen, G., Schlömer, S., et al., Eds.; Cambridge University Press, Cambridge, United Kingdom and New York, NY, USA, 2011.

(78) National Renewable Energy Laboratory; Roberts, B. J. Geospatial Data Science - Solar Resource Data, Tools, and Maps https://www.nrel.gov/gis/solar.html (accessed Jun 23, 2020).

(79) Perez, R.; David, M.; Hoff, T. E.; Jamaly, M.; Kivalov, S.; Kleissl, J.; Lauret, P.; Perez, M. Spatial and Temporal Variability of Solar Energy. Found. Trends ${ }^{\circledR}$ Renew. Energy 2016. https://doi.org/10.1561/2700000006.

(80) Institute of Machine Tools and Production Technology. Wind Turbine and Photovoltaic Power Plant; 2017.

(81) Hammer, A.; Beyer, H. G. Solar Radiation, Spatial and Temporal Variability. In Encylopedia of Sustainability Science and Technology; Meyer, R. A., Ed.; Springer, New York, NY, 2012.

(82) US Energy Information Administration. Rhode Island Profile - State Profile and Energy Estimates https://www.eia.gov/state/?sid=RI\#tabs-4 (accessed Oct 11, 2019).

(83) Rhode Island Office of Energy Resources. Renewable Energy Standard (2004) http://www.energy.ri.gov/policies-programs/ri-energy-laws/renewable-energystandard-2004.php (accessed Oct 11, 2019). 
(84) U.S. Energy Information Administration. International Energy Outlook 2020 with Projections to 2050. Choice Rev. Online 2020. https://doi.org/10.5860/CHOICE.44-3624.

(85) U.S. Energy Information Administration. What is U.S. electricity generation by energy source? https://www.eia.gov/tools/faqs/faq.php?id=427\&t=3 (accessed Mar 5, 2020).

Proctor, D. Rhode Island Rejects Burrillville Gas-Fired Plant https://www.powermag.com/rhode-island-rejects-burrillville-gas-fired-plant/ (accessed Oct 12, 2019).

(87) State of Rhode Island Office of Energy Resources. Governor's 1,000 by '20 Clean Energy Goal http://www.energy.ri.gov/renewable-energy/governor-cleanenergy-goal.php (accessed Dec 14, 2019).

(88) Intergovernmental Panel on Climate Change. Technology-Specific Cost and Performance Parameters;

2015. https://doi.org/10.1017/cbo9781107415416.025.

(89) Brown University. Solar and wind energy projects expected to offset 100 percent of Brown's on-campus electricity use https://www.brown.edu/news/2019-01-17/renewable (accessed Nov 13, 2019).

(90) University of Rhode Island Department of External Relations and Communications. URI-town consortium turns former disposal industrial sites into solar farms https://today.uri.edu/news/uri-town-consortium-turns-formerdisposal-industrial-sites-into-solar-farms/ (accessed Nov 13, 2019). 
(91) Popovich, N.; The New York Times. How Does YourState Make Electricity? https://www.nytimes.com/interactive/2018/12/24/climate/how-electricitygeneration-changed-in-your-state.html (accessed Jul 10, 2020).

(92) Rhode Island Department of Administration; Division of Planning. Energy 2035 - Rhode Island State Energy Plan. 2015.

(93) Yoo, D. G.; Suh, M. Y.; Kim, J. H.; Jun, H.; Chung, G. Subsystem-Based Pressure Dependent Demand Analysis in Water Distribution Systems Using Effective Supply. KSCE J. $\quad$ Civ. $\quad$ Eng. 2012, 16 (3), 457-464. https://doi.org/10.1007/s12205-012-1448-1.

(94) US Energy Information Administration. Rhode Island Electricity Profile 2017 Summary Statistics https://www.eia.gov/electricity/state/rhodeisland/ (accessed Dec 14, 2019).

(95) Kuffner, A. R.I. says clean energy plan falls short https://www.providencejournal.com/news/20190728/ri-says-clean-energy-planfalls-short (accessed Dec 14, 2019).

(96) Ørsted U.S. Offshore Wind. Rhode Island Regulators Approve Revolution Wind Power Contract https://us.orsted.com/News-Archive/2019/05/Rhode-IslandRegulators-Approve-Revolution-Wind-Power-Contract (accessed Dec 14, 2019).

(97) Kuffner, A. Deepwater Wind to invest $\$ 250$ million in Rhode Island to build utility-scale offshore wind farm https://www.providencejournal.com/news/20180530/deepwater-wind-to-invest- 
250-million-in-rhode-island-to-build-utility-scale-offshore-wind-farm (accessed Dec 14, 2019).

(98) Solar Energy Industries Association. Major Solar Projects List https://www.seia.org/research-resources/major-solar-projects-list (accessed Dec 14, 2019).

(99) Gleick, P. H. Water and Energy. Annu. Rev. Energy Environ. 1994, 19, 267-299.

(100) Liu, J.; Mei, C.; Wang, H.; Shao, W.; Xiang, C. Mutual Adaptability of Renewable Energy and Water-Supply Systems in Islands. Energy Procedia 2017, 105, 799-804. https://doi.org/10.1016/j.egypro.2017.03.392.

(101) Santana, M. V. E.; Zhang, Q.; Mihelcic, J. R. Influence of Water Quality on the Embodied Energy of Drinking Water Treatment. 2014.

(102) Ramos, H. M.; Vieira, F.; Covas, D. I. C. Energy Efficiency in a Water Supply System : Energy Consumption and CO 2 Emission. Water Sci. Eng. 2010, 3 (3), 331-340. https://doi.org/10.3882/j.issn.1674-2370.2010.03.009.

(103) Horvath, Arpad; Stokes, J. R. Energy and Air Emission Effects of Water Supply. Environ. Sci. Technol. 2009, 43 (8), 2680-2687.

(104) Fooladivanda, D.; Domínguez-garcía, A. D.; Sauer, P. W. Utilization of Water Supply Networks for Harvesting Renewable Energy. Univ. Illinois Dep. Electr. Comput. Eng. 2018.

(105) Meschede, H. Increased Utilisation of Renewable Energies through Demand Response in the Water Supply Sector e A Case Study. Energy 2019, 175, 810- 
817. https://doi.org/10.1016/j.energy.2019.03.137.

(106) Shahabi, M. P.; Mchugh, A.; Anda, M.; Ho, G. Environmental Life Cycle Assessment of Seawater Reverse Osmosis Desalination Plant Powered by Renewable Energy. Renew. Energy 2014, 67, 53-58. https://doi.org/10.1016/j.renene.2013.11.050.

(107) Budris, A. R. Pumped Storage: Using Water Towers, Aquifer Well Pumps to Generate Energy During Peak Demand Periods https://www.waterworld.com/water-utility-management/energymanagement/article/16192848/pumped-storage-using-water-towers-aquiferwell-pumps-to-generate-energy-during-peak-demand-periods (accessed Nov 13, 2019).

(108) Giri, S. K. Design of a Water Tower Energy Storage System, University of Missouri, 2013.

(109) Oikonomou, Konstantinos; Parvania, M.; Burian, S. Integrating Water Distribution Energy Flexibility in Power Systems Operation. IEEE 2017, 1-5.

(110) Gellings, C. W. Evolving Practice of Demand-Side Management. J. Mod. Power Syst. Clean Energy 2017. https://doi.org/10.1007/s40565-016-0252-1.

(111) Gellings, C. W. The Concept of Demand-Side Management for Electric Utilities. Procedings IEEE 1985, 73 (10), 1468-1470.

(112) Koksoy, C. E.; Ozkan, M. B.; Buhan, S.; Demirci, T.; Arslan, Y.; Birturk, A.; Karagoz, P. Improved Wind Power Forecasting Using Combination Methods. In 
Proceedings - 2015 IEEE 14th International Conference on Machine Learning and Applications, ICMLA 2015; 2016. https://doi.org/10.1109/ICMLA.2015.60.

(113) Guo, J.; You, S.; Huang, C.; Liu, H.; Zhou, D.; Chai, J.; Wu, L.; Liu, Y.; Glass, J.; Gardner, M.; et al. An Ensemble Solar Power Output Forecasting Model through Statistical Learning of Historical Weather Dataset. In IEEE Power and $\begin{array}{llll}\text { Energy Society } & \text { General } & \text { Meeting; } & 2016 .\end{array}$ https://doi.org/10.1109/PESGM.2016.7741059.

(114) Bozikowski, B.; University of Rhode Island Services Facilities. Water Supply Management Plan; 2017.

(115) Manwaring, M.; Rodgers, K.; Flake, S.; Erpenbeck, D. Pumped Storage Report; 2018.

(116) Thiede, S.; Juraschek, M.; Herrmann, C. Implementing Cyber-Physical Production Systems in Learning Factories. In Procedia CIRP; 2016. https://doi.org/10.1016/j.procir.2016.04.098.

(117) Rhode Island Department of Health; University of Rhode Island Facilities Operations. Consumer Confidence Report 2019; 2019.

(118) Town of South Kingstown. Town of South Kingstown Web GIS http://gis.southkingstownri.com/webgis/ (accessed Jan 7, 2020).

(119) Rhode Island Water Resources Board. 2012 Strategic Plan; 2012.

(120) ESRI; Digital Globe; GeoEye; i-cubed; USDA FSA; USGS; AEX; Getmapping; Aerogrid; IGN; et al. World Street Map https://www.arcgis.com/index.html 
(accessed Mar 5, 2020).

(121) University of Rhode Island Environmental Data Center; Rhode Island Geographic Information System Consortium. Rhode Island Shaded Relief https://maps.edc.uri.edu/arcgis/rest/services/Atlas_elevation/Shaded_Relief/Ma pServer.

(122) University of Rhode Island Environmental Data Center; Rhode Island Geographic Information System Consortium; US Geological Survey. Statewide

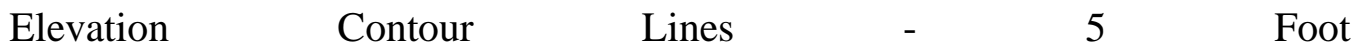
https://maps.edc.uri.edu/rigis/rest/services/TOPO/Contours_05ft_2011_spf/Feat ureServer (accessed Jun 23, 2020).

(123) Pipe Flow Software. Pipe Roughness - Pipe Materials and Common Pipe Roughness Values https://www.pipeflow.com/pipe-pressure-dropcalculations/pipe-roughness (accessed Jun 23, 2020).

(124) Smith, S. A.; Comesky, A. E. Sustainable Wells: Maintenance, Problem Prevention, and Rehabilitation; Taylor \& Francis Inc, 2009.

(125) University of Rhode Island. About: Facts - Students https://www.uri.edu/about/facts/.

(126) University of Rhode Island. Greek Life - Fraternity Circle https://web.uri.edu/greek/fraternity-circle-map/ (accessed Jun 23, 2020).

(127) University of Rhode Island. College of Engineering - International Engineering Program - $\quad$ Living \& $\quad \& \quad$ Learning $\quad$ Community 
https://web.uri.edu/engineering/academics/iep/curriculum/living-learningcommunity/ (accessed Jun 23, 2020).

(128) University of Rhode Island. Housing and Residential Life - Housing Options https://web.uri.edu/housing/housing-options/ (accessed Jun 23, 2020).

(129) Alvisi, S.; Franchini, M.; Marinelli, A. A Short-Term, Pattern-Based Model for Water-Demand $\quad$ Forecasting. $\quad J . \quad$ Hydroinformatics 2007. https://doi.org/10.2166/hydro.2006.016.

(130) Wang, B.; Shi, W.; Miao, Z. Confidence Analysis of Standard Deviational Ellipse and Its Extension into Higher Dimensional Euclidean Space. PLoS One 2015. https://doi.org/10.1371/journal.pone.0118537.

(131) New England Power Pool. Welcome Page - Home http://nepool.com/Home_Page.php (accessed Jul 1, 2020).

(132) National Grid. Rhode Island Disclosure Label February 2020 - Do You Know Where Your Power Comes From?; 2020.

(133) New England Power Pool. Generation Information System - System Mix; 2019.

(134) Schulze, C.; Blume, S.; Siemon, L.; Herrmann, C.; Thiede, S. Towards Energy Flexible and Energy Self-Sufficient Manufacturing Systems. In Procedia CIRP; 2019. https://doi.org/10.1016/j.procir.2019.03.176.

(135) European Commission. EU Science Hub - Photovoltaic Geographical Information System https://re.jrc.ec.europa.eu/pvg_tools/en/tools.html (accessed Jun 12, 2020). 
(136) University of Denmark; World Bank. Global Wind Atlas 3.0, a free, web-based application developed, owned and operated by the Technical University of Denmark (DTU). The Global Wind Atlas 3.0 is released in partnership with the World Bank Group, utilizing data provided by Vortex, using fundi https://globalwindatlas.info/ (accessed May 5, 2020).

(137) Schlömer, S.; Bruckner, T.; Fulton, L.; Hertwich, E.; McKinnon, A.; Perczyk, D.; Roy, J.; Schaeffer, R.; Sims, R.; Smith, P.; et al. Annex III: TechnologySpecific Cost and Performance Parameters. In Climate Change 2014: Mitigation of Climate Change. Contribution of Working Group III to the Fifth Assessment Report of the Intergovernmental Panel on Climate Change; [Edenhofer, O., R. Pichs-Madruga, Y. Sokona, E. Farahani, S. Kadner, K. Seyboth, A. Adler, I. Baum, S. Brunner, P. Eickemeier, B. Kriemann, J. Savolainen, S. Schlömer, C. von Stechow, T. Z. and J. C. M., Ed.; Cambridge University Press, Cambridge, United Kingdom and New York, NY, USA, 2014.

(138) Anylogic. Home https://www.anylogic.com/ (accessed Jun 7, 2020). 


\section{BIBLIOGRAPHY}

Alley, William M.; Reilly, Thomas E.; Franke, O. L., \& U.S. Geological Survey. (1999). Sustainability of Ground-Water Resources, U.S. Geological Survey

Circular 1186. Retrieved from https://pubs.usgs.gov/circ/circ1186/pdf/circ1186.pdf

Alvisi, S., Franchini, M., \& Marinelli, A. (2007). A short-term, pattern-based model for water-demand forecasting. Journal of Hydroinformatics. https://doi.org/10.2166/hydro.2006.016

Anylogic. (2020). Home. Retrieved June 7, 2020, from https://www.anylogic.com/

Arvizu, D., Balaya, P., Cabeza, L., Hollands, T., Jäger-Waldau, A., Kondo, M., ... Zilles, R. (2011). Direct Solar Energy. In O. Edenhofer, R. Pichs-Madruga, Y. Sokona, K. Seyboth, P. Matschoss, S. Kadner, ... C. von Stechow (Eds.), IPCC Special Report on Renewable Energy Sources and Climate Change Mitigation. Cambridge University Press, Cambridge, United Kingdom and New York, NY, USA.

BGS Minerals UK, \& Centre for sustainable mineral development. (2017). What is the difference between resources and reserves? Retrieved May 7, 2020, from https://www.bgs.ac.uk/mineralsuk/mineralsYou/resourcesReserves.html

Bozikowski, B., \& University of Rhode Island Services Facilities. (2017). Water Supply Management Plan.

Brown University. (2019). Solar and wind energy projects expected to offset 100 percent of Brown's on-campus electricity use. Retrieved November 13, 2019, from https://www.brown.edu/news/2019-01-17/renewable 
Brown, G. O. (2002). The history of the Darcy-Weisbach equation for pipe flow resistance. Proceedings of the Environmental and Water Resources History. https://doi.org/10.1061/40650(2003)4

Budris, A. R. (2014). Pumped Storage: Using Water Towers, Aquifer Well Pumps to Generate Energy During Peak Demand Periods. Retrieved November 13, 2019, from WaterWorld website: https://www.waterworld.com/water-utilitymanagement/energy-management/article/16192848/pumped-storage-using-watertowers-aquifer-well-pumps-to-generate-energy-during-peak-demand-periods

Bundesanstalt für Geowissenschaften und Rohstoffe. (2016). Energy Study 2016. Reserves, Resources and Availability of Energy Resources. Reserves, Resources and Availability of Energy Resources.

Bundesverband Erdgas Erdöl und Geoenergy e.V. (2020). Reichweite fossiler Rohstoffe. Retrieved May 7, 2020, from https://www.bveg.de/Erdgas/Rohstoffe/Reichweite-fossiler-Rohstoffe

Center For Climate and Energy Solutions, \& World Resources Institute. (2020). Climate Basics, Energy/Emission Data - Global Emissions. Retrieved July 10, 2020, from https://www.c2es.org/content/international-emissions/

Commoner, B. (1972). Economic Growth and Ecology - a Biologist's View. Population, Resources and the Evironment, 94(11), 3-13.

Deconinck, G., \& Thoelen, K. (2019). Lessons From 10 Years of Demand Response Research: Smart Energy for Customers? IEEE Systems, Man, and Cybernetics Magazine, 5(3), 21-30. https://doi.org/10.1109/MSMC.2019.2920160

Dincer, I. (2018). Comprehensive Energy Systems. Oliver Walter. 
Dyckhoff, H. (1994). Betriebliche Produktion - Theoretische Grundlagen einer umweltorientierten Produktionswirtschaft. https://doi.org/10.1007/978-3-642$57959-2$

Edenhofer, O., Pichs-Madruga, R., Sokona, Y., Seyboth, K., Eickemeier, P., Matschoss, P., ... Stechow, C. Von. (2011). IPCC, 2011: Summary for Policymakers. In: IPCC Special Report on Renewable Energy Sources and Climate Change Mitigation. In Cambridge University Press. https://doi.org/10.5860/CHOICE.49-6309

Eker, I., \& Kara, T. (2003). Operation and control of a water supply system. ISA Transactions. https://doi.org/10.1016/S0019-0578(07)60147-5

ESRI, Digital Globe, GeoEye, i-cubed, USDA FSA, USGS, ... GIS User Community. (2020). World Street Map. Retrieved March 5, 2020, from https://www.arcgis.com/index.html

European Commission. (2020). EU Science Hub - Photovoltaic Geographical Information System. Retrieved June 12, 2020, from https://re.jrc.ec.europa.eu/pvg_tools/en/tools.html

European Commission -- Joint Research Centre -- Institute for Environment and Sustainability. (2010). International Reference Life Cycle Data System (ILCD) Handbook -- General guide for Life Cycle Assessment -- Detailed guidance. In Constraints. https://doi.org/10.2788/38479

Ferro, M. (2012). Experimental Study on Turbulent Pipe Flow. KTH Mechanics, Royal Institute of Technology Stockholm.

Figge, F., Young, W., \& Barkemeyer, R. (2014). Sufficiency or efficiency to achieve lower resource consumption and emissions? the role of the rebound effect. Journal of Cleaner Production. https://doi.org/10.1016/j.jclepro.2014.01.031 
Fooladivanda, D., Domínguez-garcía, A. D., \& Sauer, P. W. (2018). Utilization of Water Supply Networks for Harvesting Renewable Energy. University of Illinois Department of Electrical and Computer Engineering.

Fraiberger, S. P., \& Sundararajan, A. (2015). Peer-to-Peer Rental Markets in the Sharing Economy. SSRN Electronic Journal. https://doi.org/10.2139/ssrn.2574337

Gellings, C. W. (2017). Evolving practice of demand-side management. Journal of Modern Power Systems and Clean Energy. https://doi.org/10.1007/s40565-0160252-1

Gellings, C. W. (1985). The Concept of Demand-Side Management for Electric Utilities. Procedings of the IEEE, 73(10), 1468-1470.

Giri, S. K. (2013). Design of a water tower energy storage system, University of Missouri.

Gleick, P. H. (1994). Water and Energy. Annual Review of Energy and the Environment, 19, 267-299.

Guo, J., You, S., Huang, C., Liu, H., Zhou, D., Chai, J., ... Black, C. (2016). An ensemble solar power output forecasting model through statistical learning of historical weather dataset. IEEE Power and Energy Society General Meeting. https://doi.org/10.1109/PESGM.2016.7741059

Hammer, A., \& Beyer, H. G. (2012). Solar Radiation, Spatial and Temporal Variability. In R. A. Meyer (Ed.), Encylopedia of Sustainability Science and Technology. Springer, New York, NY.

Hanke, S. H. (1972). Pricing Urban Water. Public Prices for Public Products, Washinton. 
Hauschild, M. Z., Rosenbaum, R. K., \& Olsen, S. I. (2017). Life Cycle Assessment: Theory and Practice. In Life Cycle Assessment: Theory and Practice. https://doi.org/10.1007/978-3-319-56475-3

Hilborn, R., Walters, C. J., \& Ludwig, D. (1995). Sustainable exploitation of renewable resources. Annual Review of Ecology and Systematics. https://doi.org/10.1146/annurev.es.26.110195.000401

Holdren, J. P., \& Ehrlich, P. R. (1974). Human population and the global environment. American Scientist.

Horvath, Arpad; Stokes, J. R. (2009). Energy and Air Emission Effects of Water Supply. Environmental Science and Technology, 43(8), 2680-2687.

Huber, J. (2000). Towards industrial ecology: Sustainable development as a concept of ecological modernization. Journal of Environmental Policy and Planning. https://doi.org/10.1080/714038561

Institute of Machine Tools and Production Technology. (2017). Wind Turbine and Photovoltaic Power Plant.

Intergovernmental Panel on Climate Change. (2015). Technology-specific Cost and Performance Parameters. In Climate Change 2014 Mitigation of Climate Change. https://doi.org/10.1017/cbo9781107415416.025

IPCC. (2018). Summary for Policymakers. Global Warming of $1.5^{\circ} \mathrm{C}$. An IPCC Special Report on the impacts of global warming of $1.5^{\circ} \mathrm{C}$ above pre-industrial levels. In Global Warming of $1.5^{\circ} \mathrm{C}$. An IPCC Special Report on the impacts of global warming of $1.5^{\circ} \mathrm{C}$ above pre-industrial levels and related global greenhouse gas emission pathways, in the context of strengthening the global response to the threat of climate change,. https://doi.org/10.1017/CBO9781107415324 
Japan Ministry of the Environment. (2013). Progress on off-site clean up efforts in Japan. Retrieved from http://www.icrp.org/docs/Tsutomu Sato Progress on Offsite Cleanup Efforts in Japan.pdf

Kaya, Y., \& Yokobori, K. (1997). Environment, Energy, and Economy: Strategies for Sustainability. New York: United Nations University Press.

Kenway, S. J., \& Lam, K. L. (2016). Quantifying and managing urban water-related energy use systemically: case study lessons from Australia. International Journal of Water Resources Development. https://doi.org/10.1080/07900627.2015.1132195

Kiefer, H., \& Koelzer, W. (1987). Strahlen und Strahlenschutz - Vom verantwortungsbewussten Umgang mit dem Unsichtbaren (2nd ed.). Springer, Berlin / Heidelberg.

Koksoy, C. E., Ozkan, M. B., Buhan, S., Demirci, T., Arslan, Y., Birturk, A., \& Karagoz, P. (2016). Improved wind power forecasting using combination methods. Proceedings - 2015 IEEE 14th International Conference on Machine Learning and Applications, ICMLA 2015. https://doi.org/10.1109/ICMLA.2015.60

Kuffner, A. (2019). R.I. says clean energy plan falls short. Retrieved December 14, 2019, from Providence Journal website: https://www.providencejournal.com/news/20190728/ri-says-clean-energy-planfalls-short

Kuffner, A. (2018). Deepwater Wind to invest $\$ 250$ million in Rhode Island to build utility-scale offshore wind farm. Retrieved December 14, 2019, from Providence Journal website: https://www.providencejournal.com/news/20180530/deepwaterwind-to-invest-250-million-in-rhode-island-to-build-utility-scale-offshore-windfarm 
Lamberton, G. (2005). Sustainable sufficiency - An internally consistent version of sustainability. Sustainable Development. https://doi.org/10.1002/sd.245

Lang, Cornelia; Stache, N. (2010). Hydraulik von Rohrsystemen. Karlsruher Intitut für Technologie.

Lindsey, R., Climate.gov, NOAA National Centers for Environmental information, \& ESCI. (2020). Understanding Climate - Climate Change: Atmospheric Carbon Dioxide. Retrieved October 7, 2020, from https://www.climate.gov/newsfeatures/understanding-climate/climate-change-atmospheric-carbon-dioxide

Liu, J., Mei, C., Wang, H., Shao, W., \& Xiang, C. (2017). Mutual adaptability of renewable energy and water-supply systems in islands. Energy Procedia, 105, 799-804. https://doi.org/10.1016/j.egypro.2017.03.392

Manwaring, M., Rodgers, K., Flake, S., \& Erpenbeck, D. (2018). Pumped Storage Report. Retrieved from www.hydro.org

Mazumder, R. K., Salman, A. M., Li, Y., \& Yu, X. (2018). Performance evaluation of water distribution systems and asset management. Journal of Infrastructure Systems. https://doi.org/10.1061/ (ASCE)IS.1943-555X.0000426

Menon, E. S. (2004). Liquid Pipeline Hydraulics. In Liquid Pipeline Hydraulics. https://doi.org/10.1201/9780203021385

Meschede, H. (2019). Increased utilisation of renewable energies through demand response in the water supply sector e A case study. Energy, 175, 810-817. https://doi.org/10.1016/j.energy.2019.03.137

Metzner-Szigeth, A. (2019). Strategies for Eco-Social Transformation: Comparing Efficiency, Sufficiency and Consistency. Proceedings of the LeNS Conference. Retrieved from 
http://lensconference3.org/index.php/program/presenters/item/124-milan-oralandreas-metzner-szigeth

National Grid. (2020). Rhode Island Disclosure Label February 2020 - Do you know where your power comes from? Retrieved from https://www.nationalgridus.com/media/pdfs/billing-payments/billinserts/ri/cm4391_ri-edisclosure.pdf

National Renewable Energy Laboratory, \& Roberts, B. J. (2018). Geospatial Data Science - Solar Resource Data, Tools, and Maps. Retrieved June 23, 2020, from https://www.nrel.gov/gis/solar.html

National Research Council. (2007). Drinking water distribution systems: Assessing and reducing risks. In Drinking Water Distribution Systems: Assessing and Reducing Risks. https://doi.org/10.17226/11728

New England Power Pool. (2020). Welcome Page - Home. Retrieved July 1, 2020, from http://nepool.com/Home_Page.php

New England Power Pool. (2019). Generation Information System - System Mix.

O’Neill, D. W., Fanning, A. L., Lamb, W. F., Steinberger, J. K., \& Rockström, J. (2015). Bounding the Planetary Future: Why We Need a Great Transition. https://doi.org/10.1038/s41893-018-0021-4

Oikonomou, Konstantinos; Parvania, M., \& Burian, S. (2017). Integrating Water Distribution Energy Flexibility in Power Systems Operation. IEEE, 1-5.

Ørsted U.S. Offshore Wind. (2019). Rhode Island Regulators Approve Revolution Wind Power Contract. Retrieved December 14, 2019, from https://us.orsted.com/News-Archive/2019/05/Rhode-Island-Regulators-ApproveRevolution-Wind-Power-Contract 
Parrondo, J. L., Velarde, S., \& Santolaria, C. (1998). Development of a predictive maintenance system for a centrifugal pump. Journal of Quality in Maintenance Engineering. https://doi.org/10.1108/13552519810223490

Perez, R., David, M., Hoff, T. E., Jamaly, M., Kivalov, S., Kleissl, J., ... Perez, M. (2016). Spatial and Temporal Variability of Solar Energy. Foundations and Trends ${ }^{\circledR}$ in Renewable Energy. https://doi.org/10.1561/2700000006

Pipe Flow Software. (2020). Pipe Roughness - Pipe Materials and Common Pipe Roughness Values. Retrieved June 23, 2020, from https://www.pipeflow.com/pipe-pressure-drop-calculations/pipe-roughness

Popovich, N., \& The New York Times. (2018). How Does YourState Make Electricity? Retrieved July 10, 2020, from https://www.nytimes.com/interactive/2018/12/24/climate/how-electricitygeneration-changed-in-your-state.html

Proctor, D. (2019). Rhode Island Rejects Burrillville Gas-Fired Plant. Retrieved October 12, 2019, from https://www.powermag.com/rhode-island-rejectsburrillville-gas-fired-plant/

Public Water Corporation; Ministry of Irrigation and Water Resources of Sudan. (2009). Technical Guidelines for the Construction and Management of Drinking Water Distribution Networks - A Manual for Field Staff and Praticioners. Retrieved from https://docuri.com/download/waterdistributionnetworkpdf_59c1cf2bf581710b286 3bed1_pdf

Purvis, B., Mao, Y., \& Robinson, D. (2019). Three pillars of sustainability: in search of conceptual origins. Sustainability Science. https://doi.org/10.1007/s11625-0180627-5 
Ramos, H. M., Vieira, F., \& Covas, D. I. C. (2010). Energy efficiency in a water supply system : Energy consumption and CO 2 emission. Water Science and Engineering, 3(3), 331-340. https://doi.org/10.3882/j.issn.16742370.2010.03.009

Rhode Island Department of Administration, D. of P. (2012). Rhode Island Water 2030 - Management of drinking water supply resources in the State of Rhode Island.

Rhode Island Department of Administration, \& Division of Planning. (2016). Water Quality 2035 - Rhode Island Water Quality Management Plan.

Rhode Island Department of Health, \& University of Rhode Island Facilities Operations. (2019). Consumer Confidence Report 2019.

Rhode Island Office of Energy Resources. (2004). Renewable Energy Standard (2004). Retrieved October 11, 2019, from http://www.energy.ri.gov/policiesprograms/ri-energy-laws/renewable-energy-standard-2004.php

Rhode Island Water Resources Board. (2019). Water Suppliers - District Maps. Retrieved July 5, 2020, from http://www.wrb.ri.gov/data_watersuppliers.html

Rhode Island Water Resources Board. (2012). 2012 Strategic Plan. Retrieved from http://www.wrb.ri.gov/policy_statutes_planning/WRB_StrategicPlan_031612.pdf

Robbins, P. (2014). Safe Drinking Water Act (SDWA). In Encyclopedia of Environment and Society. https://doi.org/10.4135/9781412953924.n941

Santana, M. V. E., Zhang, Q., \& Mihelcic, J. R. (2014). Influence of Water Quality on the Embodied Energy of Drinking Water Treatment.

Schlömer, S., Bruckner, T., Fulton, L., Hertwich, E., McKinnon, A., Perczyk, D., ... Wiser, R. (2014). Annex III: Technology-specific cost and performance parameters. In T. Z. and J. C. M. [Edenhofer, O., R. Pichs-Madruga, Y. Sokona, 
E. Farahani, S. Kadner, K. Seyboth, A. Adler, I. Baum, S. Brunner, P. Eickemeier, B. Kriemann, J. Savolainen, S. Schlömer, C. von Stechow (Ed.), Climate Change 2014: Mitigation of Climate Change. Contribution of Working Group III to the Fifth Assessment Report of the Intergovernmental Panel on Climate Change. Cambridge University Press, Cambridge, United Kingdom and New York, NY, USA.

Schulze, C., Blume, S., Siemon, L., Herrmann, C., \& Thiede, S. (2019). Towards energy flexible and energy self-sufficient manufacturing systems. Procedia CIRP. https://doi.org/10.1016/j.procir.2019.03.176

Schwarzwald Energy. (2017). Stromerzeugung - Kohlekraftwerk. Retrieved May 7, 2020, from https://www.schwarzwald-energy.de/kohlekraftwerke.html

Shahabi, M. P., Mchugh, A., Anda, M., \& Ho, G. (2014). Environmental life cycle assessment of seawater reverse osmosis desalination plant powered by renewable energy. Renewable Energy, 67, 53-58. https://doi.org/10.1016/j.renene.2013.11.050

Shaheen, S., Cohen, A., \& Farrar, E. (2019). Carsharing's impact and future. In Advances in Transport Policy and Planning. https://doi.org/10.1016/bs.atpp.2019.09.002

Simmon, R., NASA Goddard Institue for Space Studies, NOAA National Climatic Data Center, Met Office Hadley Centre/Climatic Research Unit, \& Japanses Metorologic Agency. (2020). Global Temperature Anomaly, 1880-2013. Retrieved July 10, 2020, from https://earthobservatory.nasa.gov/images/82908/global-temperature-anomaly18802013

Skone, T. J., \& U.S. Energy Information Administration. (2015). Life Cycle Greenhouse Gas Emissions: Natural Gas and Power Production. Proceedings of 
the 2015 EIA Energy Conference, Washington, D.C. Retrieved from https://www.eia.gov/conference/2015/pdf/presentations/skone.pdf

Smith, S. A., \& Comesky, A. E. (2009). Sustainable Wells: Maintenance, Problem Prevention, and Rehabilitation. Taylor \& Francis Inc.

Snurr, R., \& Freude, D. (2020). Energy Fundamentals - Physics of Wind Turbines. Retrieved May 7, 2020, from https://home.uni-leipzig.de/energy/energyfundamentals/15.htm

Solar Energy Industries Association. (2019). Major Solar Projects List. Retrieved December 14, 2019, from https://www.seia.org/research-resources/major-solarprojects-list

Spiecker, S., \& Weber, C. (2014). The future of the european electricity system and the impact of fluctuating renewable energy - A scenario analysis. Energy Policy. https://doi.org/10.1016/j.enpol.2013.10.032

State of Rhode Island Division of Public Utilities and Carriers. (2008). Rules as Regulations Prescribing Standards for Water Utilities. Retrieved from http://www.ripuc.ri.gov/rulesregs/divrules/WaterRules_08.pdf

State of Rhode Island Office of Energy Resources. (2019). Governor's 1,000 by '20 Clean Energy Goal. Retrieved December 14, 2019, from http://www.energy.ri.gov/renewable-energy/governor-clean-energy-goal.php

Stewart, M., \& Arnold, K. (2015). Surface production operations. Volume III, Facility piping and pipeline systems. In Facility piping and pipeline systems.

Stokes, C. S., Simpson, A. R., \& Maier, H. R. (2015). A computational software tool for the minimization of costs and greenhouse gas emissions associated with water distribution systems. Environmental Modelling and Software. https://doi.org/10.1016/j.envsoft.2014.11.004 
Surek, D., \& Stempin, S. (2014). Technische Strömungsmechanik. In Technische Strömungsmechanik. https://doi.org/10.1007/978-3-658-06062-6

Thiede, S., Juraschek, M., \& Herrmann, C. (2016). Implementing Cyber-physical Production Systems in Learning Factories. Procedia CIRP. https://doi.org/10.1016/j.procir.2016.04.098

Town of South Kingstown. (2020). Town of South Kingstown Web GIS. Retrieved January 7, 2020, from http://gis.southkingstownri.com/webgis/

U.S. Department of Commerce; Economics and Statistics Administration; U.S. Census Bureau. (2019). 2010 Census: Rhode Island Profile - Population density by census tract.

U.S. Energy Information Administration. (2020). What is U.S. electricity generation by energy source? Retrieved March 5, 2020, from https://www.eia.gov/tools/faqs/faq.php?id=427\&t=3

U.S. Energy Information Administration. (2020). Nuclear explained - Nuclear power plants. Retrieved May 7, 2020, from https://www.eia.gov/energyexplained/nuclear/nuclear-power-plants.php

U.S. Energy Information Administration. (2020). International Energy Outlook 2020 with projections to 2050. Choice Reviews Online. https://doi.org/10.5860/CHOICE.44-3624

U.S. Energy Information Administration. (2019). Renewable energy explained. Retrieved March 4, 2020, from https://www.eia.gov/energyexplained/renewablesources/

Umweltbundesamt. (2020). Konventionelle Kraftwerke und Erneuerbare Energien. Retrieved May 7, 2020, from 
https://www.umweltbundesamt.de/daten/energiebereitstellungverbrauch/konventionelle-kraftwerke-erneuerbare-energien\#textpart-2

United Nations. (2020). Global Issues - Climate Change. Retrieved July 10, 2020, from https://www.un.org/en/sections/issues-depth/climate-change/

United Nations. (2019). UN Sustainable Development Goals - Goal 7: Ensure access to affordable, reliable, sustainable and modern energy. Retrieved October 11, 2019, from https://www.un.org/sustainabledevelopment/energy/

United Nations. (2019). UN Sustainable Development Goals: Goal 13 - Take urgent action to combat climate change and its impacts. Retrieved October 11, 2019, from https://www.un.org/sustainabledevelopment/climate-change/

United States Geological Survey; United States Department of the Interior. (2015). Water Availability and Use Science Program - Estimated Use of Water in the United States in 2015.

University of Denmark, \& World Bank. (2020). Global Wind Atlas 3.0, a free, webbased application developed, owned and operated by the Technical University of Denmark (DTU). The Global Wind Atlas 3.0 is released in partnership with the World Bank Group, utilizing data provided by Vortex, using fundi. Retrieved May 5, 2020, from https://globalwindatlas.info/

University of Rhode Island. (2020). College of Engineering - International Engineering Program - Living \& Learning Community. Retrieved June 23, 2020, from https://web.uri.edu/engineering/academics/iep/curriculum/living-learningcommunity/

University of Rhode Island. (2020). Housing and Residential Life - Housing Options. Retrieved June 23, 2020, from https://web.uri.edu/housing/housing-options/ 
University of Rhode Island. (2020). Greek Life - Fraternity Circle. Retrieved June 23, 2020, from https://web.uri.edu/greek/fraternity-circle-map/

University of Rhode Island. (2020). About: Facts - Students. Retrieved from https://www.uri.edu/about/facts/

University of Rhode Island Department of External Relations and Communications. (2018). URI-town consortium turns former disposal industrial sites into solar farms. Retrieved November 13, 2019, from https://today.uri.edu/news/uri-townconsortium-turns-former-disposal-industrial-sites-into-solar-farms/

University of Rhode Island Environmental Data Center, \& Rhode Island Geographic Information System Consortium. (2018). Rhode Island Shaded Relief. Retrieved from

https://maps.edc.uri.edu/arcgis/rest/services/Atlas_elevation/Shaded_Relief/Map Server

University of Rhode Island Environmental Data Center, Rhode Island Geographic Information System Consortium, \& US Geological Survey. (2020). Statewide Elevation Contour Lines - 5 Foot. Retrieved June 23, 2020, from https://maps.edc.uri.edu/rigis/rest/services/TOPO/Contours_05ft_2011_spf/Featu reServer

US Department of the Interior, \& US Geological Survey. (2017). Water Availability and Use Science Program Estimated Use of Water in the United States in 2015.

US Energy Information Administration. (2020). Electric Power Monthly, Data for April 2020. Retrieved May 7, 2020, from https://www.eia.gov/electricity/monthly/

US Energy Information Administration. (2017). Rhode Island Electricity Profile 2017 - Summary Statistics. Retrieved December 14, 2019, from https://www.eia.gov/electricity/state/rhodeisland/ 
US Energy Information Administration. (2019). Rhode Island Profile - State Profile and Energy Estimates. Retrieved October 11, 2019, from https://www.eia.gov/state/?sid=RI\#tabs-4

US Environmental Protection Agency. (2002). The Clean Water and Drinking Water Infrastructure Gap Analysis. EPA-816-R-02-020. EPA816R02020.

US Environmental Protection Agency. (1972). Summary of the Clean Water Act. United States Envitonmental Protection Agency.

US Environmental Protection Agency. (n.d.). Water Sense - An EPA Partnership Program - Our Water - Tomorrow and Beyond. Retrieved November 18, 2019, from https://19january2017snapshot.epa.gov/www3/watersense/our_water/tomorrow_b eyond.html

US Geological Survey. (2015). Total Water Use in the United States. Retrieved December 12, 2019, from https://www.usgs.gov/special-topic/water-scienceschool/science/total-water-use-united-states?qt-science_center_objects=0\#qtscience_center_objects

US Geological Survey, Perlman, H., \& Evans, J. (2019). The Water Cycle (Natural water cycle). Retrieved July 13, 2020, from https://www.usgs.gov/media/images/water-cycle-natural-water-cycle

van Zyl, J. (2014). Introduction to Operation and Maintenance of Water Distribution Systems. In Water Research Commision.

Volk, M. (2013). Pump Characteristics and Applications. In Pump Characteristics and Applications. https://doi.org/10.1201/b15559

von Carlowitz, H. C. (1732). Sylvicultura Oeconomica. Leipzig. 
Wakeel, M., Chen, B., Hayat, T., Alsaedi, A., \& Ahmad, B. (2016). Energy consumption for water use cycles in different countries: A review. Applied Energy. https://doi.org/10.1016/j.apenergy.2016.06.114

Walski, T. M., Chase, D. V., Savic, D. A., Grayman, W., Beckwith, S., \& Koelle, E. (2003). Advanced Water Distribution Modeling and Management. Methods. https://doi.org/10.3844/ajassp.2012.1974.1978

Walski, Thomas M.; Chase, Donald V.; Savic, D. A. (2001). Water Distribution Modeling. Retrieved from https://ecommons.udayton.edu/cee_fac_pub/17\%0A

Wang, B., Shi, W., \& Miao, Z. (2015). Confidence analysis of standard deviational ellipse and its extension into higher dimensional Euclidean space. PLOS ONE. https://doi.org/10.1371/journal.pone.0118537

Water in the West. (2008). Water Energy Nexus: Literature Review.

WCED. (1987). Our Common Future (The Brundtland Report). In Medicine and War. https://doi.org/10.1080/07488008808408783

Winter, T. C., Harvey, J. W., Franke, O. L., \& Alley, W. M. (1998). Ground Water Surface Water and A Single Resource. In USGS Publications.

WorldAtlas. (2019). Rhode Island Precipitation Map. Retrieved November 19, 2019, from https://www.worldatlas.com/webimage/countrys/namerica/usstates/weathermaps/ riprecip.htm

Yoo, D. G., Suh, M. Y., Kim, J. H., Jun, H., \& Chung, G. (2012). Subsystem-based pressure dependent demand analysis in water distribution systems using effective supply. KSCE Journal of Civil Engineering, 16(3), 457-464. https://doi.org/10.1007/s12205-012-1448-1 
Zhao, G., \& Gao, H. (2019). Estimating reservoir evaporation losses for the United States: Fusing remote sensing and modeling approaches. Remote Sensing of Environment. https://doi.org/10.1016/j.rse.2019.03.015 